Dritter Beratungsgegenstand:

\title{
Finanzautonomie und Finanzverflechtung in gestuften Rechtsordnungen
}

1. Bericht von Professor Dr. Christian Waldhoff, Bonn

Inhalt

Seite

I. Die Rückkehr zu den Grundlagen der Finanzverfassung . . 218

II. Der doppelgliedrige Begriff der Finanzautonomie in der Mehrebenenstruktur: Der Verantwortungszusammenhang zwischen Einnahmen und Ausgaben . . . . . . . . . . 224

1. Das Denken von der Ausgabenseite her . . . . . . . . . 224

2. Die Notwendigkeit des Einbezugs der Einnahmenseite . 227

3. Finanzautonomie im Fokus des europäischen Beihilfenregimes ............... . . 227

4. Finanzautonomie als Verfassungsprinzip . . . . . . 229

5. Finanzverflechtung als empirische Bestandsaufnahme . . 229

III. Die Rekonstruktion der Finanzordnung der

Mehrebenenstruktur aus ihrem Individualbezug . . . . . . 231

1. Fundierung der Finanzordnung durch das Demokratieprinzip . . . . . . . . . . . . . 231

2. Individualschützende Funktionen der finanzverfassungsrechtlichen Kompetenzordnung . . . . . . . . . . 235

3. Kongruenz zwischen demokratischer Legitimation und finanzwirtschaftlicher Verantwortung als Postulat der Steuerrechtfertigung . . . . . . . . . . . . 237

a) Demokratische Rückkoppelung der Finanzierung öffentlicher Gemeinwesen . . . . . . . . . . . . 237

b) Verantwortungszusammenhänge und Verantwortungsklarheit . . . . . . . . . 238

c) Die Steuerrechtfertigung als Verbindung von persönlicher Anknüpfung und territorialer Radizierung . . . 240

d) Ansätze finanzwirtschaftlicher Verantwortungszusammenhänge in der Judikatur des Bundesverfassungsgerichts - insbesondere die Rechtsprechung zu den Sonderabgaben 
4. Keine Inkompatibilität zur geltenden Finanzverfassung: Die Grenzen des Konzepts der Finanzverfassung als „Folgeverfassung“ . . . . . . . . . . . . 246

5. Die begrenzte Direktionskraft des Postulats „einheitlicher" oder „gleichwertiger Lebensverhältnisse im Bundesgebiet" . . . . . . . . . . . . . 248

6. Keine Wettbewerbsfeindlichkeit der hoheitlichen Finanzwirtschaft . . . . . . . . . . . . . 252

IV. Konsequenzen der Interdependenz zwischen demokratischer Legitimation und Finanzordnung . . . . . . . . . . . 257

1. Die legitimatorisch abgeleiteten Ebenen: Gesetzesgebundene Finanzautonomie der Gemeinden, die Mitgliedstaaten als „Herren“ über die Einnahmen der Europäischen Union . . . . . . . . . . . . . 257

2. Die Notwendigkeit eigengestaltbarer Einnahmen der Länder . . . . . . . . . . . . . . . . 260

3. Das Postulat fairen Steuerwettbewerbs . . . . . . . 265

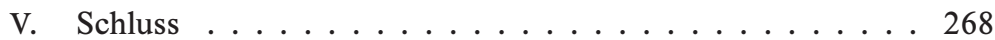




\section{Die Rückkehr zu den Grundlagen der Finanzverfassung}

Als sich diese Vereinigung 1955 in Hamburg mit der „Finanzverfassung im Rahmen der Staatsverfassung“ befasste, konnte der Erstberichterstatter Karl Maria Hettlage feststellen: „Die deutsche Finanzverfassung ist seit der Verabschiedung des Grundgesetzes eine offene Frage. " 1 Die Formulierung des damaligen Themas deutet darauf hin, dass es zunächst darum gehen musste, dieses besondere Gebiet des Verfassungsrechts gleichrangig in Verfassungsrechtsdogmatik und Bewusstsein der Teilnehmer zu verankern. 1992 wurden in Bayreuth „Grundsätze der Finanzverfassung des vereinten Deutschlands“ verhandelt. ${ }^{2}$ Erkennbar ging es um die finanzwirtschaftliche Integration der neuen Länder in die überkommene Finanzordnung des Grundgesetzes. Was ist der Anlass für die jetzt schnellere erneute Behandlung, nachdem die Finanzordnung in der Staatsverfassung angekommen is ${ }^{3}$ und sich die Finanzintegration nach der Wiedervereinigung trotz aller Verzögerungen und Enttäuschungen normalisiert? Waren die Referate 1992 noch durch „Landesberichte“ der deutschsprachigen Nachbarländer angereichert, so wird die Finanzverfassung heute sogleich und ohne Alternative in der Mehrebenenstruktur ${ }^{4}$

1 VVDStRL 14 (1956), 1 (2); der Zweitbericht wurde seinerzeit von Theodor Maunz erstattet, ebd. $37 \mathrm{ff}$. In der Ursprungsfassung des Grundgesetzes war im Wege einer zurückgestellten Verfassunggebung der zehnte Abschnitt des Grundgesetzes in einem Spannungsverhältnis zum Verfassungsvorbehalt zunächst nur provisorisch geregelt und der unterverfassungsrechtlichen Gesetzgebung überlassen worden, H. Pagenkopf Der Finanzausgleich im Bundesstaat, 1981, 162; W. Renzsch Finanzverfassung und Finanzausgleich, 1991, 54 ff., 75 ff.; A. Bauer/M. Jestaedt Das Grundgesetze im Wortlaut, 1997 , $20 \mathrm{ff}$.; S. Oeter Integration und Subsidiarität im deutschen Bundesstaatsrecht, 1998, $172 \mathrm{ff}$. Anlass für die Themenwahl war wohl auch die Redeweise G. Wackes, Das Finanzwesen der Bundesrepublik, 1950, der mit seiner Begriffsprägung von der „Finanzfunktion“ des Staates, nicht zuletzt inspiriert durch die verfassungssystematische Neuerung eines eigenen Gliederungsabschnitts des Grundgesetzes, die von ihm als Ausnahmebestimmungen interpretierten finanzverfassungsrechtlichen Kompetenzen gerade aus dem „normalen“ Staatsrecht mehr oder weniger ausgegliedert hatte; vgl. auch W. Heun in: Dreier (Hrsg.), GG, Bd. 3, 2000, Vorb. zu Art. 104a-115 Rn. 19 mit Fn. 111.

2 P. Selmer VVDStRL 52 (1993), $10 \mathrm{ff}$.; F. Kirchhof ebd., $71 \mathrm{ff}$.; ergänzt durch den Landesbericht Österreich von $H$. Haller, $111 \mathrm{ff}$., und den Landesbericht Schweiz von T. Jaag, $123 \mathrm{ff}$.

${ }^{3}$ K. Stern Das Staatsrecht der Bundesrepublik Deutschland, Bd. 2, 1980, 1055. Die These von der Sonderstellung der Finanzverfassung, insbesondere die daraus gezogene Konsequenz einer verringerten Justiziabilität, vgl. F. Ossenbühl FS Carstens, Bd. 2, 743; ders. Verfassungsrechtliche Grundfragen des Länderfinanzausgleichs gem. Art. 107 II GG, 1984, 92, dürfte so nicht mehr vertreten werden, vgl. R. Prokisch Justiziabilität der Finanzverfassung, 1993; C. Waldhoff HStR V, 3. Aufl. 2007, § 116 Rn. $148 \mathrm{ff}$.

${ }^{4}$ Die Redeweise von der gestuften Rechtsordnung, vom Mehrebenensystem oder von der Mehrebenenstruktur impliziert kein bestimmtes rechtstheoretisches Modell 
verhandelt. ${ }^{5}$ Das liegt nicht nur daran, dass die Kategorien von Finanzautonomie und Finanzverflechtung für den Einheitsstaat grundsätzlich bedeutungslos sind. ${ }^{6}$ Die ökonomische wie rechtliche Interdependenz ${ }^{7}$

oder Vorverständnis der internationalen Ordnung (etwa einer Konstitutionalisierung des Völkerrechts, vgl. nur $R$. Uerpmann JZ 2001, $566 \mathrm{ff}$.). Die Begriffe werden hier vielmehr als Chiffren für die zunehmende Verflechtung und Interdependenz staatlicher, insbesondere jedoch bundesstaatlicher Ordnungen im europäischen Kontext einer voranschreitenden Integration verwendet, vgl. etwa $R$. Wahl in: ders., Verfassungsstaat, Europäisierung, Internationalisierung, 2003, 53 (54f.); vgl. in diesem Sinne auch die unspezifische Verwendung bei U. Di Fabio Der Verfassungsstaat in der Weltgesellschaft, 2001, 23 und durchgehend; F. Kirchhof DVB1. 2004, 977. Die vornehmlich aus der Politikwissenschaft rezipierte Formel des Mehrebenensystems geht u. a. zurück auf das Politikverflechtungsparadigma F.W. Scharpfs, vgl. etwa dens./B. Reissert/F. Schnabel Politikverflechtung, 1976; F.W. Scharpf Optionen des Föderalismus in Deutschland und Europa, 1994; ferner T. König u.a. (Hrsg.), Das europäische Mehr-Ebenen-System, 1996. A. Peters Elemente einer Theorie der Verfassung Europas, 2001, $179 \mathrm{ff}$., weist darauf hin, dass die auch hier verwendete neue Begrifflichkeit eines „europäischen Föderalismus" gerade nicht die Finalität in Richtung auf einen Bundesstaat impliziert. Die „untechnische“ Verwendung dieser Topoi zeigt sich auch darin, dass die kommunale Ebene grds. miteinbezogen ist, zumindest sein sollte, so insbes. F. Schoch in: Henneke (Hrsg.), Verantwortungsteilung zwischen Kommunen, Ländern, Bund und EU, 2001, $21 \mathrm{ff}$.; abweichend etwa C. Gröpl DVB1. 2006, 1079 (1081).

5 Vgl. für das Thema Föderalismus bereits $H$. Bülck VVDStRL 21 (1964), 1 ff.; zu dem Zusammenhang zwischen ,äußerer“ und „innerer“ Autonomie im Bundesstaat $U$. Volkmann DÖV 1998, 613 (614); im finanzverfassungsrechtlichen Kontext J.J. Hesse in: Büttner (Hrsg.), Finanzverfassung und Föderalismus in Deutschland und Europa, 2000, 9 (insbes. $27 \mathrm{ff}$.); H. Kube Finanzgewalt in der Kompetenzordnung, 2004, 20; L. Osterloh GS Trzaskalik, 2005, 181 (184); unter seinem Erkenntnisgegenstand des Wettbewerbs im öffentlichen Sektor V. Mehde Wettbewerb zwischen Staaten, 2005, $47 \mathrm{ff}$; ; in den Finanzwissenschaften als volkswirtschaftlicher Teildisziplin werden diese Fragen schon lange als einander gegenübergestellter und teilweiser verschränkter nationaler und internationaler Finanzausgleich verhandelt, vgl. nur N. Andel Finanzwissenschaft, 4. Aufl. 1998, $502 \mathrm{ff}$., $533 \mathrm{ff}$; M. Kraff Der Finanzausgleich in der Europäischen Union, 1997.

6 C. Gröpl DVB1. 2006, 1079 (1081).

${ }^{7}$ Zur zunehmenden Interdependenz im wirtschaftlich-rechtlichen Bereich und ihrer Bewältigung zunächst grundlegend $K$. Vogel Die Verfassungsentscheidung des Grundgesetzes für eine internationale Zusammenarbeit, 1964; S. Langer Grundlagen einer internationalen Wirtschaftsverfassung, 1995; im übrigen kann auf die je unterschiedlichen Analysen von $S$. Hobe Der offene Verfassungsstaat zwischen Souveränität und Interdependenz, 1998; C. Möllers in: Anderheiden u.a. (Hrsg.), Globalisierung als Problem von Gerechtigkeit und Steuerungsfähigkeit des Rechts, 2001, $41 \mathrm{ff}$; W. Graf Vitzthum Der Staat der Staatengemeinschaft, 2006, verwiesen werden. Die Analyse, Bundesstaatlichkeit käme durch diese Verflechtungen, durch den Souveränitätsverlust nach außen in besonderem Maße unter Druck (vgl. nur U. Volkmann DÖV 1998, 613 (616f.)) trifft sicher in zahlreichen Bereichen zu - man denke nur an die vielbeschworene „Landesblindheit" der EG und ihre Folgen; auf einer theoretischeren Ebene sind derartige Schlussfolgerungen jedoch nicht zwingend: Wenn föderale Gliederung als Vehikel der 
zu anderen Staaten und supranationalen Verbünden kommt im Finanzbereich besonders deutlich zum Ausdruck. Diskussionen über die Chancen, Folgen und Rückwirkungen des (internationalen) Steuerwettbewerbs sind ubiquitär. ${ }^{8}$ Aktueller äußerer Anlass der erneuten Befassung ist die desolate Situation der staatlichen Finanzen in der Bundesrepublik in einem finanzwirtschaftlich oftmals besser gestellten internationalen Umfeld. Tieferer Grund der Themenstellung scheint die Unfähigkeit zu sein, derartige Verteilungsentscheidungen im Bundesstaat im Rahmen von Finanz- oder Verfassungsreformen anzugehen und diese auf die inter- und supranationalen Herausforderungen einzustellen. Gleichzeitig belehrt die Ökonomie über die Ineffizienzen der überkommenen Ausgestaltung. ${ }^{9}$ Der Grundlagenbezug blieb in der bisherigen Diskussion

Leistungssteigerung, der Optimierung staatlicher Organisation gesehen wird und sich Bundesstaatlichkeit dann noch mit Regionalisierungstendenzen trifft, muss die interund supranationale Verflechtung nicht zwangsläufig bundesstaatszersetzend wirken; vgl. in jeweils anderen Zusammenhängen etwa T. Wiedmann Idee und Gestalt der Region in Europa, 1996; J. Isensee FG 50 Jahre Bundesverfassungsgericht, Bd. 2, 2001, 719 (770); M. Kotzur JöR 50 (2002), 257 ff.; A. Hinsch Neugliederung des Bundesgebiets und europäische Regionalisierung, 2002.

8 Vgl. nur G. Krause-Junk Internationaler Wettbewerb der Steuersysteme, 1990; S. Steinmo Taxation and Democracy, 1993, 156 ff.; V. Tanzi in: Krause-Junk (Hrsg.), Steuersysteme der Zukunft, 1998, 11 ff.; T. Plümper/G.G. Schulz PVS 40 (1999), 445; L.P. Feld Steuerwettbewerb und seine Auswirkungen auf Allokation und Distribution, 2000; W. Schön in: Pelka (Hrsg.), Europa- und verfassungsrechtliche Grenzen der Unternehmensbesteuerung, 2000, 191 ff.; H.J. Ault FS Vogel, 2000, 1117 ff.; J. Malherbe ebd., 1125 ff.; J. Wieland EuR 2001, $119 \mathrm{ff}$; C. Esser Internationaler Steuerwettbewerb, 2004; J. Hey FS Solms, 2005, $35 \mathrm{ff}$.; dies. JZ 2006, 851 (852ff.); C. Spengel Gutachten G zum 66. DJT 2006; G. Frotscher (Hrsg.), Anforderungen an ein modernes Steuersystem angesichts der Globalisierung, 2006; R. Müller StuW 2006, 173; zu den Reaktionsmöglichkeiten in Wettbewerbssituationen A.O. Hirschman Abwanderung und Widerspruch, 1974.

${ }^{9}$ Allgemein zum Nutzen einer (auch) ökonomischen Betrachtung des Staates B. Grzeszick HStR IV, 3. Aufl. 2006, § 78 Rn. 14ff.: präzise Ermittlung der Rationalität des Staates; ferner M. Wallerath JZ 2001, $209 \mathrm{ff}$; auf die hiesige Fragestellung bezogen müssen verschiedene Stränge unterschieden werden; traditionsreich sind ökonomische Modelle der Analyse von Wettbewerb zwischen lokalen Gebietskörperschaften, vgl. vorrangig C. Tiebout Journal of Political Economy 64 (1956), 416; aus dem deutschsprachigen Schrifttum K.-H. Hansmeyer in: Probleme des Föderalismus, 1985, $107 \mathrm{ff}$.; Feld Steuerwettbewerb (Fn. 8), 27 ff.; V. Mehde Wettbewerb (Fn. 5), $36 \mathrm{ff}$.; im sog. Fiscal Federalism haben sich derartige Untersuchungen mit der dem Public Choice-Ansatz verbundenen Institutionenökonomik verbunden; wegweisend hier W.E. Oates Fiscal Federalism, 1972; A. Breton/A.D. Scott The Economic Constitution of Federal States, 1978; B. Dafflon Federal Finance in Theorie and Practice, 1977; deutsche Übersetzungen zentraler Texte in dem Sammelband G. Kirsch (Hrsg.), Föderalismus, 1977; für einen Überblick C.B. Blankart Öffentliche Finanzen in der Demokratie, 6. Aufl. 2006, 
aus zwei Gründen unterentwickelt: Zunächst behindert die Singularität jedes Bundesstaats in seinem konkreten historischen und sozio-ökonomischen Umfeld übergreifende theoretische Überlegungen zum staatsrechtlichen Problemfeld föderaler Finanzordnungen. ${ }^{10}$ Auf der anderen Seite des Spektrums öffnen die jeweils aktuellen Verfahren vor dem Bundesverfassungsgericht zur bundesstaatlichen Finanzordnung ${ }^{11}$ ganz überwiegend nur einen Argumentationsrahmen innerhalb der geltenden Ordnung und befördern damit Erörterungen auf einer eher technischdetailbezogenen Ebene. ${ }^{12}$

Die hier nur schlaglichtartig angesprochenen Faktoren führen zu einer Rückbesinnung auf die rechtlichen und theoretischen Grundlagen staatlicher, supranationaler und internationaler Finanzordnungen. ${ }^{13}$ Die Tendenz in der deutschen Bundesstaatslehre, der jeweiligen föderalen Wirklichkeit von vornherein „eine sowohl juristische als auch politisch-theoretische Generalabsolution" 14 zu erteilen, erstaunt angesichts der Erschöpfung des Kritikpotentials rein verfassungsimmanent verbleibender Deutungen. Durch Möglichkeiten der Einbeziehung theoretischer Erwägungen, diachroner ${ }^{15}$ und synchroner Vergleche, ${ }^{16}$ durch die genauere Analyse von Alternativmodellen hat sich das

595 ff.; vgl. zum Ganzen S. Oeter in: Engel/Morlok (Hrsg.), Öffentliches Recht als ein Gegenstand ökonomischer Forschung, 1998, $119 \mathrm{ff}$.

10 Eingehend R. Lhotta in: Jahrbuch des Föderalismus 2001, $35 \mathrm{ff}$.; ferner P. Häberle Die Verwaltung 24 (1991),169 (183f.); Oeter Integration und Subsidiarität (Fn. 1), V, spricht von einer in Deutschland vorherrschenden „Phobie gegenüber allen Formen der Bundesstaatstheorie“.

${ }^{11} \mathrm{Zu}$ nennen sind BVerfGE 1, 117 (erstes Finanzausgleichsurteil); 72, 330 (Erdölförderzins Niedersachsen); 86, 148 (extreme Haushaltsnotlage Saarland und Bremen I); 101, 158 (Maßstäbegesetz), sowie die laufenden Verfahren 2 BvF 3/03 (extreme Haushaltsnotlage Berlin; Urteil vom 19. Oktober 2006); 2 BvF 3/05 (extreme Haushaltsnotlage Saarland II); 2 BvF 1/06 (extreme Haushaltsnotlage Bremen II).

12 Vgl. allgemein B. Schlink Der Staat 28 (1989), 161 (165, 167 f.); M. Jestaedt, Verfassungsgerichtspositivismus, in: Depenheuer u.a. (Hrsg.), Nomos und Ethos, 2002, S. 183.

13 Das gilt zwingend für die allgemeine Bundesstaatsdiskussion, vgl. U. Volkmann DÖV 1998, 613 (623), der die prinzipielle „Disproportionalität von theoretischen Voraussetzungen und legitimierenden Wurzeln einerseits und konkret-praktischer Ausgestaltung andererseits“ als tieferen Grund der allgemeinen Krise von Bundesstaatlichkeit und Föderalismus diagnostiziert.

14 C. Möllers in: Aulehner u.a. (Hrsg.), Föderalismus - Auflösung oder Zukunft der Staatlichkeit? 1997, 81 (96).

15 Vgl. zur historischen Dimension von Phänomenen des Steuerwettbewerbs M. Spoerer in: Jahrbuch für Wirtschaftsgeschichte 2002/2, $35 \mathrm{ff}$.

${ }^{16}$ Zur Rechtsvergleichung von bundesstaatlichen Ordnungen M. Bothe Die Kompetenzstruktur des modernen Bundesstaates in rechtsvergleichender Sicht, 1977; K. Weber Kriterien des Bundesstaates, 1980; F. Ossenbühl (Hrsg.), Föderalismus und Regionalis- 
Argumentationspotenzial - auch und gerade wegen der inzwischen systemprägenden Mehrstufigkeit der Rechtsordnung - notwendig ausgedehnt. ${ }^{17}$ Diese Perspektivenerweiterungen sind für die Analyse bun-

mus in Europa, 1990; W. Hertel in: Graf Vitzthum (Hrsg.), Europäischer Föderalismus, 2000, 13 ff.; A.B. Gunlicks in: von Arnim u.a. (Hrsg.), Föderalismus - Hält er noch, was er verspricht? 2000, 41 ff.; M. Hartwig/W. Heun/F. Kirchhof/C. Waldhoff, Föderalismus in der Diskussion, 2001; V. Mehde Wettbewerb (Fn. 5), v.a. $360 \mathrm{ff.;} \mathrm{finanzverfassungs-}$ rechtliche Vergleiche finden sich bereits in der ersten substanziellen Abhandlung über föderalistische Finanzverfassungen durch $A$. Hensel Der Finanzausgleich im Bundesstaat, 1922, 13, $32 \mathrm{ff}$; ferner bei $D$. Schönherr Der föderative Finanzausgleich in den Vereinigten Staaten von Amerika, Kanada und der Bundesrepublik Deutschland, Diss. phil. Bonn 1984; R.M. Bird Federal Finance in Comparative Perspective, 1986; T. Ter-Minassian/International Monetary Fund (ed.), Fiscal Federalism in Theory and in Practice, 1997; C. Waldhoff Verfassungsrechtliche Vorgaben für die Steuergesetzgebung im Vergleich Deutschland-Schweiz, 1997; K. Vogel/C. Waldhoff in: Dolzer/Vogel/Graßhof (Hrsg.), BK GG, Vorb. z. Art. 104a-115 Rn. 672 ff. (= dies. Grundlagen des Finanzverfassungsrechts, 1999); G. Färber in: von Arnim u.a. (Hrsg.), Föderalismus - Hält er noch, was er verspricht? 2000, 125 (143ff.); A. Jörg Finanzverfassung und Föderalismus in Deutschland und in der Schweiz, 1998; W. Heun in: Dreier (Hrsg.), GG, Bd. 3, 2000, Vorb. zu Art. 104a-115 Rn. 12ff.; W. Renzsch in: Jahrbuch des Föderalismus 2000, 42 ff.; L. Helms ZfP 49 (2002), 125 (135ff.); E. Döhler Besteuerungsrechte für Gliedstaaten und Gemeinden in ausgewählten föderativen Finanzverfassungen, 2002; M. Heintzen in: von Münch/Kunig (Hrsg.), GGK III, 4./5. Aufl. 2003, Vorb. Art. 104a-115 Rn. 24;H.-J. Blanke in: ders./Schwanengel (Hrsg.), Zustand und Perspektiven des deutschen Bundesstaates, 2005. Speziell zur US-amerikanischen Finanzverfassung ferner: F.H. Stamm Die Bundesfinanzen der Vereinigten Staaten von Amerika, 1969; W. Heun Das Budgetrecht im Regierungssystem der USA, 1989; ders. Staatswissenschaften und Staatspraxis 1994, 97 ff.; J.-D. Kramer in: ders. (Hrsg.), Grundzüge des US-amerikanischen Steuerrechts, 1990; zur Schweiz ergänzend: T. Jaag VVDStRL 52 (1993), 123 ff.; $S$. Morandi Die Begrenzung der Steuerlast durch verfassungsrechtliche Bindungen des schweizerischen Steuergesetzgebers, 1997, $111 \mathrm{ff}$. Rechtsvergleichende Hinweise zu den Finanzkompetenzen in den jüngst dezentralisierten Einheitsstaaten bei $R$. Grote ZaöRV 58 (1998), 109 (130f., 134f., 140f.); C. Jeffrey in: Glaeßner u.a. (Hrsg.), Verfassungspolitik und Verfassungswandel, 2001, $125 \mathrm{ff}$; T.J. von Andreae Devolution und Bundesstaat, 2005, 364ff.; allgemein $A$. Gamper Die Regionen mit Gesetzgebungshoheit, 2004; in diesem Zusammenhang zu Tendenzen zu „asymmetrischen“ föderalen Modellen K. von Beyme in: Wagschal/Lentsch (Hrsg.), Der Preis des Föderalismus, 2002, $29 \mathrm{ff}$.

${ }^{17}$ C. Möllers in: Aulehner u.a. (Hrsg.), Föderalismus - Auflösung oder Zukunft der Staatlichkeit? 1997, 81 (96 Zitat); zum methodischen Problem ebd., 111: „Eine Immunisierung der verfassungsrechtlichen Fragestellung von verfassungspolitischen Argumenten befreit die Debatte ebenso vom Rekurs auf uneindeutige soziologische Befunde wie von falschen Rechtfertigungszwängen. Ein solcher Zugriff vermittelt ein Bild demokratischer Bundesstaatlichkeit unter dem Grundgesetz, das weder verfassungswidrig noch zufriedenstellend ist." Programmatisch für die vergleichende Analyse des Finanzausgleichs bereits die begriffsprägende Dissertation Hensel Finanzausgleich (Fn. 16), 13; dazu E. Reimer/C. Waldhoff in: dies. (Hrsg.), Albert Hensel. System des Familien- 
desstaatlicher Probleme umso unverzichtbarer, ${ }^{18}$ als der normative Mehrwert des bundesstaatlichen Strukturprinzips jenseits der verfassungsrechtlichen Kompetenzaufteilung begrenzt bleibt. ${ }^{19}$ Der hier propagierte Rückbezug auf verfassungstheoretische wie staatsrechtliche Grundfragen soll sowohl Ertrag für die Konkretisierung der Auslegungsspielräume im geltenden Verfassungsrecht ${ }^{20}$ als auch Erkenntnisse verfassungspolitischer Art hervorbringen. ${ }^{21} \mathrm{Da}$ sich die Finanzverfassung trotz oder wegen ihrer häufigen Reformfrequenz ${ }^{22}$

steuerrechts und andere Schriften, 2000, 1 (47ff.); zur historischen Dimension S. Ruppert RJ 18 (1999), $50 \mathrm{ff}$.

18 M. Nettesheim FS Badura, 2004, 363 (369): „Verfassungsprinzipien vom Rang des Bundesstaatsprinzips lassen sich interpretativ gewinnbringend nur dadurch erschließen, daß man sie im Lichte der Verfassungstheorie konkretisiert."; B. Grzeszick in: Maunz/ Dürig, GG, Art. 20 IV Rn. 17 ff.; L. Michael JZ 2006, 884f.; auf die Finanzverfassung bezogen H.-J. Blanke in: ders./Schwanenengel (Hrsg.), Zustand und Perspektiven des deutschen Bundesstaates, 2005, $127 \mathrm{ff}$; zu Verfassungsprinzipien allgemein F. Reimer Verfassungsprinzipien, 2001.

19 J. Isensee HStR IV, 2. Aufl. 1999, § 98 Rn. 6; P.M. Huber Gutachten D zum 65. DJT, 2004, D 38f. Allgemein gegen Zirkularitätseinwände eines derartigen methodischen Vorgehens der Bestimmung von Verfassungsgehalten im Wechselspiel zu einer prinzipielleren, theoretischen Ebene P. Unruh Der Verfassungsbegriff des Grundgesetzes, 2002, 28 ff.; auf die Bundesstaatsdogmatik bezogen W. Geiger Missverständnisse um den Föderalismus, 1962, 2f.; J. Isensee in: FG 50 Jahre BVerfG, 2001, 719 (730ff.); zu radikal mit seinem summativen Bundesstaatsverständnis demgegenüber E. Šarčević Das Bundesstaatsprinzip, 2000.

${ }^{20} \mathrm{Zu}$ diesen F. Kirchhof VVDStRL 52 (1993), 71 (76f.); K.-P. Sommermann in: von Mangoldt/Klein/Starck, GG, Bd. 2, 5. Aufl. 2005, Art. 20 Abs. 1 Rn. 55; P.M. Huber Deutschland in der Föderalismusfalle? 2003, 19; Mehde Wettbewerb (Fn. 5), $117 \mathrm{ff}$;; M. Jestaedt HStR II, 3. Aufl. 2004, § 29 Rn. 14 weist darauf hin, dass Sichtweisen wie der „unitarische“, der „kooperative“, der „kompetitive“ oder der „europäisierte“ Bundesstaat Phänomene einer rahmenausfüllenden Verfassungsinterpretation darstellen; J. Isensee FG 50 Jahre BVerfG, Bd. 2, 2001, 719 (724ff.); allgemein zu Normierungsstil und Konkretisierungsbedarf der Normen des GG B.-O. Bryde Verfassungsentwicklung, 1982, $80 \mathrm{ff}$.

${ }^{21} \mathrm{Zu}$ dieser Zweispurigkeit U. Volkmann DÖV 1998, 613 (621); L. Michael JZ 2006, 884 ff.; auf die Finanzverfassung bezogen C. Waldhoff ZG 2000, 193 ff.; vgl. ferner bereits Hensel Finanzausgleich (Fn. 16), 147; zu den Gefahren einer rein deskriptiven Behandlung finanzverfassungsrechtlicher Probleme und für eine entsprechende Perspektivenerweiterung eindringlich $W$. Heun Der Staat 31 (1992), 205 (207).

22 W. Heun in: Dreier (Hrsg.), GG, Bd. 3, 2000, Vorb. zu Art. 104a-115 Rn. 10: „Spannung zwischen den hohen Flexibilitäts- und Anpassungsbedürfnissen einer bundesstaatlichen Finanzordnung ... und der Normierungssucht des Verfassungsgebers"; W. Renzsch in: Jahrbuch des Föderalismus 2000, 42; zur Entwicklung eingehend ders. Finanzverfassung (Fn. 1); im Überblick K. Vogel/C. Waldhoff in: Dolzer/Vogel/Graßhof (Hrsg.), BK GG, Vorb. z. Art. 104a-115 Rn. 199 ff. (= dies. Grundlagen des Finanzverfassungsrechts, 1999); in ökonomischer Analyse T. Schmidt Finanzreformen in der Bundesrepublik Deutschland, 2001. 
ständig in der Diskussion befindet, ${ }^{23}$ erscheint gerade dieser Zugriff legitim. ${ }^{24}$

\section{Der doppelgliederige Begriff der Finanzautonomie in der Mehrebenenstruktur: Der Verantwortungszusammenhang zwischen Einnahmen und Ausgaben}

\section{Das Denken von der Ausgabenseite her}

Der in jeder Hinsicht schillernde Begriff der „Autonomie“25 ist in dieser Allgemeinheit kein Rechtsbegriff. ${ }^{26}$ Üblicherweise ${ }^{27}$ wird in

${ }^{23}$ Überblicke über die Reformszenarien bei H.-G. Henneke Reform der Aufgabenund Finanzbeziehungen von Bund, Ländern und Kommunen, 1999; C. Waldhoff Die Verwaltung 39 (2006), 155 ff.; Überblick über die angestoßenen Föderalismus-Reformprojekte allgemein $U$. Münch/T. Zinterer ZParl. 2000, 657 ff.; $U$. Thaysen Aus Politik und Zeitgeschichte B 29-30/2003, $14 \mathrm{ff}$.

${ }^{24}$ Betont zurückhaltend S. Korioth in: DJT 2004, P 89 ff.; demgegenüber erscheint der methodische Zugriff Oeters Integration und Subsidiarität (Fn. 1), vorzugswürdig, der einer vermeintlich (vor-)wertungsfreien und rein textimmanenten Behandlung bundesstaatlicher Themen misstraut und stattdessen die Aufdeckung entsprechender Vorverständnisse und Theorieangebote propagiert.

${ }^{25}$ In einem unspezifischen, übergreifenden Sinn ist „Unabhängigkeit“ oder „Selbständigkeit“ gemeint, im engeren Wortsinn „Selbstgesetzgebung“ oder „Selbstgesetzlichkeit“, die im griechischen Entstehungskontext als „Freiheit“ gedeutet wurden. Praktisch verwertbar wird der Begriff erst sachbereichsspezifisch: „Sein spezifischer Gehalt wird ... abhängig vom jeweiligen Problemumfeld.“; dann können die ethische (philosophische), die psychologische und die rechtliche Autonomie unterschieden werden. Im rechtlichen Kontext entstand die Begriffsverwendung in den konfessions- und verfassungspolitischen Auseinandersetzungen der Frühen Neuzeit. Parallel zum Aufstieg zum Zentralbegriff Kantischer Philosophie etablierte sich Autonomie als Rechtsbegriff auf politische Körperschaften bezogen als „Fähigkeit, nach eigenen Gesetzen zu leben“. Autonomie im Rechtssinne wurde später weiter differenziert, u.a. als „Satzungsautonomie“ i.S.v. Regelungsbefugnissen im Bereich der Selbstverwaltung und als „völkerrechtliche Autonomie“ i.S.v. völkerrechtlicher Selbstbestimmung. Jenseits des Öffentlichen prägten sich Autonomie als Privatfürstenrecht und letztlich die Privatautonomie aus; vgl. R. Pohlmann in: Historisches Wörterbuch der Philosophie, Bd. 1, 1971, 701 ff.; H. Oberreuter in: Staatslexikon, Bd. 1, 7. Aufl. 1985/95, 490 ff.; S. Lehmann-Brauns in: Jaeger (Hrsg.), Enzyklopädie der Neuzeit, Bd. 1, 2005, 889 ff., S. Hofer ebd., 893 ff.; moderner Versuch einer Fruchtbarmachung von Autonomie als herrschaftsbegründende Kategorie unter dem Grundgesetz bei Unruh Verfassungsbegriff (Fn. 19), $7 \mathrm{ff} ., 340 \mathrm{ff}$.

${ }^{26}$ Die Satzungsautonomie im technischen Sinne aus dem Recht der Selbstverwaltung ist im hiesigen Zusammenhang nicht gemeint; vgl. dazu nur BVerfGE 10, 20; 33, 125; H. Maurer DÖV 1993, 184; W. Schick in: EvStL, Bd. 1, 3. Aufl. 1987, Sp. 159 ff.; T. Clemens FS Böckenförde, 1995, 259 (263 ff.); C. Waldhoff FS Vogel, 2000, $495 \mathrm{ff}$.

${ }^{27} \mathrm{Im}$ rechtswissenschaftlichen Schrifttum wohl zuerst im Anschluss an das zeitgenössische finanzwissenschaftliche Schrifttum Hensel Finanzausgleich (Fn. 16), 14: „Die 
Deutschland Finanzautonomie mit Finanzhoheit und d.h. mit hinreichender finanzieller Ausstattung eines Teils des Bundesstaats oder einer Gebietskörperschaft gleichgesetzt: Finanzautonomie als aufgabenadäquate, verfassungsrechtlich abgesicherte Finanzausstattung, die vornehmlich durch die Zuweisung von Ertragshoheit gesichert erscheint, 28 Finanzen als Mittel und Voraussetzung von Autonomie i.S.v. „Sachautonomie“. ${ }^{29}$ In der Redeweise von der ,autonomiegerechten Finanzausstattung“ 30 wird dies auf den Begriff gebracht. Das ist letztlich auch die Sicht des Bundesverfassungsgerichts: Gesamtstaat und Gliedstaaten sollen am Ertrag der Volkswirtschaft sachgerecht beteiligt werden. ${ }^{31}$ In seiner Judikatur zum Länderfinanzausgleich dient dem Gericht als Analyseraster zur Bändigung der widerstreitenden Prinzipien neben dem „bündischen Prinzip des Eintretens füreinander“ die „Eigenstaatlichkeit und Eigenverantwortung“ der Länder;32 diese werde durch die

Durchführung jeder finanziellen Maßnahme durch den Staat ist somit niemals primärer, sondern stets nur sekundärer Staatszweck. Grundsätzlich haben sich in jedem Staate im Gegensatz zur Wirtschaft des Einzelnen die Einnahmen nach den Ausgaben zu richten.“

${ }^{28}$ Deutlich bereits durch den Titel des Beitrags: K.-A. Schwarz Der Finanzausgleich als Ordnungsrahmen effektiver Aufgabenerfüllung, in: Blanke/Schwanengel (Hrsg.), Zustand und Perspektiven des deutschen Bundesstaates, 2005, 107; P. Kirchhof JZ 1979, 153 (158): „Die Finanzausstattung des Staates folgt seinen Bewirkungsbefugnissen; sie ist aufgabenakzessorisch.“; U. Volkmann DÖV 1998, 613 (615); J. Wieland FG 50 Jahre BVerfG, Bd. 2, 2001, 771; K. Kruis DÖV 2003, 10; C. Hillgruber JZ 2004, 837 (844).

${ }^{29}$ Begriff nach $R$. Hendler in: Henneke (Hrsg.), Verantwortungsteilung zwischen Kommunen, Ländern, Bund und EU, 2001, 235 (236); ferner H.J. Blanke in: ders./ Schwanengel (Hrsg.), Zustand und Perspektiven des deutschen Bundesstaates, 2005, 127; vgl. auch L. Osterloh GS Trzaskalik, 2005, 181 (183): „Bei Autonomie geht es um die organbezogene Politikfähigkeit des Landes ....".

30 P. Kirchhof Der Verfassungsauftrag zum Länderfinanzausgleich als Ergänzung fehlender und als Garant vorhandener Finanzautonomie, 1982, 5; ebd.: „Finanzautonomie vermittelt Entscheidungsfreiheit und hat deshalb langfristig eine Verschiedenheit je nach vorangegangener Entscheidung zur Folge. Die bundesstaatliche Finanzverfassung steht vor der Aufgabe, die finanzwirtschaftliche Autonomie der einzelnen Länder durch entsprechende Ertragsausstattung zu erhalten ..." [Hervorhebung nur hier]. Insofern ist es folgerichtig, wenn bei der Verhandlung finanzverfassungsrechtlicher Reformen das „Ausblenden der Einnahmen zugunsten der Konzentration auf Aufgaben und Ausgaben“ zum Programm erhoben wird, vgl. so etwa F. Kirchhof Gutachten D zum 61. DJT, 1996, D 11.

31 BVerfGE 55, 274 (300).

32 BVerfGE 72, 330 (387); allgemein für diese Sicht auch P. Kirchhof Verfassungsauftrag (Fn. 30), 5; K. Stern Das Staatsrecht der Bundesrepublik Deutschland, Bd. 1, 2. Aufl. 1984, S. 667 f.; für den Finanzausgleich Pagenkopf (Fn. 1), S. 156; I. Kesper Bundesstaatliche Finanzordnung, 1998, 51 ff.; S. Korioth Der Finanzausgleich zwischen Bund und Ländern, 1997, $99 \mathrm{ff}$. 
Finanzausstattung ${ }^{33}$ sichergestellt. ${ }^{34}$ Auch wenn von ,finanzieller Selbstständigkeit" der Länder die Rede ist, ${ }^{35}$ ist damit regelmäßig nur der durch ausreichende Finanzmittel eröffnete politische Handlungsspielraum, d.h. eine politische Autonomie gemeint, nicht jedoch aktive Gestaltungsmöglichkeiten zur eigenverantwortlichen Finanzpolitik. ${ }^{36}$ Eine weiterreichende Finanzautonomie der Länder besteht nur auf der Ausgabenseite des staatlichen Finanzgeschehens, und auch diese schrumpft angesichts der Überlagerung durch nationale und europäische Stabilitätspakte. ${ }^{37}$

33 BVerfGE 72, 330 (386).

34 BVerfGE 72, 330 (383).

${ }^{35}$ BVerfGE 72, 330 (386).

${ }^{36}$ Deutlich etwa in BVerfGE 86, 148 (264): „Die finanzverfassungsrechtlichen Normen des Grundgesetzes sollen insgesamt eine Finanzordnung sicherstellen, die Bund und Länder am Finanzaufkommen sachgerecht beteiligt und finanziell in die Lage versetzt, die ihnen verfassungsrechtlich zukommenden Aufgaben auch wahrzunehmen ... Ihr Sinn und Zweck ist nicht allein, eine geordnete öffentliche Finanzwirtschaft der verschiedenen staatlichen Aufgabenträger zu ermöglichen, sondern ebenso, die Voraussetzungen dafür zu schaffen, daß die staatliche Selbständigkeit von Bund und Ländern real werden, ihre politische Autonomie sich in der Eigenständigkeit und eigenverantwortlichen Aufgabenwahrnehmung und der Haushaltswirtschaft (Art. 109 Abs. 1 GG) entfalten ...“ (Hervorhebung nur hier); vgl. auch C. Trzaskalik VVDStRL 52 (1993), 164 (165); Kommission Finanzverfassungsreform Baden-Württemberg Zwischenbericht, 1992, 14; K. Vogel/C. Waldhoff in: Dolzer/Vogel/Graßhof (Hrsg.), BK GG, Vorb. z. Art. 104a-115 Rn. 76; Kesper Finanzordnung (Fn. 32), 52f. Zu den grundsätzlichen Anknüpfungspunkten von Finanzautonomie K.-D. Henke in: Der Präsident des Niedersächsischen Landtages (Hrsg.), Die Stärkung der Finanzautonomie im föderativen System der Bundesrepublik Deutschland, 1995, 36 (37).

${ }^{37}$ Art. 104 EGV; Entschließung des Europäischen Rates über den Stabilitäts- und Wachstumspakt (AB1.EG 1997 Nr. C 236/1), Verordnung Nr. 1466/97 des Rates vom 7. Juli 1997 über den Ausbau der haushaltspolitischen Überwachung und der Überwachung und Koordinierung der Wirtschaftspolitiken (AB1.EG 1997 Nr. L 209/1), zuletzt geändert durch VO [EG] Nr., 1055/2005 des Rates vom 27. Juni 2005 (ABl.EG 2005 Nr. L 174/1) und der Verordnung Nr. 1467/97 des Rates vom 7. Juli 1997 über die Beschleunigung und Klärung des Verfahrens bei einem übermäßigen Defizit (ABl.EG 1997 Nr. L 209/6), zuletzt geändert durch VO [EG] Nr. 1056/2005 des Rates vom 27. Juni 2005 (AB1.EG 2005 Nr. L 174/5). Der sog. Nationale Stabilitätspakt besteht z.Z. aus dem auf Art. 109 Abs. 3 GG gestützten § 51a HGrG sowie den durch die Föderalismusreform 2006 eingefügten Art. 109 Abs. 5 GG; zur Problematik des Nationalen Stabilitätspakts U. Hartmann Europäische Union und Budgetautonomie, 1994; K. Stern FS Everling, Bd. 2, 1995, 1469 ff.; W. Höfling ZRP 1997, 231 ff.; P.J. Glauben ZG 1997, 233 ff; V. Mehde DÖV 1997, $616 \mathrm{ff}$.

Die Redeweise von der Finanzautonomie der Länder entlarvt sich in gewisser Weise selbst, wenn sie in Beziehung zur sog. Eigenstaatlichkeit der Länder gebracht wird (BVerfGE 72, 330 (386f. und öfter); ähnlich auch der Grundzug bei C. Gröpl DVB1. 2006, $1079 \mathrm{ff}$. .). Beide Kategorien werden weder durch eine normative, noch durch eine 


\section{Die Notwendigkeit des Einbezugs der Einnahmenseite}

Finanzautonomie in einer sinnvollen Wortbedeutung umfasst - wie noch näher zu entfalten sein wird - das gestaltende und damit das politische Element der Finanzpolitik, insbesondere im Hinblick auf die Einnahmenseite. Ausgabenautonomie könnte auch dann keine vollwertige Selbstbestimmung darstellen, wenn die Gestaltungsspielräume der Haushalte durch langfristige Bindungen, ${ }^{38}$ allgemeine Finanznot und supranationale Verschuldungsrestriktionen ${ }^{39}$ nicht ohnehin derart begrenzt erschienen. Ausgabenautonomie wird sich stets - wie sich am Beispiel der EG-Finanzierung zeigen lässt - als amputierte Finanzautonomie gerieren. ${ }^{40}$

\section{Finanzautonomie im Fokus des europäischen Beihilfenregimes}

Aus seiner Sachlogik heraus bringt das Europarecht hier eine Präzisierung. ${ }^{41}$ In seinem Schlussantrag in der Rechtssache über Steuervergünstigungen Portugals auf den Azoren ${ }^{42}$ hat Generalanwalt Geelhoed unzulässige Steuervergünstigungen ${ }^{43}$ im Sinne des Beihilfenregimes von

politisch-faktische Analyse gestützt; kritisch zu dem Argumentationstopos der „Eigenstaatlichkeit der Länder“ E. Denninger Staatsrecht 2, 1979, 95ff.; Korioth Finanzausgleich (Fn. 32), 93 ff.; C. Möllers Staat als Argument, 2000, 350 ff.; A. Hanebeck Der demokratische Bundesstaat des Grundgesetzes, 2004, $43 \mathrm{ff}$.

${ }^{38}$ C. Gröpl Haushaltsrecht und Reform, 2001, 155.

39 Vgl. die Nachweise oben Fn. 37.

40 Zur Bedeutung der Möglichkeit der Gestaltung qua Gesetzgebung allgemein und den Gegenreflexen in der deutschen Staatsrechtslehre R. Hendler ZG 1987, 210 (225ff.).

41 W. Schön in: Koenig u.a. (Hrsg.), Aktuelle Fragen des EG-Beihilfenrechts, 2001, 106 (129f.), weist darauf hin, dass ein unmittelbarer Zusammenhang zwischen verbotenen steuerlichen Beihilfen und den Bemühungen der EG-Kommission, schädlichen Steuerwettbewerb zu identifizieren und zu unterbinden (siehe unten unter III 6 und IV 3), besteht.

42 Rs. C-88/03 - Portugiesische Republik/Kommission der Europäischen Gemeinschaften, Schlussantrag vom 20. Oktober 2005; vgl. jetzt sich anschließend das Urteil des EuGH vom 6. September 2006, Tz. $52 \mathrm{ff}$; allgemein zu Steuervergünstigungen zur Förderung der wirtschaftlichen Entwicklung bestimmter Gebiete G. Jochum Die Steuervergünstigung, 2006, $434 \mathrm{f}$.

43 Allgemein zur Überprüfung von Steuertatbeständen am Beihilfenregime der Verträge: Mitteilung der Kommission über die Anwendung der Vorschriften über staatliche Beihilfen auf Maßnahmen im Bereich der direkten Unternemensbesteuerung, AB1.EG 1998 Nr. C 384/3 vom 10. Dezember 1998; K.A. Frick Einkommensteuerliche Steuervergünstigungen und Beihilfeverbot nach dem EG-Vertrag, 1994; W. Schön CMLRev. 36 (1999), 911 ff.; ders. in: Koenig u.a. (Hrsg.), Aktuelle Fragen des Beihilfenrechts, 2001, $106 \mathrm{ff}$; M.M. Koschyk Steuervergünstigungen als Beihilfen nach Artikel 92 EG-Vertrag, 1999; J. Blumenberg/M. Lausterer FS Rädler, 1999, 1 ff.; L. Wartenburger IStR 2001, 
Steuernormierungen als Ausfluss „wirklicher Autonomie“ unterschieden und sah sich bei diesem Unterfangen genötigt, Kriterien für (Finanz-)Autonomie zu entwickeln. Wettbewerbsvor- oder -nachteile, die Unternehmen durch die unterschiedliche Steuerbelastung im Gemeinsamen Markt haben, stellen mangels nationalen Vergleichsmaßstabs ${ }^{44}$ grundsätzlich keine unzulässigen Beihilfen dar, ${ }^{45}$ genauso wie die unterschiedliche Steuerbelastung als solche nicht diskriminierend oder beschränkend gegen Grundfreiheiten verstößt. ${ }^{46}$ „Wirkliche Autonomie“ ${ }^{47}$ bedeute beihilfenrechtlich, dass keine Quersubventionierungen der zentralen Ebene die Folgen der niedrigeren Einnahmen für die autonome Region ausgleichen, sondern von der beschließenden Region selbst getragen werden. ${ }^{48}$ Autonomie in diesem Sinne setzt Einnahmen und Ausgaben finanzwirtschaftlich zueinander in Beziehung und stellt einen Verantwortungszusammenhang für die Entscheidung auf der Einnahmenseite her.

397 ff.; D. Kellersmann/C. Treisch Europäische Unternehmensbesteuerung, 2002, 295 ff.; H. Kube in: Becker/Schön (Hrsg.), Steuer- und Sozialstaat im europäischen Systemwettbewerb, 2005, $99 \mathrm{ff}$; W.-H. Roth ebd., $119 \mathrm{ff}$; Jochum Steuervergünstigung (Fn. 42), 422 ff.; zu dem Parallelproblem im Rahmen von GATT/WTO J. Wagner Direkte Steuern und Welthandelsrecht, 2006.

44 Schlussantrag Generalanwalt Geelhoed (Fn. 42), Tz. 52f. Werden regionale Steuervergünstigungen von der Zentralregierung einseitig gewährt, ist demgegenüber das Beihilfenrecht stets relevant: Anwendungsfälle der Praxis der Gemeinschaft waren hier u.a. die Steuervergünstigungen für die neuen Länder in Deutschland (dazu etwa EuGH, Slg. 2000, I-6857 - Deutschland/Kommission; Koschyk Steuervergünstigungen (Fn. 43), 220 ff.; J. Blumenberg/M. Lausterer FS Rädler, 1999, 1 (8ff.)), sog. Coordination Centers in Belgien (dazu etwa Koschyk $244 \mathrm{ff}$.; Blumenberg/Lausterer 4f.), das International Financial Service Center im Dubliner Hafen (Koschyk $259 \mathrm{ff}$.; Blumenberg/Lausterer $6 \mathrm{f}$.) oder Off Shore-Geschäftszentren in Portugal, etwa auf Madeira (E. Pausenberger) C. Schmidt IStR 1996, $415 \mathrm{ff}$.).

45 EuG, verb. Rs. T 346/99, T-347/99 und T-348/99, Slg. 2002, II-4259 - Territorio Histórico de Álava - Diputación Foral de Álava u. a./Kommission, Rn. 62; Mehde Wettbewerb (Fn. 5), 243; nicht auf Steuern begrenzt C. Koenig/J. Kühling EuZW 1999, 517 ff.

46 Vgl. etwa EuGH Urt. v. 12. Mai 1998, Rs. C-336/96, Slg. 1998, I-2793 - Gilly, Tz. 34; dazu A. Cordewener Europäische Grundfreiheiten und nationales Steuerrecht, 2002, 590 ff.; Steuersatzunterschiede dürfen allerdings Ausländer im Inland nicht diskriminieren, EuGH Urt. v. 12. Juni 2003, Rs. C-234/01, Slg. 2003, I-5933 - Gerritse, Tz. 43 ff.; M. Lehner in: DStJG (Hrsg.) Besteuerung von Kapitaleinkünften, 2007.

47 Schlussantrag Geelhoed (Fn. 42), Tz. 54.

48 Schlussantrag Geelhoed (Fn. 42), Tz. 60: „Wenn ... der Beschluss der lokalen Körperschaft in wirklicher Autonomie ... gegenüber der Zentralregierung ergeht, so besteht kein logischer oder dogmatischer Grund für eine Unterscheidung zwischen symmetrischer Devolution von steuerlichen Befugnissen ... in dem sämtliche lokalen Körperschaften die gleichen autonomen steuerlichen Befugnisse haben ... und asymmetrischer Devolution von steuerlichen Befugnissen ... in dem nur einige, aber nicht alle lokalen Körperschaften autonome steuerliche Befugnisse haben“. 


\section{Finanzautonomie als Verfassungsprinzip}

Jeder Bundesstaat stellt ein Unikat dar. Dem Grundgesetz und darauf aufbauend der Rechtsprechung des Bundesverfassungsgerichts liegt keine übergeordnete Bundesstaatstheorie zugrunde. ${ }^{49}$ Gerade darin liegt die Chance des Arbeitens mit Grundprinzipien. Eine nicht nur ökonomisch, sondern verfassungstheoretisch unterfütterte Finanzautonomie als Verfassungsprinzip ${ }^{50}$ mag die - trotz der Technizität des zehnten Abschnitts des Grundgesetzes ${ }^{51}$ - beachtlichen Auslegungsspielräume zu konkretisieren helfen. Wenn Lerke Osterloh feststellt: „Eine Priorität des Ziels der Finanzautonomie findet weder im Verfassungstext noch in der deutschen Verfassungstradition eine Grundlage“ und damit von einer Polarität zwischen Autonomie und Verflechtung ausgeht mit der Folge, „praktische Konkordanz“ im konkreten Auslegungsprozess zu erzielen, ${ }^{52}$ kommt es entscheidend auf die Kompatibilität dieses Verfassungsprinzips mit anderen Staatsstrukturentscheidungen an. Das wird am Beispiel des Demokratieprinzips zu exemplifizieren sein.

\section{Finanzverflechtung als empirische Bestandsaufnahme}

Die geltende deutsche Finanzverfassung erweist sich als Hort extremer Verflechtung: ${ }^{53}$

- die fehlende Steuerautonomie der Länder wird durch Mitwirkungsrechte bei der Bundessteuergesetzgebung zu kompensieren gesucht (Art. 105 Abs. 3 GG); ${ }^{4}$

49 Vgl. etwa F. Ossenbühl in: ders. (Hrsg.), Föderalismus und Regionalismus in Europa, 1990, 117 (124, 160); A. Benz DÖV 1991, 586; H. Bauer DÖV 2002, 837 (838f.); zur Asymmetrie in der Entfaltung des Rechtsstaats- und des Demokratieprinzips einerseits, des Bundesstaatsprinzips andererseits in der deutschen Verfassungsjudikatur M. Nettesheim FS Badura, 2004, 363 (367). Zur Funktion von Verfassungsprinzipien und ihren Grenzen im hiesigen Kontext bereits Hensel Finanzausgleich (Fn. 16), 13, 22 ff., 147.

$50 \mathrm{Vgl}$. allgemein zu Verfassungsprinzipien im Staatsorganisationsrecht $V$. Mehde Die Verwaltung 34 (2001), 93 ff.; insgesamt F. Reimer Verfassungsprinzipien, 2001.

51 J. Isensee FS Ipsen, 1977, 409 (427); ders. HStR IV, 2. Aufl. 1999, § 98 Rn. 210; A. Voßkuhle AöR 119 (1994), 35 (43f.).

52 EuGRZ 2002, 309 (313); zu dem Zusammenwirken von Regelungen und Verfassungsprinzipien im Prozess der Konkretisierung der Regelungen Reimer Verfassungsprinzipien (Fn. 50), $284 \mathrm{ff} ., 439 \mathrm{ff}$.

53 P.M. Huber DJT-Gutachten (Fn. 19), D 25.

${ }^{54}$ Die Grundentscheidung des Grundgesetzes bei der Verteilung der bundesstaatlichen Zuständigkeit wiederholt sich im Bereich der Finanzverfassung, die ihrerseits die Verteilung finanzieller Ressourcen von der Wahrnehmung von Sachaufgaben entkoppelt: Die einzelnen Staatsfunktionen sind nicht en bloc einer Ebene zugeordnet, son- 
- schon auf der Ebene der „eigenen Finanzausstattung“, der ersten Stufe der Steuerverteilung (Art. 107 Abs. 1 GG), werden bei der Umsatzsteuerverteilung 55 umverteilende, bedarfsbezogene Elemente systemwidrig berücksichtigt;

- ein historisch und rechtsvergleichend einmaliger, übernivellierender Länderfinanzausgleich (Art. 107 Abs. 2 Satz 1 GG) gleicht schon vor dem hinzutretenden vertikalen Ausgleich durch Bundesergänzungszuweisungen (Art. 107 Abs. 2 Satz 3 GG) die Finanzkraft der Länder bis auf 99,5\% der durchschnittlichen Finanzkraft an, seit der Umsetzung des Urteils zum Maßstäbegesetz abgesenkt auf einen Wert zwischen 93 und $95 \% ; 56$

- die - inzwischen reformierten - Gemeinschaftsaufgaben, verbunden mit den ausdehnend interpretierten Ausnahmen der Finanzierungslast (v.a. Art. 104a Abs. 4 GG) begünstigen Mischfinanzierungen;57

- die Konnexität der Finanzierungslast in Art. 104a Abs. 1 GG in Anlehnung an die Verwaltungszuständigkeit spiegelt das Konzept des Exekutivföderalismus in der Finanzverfassung.

Die hier nur angerissenen Zonen finanzwirtschaftlicher Verflechtung begünstigten und begünstigen die historisch wie vergleichend exorbitante Flucht sämtlicher Ebenen in die Staatsverschuldung.

dern werden je einzeln aufgeteilt. Man kann dies als funktionale- im Gegensatz zu einer Aufteilung der (Finanz-)Hoheiten nach Politikbereichen bezeichnen. Steuergesetzgebungs-, Steuerertrags-, Steuerverwaltungs- und Steuerrechtsprechungshoheit im Hinblick auf einzelne Steuerarten erscheinen so in einem Kompetenzgeflecht zwischen Bund und Ländern, die Verschränkung derartiger Funktionsbereiche ist typusbildend. Die Steuergesetzgebungskompetenz ist durch die Umkehrung des Verteilungsmodus aus Art. 70 Abs. 1 GG und durch die Ausschöpfung der Möglichkeiten des Bundes zur konkurrierenden Gesetzgebung auf der Grundlage des alten Art. 72 Abs. 2 GG weitestgehend zentralisiert. Die Landessteuerautonomie bezieht sich praktisch nur noch auf die örtlichen Verbrauch- und Aufwandsteuern, mit den Gemeindesteuern also auf Abgaben, die gar nicht ,ihre“ Ebene in der Mehrebenenstruktur betrifft. Die fehlende eigene Gestaltungsmacht der Länder soll durch die Mitwirkung am übergeordneten Rechtsetzungsprozess kompensiert werden (Art. 105 Abs. 3 GG). Die eigenen Gestaltungsmöglichkeiten gehen so verloren, da über den Bundesrat stets nur eine Ländermehrheit wirksam agieren kann und ein spezifisches Profil des je einzelnen Landes von vornherein ausgeschlossen erscheint; letztlich handelt es sich um das Vortäuschen einer „föderalistischen Äquivalenz", die so nicht besteht und niemals bestehen kann.

55 Vgl. etwa H.-G. Henneke Öffentliches Finanzwesen, Finanzverfassung, 2. Aufl. 2000, Rn. $741 \mathrm{ff}$.

${ }^{56} \mathrm{Zu}$ den verschiedenen Berechnungsmethoden vgl. P. M. Huber in: von Mangoldt/ Klein/Starck, GG, Bd. 3, 5. Aufl. 2005, Art. 107, Rn. 132, Fn. 102., zu den damit verbundenen Fehlanreizen S. Homburg FinArch. 51 (1994), 312ff.

57 Vgl. etwa Henneke Öffentliches Finanzwesen (Fn. 55), Rn. $227 \mathrm{ff}$. 


\section{Die Rekonstruktion der Finanzordnung der Mehrebenenstruktur aus ihrem Individualbezug}

\section{Fundierung der Finanzordnung durch das Demokratieprinzip}

Alle Legitimationsfragen müssen bei der freien, autonomen Person ansetzen oder zu ihr zurückführen; das Individuum erweist sich als letzte Bezugsgröße des Rechts. Nur von der autonomen Person aus kann Herrschaft und können institutionelle Regelungen ihre Rechtfertigung erfahren. ${ }^{58}$ Dies ist im demokratischen Verfassungsstaat Folge des notwendigen Aufeinanderbezogenseins individueller und demokratischer Selbstbestimmung, ${ }^{59}$ individueller und demokratischer Freiheit. ${ }^{60}$ Individuelle und staatliche Autonomie werden damit nicht gleichgesetzt; ${ }^{61}$ die wechselseitige Bezogenheit ist vielmehr Element eines Legitimationszusammenhangs zwischen Individuum und Herrschaft. ${ }^{62}$ Staatsorganisationsrechtliche Prinzipien und Staatsstrukturentscheidungen werden in der deutschen Tradition demgegenüber ganz überwiegend traditional ${ }^{63}$

58 I. Kant Metaphysik der Sitten, Einleitung in die Rechtslehre, § B (AA VI 230), Rechtslehre, $\$ 46$ (AA VI 313 f.); ders. Über den Gemeinspruch: Das mag in der Theorie richtig sein, taugt aber nichts für die Praxis, Vom Verhältniß der Theorie zur Praxis im Staatsrecht (AA VIII 289f.); J. Habermas Faktizität und Geltung, 1992, 15 f., 122 ff.; vgl. ferner etwa auch Unruh Verfassungsbegriff (Fn. 19), $7 \mathrm{ff} ., 340 \mathrm{ff} . ;$ A. Janssen in: Henneke (Hrsg.), Verantwortungsteilung zwischen Kommunen, Ländern, Bund und EU, 2001, 59 (63); R. Wahl, Herausforderungen und Antworten: Das öffentliche Recht der letzten fünf Jahrzehnte, 2006, $20 \mathrm{ff}$.

59 C. Möllers Gewaltengliederung, 2006, $15 \mathrm{ff}$., $28 \mathrm{ff}$.

60 J. Isensee Der Staat 20 (1981), $161 \mathrm{ff}$; C. Starck HStR III, 3. Aufl. 2005, § 33 Rn. 2 und durchgehend; U. Di Fabio Der Verfassungsstaat in der Weltgesellschaft, 2001, 17f.; ders. FS Badura, 2004, $77 \mathrm{f}$.

61 Vgl. zur (individuellen) Autonomie als Grundlegitimationsfigur von Recht Unruh Verfassungsbegriff (Fn. 19).

62 Vgl. auch A. Janssen in: Henneke (Hrsg.), Verantwortungsteilung zwischen Kommunen, Ländern, Bund und EU, 2001, 59 (63); R. Wahl in: ders., Verfassungsstaat, Europäisierung, Internationalisierung, 2003, 53; Möllers Gewaltengliederung (Fn. 59), 32; ähnlich Hanebeck Bundesstaat (Fn. 37); ferner R. Eckertz FS Böckenförde, 1995, 14 (23f.).

63 Isensee AöR 115 (1990), 248 (251 f.); ders. HStR IV, 2. Aufl. 1999, § 98 Rn. 1, 10; Jestaedt HStR II, 3. Aufl. 2004, § 29 Rn. 2ff.; zu den Grenzen ebd. Rn. 11: „Der Verweis auf die Geschichte stillt ... den Legitimationsbedarf nicht.“; B. Grzeszick in: Maunz/Dürig, GG, Art. 20 IV Rn. 2 ff.; Aufdeckung der überholten ideengeschichtlichen Schlacken v.a. bei $S$. Oeter Integration und Subsidiarität im deutschen Bundesstaatsrecht, 1998; ferner Hanebeck Bundesstaat (Fn. 37), 64 ff.; geschichtliche Darstellungen bei H. Maier AöR 115 (1990), 213 ff.; B. Grzeszick, Vom Reich zur Bundesstaatstheorie, 1996; H. Holste, Der deutsche Bundesstaat im Wandel (1867-1933), 2002. 
oder funktional ${ }^{64}$ legitimiert. ${ }^{65}$ Der Individualbezug erscheint in dieser Sichtweise eher negativ: Es wird ein Spannungsverhältnis zwischen Bundesstaatlichkeit und (parlamentarisch-)demokratischem Verfassungsprinzip konstatiert, es werden die eher gegenläufigen Wirkungen analysiert. ${ }^{66}$ Aus dem Dargelegten wird dann vielfach ein vermeintlich „unpolitischer" Charakter des Bundesstaats hergeleitet. ${ }^{67}$

Der dargelegte Zusammenhang gilt für die Grundfragen der Staatsfinanzierung in besonderem Maße: 68 „No taxation without representation“ als Kampfbegriff der amerikanischen Revolution machte die hier zugrunde gelegte Prämisse, „dass jeder Verteilung von öffentlichen Geldern zunächst ein Zugriff auf private Gelder vorausgeht“"69 zum All-

${ }^{64}$ R. Mayntz AöR 115 (1990), 232 ff.; zur Kritik B.-O. Bryde in: Sitter-Liver (Hrsg.), Herausgeforderte Verfassung, 1999, 223 (227f.): „funktionalistischer Kurzschluss“, indem versucht wird ein „mehrdimensionales Problem eindimensional zu lösen“; hier wäre auch die ökonomische Theorie des Bundesstaats als neueren Ansatz einzuordnen, vgl. statt vieler D. Sauerland Föderalismus zwischen Freiheit und Effizienz, 1997; Oeter in: Engel/Morlok (Hrsg.), Öffentliches Recht als ein Gegenstand ökonomischer Forschung, 1998, $119 \mathrm{ff}$., sowie die Nachweise oben in Fn. 9.

${ }^{65}$ Diese Legitimationsmodelle können - im Gegensatz zu dem hier verfolgten - als „output-orientiert“ bezeichnet werden. $\mathrm{Zu}$ dem Übergang von der traditionalen zur funktionalen Legitimation G. Kisker in: Probleme des Föderalismus, 1985, $23 \mathrm{ff}$. Generell für eine erweiterte Sicht verfassungsrechtlicher Kompetenzen, jedoch ohne das hier verfolgte Anliegen, R. Stettner Grundfragen einer Kompetenzlehre, 1983. Ein traditionsreicher Verbindungsstrang zwischen Staatsorganisation und Demokratieprinzip ist die Herleitung und Rechtfertigung des überkommenen Typus der hierarchischen Ministerialverwaltung aus dem Demokratieprinzip (vgl. nur H. Dreier Hierarchische Verwaltung und demokratischer Staat, 1991; U. Di Fabio VVDStRL 56 (1997), 235 (263ff.); A. Musil Wettbewerb in der staatlichen Verwaltung, 2005, $117 \mathrm{ff}$.$) ; dort fehlt jedoch die$ Mehrebenenproblematik, der bundesstaatliche Bezug.

66 Einflussreich E. Kaufmann Bismarcks Erbe in der Reichsverfassung, 1917, $67 \mathrm{ff}$.; C. Schmitt Verfassungslehre, 1928, 334, 388 ff.; Kontinuität dieser Ansätze in der jungen Bundesrepublik v.a. über W. Weber Spannungen und Kräfte im westdeutschen Verfassungssystem, 3. Aufl. 1970, 57 (63 ff.); vgl. dazu jeweils W. Kägi in: Juristische Fakultäten der schweizerischen Universitäten (Hrsg.), Die Freiheit des Bürgers im schweizerischen Recht. FG zur Hundertjahrfeier der Bundesverfassung, 1948, 53 (61 ff.); R. Eckertz FS Böckenförde, 1995, 13 (16ff.); R. Lhotta in: Jahrbuch des Föderalismus 2001, 35 (41 ff.); Hanebeck Bundesstaat (Fn. 37), 278ff.; B. Grzeszick in: Maunz/Dürig, GG, Art. 20 IV Rn. 44; Möllers in: Aulehner u.a. (Hrsg.), Föderalismus - Auflösung oder Zukunft der Staatlichkeit? 1997, 81 ff.; A. Peters Elemente einer Theorie der Verfassung Europas, 2001, 636.

${ }^{67}$ Isensee AöR 115 (1990), 248 (258f.).

${ }^{68}$ Vgl. etwa Diskussionsbemerkung A. Merkl VVDStRL 14 (1956), 85.

69 P. Kirchhof VVDStRL 52 (1993), 147 (148): „Die Finanzverfassung darf nicht, wie es gelegentlich geschieht, nur als Verteilungsproblem behandelt werden; vielmehr rückt 
gemeingut. ${ }^{70}$ Gleichwohl verfehlten und verfehlen weite Teile der seit Existenz des deutschen Nationalstaats permanent geführten Debatte über die bundesstaatliche Finanzverfassung diesen Zusammenhang. ${ }^{71}$ Das Programm „No taxation without representation“ ist Stufungen wie im Bundesstaat oder im Staatenverbund niemals angepasst worden. Im Rahmen der völlig parallel laufenden, weitgehend unkoordinierten Kompetenzaufteilung nach der amerikanischen bundesstaatlichen Tradition führte das auch nicht zu größeren Verwerfungen. Für die funktionale Aufteilung der Kompetenzen in der deutschen und in der gemeinschaftsrechtlichen Tradition gilt anderes. Die fehlende Beziehung zwischen demokratischer Partizipation an der Regelung der Staatsfinanzierung und föderaler Ordnung mag für ein Verfassungssystem wie dasjenige des Bismarckreichs mit seinem grundlegend anders gearteten Legitimationsmodus als „Bund“ souveräner Fürstenhäuser ${ }^{72}$ noch nachvollziehbar sein; überhaupt standen im konstitutionellen Zeitalter Föderalismus und Bundesstaatlichkeit in Deutschland für monarchische Legitimität und Partikularismus und damit gegen die zukunftsweisenden, an das Individuum anknüpfenden Bewegungen von Nation und Demokratie. ${ }^{73}$ Das stellt als historische Hypothek einen entscheidenden Legi-

sie in ihrem systematischen Aufbau und in ihren Kernaussagen nachdrücklich ins Bewusstsein, dass der Umverteilung die Nahme vorausgeht. Finanzstaatlichkeit beginnt mit der Besteuerung.“ Im Ansatz anders F. Schoch in: Henneke (Hrsg.), Verantwortungsteilung zwischen Kommunen, Ländern, Bund und EU, 2001, 21 (22): „Unterscheidung zwischen dem demokratietheoretischen Zugang zu der Thematik und dem Föderalismusproblem“.

${ }^{70}$ Manifestiert etwa in der Petition des Kolonialparlaments von New York gegen das Zuckergesetz vom 18. Oktober 1764, abgedruckt bei A. und W.P. Adams (Hrsg.), Die Amerikanische Revolution und ihre Verfassungen 1754-1791, 1987, 27; zum historischen und sozio-ökonomischen Hintergrund W.P. Adams Die Vereinigten Staaten von Amerika, 1977, 31; H. Dippel Die Amerikanische Revolution 1763-1787, 1985, $43 \mathrm{ff}$.

${ }^{71}$ Bemerkenswert ist, dass in den Referaten und vor allem in der Diskussion der Hamburger Staatsrechtslehrertagung 1955 die Verknüpfung noch präsenter ist (vg1. Hettlage VVDStRL 14 (1956), 1 (4ff.), Schlusswort 92 ff.; Diskussionsbemerkungen Forsthoff, Weber, Merkl u.a.), auf der Bayreuther Tagung 1992 jedoch weitgehend ausgeblendet bleibt. Deutliche Zurückhaltung etwa auch bei H. Fischer-Menshausen in: von Münch/Kunig, GGK, Bd. 3, 2. Aufl. 1983, Art. 105 Rn. 5; R. Wendt HStR IV, 2. Aufl. 1999, § 104 Rn. 17.

72 Vgl. nur D. Willoweit Deutsche Verfassungsgeschichte, 5. Aufl. 2005, $325 \mathrm{ff}$., $334 \mathrm{ff}$.; zur Legitimationsgrundlage des konstitutionell-monarchischen Staats allgemein D. Grimm Deutsche Verfassungsgeschichte 1776 - 1866, 1988, $110 \mathrm{ff}$.

73 Vgl. mit Bezug auf die Finanzordnung W. Gerloff Die Finanzgewalt im Bundesstaat, 1948, 9ff.; J.-P. Schneider Der Staat 40 (2001), 272 (282); zu Bismarcks Instrumentalisierung der föderalen Reichsstruktur gegen den Parlamentarismus Möllers in: Aulehner u.a. (Hrsg.), Föderalismus - Auflösung oder Zukunft der Staatlichkeit? 1997, $82 \mathrm{ff}$. 
timitätsunterschied etwa zum US-amerikanischen oder schweizerischen Föderalismus bis in die jeweilige bundesstaatliche Finanzordnung dar. ${ }^{74}$ Speziell für die Finanzverfassung kommen Entstehensbedingungen hinzu, wie sie für eine föderalistisch-freiheitliche Interpretation ungünstiger kaum sein könnten. ${ }^{75}$ Der maßgebliche Berichterstatter im Parlamentarischen Rat, der ehemalige preußische Finanzminister Hermann Höpker Aschoff, zeichnete sich - verstärkt durch Abwehrreflexe gegen bundesstaatliche Vorgaben der alliierten Siegermächte ${ }^{76}$ - durch ein politisch wie biographisch ${ }^{77}$ geprägtes zentralistisch-technokratisches Grundverständnis aus und wollte in Anknüpfung an Weimarer Verfassungszustände (hier vornehmlich die zentralisierende Erzbergersche Finanzreform von 1919/20) ${ }^{78}$ ein die föderale Gliederung letztlich negierendes Regime errichten. ${ }^{79}$ Eine demokratische Neufundierung der föderalistischen Staatsordnung konnte in einem derartigen Umfeld nicht stattfinden. ${ }^{80}$ Aus dieser Vorprägung hat sich die bundesstaatliche Fi-

${ }^{74}$ T. Nipperdey in: ders., Nachdenken über die deutsche Geschichte, 1986, $71 \mathrm{ff}$.; W. Kägi in: Juristische Fakultäten der schweizerischen Universitäten (Hrsg.), Die Freiheit des Bürgers im schweizerischen Recht. FG zur Hundertjahrfeier der Bundesverfassung, 1948, 53 (65ff.); H. Dippel Der Staat 38 (1999), 221 ff.; S. Fisch in: von Arnim u.a. (Hrsg.), Föderalismus - Hält er noch, was er verspricht? 2000, 29 (34); Waldhoff Verfassungsrechtliche Vorgaben (Fn. 16), 38 ff.; K. Kruis DÖV 2003, 10 (11).

75 Analyse zentralistischer und unitarischer Bestrebungen im und um den Parlamentarischen Rat und die früh-bundesrepublikanische Bundesstaatslehre bei Oeter Integration und Subsidiarität (Fn. 1), $96 \mathrm{ff} ., 143 \mathrm{ff}$.

${ }^{76}$ H.J. Fischer Parlamentarischer Rat und Finanzverfassung, Diss. iur. Kiel 1970; F.W. Scharpf Föderale Politikverflechtung, MPIfG Working Paper 99/3, 1999, 4, 5.

77 T. Aders Die Utopie vom Staat über den Parteien - Biographische Annäherungen an Hermann Höpker Aschoff (1883-1954), 1994; F. Spieker Hermann Höpker Aschoff Vater der Finanzverfassung, 2004, insbes. $41 \mathrm{ff}$., $52 \mathrm{ff}$.; C. Waldhoff Die Verwaltung 39 (2006), 155 (168f.).

78 Zeitgenössische Bewertung bei Hensel Finanzausgleich (Fn. 16), 174ff.; Einzelheiten bei F. Menges Reichsreform und Finanzpolitik, 1971, $184 \mathrm{ff}$.; Pagenkopf Finanzausgleich (Fn. 1), S. 113; K. M. Hettlage in: Jeserich/Pohl/von Unruh (Hrsg.), Deutsche Verwaltungsgeschichte, Bd. 4, 1985, 177 ff.; G. Höfler Erzbergers Finanzreform und ihre Rückwirkung auf die bundesstaatliche Struktur des Reiches vorwiegend am bayerischen Beispiel, Diss. phil. Freiburg 1955.

${ }^{79} \mathrm{Zu}$ diesen ausgesprochen zentralistischen Grundprägungen W. Gerloff Die Finanzgewalt im Bundesstaat, 1948; H. Höpker Aschoff AöR 75 (1949), 306ff.; G. Strickrodt Die Finanzverfassung des Bundes als politisches Problem, 1951, 13; Renzsch Finanzverfassung (Fn. 1), 54 ff.; J.-P. Schneider Der Staat 40 (2001), 272 (283); S. Korioth in: DJT 2004, P 89 (P 98); Höpker Aschoffs Wirken in diese Richtung reicht bis in das erste Urteil des Bundesverfassungsgerichts zum Länderfinanzausgleich hinein (BVerfGE 1, 117), vgl. Oeter Integration und Subsidiarität (Fn. 1), $193 \mathrm{ff}$.

${ }^{80}$ Eingehend W. Schmidt AöR 87 (1962), 253 ff.; H. Abromeit Der verkappte Einheitsstaat, 1992, 33 ff.; Hanebeck Bundesstaat (Fn. 37), 136 ff.; zu dem Problem aus dem zeit- 
nanzverfassung letztlich nie befreien können; in der großen Finanzreform 1967/6981 wurde die unitarisch-technokratische Grundprägung nur durch ein neues, ökonomisch inzwischen alles andere als unstrittiges Paradigma, die staatliche Konjunkturpolitik im Sinne der sog. Globalsteuerung ersetzt. ${ }^{82}$ Für den auf der Volkssouveränität aufbauenden und damit gerade beim autonomen Individuum anknüpfenden Verfassungsstaat kann das auch in bundesstaatlicher Hinsicht nicht das letzte Wort sein. ${ }^{83}$

\section{Individualschützende Funktionen der finanzverfassungsrechtlichen Kompetenzordnung}

Das Zusammengreifen von organisationsrechtlich-bundesstaatlichem Finanzverfassungsrecht und inhaltlichen Vorgaben für die staatliche Finanzgebarung, das wechselseitige funktionale Ineinandergreifen fehlender inhaltlicher Begrenzungen mit institutionellen Arrangements ist gerade im Finanzverfassungsrecht alles andere als neu. ${ }^{84}$ Das Bundesverfassungsgericht betont in ständiger Rechtsprechung die „Begrenzungs- und Schutzfunktion der Finanzverfassung““:85 Der Bürger soll

genössischen Schrifttum M. Weber Parlament und Regierung im neugeordneten Deutschland, 1918, $131 \mathrm{ff}$., $150 \mathrm{ff}$.

81 Zur Legislationsgeschichte Renzsch Finanzverfassung (Fn. 1), 209ff.; die Grundlagen sind aus dem sog. Troeger-Gutachten ersichtlich, Kommission für die Finanzreform, Gutachten über die Finanzreform in der Bundesrepublik Deutschland, 1966.

82 Vgl. auch Mehde Wettbewerb (Fn. 5), 153 ff.; zur Nichterfüllung der damit verbundenen Erwartungen nur F.W. Scharpf in: Bundesrat (Hrsg.), Vierzig Jahre Bundesrat, 1989, 121 (149); Selmer VVDStRL 52 (1993), 10 (15); H.D. von Loeffelholz in: Probleme des Finanzausgleichs in nationaler und internationaler Sicht, 1993, $29 \mathrm{ff}$;; angesichts der weiter zunehmenden europäischen und internationalen Verflechtung wird diese nachfrageorientierte Ausrichtung aller Voraussicht nach noch weiter an Gewicht verlieren, vgl. nur Henneke Finanzverfassung (Fn. 55), Rn. 1050.

83 A. Janssen in: Henneke (Hrsg.), Verantwortungsteilung zwischen Kommunen, Ländern, Bund und EU, 2001, 59 (62ff.); K. Kruis DÖV 2003, 10 (13ff.); strukturell ähnliche Beobachtung der unterlassenen Neufundierung der Bundesstaatlichkeit nach dem Wechsel zum Prinzip der Volkssouveränität in je anderen Zusammenhängen bei S. Fisch in: von Arnim u.a. (Hrsg.), Föderalismus - Hält er noch, was er verspricht? 2000, 29 (34ff.); W. Schmidt AöR 87 (1962), 253 (257); G. Zimmer Funktion - Kompetenz - Legitimation, 1978, S. 33 ff., 57 ff.; M. Heckel FS Badura, 2004, 169 (171 ff.); vgl. auch die Feststellung bei R. Stettner in: Dreier, GG, Bd. 2, 2. Aufl. 2006, Art. 70 Rn. 19; einen sehr eigenständigen Ansatz in diesem Zusammenhang bringt A.R. Greber Die vorpositiven Grundlagen des Bundesstaates, 2000, $193 \mathrm{ff}$.

84 Vgl. bereits Hettlage VVDStRL 14 (1956), 1 (4-10).

${ }^{85}$ Zuletzt BVerfGE 108, 1 (17) - Studien-Rückmeldegebühr BaWü; zuvor BVerfGE 55, 274 (300, 302) - Berufsausbildungsabgabe; 67, 256 (290) - Investitionszwangsan- 
nur durch kompetenzgemäß erhobene Abgaben belastet werden, er muss sich darauf verlassen können, nur in dem durch die Finanzverfassung vorgezeichneten Rahmen abgeschöpft zu werden. Diese individualschützende Seite der finanzverfassungsrechtlichen ${ }^{86}$ Kompetenzordnung hat in ihren verschiedenen Spielarten die Gemeinsamkeit, dass es um Freiheitsschutz, in jedem Fall um eine abwehrrechtliche Dimension aus der Perspektive des Bürgers geht. Auf die Ebene der allgemeinen Bundesstaatsdogmatik gehoben spiegeln sich hier Elemente der vertikalen Gewaltenteilung. ${ }^{87}$ Es ist kein Zufall, dass diese „negativen“, freiheitsschützenden Wirkungen des Bundesstaats als letztes bundesstaatliches Legitimationsreservoir gerade in der Lehre vom „unitarischen Bundesstaat" Konrad Hesses fungieren.88 Positiv wurde in den überkommenen Rechtfertigungsversuchen in Bezug auf das Demokratieprinzip lediglich die Vervielfachung demokratischer Teilhabe angesichts einer Vermehrung dafür geeigneter Ebenen ins Feld geführt ${ }^{89}$ oder das Anliegen, effiziente staatliche Handlungsmacht mit „der Sicherung

leihe; 93, 319 (342f.) - Wasserpfennig; K. Vogel/C. Waldhoff in: Dolzer/Vogel/Graßhof (Hrsg.), BK GG, Vorb. Z. Art. 104a-115 Rn. 33, 69; M. Heintzen in: von Münch/Kunig (Hrsg.), GGK III, 4./5. Aufl. 2003, Vorb. Art. 104a-115 Rn. 26.

86 Vgl. allgemein Stettner Kompetenzlehre (Fn. 65), S. 320 ff.; warum diese Wirkung auf die Finanzverfassung beschränkt sein soll, bleibt dunkel; so aber M. Heintzen in: Dolzer/Vogel/Graßhof (Hrsg.), BK GG, Art. 70 Rn. 52.

${ }^{87}$ Vgl. etwa BVerfGE 12, 205 (229); K. Hesse Grundzüge des Verfassungsrechts der Bundesrepublik Deutschland, 20. Aufl. 2005, Rn. 231 f.; C. Starck HStR III, 3. Aufl. 2005, § 33 Rn. 35; Unruh Verfassungsbegriff (Fn. 19), S. 560 ff.; differenziert E.-W. Böckenförde in: ders., Staat - Nation - Europa, 1999, 183 (192ff.); zu Parallelen in der amerikanischen Bundesstaatsdoktrin W. Schmidt AöR 87 (1962), 253 (265ff.); zur ökonomischen Formulierung dieser Wirkung S. Oeter in: Engel/Morlok (Hrsg.), Öffentliches Recht als ein Gegenstand ökonomischer Forschung, 1998, 119 (120ff.).

${ }^{88}$ Der unitarische Bundesstaat, 1962, $26 \mathrm{ff} . ;$ kritisch C. Möllers in: Aulehner u.a. (Hrsg.), Föderalismus - Auflösung oder Zukunft der Staatlichkeit? 1997, 81 (94, 101); Hanebeck Bundesstaat (Fn. 37), 31 f. spricht in Bezug auf das Konzept der vertikalen Gewaltenteilung von einer „Legitimitätstransplantion“ zugunsten des Bundesstaats; grds. ablehnend zu Figur und Wirksamkeit vertikaler Gewaltenteilung T. Schodder Föderative Gewaltenteilung in der Bundesrepublik Deutschland, 1988; differenziert-kritisch auch H.H. Rupp FG zum 10jährigen Jubiläum der Gesellschaft für Rechtspolitik, 1984, 377 ff.; W.-R. Schenke JuS 1989, 698 ff. Zu dem Zusammenhang zwischen der Integrationslehre Smends und Hesses Konzeption kritisch S. Korioth Integration und Bundesstaat, 1990, $280 \mathrm{ff}$;; Oeter Integration und Subsidiarität (Fn. 1), $249 \mathrm{ff}$.

89 J. Isensee HStR IV, 2. Aufl. 1999, § 98 Rn. 18; K. Rennert Der Staat 32 (1993), 269 (273f.); Jestaedt HStR II, 3. Aufl. 2004, § 29 Rn. 12; C. Möllers Gewaltengliederung (Fn. 59), 15 ff., 81 ff., 331 ff.; B. Grzeszick in: Maunz/Dürig, GG, Art. 20 IV Rn. 24; vgl. jetzt den Neuansatz, das Demokratieprinzip als Direktive und Maßstab für „bundesstaatliche Entflechtungen“ fruchtbar zu machen bei Huber Föderalismusfalle (Fn. 20), 17 ff.; ders. DJT-Gutachten (Fn. 19), D 33 ff. 
und Stärkung menschlicher Autonomie und Freiheit in Ausgleich zu bringen". .90

\section{Kongruenz zwischen demokratischer Legitimation und finanzwirt-} schaftlicher Verantwortung als Postulat der Steuerrechtfertigung

\section{a) Demokratische Rückkoppelung der Finanzierung öffentlicher Gemeinwesen}

Der ausgeprägte Individualbezug im Recht der Staatsfinanzierung erschöpft sich nach überkommener Sicht über den Vorbehalt des Gesetzes in der besonderen Gesetzesgebundenheit des Abgabenrechts. ${ }^{91}$ Ein Bezug zur bundesstaatlichen Finanzordnung wird nicht gezogen. Das Steuerrecht lebt - nach einer vielzitierten Wendung des Bundesverfassungsgerichts - aus dem „Diktum des Gesetzgebers“92 - unter dem Grundgesetz müsste man ergänzen: des Bundesgesetzgebers. Der steuerrechtliche Gesetzesvorbehalt ist nicht nur historisch Vorbild für den allgemeinen Gesetzesvorbehalt gewesen, ${ }^{93}$ das Steuer- und Abgabenrecht unterliegt auch in der geltenden Verfassungsordnung einer strikten Gesetzesbindung. ${ }^{94}$ Im Verfassungsstaat kann sich die demokra-

90 Kisker in: Probleme des Föderalismus, 1985, 23 (25ff.); Bauer DÖV 2002, 837 (838); Nettesheim FS Badura, 2004, 363 (369).

${ }_{91} \mathrm{Zu}$ dieser Schutzfunktion etwa Y. Kovacs No Taxation Without Representation Die Gesetzesdelegation im Steuerrecht unter besonderer Berücksichtigung des zürcherischen Steuergesetzes, 1991, 6.

92 BVerfGE 13, 318 (328) im Anschluss an O. Bühler/G. Strickrodt Steuerrecht, Bd. 1, 3. Aufl. $1960,658$.

93 F. Drewes Die steuerrechtliche Herkunft des Grundsatzes der Gesetzmäßigkeit der Verwaltung, Diss. iur. Kiel 1958; E.-W. Böckenförde Gesetz und gesetzgebende Gewalt, 2. Aufl. 1981, $47 \mathrm{ff}$; H.-J. Papier Die finanzrechtlichen Gesetzesvorbehalte und das grundgesetzliche Demokratieprinzip, 1973, 15 ff.; H.J. Cremer Titel VII $\S \S 3$ bis 6 der Verfassungsurkunde für das Königreich Bayern vom 26. Mai 1818, 1994; Waldhoff Verfassungsrechtliche Vorgaben (Fn. 16), $110 \mathrm{ff}$.

94 Papier Gesetzesvorbehalte (Fn. 93), 117 ff., $156 \mathrm{ff}$., $172 \mathrm{ff} ., 202 \mathrm{ff}$.; J. Isensee Die typisierende Verwaltung, 1976, $101 \mathrm{ff} . ;$ R. Mußgnug Der Haushaltsplan als Gesetz, 1976, 322; W.R. Walz Steuergerechtigkeit und Rechtsanwendung, 1980, 138f.; kritisch differenziert demgegenüber $L$. Osterloh Gesetzesbindung und Typisierungsspielräume bei der Anwendung der Steuergesetze, 1992, 93 ff. Der im Text dargelegte Zusammenhang zeigt sich bei einem Vergleich mit dem anderen klassischen Bereich der Eingriffsverwaltung, dem Polizeirecht (vgl. bereits O. Mayer Deutsches Verwaltungsrecht, Bd. 1, 3. Aufl. 1924, 315; jetzt aufgenommen durch BVerfG NJW 2006, 1191 (1193) - Kumulation von Einkommensteuer und Gewerbesteuer)). Wird dieses durch Ermessenstatbestände und unbestimmte Rechtsbegriffe charakterisiert, empfängt seine Feinsteuerung letztlich aus in der Wirklichkeit vorgezeichneten Lagen der Gefahrenabwehr, ist das sehr viel abs- 
tische Fundierung der Steuer nicht in dem formalen Erfordernis der gesetzlichen Grundlage der Abgabenerhebung erschöpfen; auch die Verwendung der erhobenen Steuern ist in spezifischer Weise demokratisch rechtfertigungsbedürftig. Dies wird - bei aller Steuerungsschwäche ${ }^{95}-$ durch das Budgetrecht des Parlaments im Sinne einer politischen Gesamtentscheidung über die Staatsausgaben gewährleistet, durch welche neben das Verwaltungsrecht als Sachrecht die Zuweisung finanzieller Mittel zur Verwirklichung materieller Verwaltungszwecke tritt. ${ }^{96}$ Art. 109 Abs. 1 GG ist treffend als „finanzielle“ Ausprägung des Demokratieprinzips bezeichnet worden; ${ }^{97}$ diese funktioniert jedoch nur jeweils innerhalb einer Ebene, nicht ebenenübergreifend. ${ }^{98} \mathrm{Um}$ Missverständnisse zu vermeiden: Die Individualzentrierung und demokratische Verankerung der Steuer als Hauptmittel der Staatsfinanzierung verlangt keine föderalistische Stufung des besteuernden Gemeinwesens, ${ }^{99}$ vorliegend geht es um Organisation und Entwicklung des Finanzwesens in einer existenten Mehrebenenstruktur.

\section{b) Verantwortungszusammenhänge und Verantwortungsklarheit}

Verantwortungszusammenhänge in der Demokratie bauen auf der Zurechenbarkeit von Verantwortung auf. ${ }^{100} \mathrm{Um}$ die demokratische

traktere Steuerrecht mit seinem an Konturenlosigkeit kaum zu überbietenden Medium des Geldes (vgl. nur K. Vogel HStR II, 3. Aufl. 2004, § 30 Rn. 4 ff.) auf das Gesetz als solches verwiesen.

95 Vgl. nur W. Heun Staatshaushalt und Staatsleitung, 1989; Gröpl Haushaltsrecht (Fn. 38), 152 ff., 165 und öfter.

96 P. Kirchhof NVwZ 1983, 505 ff.; W. Heun Staatshaushalt (Fn. 95), 270ff.; F. Kirchhof VVDStRL 52 (1993), 71 (85); C. Waldhoff StuW 2002, 285 (299); finanzwissenschaftlich Blankart Öffentliche Finanzen (Fn. 9), 457.

${ }^{97}$ F. Kirchhof DJT-Gutachten (Fn. 30), D 53 Fn. 215.

98 M. Heintzen in: von Münch/Kunig (Hrsg.), GGK III, 4./5. Aufl. 2003, Vorb. Art. 104a-115 Rn. 46; C. Hillgruber JZ 2004, 837 (845). Von seinem Ausgangspunkt, die demokratische und die föderale Frage getrennt zu denken, ist dies für F. Schoch in: Henneke (Hrsg.), Verantwortungsteilung zwischen Kommunen, Ländern, Bund und EU, 2001, 21 (24), folgerichtig.

${ }^{99}$ Für eine verfassungsrechtliche Verankerung des Subsidiaritätsgedankens gibt es zwar punktuelle Ansatzpunkte (Art. 28 Abs. 2 GG; Art. 72 Abs. 2 GG n.F. u.a.), die überwiegende Meinung lehnt jedoch ein Verfassungspostulat, Aufgaben auf möglichst niedriger Stufe anzusiedeln, in dieser Pauschalität ab; teilweise abweichend Isensee Subsidiaritätsprinzip und Verfassungsrecht, 1968; B.O. Bryde in: Sitter-Liver (Hrsg.), Herausgeforderte Verfassung, 1999, 223 ff.; R.-O. Schultze ZParl. 21 (1990), 475 (489); vgl. für das Verhältnis zwischen Gemeinden und Kreisen jedoch BVerfGE 79, 127 (143ff.) Rastede.

100 H.-J. Vogel in: Benda/Maihofer/Vogel (Hrsg.); Handbuch des Verfassungsrechts, 2. Aufl. 1994, § 22 Rn. 13; Kisker in: Probleme des Föderalismus, 1985, 23 (34); P. Ler- 
Rückkoppelung sicherzustellen, müssen diese Verantwortlichkeiten dafür im Sinne einer Verantwortungsklarheit sichtbar sein.101 Auf die Staatsfinanzierung bezogen ist dies nicht nur ein finanzpsychologisches Postulat zur Vermeidung von Abgabenwiderstand und damit zur Hebung der Steuermoral, ${ }^{102}$ sondern essentieller Bestandteil demokratischer Legitimationsstiftung. ${ }^{103}$ Die zentrale finanzwissenschaftliche Erkenntnis vom Nutzen sog. institutioneller oder fiskalischer Äquivalenz als Einheit von Kostenträgern und Nutznießern (sog. Steuer-Ausgaben-Mechanismus) erscheint verfassungsrechtlich reformuliert. ${ }^{104}$ Die traditionelle

che in: Maunz/Dürig, GG, Art. 83 Rn. 107, 110; U. Volkmann DÖV 1998, 613 (615); E. Schmidt-Jortzig DÖV 1998, 746 (748f.); P. Kirchhof FS Badura, 2004, 237 (254); Mehde Wettbewerb (Fn. 5), 126.

101 Damit wird der einen Kern des Demokratieprinzips darstellende Zusammenhang der Koppelung von Politik, öffentlicher Meinung und individuellem Bewusstsein durch ein Sichtbarmachen politischen Entscheidens verwirklicht, vgl. U. Di Fabio Das Recht offener Staaten, 1998, 45 ff.; vgl. in bundesstaatlichem Kontext Oeter Integration und Subsidiarität (Fn. 1), 581f.; J.-P. Schneider Der Staat 40 (2001), 272 (278); C. Gröpl DVB1. 2006, 1079 (1087); Huber Föderalismusfalle (Fn. 20), 15f.; ders. DJT-Gutachten (Fn. 19), D $34 \mathrm{ff}$; ders. in: Blanke/Schwanengel (Hrsg.), Zustand und Perspektiven des deutschen Bundesstaates, 2005, 21 (22ff.) unter Hinweis auf die materielle Aufladung des demokratischen Wahlrechts aus Art. 38 GG im Maastrichturteil des Bundesverfassungsgerichts; zu eng J. Bröhmer Transparenz als Verfassungsprinzip, 2004, 310; allgemein zu dem Zusammenhang zwischen Transparenz und Demokratie G. Lübbe-Wolff VVDStRL 60 (2001), 246 (276ff.); Bröhmer a.a.O. $38 \mathrm{ff}$.

$102 \mathrm{Zu}$ dem Zusammenhang zwischen Steuerrechtfertigung und „heimlicher Steuerrevolte“ K. Vogel Der Staat 25 (1986), $481 \mathrm{ff}$;; vgl. auch U. Sacksofsky in: Bizer/Falk/ Lange (Hrsg.), Am Staat vorbei, 2004, 305; allgemein zu Steuerwiderstand und Steuermoral G. Schmölders Das Irrationale in der öffentlichen Finanzwirtschaft, 1960, 69 ff.; zu Verantwortungszusammenhängen und genereller Akzeptanz verbindlicher Entscheidungen C. Calliess Subsidiaritäts- und Solidaritätsprinzip in der Europäischen Union, 2. Aufl. 1999, $31 \mathrm{f}$.

103 Vgl. auch H.H. von Arnim Staatslehre der Bundesrepublik Deutschland, 1984, 486; C.L. Thiele FS Offerhaus, 1999, 1018; K. Oettle Die Verwaltung 32 (1999), 291 (310).

$104 \mathrm{Vgl}$. bereits E. Lindahl Die Gerechtigkeit der Besteuerung, 1919, $85 \mathrm{ff}$.; M. Olson The Principle of „Fiscal Equivalence“: The Division of Responsibilities among Different Levels of Government, American Economic Review 59 (1969), $479 \mathrm{ff}$. (deutsche Übersetzung bei Kirsch (Hrsg.), Föderalismus, 1977, 66ff.); N. Andel Finanzwissenschaft, 4. Aufl. 1998, 529f.; R. Eichenberger in: Engel/Morlok (Hrsg.), Öffentliches Recht als ein Gegenstand ökonomischer Forschung, 1998, 157 (162ff.); ders. in: von Arnim u.a. (Hrsg.), Föderalismus - Hält er noch, was er verspricht? 2000, 101 (112ff.); G. Färber in: von Arnim u.a. (Hrsg.), Föderalismus - Hält er noch, was er verspricht? 2000, 125 (130ff.); E. Döhler Autonome Besteuerungsrechte für Gliedstaaten und Gemeinden in ausgewählten föderativen Finanzverfassungen, 2002, 62ff.; C.B. Blankart Öffentliche Finanzen (Fn. 9), $606 \mathrm{ff}$., $673 \mathrm{ff}$. Ökonomisch betrachtet müssten nach der sog. Samuelson-Regel idealerweise die Grenzkosten aus der Steuererhöhung mit dem Grenznutzen des ausgabenversursachenden Projekts gleichlaufen. Methodisch proble- 
Gewährleistung des demokratischen Verantwortungszusammenhangs in der Finanzordnung über Steuergesetzesvorbehalt und Budgetrecht berücksichtigt nicht die Möglichkeiten und die Bedingungen der Mehrebenenstruktur als Folge der verfassungsrechtlichen Grundentscheidung für den Bundesstaat und die europäische Integration. Durch die der deutschen Bundesstaatstradition entsprechende funktionenspezifische Aufteilung der Finanzhoheiten hinsichtlich der einzelnen Einnahmen bei ebenenangesiedelter Budgetverantwortung fehlt ein entscheidendes Bindeglied in der Verantwortungsklarheit, der Zurechenbarkeit von Verantwortung und damit demokratischer Rückkoppelung im Bereich des Finanzwesens. ${ }^{105}$ Historisch vorbelastet harren somit die demokratischen Verantwortungszusammenhänge als Argumentationsreserve in der Anwendung der geltenden Finanzverfassung und als Leitgesichtspunkt de constitutione ferenda im bundesstaatlichen Finanzbereich der Freilegung. ${ }^{106}$

\section{c) Die Steuerrechtfertigung als Verbindung von persönlicher Anknüpfung und territorialer Radizierung}

Der Weg, um im Rahmen einer individualgestützten Legitimation finanzverfassungsrechtlicher Strukturen über das freiheitsschützende Potenzial von Bundesstaatlichkeit hinaus positive Kriterien zu gewinnen, ist die Rechtfertigung der Steuer im demokratischen Verfassungsstaat. Jenseits positivistischer Argumente, mit der Erwähnung und Verteilung der

matisch die Argumentation bei H. Schatz/R.C. van Ooyen/S. Werthes Wettbewerbsföderalismus, 2000, 46ff., 53, die das Herstellen derartiger Zusammenhänge als „vordemokratisch-autoritär“ „im Zeichen der Staatsräson“ denunzieren, ohne die hier aufgezeigten Zusammenhänge zu begreifen.

105 P. Kirchhof Verfassungsauftrag (Fn. 30), 14: „Das parlamentarische Budgetrecht, die Rechnungsprüfung und die parlamentarische Entlastung kann nur wirksam ausgeübt werden, wenn die Verantwortlichkeit für die Erträge und die Ausgaben bei ein und demselben Parlament zentralisiert sind.“ Zur insofern begrenzten Bedeutung von Art. 109 Abs. 1 GG bereits BVerfGE 1, 117 (131).

106 Die Mahnung, bei dem Projekt einer Stärkung der Landes-(finanz-)autonomie dürfe es sich nicht um einen ahistorischen Aufbruch „,zu den Quellen des deutschen Staatsorganisationsrechts“ handeln und der Gefahr „föderaler Romantik“ müsse gegengesteuert werden, daher sei eine „traditionsbewusste Reformulierung“ anzustreben (J.-P. Schneider Der Staat 40 (2001), 272 (284)) bzw. die Kompatibilität mit der „inneren Rationalität“, die „Vereinbarkeit mit der deutschen bundesstaatlichen Kultur“ sei zu berücksichtigen ( $S$. Korioth in: DJT 2004, P 89 (90, 97 ff.), darf nicht dazu führen, machtstaatlich-unitarische Tendenzen der deutschen Bundesstaatstradition zu transportieren; insofern geht es bei dem hier verfolgten Anliegen weniger um die Rekonstruktion von Verlusten, als um die Neujustierung in einer grundlegend anders legitimierten Verfassungsordnung. 
Steuern in der bundesstaatlichen Verfassung sei die Legitimation der Steuer vollzogen, ${ }^{107}$ ist nach dem inneren Grund des Steuerzugriffs zu fragen. ${ }^{108}$ Hier kann die - zumeist vorverfassungsstaatliche - Ideengeschichte der Steuerrechtfertigung nur bedingt weiterhelfen:109 Die Assekuranztheorien verglichen die Steuer mit einer pauschalen Versicherungsprämie; 110 die aus der organischen Staatslehre stammenden Opfertheorien bezogen sich auf das rechtliche Band der Staatsangehörigkeit als Legitimationsgrund ${ }^{111}$ und haben insofern angesichts der Anknüpfung an die Ansässigkeit durch praktisch alle modernen Steuersysteme keinen Erklärungswert mehr. ${ }^{112}$ In der Gegenwart werden idealtypisch der Äquivalenzgedanke und das Leistungsfähigkeitsprinzip als rechtfertigende Modelle einander gegenübergestellt. ${ }^{113}$ Da das Grundgesetz vom Vorrang der Steuerfinanzierung ausgeht, 114 stellen die Steuern

107 Die Defizite dieses Ansatzes zeigen sich schon darin, dass in traditionell einheitsstaatlichen Verfassungen diese Normen zur bundesstaatlichen Aufteilung von Besteuerungskompetenzen gerade fehlen; ein derart verkürzter Zugriff müsste sich dann - falls vorhanden - auf positivierte steuerliche Gesetzesvorbehalte stützen; vgl. zum Textbefund insoweit Waldhoff Verfassungsrechtliche Vorgaben (Fn. 16), $366 \mathrm{ff}$.

108 Grundlegend K. Vogel Der Staat 25 (1986), $481 \mathrm{ff}$.; zu den verschiedenen Ebenen der Steuerrechtfertigung - staatstheoretische, finanzwissenschaftliche usw. - K. Vogel Der Finanz- und Steuerstaat, HStR II, 3. Aufl. 2004, § 30 Rn. 64 ff.; P. Kirchhof Die verfassungsrechtliche Rechtfertigung der Steuern, in: Steuern im Verfassungsstaat, 1996, $27 \mathrm{ff}$; $M$. Rodi Die Rechtfertigung von Steuern als Verfassungsproblem, 1994; H. Weber-Grellet Steuern im modernen Verfassungsstaat, 2001, $4 \mathrm{ff}$.

${ }^{109}$ Immer noch grundlegend F.K. Mann Steuerpolitische Ideale, 1937; ferner K.H. Ossenbühl Die gerechte Steuerlast, 1972; C. Scheer in: Krause-Junk (Hrsg.), Steuersysteme der Zukunft, 1998, $155 \mathrm{ff}$.

110 G. Schmölders/K.-H. Hansmeyer Allgemeine Steuerlehre, 5. Aufl. 1980, 44.

111 Schmölders/Hansmeyer Steuerlehre (Fn. 110), $51 \mathrm{f}$.

112 Anknüpfung an die Ansässigkeit durch $\S 1$ Abs. 1 EStG i.V.m. $\S \S 8,9$ AO bzw. $\S 1$ KStG i.V.m. $\S \S 10,11$ AO; vgl. aus völkerrechtlicher Sicht Hobe Der offene Verfassungsstaat (Fn. 7), 256; zu den Restbeständen der Bedeutung der Staatsangehörigkeit als Anknüpfungspunkt für das Steuerrecht jetzt E. Reimer Staatsangehörigkeit und Steuerrecht, im Erscheinen. Grundlegend zu den möglichen Anknüpfungspunkten G. von Schanz Zur Frage der Steuerpflicht, FinArch. 9 (1892), 1 ff.; zur historischen Entwicklung im deutschen Einkommensteuerrecht M. Lehner/C. Waldhoff in: Kirchhof/Söhn/ Mellinghoff (Hrsg.), EStG, § 1 Rn. A $621 \mathrm{ff}$.

113 A. Schmehl Das Äquivalenzprinzip im Recht der Staatsfinanzierung, 2004; dazu die Kritik bei C. Waldhoff HStR V, 3. Aufl. 2007, § 116 Rn. 5; finanzwissenschaftlich Blankart Öffentliche Finanzen (Fn. 9), $194 \mathrm{ff}$.

114 Dies bleibt ungeachtet aller Angriffe und Relativierungen eindeutiges Auslegungsergebnis des Grundgesetzes, vgl. BVerfGE 93, 319 (342); 78, 249 (266f.); 67, 256 (274ff.); grundlegend J. Isensee FS Ipsen, 1977, 409ff.; K. Vogel HStR II, 3. Aufl. 2004, $\S 30$ Rn. $51 \mathrm{ff}$; M. Lehner Einkommensteuerrecht und Sozialhilferecht, 1993, $348 \mathrm{ff}$; G.F. Schuppert Staatswissenschaft, 2003, $331 \mathrm{ff} . ;$ K. Vogel/C. Waldhoff in: Dolzer/Vogel/ 
die generelle („globale“), nach Kriterien der individuellen Leistungsfähigkeit bemessene Gegenleistung für die Gesamtheit der staatlichen Leistungen dar. ${ }^{115}$ Für die im Zentrum stehenden Personalsteuern vermittelt das Kriterium der Ansässigkeit des Steuerpflichtigen den territorialen Bezug zwischen der besteuernden Körperschaft und dem Zensiten als konkreter Person. Diese Verbindung von territorialer Justierung und personaler Anknüpfung gewährleistet zugleich den Zusammenhang zwischen der kostenverursachenden Sachpolitik und der den Finanzierungszweck erfüllenden Steuerpolitik und bringt damit einen genuin demokratischen Zusammenhang zum Ausdruck. Die Wahlentscheidung des Stimmbürgers kann einen politischen Zusammenhang zwischen Staatsleistungen und Abgaben herstellen. ${ }^{116}$ Demokratische Legitima-

Graßhof (Hrsg.), BK GG, Vorb. z. Art. 104a-115 Rn. 327 ff.; je unterschiedlich kritisch zum Prinzip des Steuerstaats R. Hendler DÖV 1999, 749 ff.; U. Sacksofsky Umweltschutz durch nichtsteuerliche Abgaben, 2000, $129 \mathrm{ff}$.; dies./J. Wieland (Hrsg.), Vom Steuerstaat zum Gebührenstaat, 2004; Schmehl Äquivalenzprinzip (Fn. 113); ders. ZG 2005, 123 ff.; zur tatsächlichen Abschwächung des Steuerfinanzierungsanteils F. Kirchhof Die Verwaltung 21 (1988), $137 \mathrm{ff}$; C. Gramm Der Staat 36 (1997), $267 \mathrm{ff}$.

115 Vgl. auch BVerfGE 67, 100 (143) - Flick-Untersuchungsausschuss: „Das - auch strafrechtlich sanktionierte - Verlangen des Staates nach steuerlichen Angaben begründet sich aus dem Umstand, daß der Betroffene am staatlichen Leben teilnimmt, ihm insbesondere Schutz, Ordnung und Leistungen der staatlichen Gemeinschaft zugute kommen. Deshalb darf ihm ein Anteil an den finanziellen Lasten zur Aufrechterhaltung des staatlichen Lebens auferlegt werden.“ BVerfGE 72, 200 (246) - Verfassungsmäßigkeit der Rückwirkung bei der erweiterten beschränkten Einkommensteuerpflicht gem. § 2 AStG: „Je mehr sich demgegenüber der Betreffende noch am inländischen wirtschaftlichen Leben beteiligt, zugleich aber sich steuerliche Vorteile aus der Verlegung seines Wohnsitzes zu verschaffen sucht, um so weniger geht es ihm darum, die von Art. 2 Abs. 1 GG geschützte Ausreisefreiheit zu verwirklichen. ... Ein solcher - ehemaliger Deutscher will bei der im Steuerrecht zulässigen typisierenden Betrachtung die Vorteile beider Rechtsordnungen genießen, ohne sich den Lasten jedenfalls einer von ihnen voll zu stellen: Er will im Ausland leben und dort spürbar weniger Steuern zahlen als bei Wohnsitz im Inland hier anfallen würden. Andererseits will er aber zugleich im Inland in erheblicher Weise wirtschaftlich tätig bleiben, anstatt auch diese Tätigkeiten ins Ausland $\mathrm{zu}$ verlegen (und damit möglicherweise seiner dort besonders günstigen steuerlichen Lage verlustig zu gehen).“ Dass der der Entscheidung zugrunde liegende Steuertatbestand inzwischen in Konflikt mit dem Gemeinschaftsrecht gerät, ist für den hiesigen Argumentationszusammenhang irrelevant. Näher zu dem Steuerrechtfertigungskonzept der Globaläquivalenz mittels territorialer und personaler Justierung der Steuer M. Lehner/C. Waldhoff in: Kirchhof/Söhn/Mellinghoff (Hrsg.), EStG, § 1 Rn. A $161 \mathrm{ff}$.; zu den verschiedenen Dimensionen des Äquivalenzprinzips K. Tipke Die Steuerrechtsordnung, Bd. 1, 2. Aufl. 2000, S. $476 \mathrm{ff}$.

116 Rennert Der Staat 32 (1993), 269 (278); insoweit ist auch die Annahme falsch, „mehr Selbständigkeit der Gebietskörperschaften verändert nicht den Bestand der Staatsaufgaben, sondern ihr vertikales Arrangement; größere finanzielle Eigenständig- 
tionsketten und finanzielle Verantwortungslinien werden - im Idealfall in Kongruenz gebracht. ${ }^{117}$ Im Unterschied zu einer konkreter Äquivalenz verpflichteten Staatsfinanzierung ${ }^{118}$ - sei es durch Zwecksteuern, sei es im Rahmen einer dezentralen Zusammenführung von Aufgaben- und Ausgabenverantwortung im Sinne des sog. Neuen Steuerungsmodells bleibt dabei die Berücksichtigung von Steuergleichheit, von leistungsfähigkeitsgerechter Besteuerung und damit von sozialstaatlichen Zielen möglich und verpflichtend.119 Zudem gewinnt der demokratische Verfassungsstaat durch die im Staatshaushalt verortete Finanzmacht politischen Gestaltungsspielraum zur Durchführung seiner Sachziele. ${ }^{120}$ Durch die zentrale Entscheidung der Finanzverfassung, die Ertragshoheit von der Rechtsetzungshoheit abzukoppeln und beide unabhängig von der Gesetzgebungs- und Vollzugshoheit im außerfinanzrechtlichen Bereich auszuformen, sind diese demokratischen Verantwortungszusammenhänge gestört; ${ }^{121}$ diese als „Geniestreich des Parlamentarischen Rats" ${ }^{122}$ gefeierte Entkoppelung erweist sich als bundesstaatliches $\mathrm{Ku}$ ckucksei. Das durch die Steuerrechtfertigung hergestellte Band zwischen der Sachpolitik - etwa einer erfolgreichen, einnahmegenerierenden Wirtschaftspolitik, einer kostspieligen Sozial- oder Kulturpolitik und der Steuerpolitik ist gelockert. ${ }^{123}$ Insofern ist es im geltenden Sys-

keit insbesondere der Länder erhöht die Belastbarkeit der Volkswirtschaft durch Abgaben nicht“, S. Korioth in: DJT 2004, P 89 (97); „klassische“ Formulierungen dieses Zusammenhangs im Kontext des amerikanischen Unabhängigkeitskampfes in den Federalist Papers, Artikel 30 - 36: Über Steuern (Alexander Hamilton), dort allerdings unter umgekehrten Vorzeichen eines Kampfes, dem Bund eigene Besteuerungsbefugnisse zur Bestreitung seiner Aufgaben zuzubilligen.

117 P. Kirchhof Verfassungsauftrag (Fn. 30), 13f.; ders. FS Badura, 2004, 237 (254) spricht bei dem Projekt Maßstabgebung, Verwaltung und Finanzierung zusammenzuführen von „Verantwortungsföderalismus“; F. Kirchhof DJT-Gutachten (Fn. 30), D 54; eingehend Döhler Autonome Besteuerungsrechte (Fn. 16), 24 und durchgehend.

118 So der verfassungspolitische Vorschlag bei H. Wilms ZRP 2003, 86 (89), den Ländern die Kompetenz zur Erhebung von Zwecksteuern einzuräumen; vgl. auch W. Kluth in: Henneke (Hrsg.), Verantwortungsteilung zwischen Kommunen, Ländern, Bund und EU, 2001, 151 (166ff.); grundlegend Schmehl Äquivalenzprinzip (Fn. 113).

119 C. Waldhoff StuW 2002, 285 (304ff.).

120 Näher C. Waldhoff StuW 2002, 285 (309ff.).

121 J.-K. Fromme ZRP 1986, 289 (290), spricht von (verlorengegangener) „Merklichkeit der Aufgabenerfüllung“.

122 R. Mußgnug JZ 1992, 194.

${ }^{123}$ Für den Weimarer Verfassungszustand nach der Erzbergerschen Finanzreform 1919/20 Hensel Finanzausgleich (Fn. 16), 186: „Hier ist der schwächste Punkt des neuen Finanzausgleichs verborgen. Wir sind nach wie vor der Meinung, dass durch das zentralisierende Überweisungssystem an sich die Staatshoheit der Länder nicht berührt 
tem des „Exekutivföderalismus“ 124 nur folgerichtig, wenn über das Konnexitätsprinzip des Art. 104a Abs. 1 GG Verwaltungs- und Finanzverantwortung demselben Hoheitsträger zugeordnet werden, die (Steuer-) Gesetzgebung jedoch weitgehend unberücksichtigt bleibt. ${ }^{125}$ Dementsprechend werden über einen nivellierenden Finanzausgleich die Finanzausstattungen unabhängig von der konkret verfolgten finanzwirksamen Sachpolitik angenähert und finanzwirtschaftliche Schieflagen losgelöst von ihren Ursachen - über solidarischen Beistandspflichten des Bundes und der Ländergesamtheit praeter constitutionem weitestgehend aufgefangen. ${ }^{126}$

d) Ansätze finanzwirtschaftlicher Verantwortungszusammenhänge in der Judikatur des Bundesverfassungsgerichts - insbesondere die Rechtsprechung zu den Sonderabgaben

Dass auf die Steuerrechtfertigung als Maßgröße auch der bundesstaatlichen Finanzordnung nicht völlig verzichtet werden kann, wird in Randbereichen auch in der Judikatur des Bundesverfassungsgerichts deutlich, ohne dass daraus übergreifende Konsequenzen gezogen würden. $\mathrm{Zu}$ erwähnen ist in dem Modell des bundesstaatlichen Finanzausgleichs als aufeinander bezogene Stufenfolge die Unterscheidung zwischen dem primären, ertragszuweisenden und dem sekundären, umverteilenden Fi-

wird. Aber dieses System geht zu weit, die Restfinanzhoheit der Gliedstaaten ist nicht ausreichend bemessen. ... Zunächst einmal wird das Verantwortungsgefühl der Landesregierungen ihren Untertanen gegenüber geschwächt werden, wenn der Zusammenhang zwischen der pflichtgemäßen Leistung der Reichsunterstellten und der Tätigkeit des übergeordneten Staates gelockert wird. Eine Landesregierung, die in Zukunft eine im Augenblick erwünscht erscheinende Aufgabe in Angriff nehmen will, braucht nicht mehr besorgt zu sein, ob auch die Landeskinder die entsprechende steuerliche Belastung auszuhalten vermögen.“ (Hervorhebung nur hier). Zur notwendigen „Restfinanzhoheit" ebd., 163.

${ }_{124}$ Zur Konturierung näher P. Dann Parlamente im Exekutivföderalismus, 2004.

125 Vgl. P. Kirchhof FS Badura, 2004, 237 (253f.).

126 BVerfGE 86, 148 (260ff.); jetzt stärker eingegrenzt durch das Urteil des BVerfG vom 19. Oktober 2006 - 2 BvF 3/03; zu dem - diffusen - Tatbestand der die Beistandspflicht auslösenden sog. extremen Haushaltsnotlage eines Landes P. Selmer JuS 1995, 978 (983f.); U. Häde DÖV 1993, 461; ders. Finanzausgleich, 1996, 256f.; Korioth Finanzausgleich (Fn. 32), 662 ff.; J.W. Hidien Ergänzungszuweisungen des Bundes gem. Art. 107 II S. 3 des Grundgesetzes, 1997, 142 ff.; Kesper Finanzordnung (Fn. 32), 282 ff., 376 ff.; A. Musil/J. Kroymann DVB1. 2004, 1204; J. Wieland FS Selmer, 2004, 973 (980ff.); D. Birk/R. Wernsmann DÖV 2004, 868; W. Höfling FS von Arnim, 2004, 259; M. Heintzen FS Raue, 2006, 83 (95f.); J. Wieland in: Dannemann/Luft (Hrsg.), Die Zukunft der Stadtstaaten, 2006, 191; R. Wendt/W. Förster Wirtschaftsdienst 2006, 133; M. Stauch NordÖR 2006, 133; P. Selmer NordÖR 2006, 221 sowie die Beiträge aus verschiedenen Disziplinen in K.A. Konrad/B. Jochimsen (Hrsg.), Finanzkrise im Bundesstaat, 2006. 
nanzausgleich. ${ }^{127}$ Wenn das Gericht von der „originär zustehenden“, der „eigenen“ Finanzausstattung der Länder ${ }^{128}$ oder im Rahmen der umverteilenden Korrektur von dem Zugriff auf „Eigenes“ spricht, so erscheint als Band, welches dieses „Eigene“ umschließt, das Prinzip der - ggf. korrigierten - örtlichen Vereinnahmung der Steuern. ${ }^{129}$

Im Rahmen der Aufteilung der Umsatzsteueranteile zwischen Bund und Ländern folgen aus den aufeinander abzustimmenden „Deckungsbedürfnisse[n] des Bundes und der Länder" Ansprüche beider Seiten, ihre „notwendigen Ausgaben“ „unter Berücksichtigung einer mehrjährigen Finanzplanung“ zu decken. Indem das Bundesverfassungsgericht in seinem Finanzausgleichsurteil aus dem Jahr 1999 ausführt, die „notwendigen“ Ausgaben seien nicht die tatsächlich veranschlagten Ausgaben, ${ }^{130}$ wird ein „Auftrag zum Wägen und Gewichten der jeweiligen Deckungsbedürfnisse“ postuliert: Nicht jede politisch gewollte Ausgabe führt zu einer entsprechenden Beteiligung am variablen „Finanzkuchen“, sondern die Notwendigkeit der Ausgabe muss gerechtfertigt werden; nicht die Bedarfsdeckung allein bestimmt das zugeteilte Finanzvolumen. ${ }^{131}$ An dieser zentralen Stelle der geltenden bundesstaatlichen Finanzverfassung müsste die Rechtfertigung gegenüber dem letztlich alles finanzierenden Steuerzahler hergestellt werden. ${ }^{132}$ Dass die Praxis hier anders aussieht, ist bekannt und mitursächlich für die staatliche Finanzmisere.

In der Sonderabgabenjudikatur des Bundesverfassungsgerichts verbindet sich von vornherein die Frage der Rechtfertigung einer (im Grundgesetz gar nicht vorgesehenen, nichtsteuerlichen) Abgabe mit organisationsrechtlichen Fragen der Kompetenzstruktur. ${ }^{133}$ Das Gericht

127 BVerfGE 72, 330 (383ff.); 101, 158 (214f.); K. Vogel HStR IV, 2. Aufl. 1999, § 87 Rn. 29 ff.; W. Heun Der Staat 31 (1992), 207 (226); J.-P. Schneider Der Staat 40 (2001), 272 (274ff.).

128 BVerfGE 72, 330 (385, 386).

129 BVerfGE 101, 158 (221).

130 BVerfGE 101, 158 (219f.); ausführlich zu diesem Problem bereits Sachverständigenkommission zur Vorklärung finanzverfassungsrechtlicher Fragen für künftige Neufestlegungen der Umsatzsteueranteile, Maßstäbe und Verfahren zur Verteilung der Umsatzsteuer nach Art. 106 Abs. 3 und Abs. 4 Satz 1 GG, 1981, Tz. 80 ff.

131 Ähnlich P. Kirchhof VVDStRL 52 (1993), 147 (150).

132 Deutlich bereits Wissenschaftlicher Beirat beim Bundesministerium der Finanzen, Einnahmenverteilung zwischen Bund und Ländern, 1995, 29: „Welche Ausgaben von Bund und Ländern notwendig sind, wird der eine Bürger so, der andere Bürger anders beurteilen. In einer repräsentativen Demokratie soll der Bürgerwille durch die Entscheidungen der verantwortlichen Politiker zur Geltung kommen. Deswegen ist aber gewiss nicht jede (ausgaben-)politische Entscheidung gerechtfertigt.“

133 Leitentscheidung BVerfGE 55, 274 (297ff.) - Ausbildungsplatzföderungsabgabe; im Anschluss an F. Ossenbühl DÖV 1965, 649 (657) wird die „enge sachliche Verbin- 
sah sich genötigt, angesichts der Nichtanwendbarkeit der „Steuerfinanzverfassung " 134 hier auch kompetenzielle Aussagen, insbesondere zur Ertragshoheit und zur Verwendung zu machen: Die spezifische Sachnähe der durch die Sonderabgabe belasteten Gruppe und dann vor allem das Gebot der gruppennützigen Verwendung als Kriterium der „sachgerechten Verknüpfung“135 ziehen aus der Abgabenrechtfertigung heraus organisationsrechtliche Folgerungen. Das Gericht ordnet diesen Aspekt in den überkommenen Argumentationstopos von der Schutzfunktion der Finanzverfassung ein; ${ }^{136}$ daneben geht es auch um den Schutz bestehender finanzverfassungsrechtlicher Kompetenzen, etwa der Länder. ${ }^{137}$ Letztlich wird hier jedoch ein positiver Legitimationszusammenhang hergestellt, der keinesfalls nur abwehrrechtliche Aspekte umfasst, sondern demokratische Mitbestimmung in einer Sachfrage und Staatsfinanzierung miteinander verknüpft.

\section{Keine Inkompatibilität mit der geltenden Finanzverfassung: \\ Die Grenzen des Konzepts der Finanzverfassung als „Folgeverfassung“}

Die Sichtweisen von der Finanzverfassung als „dienender“ Verfassung oder als „Folgeverfassung“ lassen in ihrer akzessorisch-instrumentellen Sicht den hier entwickelten Rechtfertigungs- und Erklärungszusammenhängen keinen Raum. ${ }^{138}$ Die Staatsfinanzierung erscheint so als rein instrumentelle Aufgabe: ${ }^{139}$ Die Aufgabenverteilung in der Mehrebenenstruktur steuert die Finanzverteilung, für Rück- oder Wechselwir-

dung zwischen Grundrechten und Kompetenznormen“ „in ständiger Rechtsprechung anerkannt"; später - mit Unterschieden im einzelnen, nicht jedoch in der hier interessierenden Frage - BVerfGE 57, 139 (165ff.) - Schwerbehinderten-Ausgleichsabgabe; 82, 159 (178ff.) - Absatzfonds für die Landwirtschaft (CMA); 89, 132 (144) - Künstlersozialversicherung; 91, 186 (201ff.) - Kohlepfennig; 92, 91 (120) - Feuerwehrabgabe Bayern und Baden-Württemberg; 110, 370 (389ff.) - Altenpflege-Umlage; 113, 128 (145ff.) - Solidarfonds Abfallrückführung.

134 W. Heun FS Selmer, 2004, 657.

135 BVerfGE 55, 274 (306ff.).

136 BVerfGE 55, 274 (300, 302); siehe auch oben unter III 2.

137 Vgl. etwa auch Stettner Kompetenzlehre (Fn. 65), S. 392 f.

${ }^{138}$ Zwar ist es problematisch, allein durch Interpretation die Grundannahmen der Großen Finanzreform 1967/69 auszuschalten oder ins Gegenteil zu verkehren; andererseits werden die Auslegungsspielräume der geltenden Finanzordnung teilweise nicht ausgenützt, um etwa eine Sichtweise, wie die hier entwickelte, einzubeziehen; abgewogen insoweit $U$. Volkmann DÖV 1998, 613 (621).

139 Zum instrumentellen Charakter innerhalb eines Konzepts von Staatsaufgaben siehe J. Isensee HStR III, 1988, § 57 Rn. 150 ff., 154; Rodi Rechtfertigung (Fn. 108), $143 \mathrm{ff}$. 
kungen bleibt kaum Raum. ${ }^{140}$ Rein instrumentell war die Staatsfinanzierung jedoch nie, Lenkungszwecke gehören zur modernen Steuer von Anfang an. ${ }^{141}$ Die ökonomische Funktion des Budgets ist eine neuere Entwicklung. ${ }^{142}$ Selbstverständlich ist, dass Aufgabenverteilung und Finanzverfassung nicht beziehungslos nebeneinander stehen, idealerweise strukturell homogen, zumindest kompatibel sind. ${ }^{143}$ Die hier kritisierte Sichtweise ist in ihrem Blick von den Staatsaufgaben auf die Finanzverfassung darüber hinaus zumindest dann zu einseitig, wenn sie suggeriert, der Staat habe so viele Finanzmittel aufzubringen, wie er zur Erfüllung seiner Aufgaben benötige. Von einem eher kleinen, verfassungsrechtlich schwer deduzierbaren Bereich staatlicher Kernaufgaben abgesehen, gibt es jedoch kaum „notwendige Staatsaufgaben“; die Frage nach den Staatsaufgaben, insbesondere den kostenintensiven sozial- und interventionsstaatlich motivierten Agenden ist in erster Linie dem politischen Prozess überantwortet. Staatliche Aufgabenerfüllung und deren Finanzierung sind außerhalb des angedeuteten Kernbereichs somit keine Einbahnstraße, sondern verfassungsrechtlich wie politisch ein Wechselwirkungsprozess. ${ }^{144}$ Das Dynamisch-Prozesshafte föderaler Ordnun-

140 F. Kirchhof VVDStRL 52 (1993), 71 (80ff.); Korioth Finanzausgleich (Fn. 32), S. 34 und durchgehend; ders. in: DJT 2004, P 91; Häde Finanzausgleich (Fn. 126), 9; demgegenüber setzt $W$. Kluth in: Henneke (Hrsg.), Verantwortungsteilung zwischen Kommunen, Ländern, Bund und EU, 2001, 151 (165) „Finanzverfassung als Folgeverfassung“ als nicht erreichtes Postulat und Ideal.

141 Zum Zusammenhang J.-P. Schneider Der Staat 40 (2001), 272 (276f.). Grundlegend zu Lenkungssteuern P. Selmer Steuerinterventionismus und Verfassungsrecht, 1972; zur historischen Dimension D.G. Bodenheim Der Zweck der Steuer, 1979, 95 ff.; Überbetonung jedoch bei $H$. Weber-Grellet Steuern im modernen Verfassungsstaat, 2001, $8 \mathrm{ff}$. und durchgehend mit der Gleichsetzung von Fiskal- und Sozialzwecken von Steuern; kritische Gesamtanalyse H. Kube Finanzgewalt in der Kompetenzordnung, 2004, 216ff.; R. Wernsmann Verhaltenslenkung in einem rationalen Steuersystem, 2005.

Es kann in diesem Zusammenhang auch noch hervorgehoben werden, dass Fragen der Staatsfinanzierung im Frühkonstitutionalismus ursächlich für die Verfassunggebung waren, da die Kreditfähigkeit des hochverschuldeten monarchischen Staates nach den Napoleonischen Kriegen nur durch eine Konstitutionalisierung des Gemeinwesens und d.h. durch eine Beteiligung des Bürgertums an den Staatsgeschäften wiederhergestellt werden konnte, vgl. nur H. Obenaus in: Ritter (Hrsg.), Gesellschaft, Parlament und Regierung, 1974, $57 \mathrm{ff}$.

142 Vgl. etwa P. Badura FS Selmer, 2004, 19 (20); auf den Haushalt bezogen A. von Mutius VVDStRL 42 (1984), 147 (168).

143 F. Schoch in: Henneke (Hrsg.), Verantwortungsteilung zwischen Kommunen, Ländern, Bund und EU, 2001, 21 (32).

${ }^{144} \mathrm{~K}$. Vogel/C. Waldhoff in: Dolzer/Vogel/Graßhof (Hrsg.), BK GG, Vorb. z. Art. 104a-115 Rn. 71; W. Heun DVB1. 1996, 1020 (1021); ders. in: Dreier (Hrsg.), GG, Bd. 3, 2000, Vorb. zu Art. 104a-115 Rn. 19; J.-P. Schneider Der Staat 40 (2001), 272 
gen, 145 das „bewegliche System des Bundesstaates“146 besitzt als integralen Bestandteil ein bewegliches System der Finanzordnung. ${ }^{147}$ Die Finanzordnung der Mehrebenenstruktur erweist sich als Teil eines beweglichen Systems zwischen Aufgaben und Finanzierung. ${ }^{148}$

\section{Die begrenzte Direktionskraft des Postulats „einheitlicher“ oder „gleichwertiger Lebensverhältnisse im Bundesgebiet “}

Aus dem in je unterschiedlichem Kontext im Grundgesetz aufscheinenden Postulat „einheitlicher“ oder „gleichwertiger Lebensverhältnisse im Bundesgebiet"149 lässt sich keine übergreifende Staatszielbestim-

(277): „Die administrative Aufgabenwahrnehmung ist jedenfalls tatsächlich in großem Umfange abhängige Variable der von der Finanzverfassung beeinflussten Finanzausstattung von Bund, Ländern und Gemeinden.“; ders. in: Denninger u.a. (Hrsg.), AK-GG, 3. Aufl. 2001, vor Art. 104a Rn. 7; M. Heintzen in: von Münch/Kunig (Hrsg.), GGK III, 4./5. Aufl. 2003, Vorb. Art. 104a-115 Rn. 28: Folgeverfassung, soweit die übrige bundesstaatliche Kompetenzstruktur akzeptiert wird, nicht hingegen, sofern dadurch Wechselwirkungen geleugnet werden sollten.

${ }^{145}$ So insbesondere der Grundzug in dem Referat von P. Lerche VVDStRL 21 (1964), 66; G.F. Schuppert Verwaltungswissenschaft, 2000, 944; politikwissenschaftlich A. Benz Föderalismus als dynamisches System, 1985.

146 S. Korioth in: DJT 2004, P 90; zur Anpassungsfähigkeit des Verfassungsprinzips ferner H. Bauer HStR I, 3. Aufl. 2003, § 14 Rn. 105; zur Beweglichkeit des föderalistischen Prinzips in historischer Perspektive T. Nipperdey in: ders., Nachdenken über die deutsche Geschichte, 1986, 71.

${ }^{147}$ K.-D. Henke/G.F. Schuppert Rechtliche und finanzwissenschaftliche Probleme der Neuordnung der Finanzbeziehungen von Bund und Ländern im vereinten Deutschland, 1993, 28; G.F. Schuppert in: Umbach/Clemens (Hrsg.), GG-Mitarbeiterkommentar, Bd. 2, 2002, vor Art. 104a ff. Rn. 26f.; F. Kirchhof VVDStRL 52 (1993), 71 (77f.); J.-P. Schneider Der Staat 40 (2001), 272 (277): „komplementäres Element im Rahmen der übergreifenden Bundesstaatsordnung“.

148 F. Schoch in: Henneke (Hrsg.), Verantwortungsteilung zwischen Kommunen, Ländern, Bund und EU, 2001, 21 (22): „Aufgaben- und Finanzzuordnung als Elemente eines Gesamtsystems“; vgl. demgegenüber schon die terminologische Differenz bei F. Kirchhof VVDStRL 52 (1993), 71 (81): „Die Finanzverfassung unterstützt das Bundesstaatsprinzip ..." (Hervorhebung nur hier).

149 Art. 72 Abs. 2 Nr. 3 GG a.F., Art. 72 Abs. 2 GG n.F. - die Bedürfnis- oder Erforderlichkeitsklausel in Form „materiellen Kompetenzzuweisungsrechts“ (M. Heintzen in: Dolzer/Vogel/Graßhof (Hrsg.) BK GG, Art. 70 Rn. 140; C. Waldhoff in: Henneke (Hrsg.), Föderalismusreform in Deutschland, 2005, 55 ff.); Art. 106 Abs. 3 Satz 4 Nr. 2 GG - eines von mehreren materiellen Kriterien für eine Neuverteilung des Umsatzsteueraufkommens zwischen Bund und Ländern im Rahmen des sog. Deckungsquotenverfahrens; in einem weiteren Sinne auch Art. 91a Abs. 1 GG (alte wie neue Fassung) „Verbesserung der Lebensverhältnisse“ sowie Art. 104a Abs. 4 GG a.F., Art. 104b Abs. 1 Nr. 2 GG n.F. „Ausgleich unterschiedlicher Wirtschaftskraft im Bundesgebiet“; 
mung, ${ }^{150}$ kein Verfassungsauftrag ${ }^{151}$ o.ä. gewinnen. ${ }^{152}$ Die zweifellos in der tatsächlichen Entwicklung deutscher Bundesstaatlichkeit hervorgetretenen politischen und gesellschaftlichen Einheitlichkeitsvorstellungen, befördert durch die unitarisierenden Wirkungen von Grundrechten und Sozialstaatlichkeit, von Parteiendemokratie, landesweiten Medien, Mobilität der Bevölkerung und wirklichen oder vermeintlichen ${ }^{153}$ Erwartungshaltungen von Bürgern, ${ }^{154}$ die zur „,wirkungsmächtigen kultu-

erwogen werden könnte auch, das „gesamtwirtschaftliche Gleichgewicht“ aus Art. 109 Abs. 2 GG einzubeziehen.

150 W. Däubler FS Mahrenholz, 1994, 455 (457); D. Carl Bund-Länder-Finanzausgleich im Verfassungsstaat, 1995, 19f.; H.-W. Arndt JuS 1993, 360 (364) spricht von einem „Verfassungsgebot“; K. Stern VVDStRL 52 (1993), 171 (172) sieht hier eine „verfassungspolitische Richtlinie“.

151 So etwa K.M. Hettlage VVDStRL 31 (1973), 99 (100f.) im Anschluss an sein Staatsrechtslehrerreferat von 1955; H. Hohmann DÖV 1991, 191 (194, 196); F. Kirchhof VVDStRL 52 (1993), 71 (83f.); gegen die Deutung als Verfassungsauftrag etwa H. Zimmermann in: Schmidt (Hrsg.), Beiträge zu ökonomischen Problemen des Föderalismus, 1987, 44; T. Maunz in: Maunz/Dürig, GG, Art. 72 Rn. 23.

152 Deutlich für eine je isolierte Betrachtung und Anwendung P. Lerche in: Maunz/ Dürig, GG, Art. 83 Rn. 45; P. Kirchhof Verfassungsauftrag (Fn. 30), 15 ff.; Kommission Finanzverfassungsreform Baden-Württemberg Zwischenbericht, 1992, $14 \mathrm{ff}$;; P. Selmer VVDStRL 52 (1993), 10 (24ff.); C. Waldhoff Verfassungsrechtliche Vorgaben (Fn. 16), $83 \mathrm{ff}$.; N. Engels Chancengleichheit und Bundesstaatsprinzip, 2001, $91 \mathrm{ff}$;; L. Osterloh EuGRZ 2002, 309 (312); M. Kloepfer DÖV 2004, 566 (567); S. Boysen Gleichheit im Bundesstaat, 2005, $119 \mathrm{ff}$;; T. Hebeler ZG 2006, $301 \mathrm{ff}$.; zurückhaltend auch Mehde Wettbewerb (Fn. 5), $141 \mathrm{ff}$., der zwar eine übergreifende, paradigmatische Bedeutung sieht, nach der Verfassungsänderung 1994 diese inhaltlich jedoch gerade auf Vielfalt, nicht auf Einheitlichkeit ausgerichtet interpretiert; ähnlich zuvor bereits C. Calliess DÖV 1997, $889 \mathrm{ff}$; W. Hertel ZRP 2000, $387 \mathrm{ff}$.

${ }^{153}$ Hier wäre anzumerken, dass unter den Bedingungen gleichhoher Steuerbelastung im Bundesgebiet die Erwartung gleicher oder vergleichbarer Staatsleistungen alles andere als fern liegt; richtigerweise müsste sich die Frage jedoch dahingehend differenzieren, ob bzw. inwieweit der Bürger bereit ist, sich in einem bestimmten Ausmaß an der Staatsfinanzierung zu beteiligen, um ein bestimmtes Leistungs- und Versorgungsniveau $\mathrm{zu}$ erreichen; genau dieser politische Zusammenhang soll durch das hier propagierte Konzept rekonstruiert werden.

154 K.M. Hettlage VVDStRL 14 (1956), 1 (19); A. Köttgen FS Muthesius, 1960, 19 (23); Kommission für die Finanzreform Gutachten über die Finanzreform in der Bundesrepublik Deutschland, 1966, Tz. 74; P. Lerche FS Berber, 1973, 299 ff.; B. Reissert Die finanzielle Beteiligung des Bundes an Aufgaben der Länder und das Postulat der „Einheitlichkeit der Lebensverhältnisse im Bundesgebiet“, 1975; E.-W. Böckenförde in: ders., Staat - Nation - Europa, 1999, 183 (187); P. Kirchhof Verfassungsauftrag (Fn. 30), 15 ff; F. Ossenbühl in: ders. (Hrsg.), Föderalismus und Regionalismus in Europa, 1990, 117 (149f., 152f.); Abromeit Einheitsstaat (Fn. 80), 121, 132; P. Selmer VVDStRL 52 (1993), 10 (20); H. Kilper/R. Lhotta Föderalismus in der Bundesrepublik Deutschland, 1996, $157 \mathrm{ff}$.; H. Schulze-Fielitz in: Henneke (Hrsg.), Verantwortungsteilung zwischen Kom- 
rellen Norm“"155 stilisiert werden und die durch die wiedervereinigungsbedingten Disparitäten neue Aktualität gewonnen haben, nehmen den „Trend ... als Faktum ..., dem sich die Rechtswelt zu fügen habe“,156 geraten in die Nähe des Sein-Sollen-Fehlschlusses. ${ }^{157}$ Das bundesstaatliche Prinzip als die übergreifende Klammer von Subsidiarität und Integration, von Autonomie und Einheitlichkeit umschreibt ein Spannungsfeld, kann hingegen nicht für übergreifende Einheitlichkeitsvorstellungen in Anspruch genommen werden. In diesem Kontext ist versucht worden, das Postulat der „Einheitlichkeit der Lebensverhältnisse“ mit der unitarisch-demokratischen Legitimationsgrundlage des deutschen Bundesstaats gleichzusetzen und damit quasi zum politischen Legitimationsgrundatz schlechthin zu erheben. ${ }^{158}$ Letztlich dürfte es sich bei solchen Versuchen um ein Weimarer Traditionen fortsetzendes Ringen um die Bewahrung oder Herstellung staatlicher Einheit angesichts identitärer demokratischer Konzeptionen handeln - mit der Pointe, daß der Zentraltopos der „politischen Einheit“ in der tatsächlichen politischen und sozialen Stabilität der Bundesrepublik aufgeht. ${ }^{159}$ Der gemeinsame normative Gehalt der die Einheitlichkeit bzw. Gleichwertigkeit der Lebensverhältnisse in Bezug nehmenden Vorschriften liegt demgegenüber in der Tatsache, daß eine gewisse - neben der normativen Mindesthomogenität im Bereich des Art. 28 Abs. 1 GG - tatsächliche Homogenität Funktionsvoraussetzung für jede bundesstaatliche Ordnung darstellt. ${ }^{160}$ Die angesprochenen Topoi üben im Sinne einer bun-

munen, Ländern, Bund und EU, 2001, 117 (128ff.); S. Boysen Gleichheit (Fn. 152), $123 \mathrm{ff}$.; Mehde Wettbewerb (Fn. 5), $147 \mathrm{ff}$.; demoskopisches Material bei N. Grube in: Jahrbuch des Föderalismus 2001, 101 (109ff.).

155 J.-P. Schneider Der Staat 40 (2001), 272 (282).

156 P. Lerche FS Berber, 1973, 299. Ebd., 301: „Verharrt man bei der traditionellen Feststellung, derartige egalitäre Tendenzen stünden mit bundesstaatlicher Eigenständigkeit in einer ,Spannungslage‘, so erhält man zwar eine Beschreibung des Problems, aber keine Antwort.“; Engels Chancengleichheit (Fn. 152), 113.

157 Vgl. auch Henke/Schuppert Finanzbeziehungen (Fn. 147), 41 ff.; deutlich dieser Gefahr erliegend etwa H.-P. Bull DÖV 1999, 269 (279).

158 In der Tendenz so E.-W. Böckenförde in: ders., Staat - Nation - Europa, 1999, 183 (192 ff.).

159 R. Eckertz FS Böckenförde, 1995, 10 (19ff.).

160 Ein „bestimmtes Maß sozialer Homogenität“ als Voraussetzung ,politischer Einheitsbildung“" erkannte - ohne explizit föderalen Bezug - bereits $H$. Heller Politische Demokratie und soziale Homogenität, 1928. Das erscheint mir als der wahre Kern eines richtig verstandenen Postulats von dem Erfordernis eines ökonomischen „Mindestniveaus“ im bundesstaatlichen Kontext, vgl. auch Wissenschaftlicher Beirat beim Bundesministerium der Finanzen Gutachten zum Länderfinanzausgleich in der Bundesrepublik Deutschland, 1992, 48; F. Kirchhof VVDStRL 52 (1993), 71 (84); Engels Chancengleich- 
desstaatlichen Verfassungsvoraussetzung ${ }^{161}$ eine Reservefunktion zur Gewährleistung eines faktischen Mindeststandards ${ }^{162}$ für außergewöhnliche Lagen von Inhomogenität aus, wie sie sich etwa zur Bekämpfung der Ungleichheiten nach der Wiedervereinigung zeigten. ${ }^{163}$ Für den Verfassungszustand der Normallage ${ }^{164}$ können derartige Einheitlichkeitsvorstellungen nicht a priori Vorrang vor widerstreitenden Prinzipien beanspruchen. Das Spannungsverhältnis zwischen (Finanz-)Autonomie und Einheitlichkeit bzw. Gleichwertigkeit der Lebensverhältnisse findet eine Gemeinsamkeit im Individualbezug, der jedoch unterschiedlich ansetzt: Die eine Ansicht postuliert eine „bürgerbezogene materiell gleichmäßige Versorgung“ durch gleichmäßige staatliche Aufgabenerfüllung, ${ }^{165}$ stellt den Bezug zum Individuum ,output“-bezogen her, die andere Sichtweise setzt beim Individuum als Legitimationssubjekt an, aktiviert einen ,input“-bezogenen Individualbezug mit der Folge unterschiedlicher Ergebnisse. Das zuerst genannte Verständnis ist seiner Tendenz nach ergebnisorientiert-technokratisch, die hier vertretene Sichtweise ist freiheitlich-offen. ${ }^{166}$

Die Formeln haben sich politisch als Bestimmungsfaktoren im kontinuierlichen Prozess föderativen Substanzverlusts erwiesen; ${ }^{167}$ sie stellen

heit (Fn. 152), 113; L. Osterloh GS Trzaskalik, 2005, 181 (186); den Zusammenhang zwischen normativer und faktischer Mindesthomogenität stellt auch K.-P. Sommermann in: von Mangoldt/Klein/Starck, GG, Bd. 2, 5. Aufl. 2005, Art. 20 Abs. 1 Rn. 29f. her.

161 Waldhoff Verfassungsrechtliche Vorgaben (Fn. 16), $89 \mathrm{ff}$.

162 P. Selmer VVDStRL 52 (1993), 10 (25f.); über das Sozialstaatsprinzip auf den Bürger bezogen ähnlich Mehde Wettbewerb (Fn. 5), $150 \mathrm{f}$.

${ }_{163}$ Mit je unterschiedlichen Akzenten M. Kilian JZ 1991, 425 ff.; Korioth DVB1. 1991, 1048 ff.; Henke/Schuppert Finanzbeziehungen (Fn. 147), 46ff.; P. Selmer VVDStRL 52 (1993), 10 (31 ff.): Finanzverantwortung für die einigungsbedingten „Einmalaufgaben“ in den neuen Bundesländern.

164 F. Kirchhof VVDStRL 52 (1993), 71 (75); Vergleichbarkeit der Ausgangslagen, die „Ausgangsverteilung“ der Ressourcen sind grundsätzlich bei jedem auf Autonomie und Wettbewerb setzenden Modell zu berücksichtigen, vgl. K. Rennert Der Staat 32 (1993), 269 (275).

165 Vgl. L. Osterloh GS Trzaskalik, 2005, $181(184,183)$.

166 L. Osterloh GS Trzaskalik, 2005, 181 (183f.): „Beide Fragen sind ... unmittelbar aufeinander bezogen wie zwei Seiten einer Medaille. Autonomie der Länder will Unterschiedlichkeit der Lebensverhältnisse ermöglichen. Wer mehr Autonomie fordert, muss auch für mehr Unterschiedlichkeit eintreten." $\mathrm{Zu}$ dem Zusammenhang zwischen Finanzautonomie, Freiheit und Gestaltungsspielraum auch W. Heun in: Dreier (Hrsg.), GG, Bd. 3, 2000, Vorb. zu Art. 104a-115 Rn. 18.

$167 \mathrm{Vgl}$. die Warnung bei B.-O. Bryde in: Sitter-Liver (Hrsg.), Herausgeforderte Verfassung, 1999, 223 (234): „Sobald man sich darauf einigt, dass bei der höheren Ebene alle Kompetenzen liegen sollten, die für ,das Funktionieren des gemeinsamen Marktes', die ,Rechts- und Wirtschaftseinheit‘, die ,Einheit der Lebensverhältnisse“ oder dergleichen wichtig sind, ist der Aufgabenwanderung nach oben kaum noch Einhalt zu gebieten.“ 
jedoch keine verfassungsrechtlich verbindlichen Direktiven für die Konkretisierung geltenden oder die Schaffung neuen Rechts dar: $168 \mathrm{Ihr}$ von Peter Lerche beschworener „magischer Glanz" 169 strahlt politisch-faktisch, nicht normativ. ${ }^{170}$ In die Zukunft gerichtet: Es wird in einem Europa zunehmender Integration immer schwerer politisch zu erklären sein, warum zwar zwischen Aachen und Görlitz gleiche Lebensverhältnisse vorherrschen sollen, dabei jedoch Brüssel und Breslau ausgeblendet bleiben.

\section{Keine Wettbewerbsfeindlichkeit der hoheitlichen Finanzwirtschaft}

Richtig balanciert hat der Wettbewerbsgedanke unter dem Leitgesichtspunkt der (Finanz-)Autonomie eine zentrale Funktion zur (nationalen wie supranationalen) institutionellen Einhegung staatlicher Steuergewalt. ${ }^{171}$ Steuerwettbewerb findet heute eher im globalen und eu-

168 Entwicklungsgeschichtlich sind die Formeln - wie etwa Oeter Integration und Subsidiarität (Fn. 1); ferner C. Waldhoff Verfassungsrechtliche Vorgaben (Fn. 16), $102 \mathrm{ff}$;; ders. Die Verwaltung 39 (2006), 155 (168ff.); S. Boysen Gleichheit (Fn. 152), 53 ff. dargelegt haben - bis in die dogmatischen Vorverständnisse und Konstruktionen der Bundesstaatsdogmatik oder - so die Theorie K. von Beymes in: Wagschal/Rentsch (Hrsg.), Der Preis des Föderalismus, 2002, 29 (31 f.) - tief in die deutsche wohlfahrtsstaatlichpaternalistische Anschauung hineinreichend: Die überschießenden national- und machtstaatlichen Euphorien im Zusammenhang mit der Bundesstaatsbildung, andererseits liberale (an einem einheitlichen Wirtschaftsraum orientierte), demokratische (die monarchische Legitimität der verbündeten Fürstenhäuser fürchtende) und sozialdemokratische (eine einheitliche Sozialpolitik präferierende) Skepsis gegenüber der föderalen Staatsform verstärken sich gegenseitig; diese Bestimmungsfaktoren sollten für die Gegenwart keine maßgebliche Relevanz mehr entfalten können.

169 FS Berber, 1973, 299.

170 Vgl. auch $P$. Kirchhof VVDStRL 52 (1993), 147 (150).

171 Allgemein zur Polarität von Staat und Wettbewerb - wobei „Wettbewerb“ noch einmal differenziert werden müsste in Belastungs- und Ideen-(Innoverations-)wettbewerb B. Grzeszick HStR IV, 3. Aufl. 2006, § 78; in den Wirtschaftswissenschaften werden ganz überwiegend die positiven Wirkungen von (System-)Wettbewerb, speziell von Steuerwettbewerb hervorgehoben; insbesondere der Public Choice-Ansatz sieht hier eine institutionelle Möglichkeit, nicht nur die Höhe der Steuerbelastung auszutarieren, sondern die Grenzkosten der Steuerzahler mit deren Grenznutzen aus den durch die öffentlichen Abgaben finanzierten Leistungen in Kongruenz zu bringen: grundlegend G. Brennan/ J.A. Buchanan Besteuerung und Staatsgewalt, 1988; die genauen Auswirkungen eines derartigen Wettbewerbs sind nicht restlos geklärt und ökonomisch nicht unstrittig, vgl. aus dem wirtschaftswissenschaftlichen Schrifttum: Jahrbuch für Neue Politische Ökonomie 17 (1998); C. Baretti/R. Fenge/B. Huber/W. Leibfritz/M. Steinherr Chancen und Grenzen föderalen Wettbewerbs, 2000; L.P. Feld Steuerwettbewerb und seine Auswirkungen auf Allokation und Distribution, 2000; T. Büttner/R. Schwager in: Jahrbücher für Nationalökonomie und Statistik 223 (2003), 532ff.; U. Wagschal/H. Rentsch (Hrsg.), Der Preis des Föderalismus, 2002; Esser Steuerwettbewerb (Fn. 8); kritisch demgegenüber mit der 
ropäischen Kontext, als innerbundesstaatlich statt. ${ }^{172}$ Wettbewerbselemente zur institutionellen Einhegung von Steuerbelastung wurden dem

Besorgnis eines race to the bottom H.-W. Sinn European Economic Review 34 (1990), 489 ff.; ders. Journal of Public Economics 66 (1997), 247 ff.; ders. in: Oberhauser (Hrsg.), Fiskalföderalismus in Europa, 1997, 9 ff.; B. Hohaus Steuerwettbewerb in Europa, 1996; historische Analyse bei M. Spoerer Jahrbuch für Wirtschaftsgeschichte 2002/2, $35 \mathrm{ff}$.

Es sei nur darauf hingewiesen, dass die verfassungsrechtlich durch Gleichheits-, Freiheitsrechte und Normen wie Art. 106 Abs. 3 Satz 4 Nr. 2 GG („Vermeidung einer Überbelastung der Steuerpflichtigen“; dazu m.w.N. Waldhoff Verfassungsrechtliche Vorgaben (Fn. 16), 254 ff.; M. Heintzen in: von Münch/Kunig (Hrsg.), GGK III, 4./5. Aufl. 2003, vorb. Art. 104a-115 Rn. 26) jenseits aller dogmatischen Unklarheiten stets geforderte Begrenzung der Steuerlast dem Bürger gegenüber im konstitutionellen Zeitalter mittels eines institutionellen Arrangements - das Zusammenspiel zwischen der kostenverursachenden monarchischen Exekutive und der, verstärkt durch ein Zensuswahlrecht (F. Schneider AöR 26 (1910), 193 ff.; N.-U. Tödter Die deutschen parlamentarischen Klassenwahlrechte im 19. und 20. Jahrhundert, Diss. iur. Hamburg 1967; P.M. Ehrle Volksvertretung im Vormärz, 1979), das Bürgertum repräsentierenden Volksvertretung - über die Zustimmungsbedürftigkeit kraft Gesetzesvorbehalt der Steuergesetze ausbalanciert wurde; in der parlamentarischen Demokratie mit seit 1919 monistischer Legitimationsgrundlage kann dieser Mechanismus nicht mehr in gleicher Weise funktionieren (vgl. nur Strickrodt Finanzverfassung (Fn. 79), 39). An seine Stelle müsste materielles Verfassungsrecht, vorzugsweise die Grundrechte treten. Da nun aber die maßgebliche Schranken-Schranke des Verhältnismäßigkeitsprinzips in der Zweck-Mittel-Relation von Staatsfinanzierung und Steuerbelastung $\mathrm{zu}$ versagen droht und das quantifizierende Konzept des sog. Halbteilungsgrundsatzes (BVerfGE 93, 121 (138) inzwischen kaum noch Gefolgschaft findet, ist das Problem ungelöst. Das Bundesverfassungsgericht hat in seiner Entscheidung zur kumulativen Wirkung von Einkommen- und Gewerbesteuer (NJW 2006, 1191 (1194)) zutreffend erkannt, dass die Prüfungen der Geeignetheit und der Erforderlichkeit nicht möglich seien und sich dann auf eine Zumutbarkeitsprüfung kapriziert; um hier Kriterien für die Abwägung zu erhalten wird angeregt, eine Art internationalen Belastungsvergleich durchzuführen, der dann spezifische Rechtfertigungslasten für den deutschen Steuergesetzgeber nach sich ziehen könnte. Bei Lichte betrachtet wird damit wieder ein institutionelles Argument durch die Hintertür zur Anwendbarmachung einer grundrechtlichen Schranken-Schranke instrumentalisiert. Zur Nichtanwendbarkeit des Verhältnismäßigkeitsprinzips auf hoheitliche Abgabenerhebung BVerfGE 63, 343 (367f.); 84, 239 (268f.); H.-J. Papier Die finanzrechtlichen Gesetzesvorbehalte (Fn. 93), 76 ff.; ders. DVB1. 1980, 787 (793); D. Birk Das Leistungsfähigkeitsprinzip als Maßstab der Steuernormen, 1983, 189; die Alternative stellt eine Durchbrechung des haushaltsrechtlichen Nonaffektationsprinzips dar, vgl. je unterschiedlich H.H. von Arnim VVDStRL 39 (1981), 286ff.; M. Elicker DVB1. 2006, 480 ff.; W. Frenz GewArch. 2006, 282 (285ff.); für steuerrechtliche Ausnahmetatbestände, etwa Vorschriften zur Verhinderung von Umgehungen, kann anderes gelten, vgl. M. Heintzen in: von Groll (Hrsg.), Verluste im Steuerrecht, 2005, 163 (179ff.); für die Lenkungsfunktion ist ohnehin eine freiheitsrechtliche Prüfung des Sozialzwecks möglich, vgl. nur Wernsmann Verhaltenslenkung (Fn. 141), $203 \mathrm{ff} ., 237 \mathrm{ff}$.

172 § 16 Abs. 4 Satz 2 GewStG, für Erhebunsgjahre ab 2004; B. Runge FS Rädler, 1999, 559; J. Hey FS Solms, 2005, 35; C. Spengel, DJT-Gutachten 2006, G 1 (G 6 ff., G 28f.); allgemein - nicht auf Besteuerung bezogen - M. Wallerath JZ 2001, 209 (213); 
deralen System und der bundesstaatlichen Finanzverfassung als deren zentralem Bestandteil fast vollständig ausgetrieben. Selbst im Bereich der Gewerbesteuer, in dem die Gemeinden mit ihrem Hebesatzrecht (Art. 28 Abs. 2 Satz 3 Hs. 2 GG) Finanzautonomie praktizieren können, wurde jüngst mit dem Verbot des Verzichts auf die Erhebung dieser Steuer ${ }^{173}$ eine gewisse Wettbewerbsphobie deutlich.

Die pauschale Verneinung der Existenz und Funktion von Wettbewerb im staatlichen Kontext ${ }^{174}$ verfehlt das hiesige Anliegen: Wettbewerb zwischen Individuen oder Unternehmen am „Markt" ist von Wettbewerbssituationen, die Ausfluss hoheitlicher Autonomie sind, zu unterscheiden. Sie treffen sich in der Gemeinsamkeit des Anliegens, durch einen institutionellen Rahmen den Gesamtnutzen mehrende Ergebnisse zu erzielen. Wenn in gestuften Rechtsordnungen den einzelnen Ebenen eigenverantwortliche Gestaltungsmöglichkeiten im finanzwirtschaftlichen Bereich zustehen, kommen folgerichtig wettbewerbsähnliche Situationen zwischen diesen mit Finanzautonomie begabten Ebenen zustande. ${ }^{175}$ Das Missverständnis besteht in der Verwechselung des Wettbewerbs innerhalb von Gebietskörperschaften oder Ebenen mit demjenigen zwischen solchen. ${ }^{176}$ Problematisch ist die stets verfäl-

differenziert mit einer Warnung vor der Überschätzung des internationalen und einer Unterschätzung des nationalen Steuerwettbewerbs M. Spoerer Jahrbuch für Wirtschaftsgeschichte 2002/2, 35 (39); ein Antrag auf einstweilige Anordnung der Aussetzung der Erhebungspflicht wurde vom BVerfG abgelehnt, E 112, 216.

${ }^{173}$ Gesetz zur Änderung des Gewerbesteuergesetzes und anderer Gesetze vom 23. Dezember 2003, B GB1 I S. 2922; J. Hey FS Solms, $41 \mathrm{f}$.

174 Pointiert $P$. Kirchhof in: von Bogdandy (Hrsg.), Europäisches Verfassungsrecht, 2002, 893 (928); ders. in: ders. (Hrsg.), Gemeinwohl und Wettbewerb, 2005, 1 (4ff.); ders. ORDO 56 (2005), 39 ff.; differenzierter ders. FS Badura, 2004, 237 (251 ff.); zuvor bereits kritisch H.H. Rupp FG zum 10jährigen Bestehen der Gesellschaft für Rechtspolitik, 1984, 377 (381 ff.); politisch-ökonomische Abwehrhaltung bei $R$. Strahm in: Wagschal/Lentsch (Hrsg.), Der Preis des Föderalismus, 2002, $135 \mathrm{ff}$.

175 C. Seiler, DJT-Gutachten 2006, F 7 (F 15f.); zu solchem Wettbewerb als „tatsächlichem Phänomen“ als Grundannahme ausführlich Mehde Wettbewerb (Fn. 5), $25 \mathrm{ff}$. und durchgehend.

176 Döhler Autonome Besteuerungsrechte (Fn. 16), 44; V. Vanberg ORDO 56 (2005), 47 (49); U. Münch in: Jahrbuch des Föderalismus 2001, 115 (126); W. Schön in: Mellinghoff u.a. (Hrsg.), Die Erneuerung des Verfassungsstaates, 2003, $143 \mathrm{ff}$.; B. Grzeszick HStR IV, 3. Aufl. 2006, $§ 78$ Rn. 9 ff.: Wettbewerb und das Staat-Bürger-Verhältnis vs. Wettbewerb und die Organisation von Hoheitsgewalt; Mehde Wettbewerb (Fn. 5), 59 ff., zu den Funktionsunterschieden ebd., 87 ff.; davon kann wiederum - gleichsam als dritte Form des Zusammentreffens von Staatlichkeit und Wettbewerb - der (Binnen-)Wettbewerb innerhalb der öffentlichen Verwaltung unterschieden werden, vgl. Musil Wettbewerb (Fn. 65), $23 \mathrm{ff}$. 
schende, da asymmetrische Teilnahme des Staates an dem von ihm mitkonstituierten Wettbewerb der gesellschaftlichen Sphäre der Freiheit, ${ }^{177}$ weniger Wettbewerbssituationen zwischen autonomen staatlichen oder quasistaatlichen Ebenen. Vom überkommenen ökonomischen Wettbewerb, der sich als Folge der Ausübung grundrechtlich umhegter Freiheit auf die Sphären von Wirtschaft und Gesellschaft bezieht, ist hier eine institutionelle Balance verschiedener staatlicher oder supranationaler Ebenen abzugrenzen: „Wettbewerb“178 als notwendige Folge von Autonomie. ${ }^{179}$ Anders gewendet: Die tatsächlichen wettbewerbsähnlichen Situationen als Folge von Autonomie sind Ausfluss politischen Wettbewerbs bei vorgegebenen Institutionen. Sie haben sich stets im Rahmen der aus den Staatsstrukturentscheidungen fließenden rechtlichen Bindungen zu bewegen. ${ }^{180}$ Föderalismus und Mehrebenenstruktur können insgesamt als groß angelegter, traditionsreicher Versuch einer Regulierung solcher Wettbewerbssituationen interpretiert werden. ${ }^{181}$ Auch dieser „Wettbewerb“ bedarf der rechtlichen Hegung. ${ }^{182}$ In diesem Sinne ist der im Ausgangspunkt bestehende Antagonismus zwischen Hoheitsprinzip und Wettbewerbselementen durch die gemeinsame Finalität im Hinblick auf das zu verwirklichende Gemeinwohl aufgehoben. ${ }^{183}$

177 Vgl. nur W. Löwer VVDStRL 60 (2001), 416ff.; A. Voßkuhle Der Staat 40 (2001), 495 (517); F.-L. Knemeyer WiVerw. 2001, 1 ff.; P. Kirchhof FS Schmitt Glaeser, 2003, $3 \mathrm{ff}$.

$178 \mathrm{Zu}$ den terminologischen Problemen C. Seiler DJT-Gutachten 2006, F 15.

179 Insofern zutreffend P. Kirchhof FS Badura, 2004, 237 (251).

180 B. Grzeszick HStR IV, 3. Aufl. 2006, § 78 Rn. 21. Zur Distinktion von politischem und wirtschaftlichem Wettbewerb M. Wallerath JZ 2001, 209 (213); Musil Wettbewerb (Fn. 5), 385 ff.: politischer Wettbewerb als Kernelement jeder Demokratie.

181 S. Homburg FinArch. 51 (1994), 312: „Finanzverfassung bildet ... den Ordnungsrahmen des föderalen Wettbewerbs“; M. Wallerath JZ 2001, 209 (213); Di Fabio Weltgesellschaft (Fn. 4), 23: „Um dem Machtverlust zu begegnen und dem Wettbewerb auch der Staaten Regeln zu geben, entwickeln sich supranationale Herrschaftsstrukturen. ... Supranationalität kann insofern als Ordnungsrahmen für den Wettbewerb fortbestehender politisch integrierter Gemeinschaften gesehen werden."; Mehde Wettbewerb (Fn. 5), $100 \mathrm{ff} ., 104 \mathrm{ff}$.

182 Blanke in: ders./Schwanengel (Hrsg.), Zustand und Perspektiven des deutschen Bundesstaates, 2005, 127 (160); jeweils aus ökonomischer Sicht $R$. Windisch Jahrbuch für Neue Politische Ökonomie 17 (1998), $121 \mathrm{ff}$.; W. Kerber ebd., 199ff.; B. Huber in: Büttner (Hrsg.), Finanzverfassung und Föderalismus in Deutschland und Europa, 2000, $123 \mathrm{ff}$.; Döhler Autonome Besteuerungsrechte (Fn. 16), $44 \mathrm{ff}$.; W. Müller/O. Fromm/ B. Hansjürgens (Hrsg.), Regeln für den europäischen Systemwettbewerb, 2001.

183 B. Grzeszick HStR IV, 3. Aufl. 2006, § 78 Rn. 18f.; vgl. auch das Credo bei Mehde Wettbewerb (Fn. 5), 32 ff., dass Wettbewerb niemals Selbstzweck, sondern stets Mittel zum Zweck sein kann; ferner Musil Wettbewerb (Fn. 65), 384 ff.; C. Kirchner in: Kirchhof (Hrsg.), Gemeinwohl und Wettbewerb, 2005, $45 \mathrm{ff}$. 
Durch das Herausstellen des Individualbezugs der Staatsfinanzierung werden durch eine verfassungsrechtlich-normative, mit staatstheoretische Erwägungen angereicherte Argumentation ähnliche Ergebnisse erzielt, wie sie von einem anderen Ausgangspunkt ${ }^{184}$ die ökonomische Analyse föderaler Systeme v.a. im Anschluss an den sog. Fiscal federalism $^{185}$ hervorbringt. ${ }^{186}$ Im Unterschied zu diesen ökonomischen Ansätzen wird jedoch von vornherein die Annahme einer Strukturgleichheit, Gleichgewichtigkeit oder Austauschbarkeit der in die Argumentation einbezogenen Ebenen vermieden: Nimmt man die Stufen als prinzipiell austauschbare „Aufgabenerfüllungsebenen“ 187 wahr, erscheint es primär als eine Frage der Effizienz, welcher Ebene welche Aufgabe zugeordnet wird, 188 im hiesigen Kontext: welche Finanzierungs- und Besteuerungsbefugnisse welcher Stufe zuzuordnen sind. Nach dem hier verfolgten Modell sollen finanzverfassungsrechtliche Befugnisse Folgen demokratischer Legitimation sein: ${ }^{189}$ „Der Bundesstaat ist mehr als nur eine Folie für allokationstheoretische Modellbildung." "190 Bedenken, unkontrolliert ökonomische Erkenntnisse in die Verfassungsauslegung einfließen zu lassen, ${ }^{191}$ die den Gesichtspunkt der Effizienz verabsolutierende Institu-

184 Auf einer abstrakten Ebene sind die Ausgangspunkte zwischen Institutionenökonomik und einem verfassungsrechtlich-staatstheoretischen Ansatz letztlich doch wieder ähnlich, sofern es um „Freiheit als Grundlage und Ziel kollektiven Handelns“ geht, vgl. für die politische Ökonomie insofern nur T. Petersen Individuelle Freiheit und allgemeiner Wille, 1996, insbes. $170 \mathrm{ff}$.

$185 \mathrm{Vgl}$. die Nachweise oben in Fn. 9.

186 Vgl. für die begrenzte wohlfahrtsstaatliche Entwicklungsdynamik in demokratischen Bundesstaaten die politikwissenschaftliche Analyse von H. Obinger/S. Leibfried/F.G. Castles Der Staat 44 (2005), $505 \mathrm{ff}$.

187 Hobe Der offene Verfassungsstaat (Fn. 7), 390 ff.: funktionale Gliederung des internationalen Systems. Vgl. mit z.T. anderen Prämissen insoweit auch P. Saladin Wozu noch Staaten? 1995, $117 \mathrm{ff}$.

188 R. Wahl in: ders., Verfassungsstaat - Europäisierung - Internationalisierung, 2003, $60 \mathrm{f}$; B.-O. Bryde in: Sitter-Liver (Hrsg.), Herausgeforderte Verfassung, 1999, 223 (227f.); Oeter in: von Bodandy (Hrsg.), Europäisches Verfassungsrecht, 2003, 59 (69). Die fehlende Austauschbarkeit der unterschiedenen Stufen oder Ebenen drückt sich auch in der altbekannten gemeinschaftsrechtlichen Problematik der Übertragbarkeit staatlicher Kategorien auf den europäischen Integrationsprozess aus, vgl. R. Wahl in: ders. Verfassungsstaat - Europäisierung - Internationalisierung, 2003, 86; A. von Bogdandy FS Badura, 2004, 1033.

189 Ähnlich $R$. Wahl in: ders., Verfassungsstaat - Europäisierung - Internationalisierung, 2003, 73.

${ }^{190}$ H. Schulze-Fielitz in: Henneke (Hrsg.), Verantwortungsteilung zwischen Kommunen, Ländern, Bund und EU, 2001, 117 (120).

191 Deutlich etwa bei H.-P. Bull DÖV 1999, $269 \mathrm{ff}$.; J.-P. Schneider in: Denninger u.a. (Hrsg.), AK-GG, 3. Aufl. 2001, vor Art. 104a Rn. 9 ff.; U. Münch in: Jahrbuch des Fö- 
tionenökonomik sei in der universellen Struktur einer zudem noch traditional mitgeprägten Verfassungsordnung nicht implementierbar, können abgeschwächt werden.

\section{Konsequenzen der Interdependenz zwischen demokratischer Legitimation und Finanzordnung}

Exemplarisch sollen die Auswirkungen auf das Recht zur Steuergesetzgebung demonstriert werden. ${ }^{192}$ Neben der Forderung nach einer Mindestfinanzautonomie der Ebenen ${ }^{193}$ folgen aus Struktur und Intensität der demokratischen Legitimation der jeweils hervorgebrachten Rechtsetzungsakte aus dem Ansatz auch Grenzen.

\section{Die legitimatorisch abgeleiteten Ebenen: Gesetzesgebundene Finanzautonomie der Gemeinden, die Mitgliedstaaten als „Herren“ über die Einnahmen der Europäischen Union}

Die spezifische demokratische Legitimation kommunaler Rechtssätze ${ }^{194}$ erklärt und rechtfertigt die kommunale Finanzautonomie über

deralismus 2001, 115 (124ff.); B. Grzeszick JZ 2003, 647 (650ff.); H. Bauer HStR I, 3. Aufl. 2003, 14 Rn. 114 ff.; Kube Finanzgewalt (Fn. 5), 518 ff.; S. Korioth in: DJT 2004, P 90; problematisch Schatz/van Ooyen/Werthes Wettbewerbsföderalismus (Fn. 104), $45 \mathrm{ff}$.

192 Ausgeschlossen bleiben damit die ebenfalls für die Exemplifikation geeigneten Felder Ausgabenlast/Konnexitätsprinzip, Staatsverschuldung. Außerdem wäre es notwendig, den hier entfalteten Ansatz auch hinsichtlich der teilweise beachtlichen Auslegungsspielräume des geltenden Finanzverfassungsrechts fruchtbar zu machen. Unbestimmte Rechtsbegriffe wie der „,angemessene Ausgleich“ in Art. 107 Abs. 2 Satz 1 GG im Rahmen des horizontalen Länderfinanzausgleichs sind erneut zu beleuchten. Bestimmte Gründe für Bundesergänzungszuweisungen (Art. 107 Abs. 2 Satz 3 GG) müssten sich stärker vor dem Verfassungsprinzip der Finanzautonomie rechtfertigen. Korrekturen liegen bei rein richterrechtlich entwickelten Instituten wie den sog. extremen Haushaltsnotlagen einzelner Länder und die durch sie hervorgerufenen Ausgleichsverpflichtungen der anderen Bundesgenossen nahe.

193 Hensel Finanzausgleich (Fn. 16), 163, spricht von der „unbedingte[n] Notwendigkeit eines gewissen Maßes gliedstaatlicher Restfinanzhoheit“; ähnlich Hanebeck Bundesstaat (Fn. 37), 343; unabhängig von finanzverfassungsrechtlichen Fragen weist U. Volkmann DÖV 1998, 613 (614f.) darauf hin, dass der Bundesstaat ,sachliche Autonomie“ der Gliedstaaten „logisch voraussetzt“; ähnlich A. Janssen in: Henneke (Hrsg.), Verantwortungsteilung zwischen Kommunen, Ländern, Bund und EU, 2001, 59 (62 ff.).

194 C. Waldhoff FS Vogel, 2000, 495 ff.; B. Grzeszick in: Maunz/Dürig, GG, Art. 20 IV Rn. 45; aus österreichischer Perspektive P. Pernthaler in: ders./Bußjäger (Hrsg.), Ökonomische Aspekte des Föderalismus, 2001, 15 (24). 
gemeindliche Steuer- und Abgabensatzungen, ermächtigt durch und in den Grenzen der Kommunalabgabengesetze auf der Rechtsgrundlage von Art. 105 Abs. 2a GG. ${ }^{195}$ Die Bedeutung der eigenverantwortlichen Gestaltung der kommunalen Abgabenerhebung wurde durch zwei Verfassungsänderungen in Art. 28 Abs. 2 Satz 3 GG betont. ${ }^{196}$ Ein gemeindliches Steuererfindungsrecht kann es nur innerhalb dieses gesetzlich vorgeformten Rahmens geben. ${ }^{197}$ Die eigentlichen Probleme der Kommunen in der Mehrebenenstruktur liegen - trotz jüngster Verbesserungen (Art. 84 Abs. 1 Satz 7 und Art. 85 Abs. 1 Satz 2 GG n.F.) - in der Problematik bundes- oder landesgesetzlicher Aufgabenzuweisungen bei ungenügender Konnexität ihrer Finanzausstattung. ${ }^{198}$

Ganz ähnlich erweist sich der demokratische Rückbezug des Finanzrechts auch oberhalb der staatlichen Ebene wiederum als begrenzender Faktor der institutionellen Ausgestaltung. Die Finanzautonomie der EU ist auf der Einnahmenseite noch weitergehender beschränkt als auf der kommunalen Ebene. ${ }^{199}$ Das Eigenmittelsystem (Art. 269 EGV i.V.m.

$195 \mathrm{Zu}$ den sich daraus eröffnenden Gestaltungsspielräumen BVerfG NVwZ 1997, 573; C. Waldhoff FS Vogel, 2000, $495 \mathrm{ff}$; ders. in: Henneke/Pünder/Waldhoff (Hrsg.), Recht der Kommunalfinanzen, 2006, § 1 Rn. $17 \mathrm{ff}$.

196 Vgl. nur F. Schoch/J. Wieland Finanzierungsverantwortung für gesetzgeberisch veranlasste kommunale Aufgaben, 1995, 182f.; H.-G. Henneke Die Kommunen in der Finanzverfassung des Bundes und der Länder, 3. Aufl. 1998, 21 f.; C. Waldhoff/H. Pünder in: Henneke/Pünder/Waldhoff (Hrsg.), Recht der Kommunalfinanzen, 2006, § 1 Rn. $11 \mathrm{ff}$.

197 BVerwGE 96, 272 (280); P. Kirchhof in: Püttner (Hrsg.), Handbuch der kommunalen Wissenschaft und Praxis, Bd. 6., 2. Aufl. 1985, 4; F. Schoch Verfassungsrechtlicher Schutz der kommunalen Finanzautonomie, 1997, 41; C. Waldhoff in: Henneke/Pünder/ Waldhoff (Hrsg.), Recht der Kommunalfinanzen, 2006, § 1 Rn. 14; § 13 Rn. 5 ff.; a.A. $H$. Meyer Die Finanzverfassung der Gemeinden, 1969, 50ff.; H. Mohl Die Einführung und Erhebung neuer Steuern aufgrund des kommunalen Steuererfindungsrechts, 1992.

198 F. Schoch/J. Wieland Finanzierungsverantwortung für gesetzgeberisch veranlasste kommunale Aufgaben, 1995; F. Schoch Verfassungsrechtlicher Schutz der kommunalen Finanzautonomie, 1997; H.-G. Henneke Finanzverfassung (Fn. 55), Rn. 824 ff.; S. Mückl Finanzverfassungsrechtlicher Schutz der kommunalen Selbstverwaltung, 1998; ders. in: Henneke/Pünder/Waldhoff (Hrsg.), Recht der Kommunalfinanzen, 2006, § 3 .

199 Art. 6 Abs. 4 (Art. F Abs. 3 a.F.) EUV bringt keine Kompetenz zur Beschaffung oder Erhebung von Finanzmitteln, BVerfGE 89, 155 (194f.); Häde Finanzausgleich (Fn. 126), 375f., 457; M. Lienemeyer Finanzverfassung der Europäischen Union, 2002, 256f.; vernachlässigbar ist hier die Eigenbesteuerung der EG-Bediensteten, vgl. etwa U. Klinke IStR 1995, 217 ff. sowie Einnahmen aus Buß-, Zwangsgeldern u.ä.; auch bestehen keine nennenswerten Verschuldungsmöglichkeiten; vgl. dazu M. Seidel RIW 1977, 665 ff.; P. Selmer in: Boeckstiegel u.a. (Hrsg.), Finanzverfassung der Europäischen Gemeinschaften, 1984, 21 ff.; R. Scheibe Die Anleihekompetenz der Gemeinschaftsor- 
dem jeweils gültigen Eigenmittelbeschluss) ${ }^{200}$ stellt sich modellkompatibel dar: Durch primäres Gemeinschaftsrecht außerhalb der Verträge wird ein absolut begrenzter Finanzrahmen zur Verfügung gestellt, während auf der Ausgabenseite das Europäische Parlament zwar nicht ein den mitgliedstaatlichen Parlamenten vergleichbares Budgetrecht besitzt, die Gemeinschaft jedoch über ihre Ausgaben weitgehend autonom befindet. ${ }^{201}$ Die Einnahmen präjudizieren vollständig die Ausgaben. Daraus ergibt sich zwar eine beträchtliche und nicht unproblematische Asymmetrie in der EU-Finanzwirtschaft;202 diese spiegelt jedoch den erreichten Integrationsstand wesentlich präziser, als integrationspolitische Programme dies könnten. ${ }^{203}$ Bezugspunkte sind stets die Mitgliedstaaten, nicht deren Bürger. Da Rechtsakte der Gemeinschaften nach wie vor nicht den gleichen Grad demokratischer Legitimation aufweisen, wie mitgliedstaatliche Steuergesetze, ${ }^{204}$ kann der integrationspoli-

gane nach dem EWG-Vertrag, 1988; $R$. Münch Die Verschuldungstätigkeit der Europäischen Gemeinschaft, 1989; D. Gesmann-Nuissl Die Verschuldungsbefugnis der Europäischen Union, 1999.

${ }^{200}$ E. Reister Haushalt und Finanzen der Europäischen Gemeinschaften, 1975; D. Strasser Die Finanzen Europas, 3. (deutschsprachige) Aufl. 1991; R. Messal Das Eigenmittelsystem der Europäischen Gemeinschaft, 1991; R. Peffekoven Die Finanzen der Europäischen Union, 1994; Häde Finanzausgleich (Fn. 126), 427 ff.; S. Hölscheidt/ C. Baldus DÖV 1997, 873; Lienemeyer Finanzverfassung der Europäischen Union (Fn. 199), $112 \mathrm{ff}$; B. Meermagen Beitrags- und Eigenmittelsystem, 2002.

201 Vgl. statt vieler M. Rossi Europäisches Parlament und Haushaltsverfassungsrecht, 1997; allgemein zu den Kompetenzen des Europäischen Parlaments vor dem Demokratieprinzip M. Kaufmann Europäische Integration und Demokratieprinzip, 1997, $226 \mathrm{ff}$.

202 Vgl. nur B. Seidel Die Einbindung der Bundesrepublik Deutschland in die Europäischen Gemeinschaften als Problem des Finanzausgleichs, 1992, 220f ff.; M. Rossi Haushaltsverfassungsrecht (Fn. 201), 246 ff.; Lienemeyer Finanzverfassung der Europäischen Union (Fn. 199), 258ff.; C. Waldhoff in: Calliess/Ruffert (Hrsg.); EUV/EGV, 3. Aufl. 2006, Art. 269 Rn. 12.

203 Vgl. auch A. von Bogdandy in: ders. (Hrsg.), Europäisches Verfassungsrecht, 2003, 149 (175 mit Fn. 106), wo die EU-Finanzverfassung als Zuspitzung des dualistischen Legitimationsmodells der Gemeinschaften interpretiert wird; ebd., 183, wird die Finanzverfassung als „eigentliche Achillesferse“ jeder föderalen Ordnung identifiziert.

${ }^{204}$ Der unendliche Diskurs über das wirkliche oder vermeintliche Demokratiedefizit auf Gemeinschaftsebene kann und soll hier nicht umfassend referiert werden; mit einer gehörigen Portion an Pauschalierung können v.a. zwei Richtungen unterschieden werden: Abgrenzung von und Integration in das Demokratiekonzept des Bundesverfassungsgerichts, v.a. im Anschluss an das Maastrichturteil BVerfGE 89, 155; auf dieser Linie etwa M. Kaufmann Europäische Integration und Demokratieprinzip, 1997; U. Di Fabio FS Badura, 2004, 77 (93 ff.); auf Finanzbefugnisse bezogen Rossi Haushaltsverfassungsrecht (Fn. 201), $259 \mathrm{ff}$; M. Traub Einkommensteuerhoheit für die Europäische Union? 2005, 84 ff.; „offenere“ Modelle etwa bei A. von Bogdandy in: ders. (Hrsg.), Europäisches Verfassungsrecht, 2003, 149 (171 ff.); ders. in: Bauer/Huber/Sommer- 
tisch häufig erhobenen Forderung nach einer EU-Steuer ${ }^{205}$ nach hiesigem Ansatz nicht gefolgt werden. In souveränitäts- und damit zugleich demokratiesensiblen Bereichen wie der Besteuerung - als Parallele wäre etwa die Ausübung physischen Zwangs zu nennen - versagen funktional-technokratisch-affirmative Kompensationsmechanismen, die in anderen Integrationsbereichen ihr Auskommen haben mögen. Bei dem derzeitigen Integrationsstand des „Staatenverbundes“ besteht auch kein Bedürfnis für den unmittelbaren Durchgriff auf die Unionsbürger zur Finanzierung der Union, Erhebungsadressaten für die sog. Eigenmittel bleiben die Mitgliedstaaten, der Unionsbürger ist finanzrechtlich mediatisiert. ${ }^{206}$ Für einen umverteilenden Finanzausgleich jenseits der aufgabengebundenen Strukturpolitik fehlen die integrationspolitischen Voraussetzungen. ${ }^{207}$

\section{Die Notwendigkeit eigengestaltbarer Einnahmen der Länder}

Angesichts der bisherigen Kompetenzausschöpfung durch den Bund fehlt es den Ländern an eigengestaltbaren Einnahmequellen. Diese Situation hat sich durch die Restriktionen hinsichtlich der Verschuldung durch die Anforderungen der Wirtschafts- und Währungsunion noch verschärft. ${ }^{208}$ Die Einräumung eines Hebesatzrechts für die Grunder-

mann (Hrsg.), Demokratie in Europa, 2005, $225 \mathrm{ff}$. Wenn S. Oeter in: von Bogdandy (Hrsg.), Europäisches Verfassungsrecht, 2003, 59 (112f.) das Transparenzdefizit dem Demokratiedefizit gegenüberstellt, werden nach hiesigem Ansatz in der Tendenz zwei Seiten einer Medaille gegeneinander ausgespielt. Vgl. insgesamt auch W. Kluth Die demokratische Legitimation der Europäischen Union, 1995; H. Bauer/P.M. Huber/K.-P. Sommermann (Hrsg.), Demokratie in Europa, 2005.

${ }^{205}$ Vgl. etwa Weber-Grellet Europäisches Steuerrecht, 2005, 24, mit dem Argument der Transparenzverbesserung der Einnahmestruktur, allerdings erst nach „Beseitigung des derzeitigen Demokratiedefizits“; vor der problematischen Prämisse einer Finalität der Union in Richtung auf einen Bundesstaat Traub Einkommensteuerhoheit (Fn. 204).

206 I.E. auch Traub Einkommensteuerhoheit (Fn. 204), 88.

207 D. Birk VVDStRL 52 (1993), 169; S. Homburg in: Oberhauser (Hrsg.), Fiskalföderalismus in Europa, 1997, 61 ff.; differenzierend K. Lammers in: Probleme des Finanzausgleichs in nationaler und internationaler Sicht, 1993, 189ff.; zum Solidaritätsprinzip im Gemeinschaftsrecht C. Tomuschat Liber Amicorum Pierre Pescatore, 1987, 729 ff.; C. Calliess Subsidiaritäts- und Solidaritätsprinzip in der Europäischen Union, 2. Aufl. 1999 , v.a. $187 \mathrm{ff}$.; C. Waldhoff ZeuS 3 (2000), $201 \mathrm{ff}$.

${ }^{208} \mathrm{Zu}$ dem Zusammenhang zwischen (Landes-)Steuerautonomie und Stabilitätspakt Henneke Finanzverfassung (Fn. 55), Rn. 1051. Zum sog. Nationalen Stabilitätspakt sei angemerkt, dass die durch die Föderalismusreform 2006 neueingefügten Art. 104a Abs. 6 und 109 Abs. 5 GG vor dem hier entfalteten Ansatz unzureichend sind: Zum einen wird das Pferd von hinten aufgezäumt, wenn in Art. 109 GG zwar ein Sanktions- 
werbsteuer durch die Föderalismusreform 2006 weist in die richtige Richtung (Art. 105 Abs. 2a Satz 2 GG) ${ }^{209}$. Heranzuziehen sind jedoch auch die Auslegungsspielräume des geltenden Rechts. Durch den Übergang von der Bedürfnis- zur Erforderlichkeitsklausel bei der Neufassung von Art. 72 Abs. 2 GG durch die Verfassungsreform 1994 und die daran anknüpfende neuere Rechtsprechung des Bundesverfassungsgerichts $^{210}$ zeitigen sich bisher wenig beleuchtete Rückwirkungen auf die Verteilung der Steuergesetzgebungskompetenzen in der geltenden Finanzverfassung. 211

verteilungssystem installiert (Zur Diskussion vor der Grundgesetzänderung M. Böhm JZ 2000, 382; W. Durner BayVB1. 2002, 745 ff.; J. Isensee in: FG 50 Jahre Bundesverfassungsgericht, Bd. 2, 2001, 719 (760ff.)), nicht hingegen die logisch, rechtlich wie politisch vordringliche Frage einer Aufteilung von Verschuldungsquoten auf die verschiedenen staatlichen Ebenen in Angriff genommen wird, der Kern des sog. nationalen Stabilitätspakts (zur bisherigen Rechtslage $U$. Häde Die innerstaatliche Verteilung gemeinschaftsrechtlicher Zahlungspflichten, 2006, $60 \mathrm{ff}$.) also weiterhin der unterverfassungsrechtlichen Ebene überantwortet bleibt; außerdem ist die konkrete Aufteilung der Zahlungsverpflichtung in beiden Bestimmungen ein Musterbeispiel für ein Verantwortungszusammenhänge vernachlässigendes Verflechtungsmodell.

209 Gesetz zur Änderung des Grundgesetzes vom 28. August 2006, BGB1. I 2034.

210 BVerfGE 106, 62 (135ff.) - Altenpflege; 110, 141 (175f.) - Kampfhunde; 111, 226 Juniorprofessur; 112, 226 - Studiengebührenverbot; 111, 10 - Ladenschluss; dazu insgesamt m.w.N. C. Waldhoff in: Henneke (Hrsg.), Föderalismusreform in Deutschland, 2005, $55 \mathrm{ff}$.

211 Nach Steuerarten differenzierend P.M. Huber DJT-Gutachten 2004, D 75f.; J. Hey FS Solms, 2005, 35 (38f.); grds. positiv für eine Veränderung angesichts der Novellierung von Art. 72 Abs. 2 GG Kommission Finanzverfassungsreform Baden-Württemberg Zwischenbericht, 1992, 30; J. Oebbecke in: Pieroth (Hrsg.), Verfassungsrecht und soziale Wirklichkeit in Wechselwirkung, 2000, 113 (134); J. Lang in: Tipke/Lang, Steuerrecht, 18. Aufl. 2005, § 3 Rn. 30; H. Siekmann in: Sachs (Hrsg.), GG, 3. Aufl. 2003, Art. 105 Rn. 21; kritisch W. Heun in: Dreier (Hrsg.), GG, Bd. 3, 2000, Art. 105 Rn. 35; M. Jachmann in: von Mangoldt/Klein/Starck, GG, Bd. 3, 5. Aufl. 2005, Art. 105 Rn. 47. Ferner könnte in der geltenden Finanzordnung erwogen werden, was aufgrund der andersgearteten demokratischen Legitimationsstruktur für die Kommunen abgelehnt wurde: Ein Landessteuererfindungsrecht. Fraglich ist jedoch, ob der zehnte Abschnitt des Grundgesetzes ein solches zulässt. Bei aller Sympathie für ein solches Anliegen bietet die Unabgestimmtheit der Steuergesetzgebungshoheit des Art. 105 und der Steuerertragshoheit des Art. 106 GG keine entsprechenden Spielräume. Angesichts des fehlenden Autonomiepotentials der Länder wird die Ertragsverteilungsnorm des Art. 106 GG zum Angelpunkt des Systems, der im Rahmen von Art. 105 Abs. 2 GG den Ländern keine Spielräume eröffnet. Hier ist strittig, ob der Katalog an Steuern in Art. 106 GG als Ansammlung von „Typenbegriffen“ abschließend ist; bejahend etwa K. Vogel HStR IV, 2. Aufl. 1999, § 87 Rn. 32, 39; D. Birk in: AK GG, Bd. 2, 2. Aufl. 1989, Art. 105 Rn. 21; Stern Staatsrecht II (Fn. 3), 1119f.; Waldhoff Verfassungsrechtliche Vorgaben (Fn. 16), 187; ders. FS Vogel, 2000, 495 (513); eine solche Begrenzung ablehnend $R$. Wendt HStR IV, 2. Aufl. 1999, § 104 Rn. 33; W. Heun in: Dreier (Hrsg.), GG, Bd. 3, 2000, Art. 105 
Zentral sind die aus dem vorgestellten Ansatz resultierenden Reformüberlegungen. Sofern es die systematische Struktur, d.h. die räumliche Radizierbarkeit dieser Steuern zulässt, sind die in Art. 106 Abs. 2 GG ausschließlich den Ländern zustehenden Steuern in deren Gesetzgebungskompetenz zu entlassen. ${ }^{212}$ Hauptansatzpunkt zur Stärkung der demokratisch begründeten Verantwortungszusammenhänge de constitutione ferenda ist jedoch die Einführung eines Hebesatz- oder $\mathrm{Zu}$ schlagsrechts der Länder auf die Einkommen- und die Körperschaftsteuer. ${ }^{213}$ Eine derartige Konstruktion würde - jenseits technischer

Rn. 33; L. Osterloh NVwZ 1991, 823 (828); R. Hendler in: Henneke (Hrsg.), Verantwortungsteilung zwischen Kommunen, Ländern, Bund und EU, 2001, 235 (241f.). Zum letztlich unabgestimmte Verhältnis von Art. 105 zu Art. 106 GG (R. Mußgnug FS Franz Klein, 1994, 651 (657) geht insoweit von einem Redaktionsversehen aus): Wenn der Bund - was in der Staatspraxis bisher nicht relevant wurde - von seinem konkurrierenden Gesetzgebungsrecht ausnahmsweise keinen Gebrauch hinsichtlich Steuern machen würde, für die ihm nach Art. 106 GG die Ertragshoheit zusteht, käme die Unabgestimmtheit zwischen Gesetzgebungs- und Ertragshoheit zum Vorschein: Einige Autoren (T. Maunz in: Maunz/Dürig, GG, Art. 105 Rn. 41; D. Birk in: AK GG, 2. Aufl. 1989, Art. 105 Rn. 14; B. Pieroth in: Jarass/Pieroth, GG, 8. Aufl. 2006, Art. 105 Rn. 25; W. Heun in: Dreier (Hrsg.), GG, Bd. 3, 2000, Art. 105 Rn. 34) nehmen dann eine Korrektur der Ertragsaufteilung des Art. 106 GG dahingehend vor, daß bei diesen dann landesgesetzlich geregelten Steuern auch eine Landesertragshoheit jenseits des Art. 106 GG eintreten soll; diese Argumentation müsste eine GG-Korrektur beim Angelpunkt der geltenden Finanzverfassung vornehmen (K. Vogel HStR IV, 2. Aufl. 1999, § 87 Rn. 39). Überzeugender erscheint daher eine einschränkende Auslegung des Art. 105 Abs. 2 GG, denn andernfalls stünde die Steuerertragsverteilung zur Disposition des einfachen (Landes-)Gesetzgebers ( $R$. Mußgnug FS Franz Klein, 1994, 651 (657f.); Waldhoff Verfassungsrechtliche Vorgaben (Fn. 16), 50). Bei den Steuern mit Ertragsanteilen des Bundes wird dann im Ergebnis durch Art. 105 Abs. 2 GG eine ausschließliche Gesetzgebungskompetenz des Bundes angeordnet, für die übrigen Steuern dieses Absatzes verbleibt es beim Wortlaut der Norm (Stern Staatsrecht II (Fn. 3), 1116; $R$. Wendt HStR IV, 2. Aufl. 1999, § 104 Rn. 31 f.). Für eine Klarstellung dieser Unabgestimmtheit mit negativen Folgen für die Autonomie überzeugend R. Hendler DÖV 1993, 292 (293f.); ders. in: Henneke (Hrsg.), Verantwortungsteilung zwischen Kommunen, Ländern, Bund und EU, 2001, 235 (240f.).

212 Vgl. auch Henke/Schuppert Finanzbeziehungen von Bund und Ländern (Fn. 147), 92f.; S. Korioth DJT-Gutachten 2004, P 89 (P 111); grds. ablehnend - allerdings auch von seinem Ausgangspunkt eines aus dem Demokratieprinzip folgenden Entflechtungsgebots inkonsequent - P.M. Huber DJT-Gutachten (Fn. 19), D 75; dagegen bereits C. Waldhoff Diskussionsbeitrag DJT 2004, P $263 \mathrm{f}$.

213 Befürwortend S.F. Franke StuW 1991, 311 (321); Wissenschaftlicher Beirat beim Bundesministerium der Finanzen, Gutachten zum Länderfinanzausgleich (Fn. 160), 92 ff.; ders. Einnahmeverteilung zwischen Bund und Ländern, 1995, 40; Henke/Schuppert Finanzbeziehungen von Bund und Ländern (Fn. 147), 93; R. Lensch Mitteilungen des Deutschen Instituts für Föderalismusforschung, September 1992, 31 (40); K.-D. Henke Staatswissenschaften und Staatspraxis 1993, 10 (14); ders. in: Die Stärkung der Finanz- 
Details der Ausgestaltung 214 - das verfassungsrechtlich stark vorgeprägte, komplexe und nicht stets transparente Element des persönlichen und sachlichen Steuertatbestands ${ }^{215}$ einschließlich der Steuerbemessungsgrundlage, einheitlich gestalten bei Differenzierungsmöglichkeiten in dem politischen Element, dem Steuertarif. ${ }^{216}$ Insofern würde die Sachlogik des Steuertatbestands hier bundesstaatlich-differenzierend aufgenommen. Die Gefahr unerträglicher Rechtszersplitterung wäre gebannt, die demokratische Transparenz erhöht. 217 Auch die EG-Kompatibilität bliebe gewahrt: ${ }^{218}$ Die OECD, ${ }^{219}$ der Europäische Gerichts-

autonomie im föderativen System der Bundesrepublik Deutschland, 2005, 36 (41 ff.); K. Rennert Der Staat 32 (1993), 269 (278); R. Hendler DÖV 1993, 298ff.; ders. in: Henneke (Hrsg.), Verantwortungsteilung zwischen Kommunen, Ländern, Bund und EU, 2001, 235 (249f.); R. Wendt HStR IV, 2. Aufl. 1999, § 104 Rn. 42 f.; ders. Staatswissenschaften und Staatspraxis 1993, 56 (72f.); C. Waldhoff Verfassungsrechtliche Vorgaben (Fn. 16), 105; ders. Die Verwaltung 39 (2006), 155 (170f.); ders. HStR V, 3. Aufl. 2007, Rn. 68; H.-G. Henneke Finanzverfassung (Fn. 55), Rn. 1049 ff.; Kesper Finanzordnung (Fn. 32), $338 \mathrm{ff}$; $A$. Boss in: Probleme des Finanzausgleichs in nationaler und internationaler Sicht, 1993, 79 (94); Bertelsmann Kommission Verfassungspolitik \& Regierungsfähigkeit Entflechtung 2005, 2000, 33f.; T. Lenk/F. Schneider in: Schmidt-Trenz/Fonger (Hrsg.), Bürgerföderalismus, 2000, 63 (75ff.); A. Janssen in: Henneke (Hrsg.), Verantwortungsteilung zwischen Kommunen, Ländern, Bund und EU, 2001, 59 (71); Blanke in: ders./Schwanengel (Hrsg.), Zustand und Perspektiven des deutschen Bundesstaates, 2005, 127 (160); T. Puhl HStR III, 3. Aufl. 2005, § 48 Rn. 28; mit gewisser Zurückhaltung wohl auch S. Korioth DJT-Gutachten 2004, P 89 (P 110 f.); ablehnend: W. Heun Der Staat 31 (1992), 205 (212 ff.); D. Birk VVDStRL 52 (1993), 169; ders. Staatswissenschaften und Staatspraxis 1993, 85 (87f.); ders. VVDStRL 52 (1993), 169; R. Sannwald ZRP 1993, 103 (107); F. Kirchhof ZG 2006, 288 (294f.); differenzierend P. Selmer VVDStRL 52 (1993), 10 (39).

${ }^{214}$ Vgl. etwa C. Baretti/R. Fenge/B. Huber/W. Leibfritz/M. Steinherr Chancen und Grenzen föderalen Wettbewerbs, 2000, 132ff.; Döhler Autonome Besteuerungsrechte (Fn. 16).

${ }^{215}$ Zur Struktur des Steuertatbestands und der je unterschiedlichen verfassungsrechtlichen Determination vgl. M. Lehner/C. Waldhoff in: Kirchhof/Söhn/Mellinghoff (Hrsg.), EStG, $\S 1$ Rn. A 40 ff., A 141 ff., insbes. A 145; C. Waldhoff HStR V, 3. Aufl. 2007 Rn. 85.

${ }^{216} \mathrm{Zu}$ dieser Unterscheidung in anderem Kontext J. Hey StuW 2004, 193; ferner C. Baretti/R. Fenge/B. Huber/W. Leibfritz/M. Steinherr Chancen und Grenzen (Fn. 214), $40,131 \mathrm{ff}$.

${ }^{217}$ A.A. P.M. Huber DJT-Gutachten (Fn. 19), D 75; unter Autonomiegesichtspunkte hält $R$. Hendler in: Henneke (Hrsg.), Verantwortungsteilung zwischen Kommunen, Ländern, Bund und EU, 2001, 235 (249), dies nur für die „zweitbeste Lösung“; die Kompatibilität mit anderen, teilweise gegenläufigen Anforderungen macht sie gleichwohl z.Z. zum Mittel der Wahl.

218 A.A. D. Birk VVDStRL 52 (1993), 169; F. Schoch in: Henneke (Hrsg.), Verantwortungsteilung zwischen Kommunen, Ländern, Bund und EU, 2001, 21 (38).

${ }_{219}$ Harmful Tax Competition, 1998, 16 Rz. 29. 
hof ${ }^{220}$ wie auch der Code of Conduct gegen schädlichen Steuerwettbewerb innerhalb der $\mathrm{EG}^{221}$ stellen regelmäßig gerade nicht die unterschiedliche Höhe von Steuersätzen oder -belastungen als „unfair“ heraus, sondern mehr oder weniger versteckte Ungleichbehandlungen im Rahmen der Steuerbemessungsgrundlage mit dem Zweck, „Steuersubstrat“ ohne adäquate Gegenleistungen anzuziehen. ${ }^{222}$ Solches "Steuerdumping“ ist die Aufhebung der fiskalischen Äquivalenz der Finanzwissenschaften, der demokratischen Steuerrechtfertigung nach dem Prinzip genereller Äquivalenz:223 In finanzwissenschaftlicher Terminologie: Erwünschter Fiskalwettbewerb wird durch problematischen Steuerwettbewerb ersetzt. ${ }^{224}$

Die Blaupause für ein föderal differenziertes Steuersystem mit einheitlicher Bemessungsgrundlage bei gliedstaatlich gestaltbaren Steuersätzen stellt die Situation der Schweiz nach Durchführung des sog. Steuerharmonisierungsprojekts der 90er Jahre dar (Art. 129 BV). ${ }^{225}$ Hatten dort - wie in praktisch allen Bundesstaaten 226 - ursprünglich die Gliedstaaten das Recht auf Regelung und Vereinnahmung der direkten, der Bund der indirekten Steuern, hatte sich die zentrale Ebene im Gefolge der beiden Weltkriege des 20. Jh. ebenfalls der Einkommensteuerautonomie bemächtigt:227 27 Einkommensteuergesetze mit beträchtlichen

220 In je unterschiedlichem Zusammenhang EuGH Rs. C-379/92, Urt. v. 14. Juli 1994, Slg. 1994, I-3453 Rn. 34 - Peralta; Rs. C-336/96, Urt. v. 12. Mai 1998, Slg. 1998, I-2793 - Gilly; dazu ausführliche Analyse bei A. Cordewener Europäische Grundfreiheiten und nationales Steuerrecht, 2002, 590 ff.; Rs. C-294/97, Urt. v. 26. Oktober 1999, Slg. 1999, I-7447 Rn. 59 - Eurowings; dazu ausführlich Cordewener a.a.O., 692ff.; K. Vogel StuW 1993, 380 (384f.); J. Wieland EuR 2001, 119 (125).

${ }^{221}$ Kommission der EG, KOM (1997), 495 endg.; BR-DrS 814/97; dazu etwa W. Schön EuZW 1998, 129.

222 Esser Steuerwettbewerb (Fn. 8), 79 ff., 85 ff.; J. Hey JZ 2006, 851 (853); Vergleich des EU-Verhaltenskodex und des entsprechenden OECD-Reports bei G. Larbig in: Müller u.a. (Hrsg.), Regeln für den europäischen Systemwettbewerb, 2001, $217 \mathrm{ff}$.

$223 \mathrm{Vgl}$. auch Esser Steuerwettbewerb (Fn. 8), 86.

${ }^{224} \mathrm{Zu}$ dieser terminologischen Unterscheidung etwa $M$. Spoerer Jahrbuch für Wirtschaftsgeschichte 2002/2, 35 (37f.); R.-D. Postlep in: Müller u.a. (Hrsg.), Regeln für den europäischen Systemwettbewerb, 2001, 409.

225 Waldhoff Verfassungsrechtliche Vorgaben (Fn. 16), $74 \mathrm{ff}$; P. Locher in: Thürer u.a. (Hrsg.), Verfassungsrecht der Schweiz, 2001, § 77 Rn. 4f.; Feld Steuerwettbewerb (Fn. 9), $193 \mathrm{ff}$; aus politikwissenschaftlicher Sicht T. Fischer/M.G. Hüttmann in: Jahrbuch des Föderalismus 2001, 128 (140f.). Kommentierung durch M. Zweifel/P. Athanas Kommentar zum Schweizerischen Steuerrecht I/1: Bundesgesetz über die Harmonisierung der direkten Steuern der Kantone und Gemeinden (StHG), 1997.

${ }^{226} \mathrm{Zu}$ dieser Regel E. Grossmann in: Jahresbericht der Universität Zürich 1944/45, 3 (10).

227 Einzelheiten zur Entwicklung der Steuergesetzgebungskompetenzen bei Waldhoff Verfassungsrechtliche Vorgaben (Fn. 16), 56ff.; allgemein zu kriegerischen Ereignissen 
Belastungsunterschieden von Kanton zu Kanton brachten im kleinräumigen Bundesstaat neben den Vorteilen fiskalischen Wettbewerbs auch beträchtliche Nachteile mit sich. In Erfüllung eines Verfassungsauftrags üben die Kantone inzwischen die Steuersatzautonomie bei - auch im Verhältnis zur Bundessteuer - einheitlicher Bemessungsgrundlage aus. Zugleich ist - schon vor diesem Projekt - die Höhe der Bundeseinkommensteuer auf Verfassungsebene quantitativ begrenzt. Diese Begrenzung dient unmittelbar nicht dem Schutz des Steuerbürgers vor übermäßiger Belastung, sondern dem Schutz des Steuersubstrats der Kantone. 228 Durch diesen Gesamtmechanismus kann über die autonome Bestimmung des Steuersatzes bei weitgehender Vermeidung von Rechtszersplitterung Finanzautonomie verwirklicht werden. Angesichts derartiger Einhegungen erscheint - übertragen auf Deutschland - das Gerede vom drohenden „föderalen Darwinismus“ überzogen.229

\section{Das Postulat fairen Steuerwettbewerbs}

Die Steuerharmonisierung auf europäischer Ebene ist im Bereich der indirekten Steuern, allen voran bei der Umsatzsteuer zumindest im Bereich einer einheitlichen Bemessungsgrundlage weit vorangeschritten. ${ }^{230}$ Nachdem die Bemühungen zur Harmonisierung der direkten Steuern an den Souveränitätsvorbehalten der Mitgliedstaaten, konkretisiert im insoweit konsequenten Einstimmigkeitserfordernis des Art. 94 EGV, weitgehend ${ }^{231}$

u.ä. als Auslöser für Steuerreformen H.W. Kruse StuW 1998, 3 ff.; zu dem grundlegenden Zusammenhang zwischen Aufstellung eines stehenden Heeres und dadurch bedingtem Aufbau eines bürokratischen Steuerapparates für die Entstehung des modernen Staates W. Reinhard Geschichte der Staatsgewalt, 1999, 24 und durchgehend.

228 U. Häfelin ZSR 93 II (1974), 75 (110); H. Letsch FS Theo Keller, 1971, 245 (248); ders. WuR 1973, 32 (35); E. Buschor Die öffentliche Finanzwirtschaft zwischen Automatismen und Mittelverknappung, 1983, 70; Waldhoff Verfassungsrechtliche Vorgaben (Fn. 16), 196ff., $202 \mathrm{ff}$.

229 Begriff etwa bei Schuppert Verwaltungswissenschaft (Fn. 145), 946f., freilich mit dem zutreffenden Hinweis, es handele sich bei der „Entthronung des Verbundföderalismus“ und der „Inthronisation des Wettbewerbsföderalismus“ um ein „rechtlich voraussetzungsvolles Vorhaben“; im Ansatz insofern durchaus richtig auch H.-P. Bull DÖV 1999, 269 (271).

230 Während die Binnenmarktneutralität angesichts einer nicht konsequenten Durchsetzung des Ursprungslandprinzips technisch defizitär bleibt; vgl. für Überblicke nur Weber-Grellet Europäisches Steuerrecht (Fn. 205), 109 ff.; C. Waldhoff in: Calliess/Ruffert (Hrsg.), EUV/EGV, 3. Aufl. 2006, Art. 93 EGV Rn. 1 ff.

${ }^{231} \mathrm{Zu}$ den wenigen verabschiedeten Richtlinien vgl. den Überblick bei $H$. WeberGrellet Europäisches Steuerrecht, 2005, 139 ff; politikwissenschaftliche Analyse dieser 
gescheitert sind, ${ }^{232}$ herrscht hier ein - durch Grundfreiheiten ${ }^{233}$ und Beihilfenrecht ${ }^{234}$ - mehr oder weniger eingebundener Systemwettbewerb. ${ }^{235}$

Treten wir abschließend gedanklich einen Schritt zurück, um uns der Mechanismen zu vergegenwärtigen, welche die eröffneten wettbewerbsähnlichen Situationen hegen und steuern: Horizontal - zwischen Gemeinden, Ländern oder Staaten - gebietet das verfassungskräftige Prinzip der Besteuerung nach der individuellen Leistungsfähigkeit ${ }^{236}$ die Vermeidung oder Beseitigung von Doppelbesteuerung. ${ }^{237} \mathrm{Im}$ Bereich der Gewerbesteuer ist damit die Zerlegungsproblematik angesprochen, auf internationaler Ebene existiert ein traditionsreiches und erprobtes Netz uni- oder bilateraler Maßnahmen zur Bewältigung des Problems. ${ }^{238}$ Derartige Lösungen wären - wie etwa das interkantonale Steuerrecht der Schweiz ${ }^{239}$ oder Gesetze des Bismarckreichs ${ }^{240}$ zeigen auch auf entsprechende innerbundesstaatliche Probleme übertragbar.

Entwicklung durch $P$. Genschel Steuerharmonisierung und Steuerwettbewerb in der Europäischen Union, 2002.

${ }^{232}$ Mehde Wettbewerb (Fn. 5), 276; Überblick über vollzogene Harmonisierungsschritte bei $H$. Weber-Grellet Europäisches Steuerrecht, 2005, $139 \mathrm{ff}$.

${ }_{233}$ M. Lehner (Hrsg.), Grundfreiheiten im Steuerrecht der EU-Staaten, 2000; A. Cordewener Europäische Grundfreiheiten und nationales Steuerrecht, 2002.

$234 \mathrm{Vgl}$. die Nachweise oben in Fn. 43.

235 Politikwissenschaftliche Analyse bei Genschel Steuerharmonisierung (Fn. 231).

236 Grundlegend Birk Leistungsfähigkeitsprinzip (Fn. 171); ferner J. Lang Die Bemessungsgrundlage der Einkommensteuer, 1988, 97 ff.; K. Vogel HStR IV, 2. Aufl. 1999, § 87 Rn. $90 \mathrm{ff}$; M. Lehner Einkommensteuerrecht und Sozialhilferecht, 1993, $302 \mathrm{ff}$; K. Tipke Die Steuerrechtsordnung, Bd. 1, 2. Aufl. 2000, $282 \mathrm{ff} . ;$ K. Vogel/C. Waldhoff in: Dolzer/Vogel/Graßhof (Hrsg.), BK GG, Vorb. z. Art. 104a-115 Rn. $500 \mathrm{ff}$; M. Lehner/C. Waldhoff in: Kirchhof/Söhn/Mellinghoff (Hrsg.), EStG, § 1 Rn. A $141 \mathrm{ff}$.

${ }^{237}$ M. Lehner/C. Waldhoff in: Kirchhof/Söhn/Mellinghoff (Hrsg.), EStG, § 1 Rn. A 496ff.; C. Waldhoff HStR V, 3. Aufl. 2007, § 116 Rn. 134; zu den volkswirtschaftlichen Nachteilen der Doppelbesteuerung statt anderer nur O.H. Jacobs Internationale Unternehmensbesteuerung, 5. Aufl. 2002, $3 \mathrm{ff}$.

238 Vgl. nur H. Schaumburg Internationales Steuerrecht, 2. Aufl. 1998; V. Kluge Das Internationale Steuerrecht, 4. Aufl. 2000; K. Vogel/M. Lehner (Hrsg.), DBA, 4. Aufl. 2003.

239 Art. 127 Abs. 3 BV (früher: Art. 46 Abs. 2 BV 1874); H. Huber in: ders., Rechtstheorie, Verfassungsrecht, Völkerrecht, 1971, 519ff.; E. Höhn in: Aubert u.a. (Hrsg.), Kommentar zur Bundesverfassung der Schweizerischen Eidgenossenschaft vom 29. Mai 1874, Art. 46; ders. Interkantonales Steuerrecht, 2. Aufl. 1989; Waldhoff Verfassungsrechtliche Vorgaben (Fn. 16), $201 \mathrm{f}$.

240 Gesetz wegen Beseitigung der Doppelbesteuerung vom 13. Mai 1870, BGB1. 119; ersetzt durch Doppelsteuergesetz vom 22. März 1909, RGB1. 332; dazu P. Laband Deutsches Reichsstaatsrecht, 6. Aufl. 1912, 48f.; C. Schönberger Unionsbürger, 2005, $234 \mathrm{f}$. mit Fn. 384. 
Im europäischen wie im internationalen Kontext treten ergänzend $\mathrm{Me}-$ chanismen zur Abstellung unfairer Steuerpraktiken hinzu. 241

Vertikal - d.h. zwischen den Ebenen - ergibt sich folgendes Tableau: Zwischen zentraler Ebene und Gliedstaaten im Bundesstaat handelt es sich um ein Problem der Kompetenzaufteilung. Die demokratische Legitimation ist hier gleichwertig und austauschbar. ${ }^{242}$ Die technische Ausgestaltung des hier propagierten, den Nachteil von Rechtszersplitterung in Grenzen haltenden Hebesatz- oder Zuschlagsmodells zugunsten der Länder könnte durch die Einräumung eines Korridors für die Landesanteile bei koordinierter Absenkung der Belastung durch die korrespondierende Bundessteuer die Gesamtbelastung der Bürger im Rahmen halten. ${ }^{243}$ Die kommunale wie die europäische Ebene haben sich hinsichtlich ihrer Finanzautonomie ohnehin abhängig von der staatlichen Ebene gezeigt. Mit diesem Tableau sind lediglich die Mechanismen der Steuerung und Hegung von Finanzautonomie angerissen, keinesfalls die Probleme gelöst. Hier wäre insbesondere die Problematik der unterschiedlich ausgeprägten Mobilität unterschiedlicher Einkunftsquellen etwa von Kapital und Arbeit - zu nennen. ${ }^{244}$ Dazu wird der Zweitbericht nähere Ausführungen bringen.

\footnotetext{
241 Zur Anwendung von Art. 87 EGV auf Steuersubventionen vgl. die Nachweise oben in Fn. 43; zur Problematik im Rahmen des Welthandelsrechts J. Wagner Direkte Steuern und Welthandelsrecht, 2006; vgl. insgesamt Mehde Wettbewerb (Fn. 5), 225 ff., $273 \mathrm{ff}$.

242 Dies wird durch Art. 28 Abs. 1 GG gewährleistet, vgl. nur U. Di Fabio FS Badura, 2004, 77 (93).

${ }^{243}$ Vgl. dazu etwa Wissenschaftlicher Beirat beim Bundesministerium der Finanzen Gutachten zum Länderfinanzausgleich (Fn. 160), $95 \mathrm{ff}$.; C. Baretti/R. Fenge/B. Huber/ W. Leibfritz/M. Steinherr Chancen und Grenzen (Fn. 214), $131 \mathrm{ff}$.; T. Büttner/R. Schwager Jahrbücher für Nationalökonomie und Statistik 223 (2003), 532ff.; dort auch differenziert-kritische Modelle zu möglichen tatsächlichen Auswirkungen.

244 Vgl. nur Wissenschaftlicher Beirat beim Bundesministerium der Finanzen Gutachten zum Länderfinanzausgleich (Fn. 160), 98f.; K.-D. Henke in: Der Präsident des Niedersächsischen Landtages (Hrsg.), Die Stärkung der Finanzautonomie im föderativen System der Bundesrepublik Deutschland, 1995, 36 (41); U. Schreiber in: Krause-Junk (Hrsg.), Steuersysteme der Zukunft, 1998, 29 (53ff.); J. Wieland EuR 2001, $119 \mathrm{ff}$.; C. Spengel Gutachten G zum 66. DJT, 2006.
} 


\section{Schluss}

Am Ende scheint mir evident zu sein, dass die Probleme weniger in der Konsistenz des entfalteten Ansatzes als in dem oft fehlenden „Willen zur Autonomie" in der politischen Praxis liegen. ${ }^{245}$ Für viele Akteure ist die begrenzt eingeräumte Autonomie eher Chance zur Kartellierung, statt zu Anstrengung und Risiko der Konkurrenz. ${ }^{246}$ Ein Ausweg war und ist stets die Flucht in die Staatsverschuldung - auch hier wird Verantwortung vermieden und auf künftige Generationen abgeladen. Dass finanzwirtschaftlicher Wettbewerb und politischer Wettbewerb letztlich zwei Seiten einer Medaille sind, wird bei alldem grundlegend verkannt. Der Versuch einer konsequenten Rückführung der Architektur föderaler Finanzbeziehungen auf das steuerzahlende Individuum entspricht institutionenökonomisch gedacht - nicht zwingend den Interessen dieser politischen Akteure. ${ }^{247}$ Gleichwohl sehe ich Chancen. Die Sackgasse, in welche die Staatsfinanzen angesichts einer unzureichenden institutionellen Rahmenordnung geraten sind, wird einen steigenden Reformdruck erzeugen. Die Zeit arbeitet für Alternativen, die internationale Verflechtung bewirkt ein Übriges. Im Rahmen einer parlamentarischen Demokratie ist außerhalb von Ausnahmesituationen der adäquate Reformtyp weniger der Systemwechsel, sondern sind dies die kleinen Schritte 248 in

${ }^{245}$ A. Janssen in: Henneke (Hrsg.), Verantwortungsteilung zwischen Kommunen, Ländern, Bund und EU, 2001, 59 (87f.); H. Bauer DÖV 2002, 837 (845); Blanke in: ders./Schwanengel (Hrsg.), Zustand und Perspektiven des deutschen Bundesstaates, 2005, 127 (161); Plädoyer für eine selbstbewusste Wahrnehmung bestehender Kompetenzen anstelle grundlegender Reformen C. Hillgruber JZ 2004, 837 (845f.); vgl. auch L. Osterloh GS Trzaskalik, 2005, 181 (189); grundsätzlich zu Akzeptanz und Legitimität als faktischer Voraussetzunge gelingender Bundesstaatlichkeit U. Volkmann DÖV 1998, 613 (615f.). Bezeichnend der Berliner Finanzsenator Thilo Sarrazin, Frankfurter Allgemeine Zeitung Nr. 87 vom 12. April 2006, 15: Vollständige Zentralisierung der Steuergesetzgebung beim Bund, die Länder als Empfänger von Zuweisungen: „Dann hätten die Länder und Gemeinden stets eine sichere und planbare Finanzausstattung. Der Bund hätte die vollständige Autonomie über das Steuerrecht.“

246 Allgemein Schuppert Verwaltungswissenschaft (Fn. 145), 948; Mehde Wettbewerb (Fn. 5), 103, 128; zu dem Beispiel des Fehlschlags des Maßstäbegesetzes S. Korioth ZG 2002, $335 \mathrm{ff}$.

${ }^{247}$ Instruktive Analyse bei G. Färber in: von Arnim u.a. (Hrsg.), Föderalismus - Hält er noch, was er verspricht? 2000, 125 (164f.).

248 W. Renzsch ZParl. 1994, 116 (133ff.); H.-P. Schneider NJW 1998, 3757 (3759); C. Waldhoff Die Verwaltung 39 (2006), 155 (185f.); für Steuerreformen vgl. die umfassende politikwissenschaftliche Studie von U. Wagschal Steuerpolitik und Steuerreformen im internationalen Vergleich, 2005. 
kontrollierter „Pfadabhängigkeit“ 249 - sowohl innerhalb der Interpretationsspielräume geltenden Rechts ${ }^{250}$ wie im Rahmen von Verfassungsreformprojekten zur Korrektur des institutionellen Rahmens. ${ }^{251}$ Diese Chancen sollten ergriffen werden. ${ }^{252}$

249 Vgl. nur G. Lehmbruch in: Jahrbuch des Föderalismus 2000, $71 \mathrm{ff}$.; W. Renzsch in: Büttner (Hrsg.), Finanzverfassung und Föderalismus in Deutschland und Europa, 2000, 39 (55f.); F. Schoch in: Henneke (Hrsg.), Verantwortungsteilung zwischen Kommunen, Ländern, Bund und EU, 2001, 21 ff.; G. Lehmbruch in: Wehling (Hrsg.), Die deutschen Länder, 2. Aufl. 2002, 313 (316ff.); M.G. Schmidt PVS 42 (2001), 474 (486ff.); U. Münch in: Jahrbuch des Föderalismus 2001, $115 \mathrm{ff}$.; T. Fischer/M.G. Hüttmann ebd., $128 \mathrm{ff}$;; für bundesstaatliche Reformen allgemein T. Puhl HStR III, 3. Aufl. 2005, § 48 Rn. 26: „Erfordernis punktueller Föderalismusreform“.

${ }^{250}$ H. Bauer DÖV 2002, 837 (844): „Unterverfassungsrechtliche Optionen für Wettbewerbsföderalismus“.

251 Vgl. auch F. Kirchhof VVDStRL 52 (1993), 71 (88f.).

${ }^{252}$ Im Sinne eines zweiten Schritts der Föderalismusreform F. Kirchhof ZG 2006, $288 \mathrm{ff}$. 
Leitsätze des 1. Berichterstatters über:

\section{Finanzautonomie und Finanzverflechtung in gestuften Rechtsordnungen}

\section{Die Rückkehr zu den Grundlagen der Finanzverfassung}

(1) Seit den Tagungen 1955 („Finanzverfassung im Rahmen der Staatsverfassung“) und 1992 („Grundsätze der Finanzverfassung des vereinten Deutschlands") haben sich Rahmenbedingungen und Perspektiven der Finanzverfassung grundlegend geändert. Die Finanzverfassung ist inzwischen in die Staatsverfassung integriert, die Staatsrechtslehre ist nicht mehr "finanzblind“. Die Finanzordnung ist in besonderer Weise der inter- und supranationalen Verflechtung des Verfassungsstaats ausgesetzt.

(2) Die einschlägige Diskussion verkennt die Grundlagen der Finanzordnung. Dies ist Folge der nach wie vor defizitären Bundesstaatstheorie wie auch der Dominanz der einschlägigen Verfahren vor dem Bundesverfassungsgericht, die eher technische Fragen betreffen.

(3) Die inter- und supranationale Verflechtung sowie die säkulare Krise staatlicher Finanzwirtschaft erfordern heute eine Perspektivenerweiterung durch diachrone und synchrone Vergleiche, kontrollierte Berücksichtigung ökonomischer Erkenntnisse und vor allem verfassungstheoretische Erwägungen. Die Diskussion muss von vornherein zweispurig erfolgen: Die Auslegungsspielräume des geltenden Verfassungsrechts und Erwägungen de constitutione ferenda ergänzen und befruchten sich gegenseitig.

II. Der doppelgliedrige Begriff der Finanzautonomie in der Mehrebenenstruktur: Der Verantwortungszusammenhang zwischen Einnahmen und Ausgaben

1. Das Denken von der Ausgabenseite her

(4) Üblicherweise werden in der deutschen Diskussion die Begriffe „Autonomie“ und „Finanzautonomie“ jenseits der kommunalen Ebene mit einer hinreichenden finanziellen Ausstattung gleichgesetzt: Finanzautonomie als aufgabenadäquate, verfassungsrechtlich abgesicherte Finanzausstattung, Finanzen als Voraussetzung von Sachautonomie. 


\section{Die Notwendigkeit des Einbezugs der Einnahmenseite}

(5) Das politisch-gestaltende Element auch der Einnahmenseite staatlicher Finanzwirtschaft kann aus der Finanzautonomie nicht ausgeblendet werden. Der verfassungsrechtliche und politische Zusammenhang zwischen Einnahmen und Ausgaben, zwischen Geben und Nehmen ginge sonst verloren.

\section{Finanzautonomie im Fokus des europäischen Beihilfenregimes}

(6) Das europäische Beihilfenrecht hat eine hilfreiche Präzisierung eines selbsttragenden und funktionstüchtigen Begriffs der Finanzautonomie hervorgebracht: „Wirkliche Autonomie“ bedeutet beihilfenrechtlich, dass keine (übermäßige) Quersubventionierung der zentralen Ebene niedrige Einnahmen als Folge autonomer Entscheidung der unteren Ebene ausgleicht, also dass die Folgen einer solchen Finanzpolitik von der autonomen Ebene grundsätzlich selbst zu tragen sind. Dadurch wird - beihilferechtlich - der Verantwortungszusammenhang für Entscheidungen auf der Einnahmenseite gestärkt.

\section{Finanzautonomie als Verfassungsprinzip}

(7) Auch wenn in der extremen Verflechtungsstruktur des deutschen Finanzverfassungsrechts das Ziel der Finanzautonomie keine Priorität beanspruchen kann, ist im Rahmen der Herstellung praktischer Konkordanz bei der Auslegung unbestimmter Rechtsbegriffe des zehnten Abschnitts des Grundgesetzes wie auch bei richterrechtlichen Begriffsschöpfungen ein Ausgleich zwischen widerstreitenden Gesichtspunkten herzustellen. Dabei kommt es entscheidend auf die Kompatibilität der Finanzautonomie mit den Staatsstrukturentscheidungen des Grundgesetzes an.

\section{Finanzverflechtung als empirische Bestandsaufnahme}

(8) Die extreme Finanzverflechtung in der geltenden Ordnung ist Folge der Aufteilung von (Finanz)Kompetenzen nach Staatsfunktionen, statt nach Politikbereichen. Sie zeigt sich seit der sog. großen Finanzreform 1967/69 u.a. in den Kompensationsversuchen fehlender Landessteuerautonomie durch die Mitwirkung der Länder bei der Bundessteuergesetzgebung (Art. 105 Abs. 3 GG), bei der systemwidrigen Berücksichtigung von Umverteilungszielen im Rahmen der primären Finanzausstattung (Art. 107 Abs. 1 $G G$ ), in dem historisch wie vergleichend einmaligen, übernivellierenden horizontalen Länderfinanzausgleich (Art. 107 Abs. 2 Satz 1 GG), in deninzwischen allerdings reformierten - Gemeinschaftsaufgaben, in den Inkonsistenzen der Regelungen zur Finanzierungslast sowie - jüngst - in der in- 
nerbundesstaatlichen Aufteilung der Sanktionentragungspflicht der EU gegenüber. Die überverflochtene Finanzverfassung hat durch ihre Auflösung von Verantwortlichkeiten und durch ihre Intransparenz die Flucht in die Staatsverschuldung auf sämtlichen Ebenen begünstigt.

III. Die Rekonstruktion der Finanzordnung der Mehrebenenstruktur aus ihrem Individualbezug

\section{Fundierung der Finanzordnung durch das Demokratieprinzip}

(9) Die Rückführung der Legitimation staatsorganisationsrechtlicher, insbesondere bundesstaatlicher Strukturen auf das Individuum als letzter Bezugsgröße jeder Rechtsordnung geschieht für die staatliche Finanzordnung traditionell durch den Steuergesetzesvorbehalt auf der Einnahmenseite und durch das Budgetrecht des Parlaments auf der Ausgabenseite. Beide Legitimationsmechanismen sind der bundesstaatlichen Gliederung und der Mehrebenenstruktur nicht angepasst.

(10) Entstehungsgeschichtlich verstärken sich in der Finanzverfassung verschiedene Faktoren gegenseitig: historische Hypotheken aus dem Bismarckreich; die das föderative Staatsprinzip vernachlässigende Umstellung der Legitimationsgrundlage durch die Reichsverfassung von Weimar; zentralistisch-technokratische Grundprägungen der maßgebenden Kräfte des Parlamentarischen Rates; ein sozial- und interventionsstaatlicher Gestaltungsanspruch aus der Zeit der sog. großen Finanzreform.

2. Individualschützende Funktionen der finanzverfassungsrechtlichen Kompetenzordnung

(11) Wie die gesamte Kompetenzordnung erfüllt auch die Finanzverfassung als Element „vertikaler Gewaltenteilung“ eine „Begrenzungs- und Schutzfunktion “: Der Bürger soll nur durch kompetenzgemäße Abgaben belastet werden.

3. Kongruenz zwischen demokratischer Legitimation und finanzwirtschaftlicher Verantwortung als Postulat der Steuerrechtfertigung

a) Demokratische Rückkoppelung der Finanzierung öffentlicher Gemeinwesen

(12) Demokratische Verantwortlichkeit endet im Finanzrecht nicht bei steuerlichem Gesetzesvorbehalt und parlamentarischem Budgetrecht. 
b) Verantwortungszusammenhänge und Verantwortungsklarheit

(13) Verantwortungszusammenhänge bauen auf Zurechenbarkeit auf. Demokratische Rückkoppelung setzt Verantwortungsklarheit voraus. Das Demokratieprinzip reformuliert im verfassungsrechtlichen Zusammenhang die zentrale finanzwissenschaftliche Erkenntnis institutioneller oder fiskalischer Äquivalenz als Einheit von Kostenträgern und Nutznießern (sog. Steuer-Ausgabe-Mechanismus). Der Übergang zu einer Staatsfinanzierung in Anlehnung an konkrete Äquivalenz als denkbarer Ausweg stellt aus grundrechtlichen, sozialstaatlichen und staatstheoretischen Erwägungen keine Alternative zur grundsätzlichen Steuerfinanzierung dar.

c) Steuerrechtfertigung als Verbindung von persönlicher Anknüpfung und territorialer Radizierung

(14) Die staatstheoretische Rechtfertigung von Personalsteuern als Gegenleistung für die Gesamtheit von Staatsleistungen (sog. generelle oder globale Äquivalenz) verbindet die persönliche Anknüpfung der Lastentragung mit dem territorialen Bezug über die Ansässigkeit und bildet damit einen finanzwirtschaftlich-demokratischen Legitimationszusammenhang ab. In einer gestuften Rechtsordnung folgt daraus eine Mindesteinnahmenautonomie der einzelnen Ebenen.

d) Ansätze finanzwirtschaftlicher Verantwortungszusammenhänge in der Judikatur des Bundesverfassungsgerichts - insbesondere die Rechtsprechung zu den Sonderabgaben

(15) Die Unterscheidung des ertragszuweisenden, primären, von dem umverteilenden, sekundären, Finanzausgleich als Stufenmodell mit der Prämisse der Erwirtschaftung von „Eigenem“ bei der primären Finanzausstattung stellt - unabhängig von allen Detailproblemen - den richtigen Ansatz dar. Die Feststellung, die „notwendigen Ausgaben “ seien nicht die tatsächlichen Ausgaben, sondern zu rechtfertigende Ausgaben im Deckungsquotenverfahren bei der variablen Umsatzsteuerverteilung zwischen Bund und Ländergesamtheit koppelt die Ausgabenverantwortung an die Finanzausstattung zurück. In der Sonderabgabenjudikatur verbindet sich von vornherein die Frage der Rechtfertigung einer (nichtsteuerlichen) Abgabe mit organisationsrechtlichen Fragen der Kompetenzstruktur.

4. Keine Inkompatibilität zur geltenden Finanzverfassung:

Die Grenzen des Konzepts der Finanzverfassung als „Folgeverfassung“

(16) Die Interpretation der Finanzverfassung als akzessorische Folgeverfassung, als Einbahnstraße von den Aufgaben hin zur Finanzierung verfehlt 
demokratische Verantwortungszusammenhänge zwischen Einnahmen und Ausgaben. Das dynamisch-prozesshafte föderaler Ordnungen, das bewegliche System Bundesstaat besitzt - jenseits staatlicher Kernaufgaben - als integralen Bestandteil ein bewegliches System der Finanzverfassung.

5. Die begrenzte Direktionskraft des Postulats „einheitlicher“ oder „gleichwertiger Lebensverhältnisse im Bundesgebiet “

(17) Eine übergreifende Staatszielbestimmung „einheitlicher“ oder „gleichwertiger Lebensverhältnisse im Bundesgebiet “ist aus den verstreuten Einzelnormierungen im GG nicht herleitbar. Der richtige normative Kern dieses Topos liegt in der Gewährleistung einer Mindesteinheitlichkeit in tatsächlicher Hinsicht. Damit ist eine Reservefunktion für außergewöhnliche Lagen, wie etwa im Zusammenhang mit der Wiedervereinigung angesprochen. Mit zunehmender inter- und supranationaler Verflechtung werden einheitliche oder gleichwertige Lebensverhältnisse weiter an Bedeutung verlieren.

\section{Keine Wettbewerbsfeindlichkeit der hoheitlichen Finanzwirtschaft}

(18) Wettbewerbsähnliche Situationen sind zwangsläufige Folgen der Einräumung von Autonomie. Sie dürfen nicht mit dem Wettbewerb zwischen Individuen oder Unternehmen der gesellschaftlichen Sphäre „am Markt“ verwechselt werden. Solche wettbewerbsähnlichen Situationen bedürfen stets der rechtlichen Hegung und Regelung.

(19) Die Rekonstruktion der Finanzordnung der Mehrebenenstruktur aus dem Individualbezug der Staatsfinanzierung nimmt die Stufen nicht - wie die ökonomische Theorie des Föderalismus - als austauschbare „Aufgabenerfüllungsebenen“ wahr. An die Stelle der Effizienz als entscheidendem Zuteilungskriterium tritt der Grad demokratischer Legitimation.

IV. Konsequenzen der Interdependenz zwischen demokratischer Legitimation und Finanzordnung

1. Die legitimatorisch abgeleiteten Ebenen: Gesetzesgebundene Finanzautonomie der Gemeinden, die Mitgliedstaaten als „Herren“ über die Einnahmen der Europäischen Union

(20) Die kommunale Finanzautonomie als Einnahmenautonomie ist verfassungsrechtlich (Art. 105 Abs. 2a; Art. 28 Abs. 2 Satz 3 GG) und gesetzlich ermächtigt und begrenzt. Ein gemeindliches Steuererfindungsrecht kann 
es außerhalb dieses Rahmens aufgrund der spezifischen demokratischen Legitimation auf kommunaler Ebene nicht geben.

(21) Angesichts des gegenwärtigen Integrationsstands der EU erweist sich der demokratische Rückbezug des Finanzrechts als begrenzender Faktor für die autonome Gestaltung der Einnahmen der Gemeinschaften. Die Asymmetrie hinsichtlich der Entscheidung über Einnahmen und Ausgaben ist hinzunehmen, einer EU-Steuer gegenwärtig eine Absage zu erteilen.

\section{Die Notwendigkeit eigengestaltbarer Einnahmen der Länder}

(22) Die defizitäre Situation hinsichtlich der Einnahmengestaltung der Länder ist durch die Zuweisung der Gesetzgebungshoheit über geeignete Steuern, die ohnehin den Ländern zustehen, abzumildern. Hinzutreten muss ein in einem vorgegebenen Rahmen sich abspielendes Hebesatz-oder Zuschlagsrecht der Länder auf die zentralen Verbundsteuern der Einkommenund der Körperschaftsteuer bei einheitlich-bundesgesetzlich gestalteter Steuerbemessungsgrundlage.

\section{Das Postulat fairen Steuerwettbewerbs}

(23) Steuerwettbewerb als Folge der Einräumung von Finanzautonomie erfüllt - wenn er rechtlich gehegt und reguliert, d.h. wenn er "fair “ ist - eine wichtige Funktion in der Mehrebenenstruktur. Auf horizontaler Ebene ist fairer Steuerwettbewerb durch das Prinzip der Besteuerung nach der individuellen wirtschaftlichen Leistungsfähigkeit als sachbereichsspezifische Ausprägung des Gleichheitssatzes zu gewährleisten. Dadurch wird (innerbundesstaatlich wie international) sowohl eine Doppelbesteuerung, als auch eine doppelte Nichtbesteuerung verboten. Ergänzt wird dieser Mechanismus durch die steuerspezifische Anwendung der Grundfreiheiten als Diskriminierungsverbote und die (u.a. beihilfenrechtliche) Beseitigung unfairer Steuerpraktiken. Ein ungezügelter Wettbewerb um Steuersubstrat verfehlt demgegenüber den hier propagierten Verantwortungszusammenhang. Vertikal ist die Finanzarchitektur als durch demokratische Verantwortungszusammenhänge geprägte Kompetenzstruktur darzustellen.

\section{Schluss}

(24) Verwirklichungschancen haben - den notwendigen „Willen zur Autonomie“ vorausgesetzt - nur kontinuierliche, das Postulat der „Pfadabhängigkeit" berücksichtigende Reformschritte. Die desolate Situation der öffentlichen Finanzwirtschaft erzeugt Reformdruck. Die bisher übermäßig 
genutzte Möglichkeit der Verantwortung auf künftige Generationen abladenden Flucht in die Verschuldung verengt sich in der europäischen Währungsunion zunehmend. Die gerade in Kraft getretene Föderalismusreform bleibt ohne eine Reform der Finanzverfassung Stückwerk. 
Dritter Beratungsgegenstand:

\title{
Finanzautonomie und Finanzverflechtung in gestuften Rechtsordnungen
}

\author{
2. Bericht von Professorin Dr. Johanna Hey, Köln
}

Inhalt

Seite

I. Ausgangspunkt: Reformbedürftige Finanzbeziehungen in der Bundesrepublik Deutschland und der Europäischen Union . 279

II. Besonderheiten der Finanzbeziehungen in gestuften Rechtsordnungen . . . . . . . . . . . . . 280

III. Finanzautonomie als Voraussetzung für Differenzierung und Wettbewerb ................... 283

1. Chancen und Risken von Fiskalwettbewerb Theorie und Praxis . . . . . . . . . . . . . . . . 283

2. Steuerungsmechanismen ............. 285

IV. Finanzautonomie in gestuften Rechtsordnungen:

Eigenverantwortung im gesamtstaatlichen Interesse . . . . 287

1. Finanzielle Eigenverantwortung . . . . . . . . . . . 287

a) Demokratische Kontrolle staatlicher Mittelbeschaffung und -verwendung . . . . . . . . . . 287

b) Berücksichtigung lokaler und regionaler Wählerpräferenzen nach ökonomischer Äquivalenz . . 289

2. Verantwortung der finanzautonomen Körperschaft gegenüber dem Gesamtstaat . . . . . . . . . . . . . . 291

a) Ausgewogenheit der Lebensverhältnisse als Mindeststandardgarantie . . . . . . . . . . . . 291

b) Bündnistreue als Solidarpflicht, Fairness- und Rücksichtnahmegebot . . . . . . . . . . . . . . 294

3. Gesamtverantwortung für ein rationales und gerechtes Steuersystem . . . . . . . . . . . . . . 297

a) Interdependenzen zwischen gestufter Finanzordnung und Steuerrechtsordnung . . . . . . . . . . . 297

b) Gesamtstaatliche Verantwortung für die Verwirklichung gleichmäßiger Besteuerung nach der wirtschaftlichen Leistungsfähigkeit . . . . . . . . 298 
V. Ein Zwischenfazit: Verantwortung als Leitmotiv der Ausgestaltung gestufter Finanzordnungen . . . . . . . . 304

VI. Reform der Finanzbeziehungen in der Bundesrepublik Deutschland: Stärkung der Finanzautonomie von Ländern und Kommunen durch maßvolle Entflechtung . . . . . . . . 304

1. Ausgangssituation nach der ersten Stufe der Föderalismusreform . . . . . . . . . . . . . . 304

2. Föderale Schuldenordnung als Einstieg in eine grundlegende Reform der Finanzverfassung . . . . . . 306

3. Stärkung der Steuerautonomie der Länder . . . . . . . 308

a) Schaffung einer Alternative zur Kreditfinanzierung . . 308

b) Steuergesetzgebung über Ländersteuern . . . . . . . 310

c) Beibehaltung des Steuerverbundes mit teilautonomer Steuersatzgestaltung der Länder . . . . . . . . . . 312

4. Bundessteuerverwaltung ............. . 314

5. Notwendige Anpassungen des Finanzausgleichs .... 315

6. Länderneugliederung und -sanierung als Vorbedingung einer sinnvollen Reform der Finanzverfassung? . . . . . 317

7. Steuerautonomie als Chance für die fünf neuen Länder? 318

8. Neuordnung der Kommunalfinanzen . . . . . . . . 320

VII. Reform der Finanzbeziehungen in der Europäischen Union zur Begrenzung des Autonomieverlusts durch Steuerwettbewerb . . . . . . . . . . . . . . 324

1. Status quo: Rechtliche und faktische Schranken der Finanzautonomie bei gleichzeitiger Haushaltsverantwortung ................... . . 324

2. Autonomieerhaltende Regelbindung des europäischen Steuerwettbewerbs ................

a) Einzelnormorientiertes Konzept des Verhaltenskodex gegen unfairen Steuerwettbewerb . . . . . . . . 325

b) Wettbewerbsoffenheit des Europäischen Gerichtshofs 325

c) Rückgewinnung der Finanzautonomie durch Harmonisierung? . . . . . . . . . . . . 


\section{Ausgangspunkt: Reformbedürftige Finanzbeziehungen in der Bundesrepublik Deutschland und der Europäischen Union}

Die deutsche Finanzverfassung gilt als Extremfall wettbewerbsfeindlicher Verflechtung, ${ }_{1}^{1}$ in der Europäischen Union tobt der Steuerwettbewerb $^{2}$ - gemeinsam ist beiden Finanzordnungen der Reformbedarf. Doch in beiden Fällen scheut die Politik vor der Reformaufgabe zurück. ${ }^{3}$ Erstaunlich ist dies nicht. Gehört doch die Auf- und Zuteilung der stets knappen Finanzmasse zu einer der großen Herausforderungen föderaler Systeme. ${ }^{4}$

Die offen, ohne Bezug zu einer bestimmten Rechtsordnung formulierte Themenstellung fordert zu der Suche nach allgemeinen Bauprinzipien einer föderalen Finanzordnung auf. In der Abstraktion vom konkreten institutionellen Rahmen wäre dies eine ökonomische Fragestellung. ${ }^{5}$ Zur Rechtsfrage wird sie aufgrund der Spannbreite föderaler Systeme $^{6}$ erst im konkreten Verfassungskontext. So aufschlussreich dabei ein umfassender Rechtsvergleich ${ }^{7}$ wäre, werde ich mich auf den Ver-

\footnotetext{
${ }^{1}$ Siehe statt vieler nur M. Kloepfer DÖV 2004, 566 (569): „unproduktive, leistungsund wettbewerbsfeindliche Verflechtungen“.

2 Im Einzelnen hierzu unten Fn. 32.

${ }^{3}$ Frühzeitig wurde die Finanzverfassung als eigenständiger Beratungsgegenstand aus der ersten Stufe der Föderalismusreform (Gesetz zur Änderung des Grundgesetzes v. 28. 8. 2006, BGB1. I 2006, 2034) ausgeklammert. Auch bei den Verfassungsberatungen der EU-Verfassung blieben die Finanzen weitgehend außen vor. Der VII. Titel des Verfassungsvertrags enthält haushaltsrechtliche Bestimmungen, aber keine umfassende Finanzordnung, vgl. C. Waldhoff in: Callies/Ruffert (Hrsg.) Verfassung der Europäischen Union, 2006, Art. I-53 Rn. 1.

4 Vgl. nur A. v. Bogdandy Europäisches Verfassungsrecht, 2003, 183: Finanzverfassung als „Achillesferse der föderalen Ordnung“; R. Scholz FS Badura, 2004, 491 (505): „Die Reform der Finanzverfassung gehört mit Sicherheit zu den schwierigsten Themen, vor denen sich die Reform des Bundesstaates gestellt sieht".

5 Zur finanzwissenschaftlichen Föderalismusforschung vgl. R. A. Musgrave Theories of Fiscal Federalism, Public Finance, Bd. 24 (1969), 521 ff.; A. Scott in: H. C. Recktenwald (Hrsg.) Finanztheorie, 1969, $120 \mathrm{ff} . ; W$. E. Oates The Political Economy of Fiscal Federalism, 1977; H. Zimmermann in: HdFW Bd. IV, 3. Aufl. 1983; E. Thöni Politökonomische Theorie des Föderalismus, 1986; D. Wellisch Dezentrale Finanzpolitik bei hoher Mobilität, 1995; G. Färber Probleme des föderativen Systems in Deutschland und Europa, 2004.

${ }^{6}$ J. Isensee HStR I, 1987, § 26 Rn. 10; M. Jestaedt HStR II, 3. Aufl. 2004, § 29 Rn. 5: Jeder Bundesstaat ist ein Unikat.

${ }^{7} \mathrm{Zu}$ den Finanzordnungen weiterer föderaler Staaten s. zB E. Döhler Autonome Besteuerungsrechte für Gliedstaaten und Gemeinden in ausgewählten föderativen Finanzverfassungen, 2002, $366 \mathrm{ff}$., mit einem Vergleich Kanadas, Australiens und der Schweiz;
} 
gleich der Mehrebenenrechtsordnungen der Bundesrepublik Deutschland und der Europäischen Union konzentrieren. Dies verspricht gerade aufgrund der Verschiedenheit der deutschen Bundesstaatlichkeit gegenüber der besonderen Bündnisform der Europäischen Union ${ }^{8}$ Erkenntnisgewinn. ${ }^{9}$

\section{Besonderheiten der Finanzbeziehungen in gestuften Rechtsordnungen}

Finanzautonomie meint in einem umfassenden Sinne das Recht zu Selbstbestimmung in finanziellen Angelegenheiten, ist mehr als ausreichende Finanzausstattung, sondern die Fähigkeit zu eigenständiger Finanzpolitik, sowohl auf der Einnahmen- als auch auf der Ausgabenseite. ${ }^{10}$ Als solche gehört sie zu den konstituierenden Merkmalen von (Eigen-)Staatlichkeit.11

Der autonome Staat entscheidet auf seinem Hoheitsgebiet souverän über Ausgaben und Einnahmen. Seine Finanzgewalt ist gegenüber der anderer Staaten lediglich durch den Grundsatz der Territorialität begrenzt. ${ }^{12}$

F. Neumark (Hrsg.) HdFW IV, 3. Aufl. 1983, mit Beiträgen zu Großbritannien, Österreich, Schweiz, Australien, Kanada und den USA; J. Hidien in: Dolzer/Vogel/Graßhof (Hrsg.) BK-GG, Art. 106 Rn. 1549 ff. (2002): Schweiz, Österreich, Belgien, USA, Australien.

${ }^{8}$ Eigenständiges föderales Rechtsgebilde, das entwicklungsoffen zwischen Staatenbund und Bundesstaat steht, vgl. auch BVerfGE 89, 155 (186, 188, 190): Europäische Union als „Staatenverbund“; dazu M. Schweitzer VVDStRL 53 (1994), $49 \mathrm{ff}$.; P. Badura FS Lerche, 1993, 369 (376ff.); W. Graf Vitzthum AöR 117 (1992), $46 \mathrm{ff}$.

${ }^{9}$ Zum Reiz des Finanzverfassungsvergleichs des reifen Föderalismus der Bundesrepublik Deutschland mit der im Entstehen befindlichen föderalen Ordnung der Europäischen Union s. U. Häde Finanzausgleich, 1996, 8f.; ferner M. Lienemeyer Die Finanzverfassung der Europäischen Union. Ein Rechtsvergleich mit bundesstaatlichen Finanzverfassungen, 2002.

${ }^{10}$ Zum Begriff der Finanzhoheit vgl. Vogel/Waldhoff in: Dolzer/Vogel/Graßhof (Hrsg.) BK-GG, Vorbem. z. Art. 104-115 Rz. 76; S. Korioth Der Finanzausgleich zwischen Bund und Ländern, 1997, 267 Fn. 2.

11 J. Bodin Sechs Bücher über den Staat, Neudruck 1981, 294; H. Siekmann in: M. Sachs (Hrsg.) GG, 3. Aufl. 2003, Art. 104a Rz. 27; W. Heun in: H. Dreier (Hrsg.) GG, 2000, Vorbem. zu Art. 104a-115 Rz. 16; G. H. Schuppert in: Umbach/Clemens (Hrsg.) GG Mitarbeiterkommentar, 2002, Bd. II, Vor Art. 104a ff. Rz. 22.

${ }_{12}$ Dazu grundlegend $K$. Vogel Der räumliche Anwendungsbereich der Verwaltungsrechtsnorm, 1965, $11 \mathrm{ff}$.; ferner H. Schaumburg Internationales Steuerrecht, 2. Aufl. 1998, 597. 
In gestuften Rechtsordnungen bedarf es - der horizontalen Kompetenzabgrenzung vorgelagert - zusätzlich einer vertikalen Aufteilung der finanziellen Ressourcen des Gesamtstaates zwischen Zentralebene und nachgeordneten Ebenen. Der Zugriff aller Ebenen auf ein und dieselbe Finanzmasse $^{13}$ nötigt zu einer Koordinierung der Zugriffsrechte.

Die Frage nach Finanzautonomie in gestuften Rechtsordnungen ist weniger eine Frage des $\mathrm{Ob}$, sondern des Ausmaßes der den einzelnen Ebenen zugestandenen Gestaltungsmöglichkeiten. Der Grad erforderlicher Finanzautonomie steht in engem Zusammenhang mit der Verteilung der Sachkompetenzen. ${ }^{14}$ Eigenverantwortliche Aufgabenwahrnehmung setzt nicht nur frei verfügbare, d.h. nicht zweckgebundene Einnahmen voraus, ${ }^{15}$ sondern die Möglichkeit der autonomen Beeinflussung der Höhe der Einnahmen unabhängig von der Zustimmung der Zentralebene oder anderer gleichgeordneter Gliedstaaten. ${ }^{16}$ Haben die Gliedstaaten dagegen lediglich die Aufgabe, die von der Zentralebene erlassenen Gesetze auszuführen, bedarf es einer möglichst gleichmäßigen Finanzausstattung. ${ }^{17}$

13 K. Stern Staatsrecht I, 2. Aufl. 1984, 657; H. Pagenkopf Der Finanzausgleich im Bundesstaat, 1981, 43; U. Häde (Fn. 9), 3; G. H. Schuppert in: Umbach/Clemens, GG Mitarbeiterkommentar, 2002, Bd. II, Vor Art. 104a ff. Rz. 22.

14 Wenig zielführend erscheint der hieraus erwachsene Streit, ob die Finanzverfassung lediglich Folgeverfassung ist, so F. Kirchhof VVDStRL 52 (1993), 71 (80); und ihm folgend S. Korioth (Fn. 10), 89; ders. 65. DJT (2004), Teil P, 91; P. M. Huber in: Mangoldt/Klein/Starck (Hrsg.) Bonner GG, 5. Aufl. 2005, Art. 107 Rn. 27; R. Wendt in: Pommerehne/Ress (Hrsg.) Finanzverfassung im Spannungsfeld zwischen Zentralstaat und Gliedstaaten, 1999, 17 (20); aA C. Waldhoff Die Verwaltung 2006, 155 (156); Vogel/ Waldhoff in: Dolzer/Vogel/Graßhof (Hrsg.) BK-GG, Vorbem. z. Art. 104a-115 Rn. 71; J.-P. Schneider Der Staat 2001, 272; G. F. Schuppert StwStp. 6 (1995), 675 (691 ff.); S. Oeter Integration und Subsidiarität im deutschen Bundesstaatsrecht, 1998, 508; W. Heun DVB1. 1996, 1020 (1021); A. Dittmann in: R. Caesar (Hrsg.) Zur Reform der Finanzverfassung und Strukturpolitik der EU, 1997, 55 (61 ff.). Zwar muss der Zuweisung von Sachaufgaben eine entsprechende Finanzausstattung folgen. Doch weder ist der Begriff der Folgeverfassung sonderlich trennscharf (s. das Eingeständnis von S. Korioth Diskussionsbeitrag, 65. DJT (2004), Teil P, 276, der gleichwohl hieran festhalten will), noch wird er den multiplen Funktionen der Finanzverfassung gerecht. Denn mittels des Finanzrechts und der Aufteilung der Finanzkompetenzen lassen sich eigenständige allokative und distributive Ziele verfolgen, die weit über die bloße Mittelbeschaffung und -verteilung hinausgehen und die jeweilige Bundesstaatlichkeit entscheidend mitprägen.

15 K.-A. Schwarz in: v. Mangoldt/Klein/Starck (Hrsg.) Bonner GG, 5. Aufl. 2005, Art. 106 Rn. 103; A. Hanebeck Der demokratische Bundesstaat, 2003, 343.

${ }^{16}$ R. Wendt (Fn. 14), 17; aA S. Korioth (Fn. 10), 101, nur das Ergebnis der angemessenen Finanzausstattung sei entscheidend.

17 Vgl. F. W. Scharpf MPIfG-Working Paper 99/3, 5. 
Finanzverflechtung ${ }^{18}$ trägt eben diesem Bedürfnis nach gleichmäßiger Verteilung der Finanzmasse Rechnung, sichert Rechts- und Wirtschaftseinheit innerhalb unitarisch ${ }^{19}$ angelegter Mehrebenenrechtsordnungen. Dabei bildet die Verflechtung durch Kooperation und Koordination den gegenüber einer Zentralisierung ohne Mitwirkungsrechte autonomieschonenderen Kompromiss zwischen zentralistischem Einheits- und dezentralem Bundesstaat. ${ }^{20}$

Allerdings begründet gerade die Pflicht zum Zusammenwirken ${ }^{21}$ die der Verflechtung eigene Unbeweglichkeit. Je unterschiedlicher die finanziellen Interessen, desto schwieriger wird die Mehrheitsbildung; die für Selbstkoordination erforderliche Einstimmigkeit lässt sich meist gar nicht erreichen. ${ }^{22}$ Finanzverflechtung hat daher eine negative Konnotation, ${ }^{23}$ gilt als Ursache von Reformblockaden, Ineffizienz, Intransparenz und mangelnder demokratischer Legitimation. Hieraus resultiert die Forderung nach Entflechtung, vor allem als Forderung nach einer Stärkung der Finanzautonomie nachgeordneter Ebenen.

\footnotetext{
18 Geprägt von F. W. Scharpf, vgl. Scharpf/Reissert/Schnabel Politikverflechtung: Theorie und Empirie des kooperativen Föderalismus in der Bundesrepublik, 1976, $28 \mathrm{ff}$.

${ }^{19}$ K. Hesse Der unitarische Bundesstaat, 1962.

${ }^{20}$ Dabei schließt die Entscheidung für eine föderale Staatsform bei aller begrifflichen Offenheit vollständige Einheitlichkeit und damit Zentralisierung aus und erlaubt, ja fordert geradezu regionale Differenzierung, vgl. A. Wolff Diskussionsbeitrag, VVDStRL 21 (1964), 138; J. Isensee Einheit in Ungleichheit, in: K. Bohr (Hrsg.) Föderalismus, 1992, 129 ff.; A. Leisner FS K. Vogel, 2000, 593 (600).

21 G. Kisker Kooperation im Bundesstaat, 1971.

$22 \mathrm{Zu}$ einer eher negativen Einschätzung der Selbstkoordination kommen auch C. Degenhart in: M. Sachs (Hrsg.) GG, 3. Aufl. 2003, Art. 72 Rz. 15; Rybak/Hofmann NVwZ 1995, 230 (232); P. M. Huber in: Mangoldt/Klein/Starck (Hrsg.) Bonner GG, 5. Aufl. 2005, Art. 107 Rz. 33; aA S. Oeter (Fn. 14), 474 ff. (im Hinblick auf die Flexibilität der Selbstkoordination); A. Schmehl DÖV 1996, 724 (726); S. Korioth (Fn. 10), 148, der gerade in der Einstimmigkeit einen entscheidenden Vorteil sieht, weil keine Körperschaft überstimmt werden kann; vgl. ferner B. Pieroth in: Pieroth/Jarass, GG, 8. Aufl. 2006, Art. 72 Rz. 10a: Bundesregel nicht erforderlich iSv Art. 72 Abs. 2 GG, soweit Selbstkoordinationsmöglichkeit besteht. Dabei verfehlt auch die Selbstkoordination die durch Autonomie nachgeordneter Ebenen bezweckten Differenzierungsmöglichkeiten, weshalb BVerfGE 106, 62 (150f.); 112, 226 (248), richtigerweise den Bund auch dann für regelungsbefugt hält, wenn andernfalls mit den anderen Ländern abgestimmte Regeln notwendig wären.

23 „Politikverflechtungsfalle“, s. F. W. Scharpf Politische Vierteljahresschrift Bd. 26 (1985), 323 (325); J. J. Hesse in: T. Büttner (Hrsg.) Finanzverfassung und Föderalismus in Deutschland und Europa, 2000, 9 (18): „spezifische Schwäche der föderalstaatlichen Entscheidungsfindung und Leistungserbringung“.
} 


\section{Finanzautonomie als Voraussetzung für Differenzierung und Wettbewerb}

\section{Chancen und Risken von Fiskalwettbewerb - Theorie und Praxis}

Zwar ließe sich Handlungsfähigkeit - um den Preis der Aufgabe der föderalen Finanzstruktur - auch durch Zentralisierung zurückgewinnen, doch es geht der Entflechtungsforderung nicht nur um die Flexibilisierung der Entscheidungsstrukturen, sondern auch um die Ermöglichung von Differenzierung und Wettbewerb. ${ }^{24}$ Dies macht Finanzautonomie als Regelungsautonomie nachgeordneter Ebenen aus der Sicht eines Konkurrenzföderalismus ${ }^{25}$ mit dem Credo des „Wettbewerbs als Entdeckungsverfahren" 26 so erstrebenswert. Die dem Abgabenwettbewerb $^{27}$ zugeschriebenen Segnungen gehen noch weiter: fiskalische Disziplinierung des Leviathans, ${ }^{28}$ Entlastung der Bürger, Effizienz und Nachfrageorientierung staatlicher Leistungen, mehr Markt und Freiheit. ${ }^{29}$

Unzweifelhaft eröffnet Steuer- und Standortwettbewerb unterentwickelten Regionen die Chance, aus eigener Kraft ökonomisch aufzuholen und kann damit langfristig zu einer Angleichung der Lebensverhältnisse führen. Ein gutes Beispiel gibt die irische Volkswirtschaft: Mit Niedrigsteuerpolitik vom Armenhaus Europas zum keltischen Tiger - und das

24 Jetzt grundlegend aus juristischer Sicht V. Mehde Wettbewerb zwischen Staaten, 2005.

${ }^{25}$ F. A. v. Hayek Der Wettbewerb als Entdeckungsverfahren (1968), in: M. Streit (Hrsg.) Friedrich August von Hayek: Rechtsordnung und Handelsordnung. Aufsätze zur Ordnungsökonomik, 2003.; C. B. Blankart Öffentliche Finanzen in der Demokratie, 5. Aufl. 2003, 564: Föderalismus als Entdeckungsverfahren.

${ }^{26}$ Befürworter einer stärker wettbewerblichen Ausrichtung etwa J. Isensee AöR 115 (1990), 248 (250); R. Scholz FS Badura, 2004, 491 (494f.); C. Callies DÖV 1997, 889 (890ff.); E. Schmidt-Jortzig DÖV 1998, $746 \mathrm{ff} . ;$ Vogel/Waldhoff in: Dolzer/Vogel/Graßhof (Hrsg.) BK-GG, Vorbem. zu Art. 104-115 Rn. 70; Stamm/Merkl ZRP 1998, $467 \mathrm{ff}$; U. Münch in: Jahrbuch des Föderalismus 2001, 115 (120ff.); W. Schwanengel DÖV 2004, 353.

${ }^{27}$ Ermöglicht durch umfassende Steuerertrags- und -gesetzgebungshoheit. Lässt sich bei reiner Ertragshoheit das Finanzvolumen nur indirekt durch erfolgreiche Ansiedlungsmaßnahmen beeinflussen, ermöglicht Steuergesetzgebungsautonomie die unmittelbare Beeinflussung der Einnahmehöhe. Im ersten Fall können Wettbewerbsvorteile nur über außersteuerliche Standortfaktoren erzielt werden, im zweiten Fall wird die Abgabenbelastung selbst zum Standortfaktor.

${ }_{28}$ Edwards/Keen Tax competition and Leviathan, European Economic Review 1996, $113 \mathrm{ff}$.

${ }^{29}$ Wettbewerb als Anreiz-, Entmachtungs- und Entdeckungsinstrument vgl. V. Vanberg in: Jahrbuch für die Ordnung von Wirtschaft und Gesellschaft Bd. 56, 2005, 47 (48). 
trotz Randlage und anfänglich schlechter Infrastruktur, allerdings mit einiger Unterstützung aus dem europäischen Kohäsionsfonds. ${ }^{30}$

Dennoch lassen die europäischen Erfahrungen Zweifel aufkommen, ob ein durch Entflechtung ermöglichter Abgabenwettbewerb erstrebenswert ist. ${ }^{31}$ Nachweisbar hat der Steuerwettbewerb zu einer Verlagerung der Belastung von mobilen zu immobilen Steuerquellen geführt. ${ }^{32}$ Besteuert wird nicht mehr nach Leistungsfähigkeit, sondern nach Mobilität. Lockangebote einerseits, Abwehrgesetzgebung andererseits kom-

${ }^{30} \mathrm{Zu}$ verdanken ist der irische Aufschwung erst dem Zusammenspiel von offensiver Wettbewerbspolitik und Transferleistungen. Irland hat zwischen 1989 und $200112 \mathrm{Mrd}$. Euro Strukturhilfen erhalten und gleichzeitig seinen Körperschaftsteuersatz von $40 \%$ auf $12,5 \%$ (seit 2003) gesenkt, nachdem es zunächst auf - inzwischen beihilferechtlich nicht mehr tolerierte - Steuervergünstigungen nur für ausländische Finanz- und Dienstleistungsunternehmen in Sonderregionen (Financial Services Centre in Dublin, Shannon Area) gesetzt hatte. Mit Hilfe dieser Strategie ist es Irland gelungen, sich von $60 \%$ des durchschnittlichen Pro-Kopf-Einkommens in der EU auf über $100 \%$ hochzuschrauben, so dass es inzwischen aus der Förderung durch den Kohäsionsfonds herausgewachsen ist, s. hierzu O. E. Kunze ifo Schnelldienst 6/2004, 58; OECD Economic Surveys 2002-2003, Ireland.

31 Krit. gegenüber der Übertragung der Wettbewerbstheorie auf staatliches Handeln H. P. Bull DÖV 1999, 269 (275); P. Kirchhof in: W. Schäfer (Hrsg.) Zukunftsprobleme der europäischen Wirtschaftsverfassung, 2004, $9 \mathrm{ff}$.; ders. in: P. Kirchhof (Hrsg.) Gemeinwohl und Wettbewerb, 2005, 1 (4); ders. in: Jahrbuch für die Ordnung von Wirtschaft und Gesellschaft, Bd. 56 (2005), $39 \mathrm{ff}$. mit Replik V. Vanberg ebenda, $47 \mathrm{ff}$. und Duplik $P$. Kirchhof ebenda, $55 \mathrm{ff}$. Dabei besteht kein Zweifel daran, dass sich Staaten wie Marktteilnehmer verhalten. Hiervon zu unterscheiden ist die Frage, ob dies wünschenswert ist. Aus ökonomischer Sicht gehört H.-W. Sinn in: A. Oberhauser (Hrsg.) Fiskalföderalismus in Europa, 1997, 9 (10) zu einem der wenigen Kritiker des Staatenwettbewerbs: Der Wettbewerb der Staaten leide unter chronischem Marktversagen, weil staatliche Tätigkeiten dem Grunde nach für einen Wettbewerb ungeeignet sind. Staaten übernehmen Aufgaben, die Private nicht ausführen, in denen der Markt gerade versagt, nämlich: Angebot öffentlicher Güter, Organisation von Umverteilung, Regulierung privaten Wettbewerbs. Diese Kritik trifft allerdings nur dann zu, soweit sich der Staat tatsächlich auf die Korrektur von Marktversagen beschränkt, so auch H.-W. Sinn Journal of Public Economics 66 (1997), 247 (270): „Competition is bad, when government intervention is good“.

32 Signifikante Entlastung von Kapital- und Unternehmenseinkommen; sichtbar vor allem anhand der Einführung niedriger Abgeltungssteuern auf Zinseinkünfte sowie der Halbierung des Körperschaftsteuersatzes seit Ende der 1980er Jahre (EU-Durchschnitt 1980: $46 \%$; 1985: 46,9\%; 1991: 40,1\%; 1999: 33,7\%; 2003: 29,8\%; 2006: 23,7\%; hierzu im Einzelnen Jarass/Obermair Wirtschaftsdienst 2004, 152 [154ff.]) bei gleich bleibender Steuerbelastung von Arbeitseinkommen und permanent steigendem Anteil der Konsumsteuern am Gesamtsteueraufkommen. Zudem ist die Belastung der Arbeitsentgelte durch die kontinuierliche Erhöhung der Sozialversicherungsabgaben gestiegen, vgl. auch K. Messere IBFD Bulletin 2004, 165 (172). 
plizieren die Steuersysteme. Nationale Gerechtigkeitsvorstellungen werden zurückgestellt. Den konkurrierenden Fisci geht es nicht um ein Entdeckungsverfahren zur Gewinnung einer gerechten Steuerrechtsordnung; es geht ihnen um Steuersubstrat.

Hinzu kommt ein Verlust an konjunktur- und sozialpolitischer Steuerungsfähigkeit. ${ }^{33}$ Zwar ist der befürchtete „race to the bottom“ unverzichtbarer staatlicher Leistungen bisher ausgeblieben, ${ }^{34}$ weil auf weniger mobile Steuerquellen ausgewichen werden konnte. ${ }^{35}$ Doch die politischen Gestaltungsspielräume werden enger, ${ }^{36}$ ohne dass die Steuer- und Abgabenquote insgesamt sinkt ${ }^{37}$ und ohne dass es bisher gelungen wäre, die Auswüchse des Leistungsstaates nennenswert zurückzudrängen.

\section{Steuerungsmechanismen}

Indes führt Finanzautonomie keineswegs automatisch in ruinösen Steuerwettbewerb, sondern nur unter ganz bestimmten Bedingungen:38 Ein auch nur vorübergehender Verzicht auf Einnahmen aus mobilen Steuerquellen setzt entweder Flexibilität auf der Ausga-

33 J.-P. Schneider Der Staat 2001, 272 (290).

${ }^{34}$ H. P. Bull DÖV 1999, 269 (271); H.-W. Sinn (Fn. 33), 9 (27); W. Schön EC Tax Review 2000, 90 (95). Allerdings kann aufgrund der ihm eigenen Dynamik des Steuerwettbewerbs ein ruinöser race to the bottom für die Zukunft nicht ausgeschlossen werden, sofern keine Gegenmaßnahmen ergriffen werden. Denn vom Steuerwettbewerb profitieren vor allem die first mover, d.h. die Staaten, die zuerst ihre Steuersätze signifikant senken. Die Mitbewerber sind gezwungen nachzuziehen, um den Verlust eigenen Steuersubstrats zu verhindern, werden aber in der Regel nicht mehr in der Lage sein, mit ihren Steuersatzsenkungen zusätzliche Investitionen anzuziehen, es sei denn sie unterbieten das Steuerniveau ihrer Mitbewerber erneut. Dies erklärt die Dynamik des Steuerwettbewerbs.

${ }^{35}$ H.-W. Sinn (Fn. 33), 9 (14ff.).

${ }^{36}$ Insbesondere wird die Gruppe derer, die mangels Mobilität zur Umverteilung herangezogen werden können, kleiner. Bürger mit niedrigeren Einkommen werden Gebietskörperschaften mit hoher Umverteilung bevorzugen, Bürger mit höheren Einkommen werden dorthin wandern, wo geringer umverteilt wird, so dass es zu einer Segmentierung in arme und reiche Gebietskörperschaften kommt, empirisch hierzu am Beispiel der Schweiz Feld/Kirchgässner Wirtschaftsdienst 1995, 562ff.; vgl. ferner De Mooij/Stevens EC Tax Review 2005, 9 (14f.); B. Huber in: T. Büttner (Hrsg.) Finanzverfassung und Föderalismus in Deutschland und Europa, 2000, 123 (130).

37 Vgl. OECD Revenue Statistics 1965-2003, 2004; zur weitgehend konstanten Steuerquote vgl. K. Messere IBFD Bulletin 2004, 165 (166f.); ähnliche Beobachtung für die Schweiz V. Mehde (Fn. 24), $96 \mathrm{ff}$.

${ }^{38} \mathrm{Zu}$ den unterschiedlichen Bestimmungsfaktoren für einen effizienten Steuerwettbewerb W. Eggert Nationale Besteuerung und wirtschaftliche Integration, 2002, insb. auch zum Einfluss unterschiedlicher Ländergröße und Anfangsausstattung. 
ben- ${ }^{39}$ oder auf der Einnahmenseite voraus, etwa indem auf substantielle immobile Steuerquellen oder in die Staatsverschuldung ausgewichen wird. $\mathrm{Ob}$ das Angebot niedriger Steuersätze angenommen wird, hängt zudem von der Wanderungsbereitschaft und der tatsächlichen wie rechtlichen Mobilität der Steuerquellen, ${ }^{40}$ d. h. vom Grad der Freizügigkeit, ab. Genau hier, in den Freizügigkeitsgarantien der gestuften Rechtsordnung, liegt übrigens der entscheidende Unterschied zum allgemeinen Staatenwettbewerb. Schließlich bedarf es eines Finanzausgleichssystems, das dem erfolgreichen Wettbewerber seinen Vorsprung belässt oder ihn durch Zuweisungen überhaupt erst zu offensiver Wettbewerbspolitik befähigt.

Wenn aber Fiskalwettbewerb ein bestimmtes Umfeld benötigt, lassen sich ihm auch implizite Grenzen setzen: Durch die Vorgabe eines einheitlichen Aufgabenniveaus, ${ }^{41}$ die Beschränkung der Steuerautonomie auf weniger mobile Steuerquellen, die Besteuerung von Kapital statt nach dem Quellen- nach dem Wohnsitzprinzip. ${ }^{42}$ Auch Verschuldungsrestriktionen wirken einem Steuerdumping entgegen. Rahmensetzende Funktion kommt zudem dem Finanzausgleich $\mathrm{zu},{ }^{43}$ dessen Wirkungen allerdings wohl dosiert sein wollen: Während der Ausgleich von unter-

39 S. Korioth 65. DJT (2004), Teil P, 109; J. Wieland JZ 2004, 774 (778). So erklärt vor allem das geringere Sozialleistungsniveau die gute Wettbewerbsposition der neuen EUMitgliedstaaten.

${ }^{40}$ Feld/Kirchgässner Wirtschaftsdienst 1995, 562 (565). Damit erklärt sich der besondere Wettbewerbsdruck auf die Besteuerung von Finanzkapital. Während bei Realinvestitionen und noch stärker bei der Wohnsitznahme eine Vielzahl von Standortfaktoren eine Rolle spielt, sind Finanzinvestitionen weitgehend unabhängig von Infrastruktur und geographischer Lage des Aufnahmestaates. Hinzu tritt ein Strukturfehler des internationalen Steuerrechts. Doppelbesteuerungsrechtlich wird das Besteuerungsrecht auf Zinsen dem Sitzstaat, das Besteuerungsrecht auf Gewinne dagegen dem Quellenstaat zugeordnet, so dass Finanzierungsgestaltungen legal nahezu beliebig eingesetzt werden können, um Gewinne, unabhängig vom Ort ihrer Erwirtschaftung, einer anderen Steuerjurisdiktion zuzuordnen. Insofern spielt es keine Rolle, dass hohe Steuersätze möglicherweise mit einem besonders guten staatlichen Leistungsangebot korrespondieren (Oates/Schwab Journal of Public Economics Bd. 35 [1988], 333 ff.). Dieses wird genutzt, ohne dass der Preis hierfür gezahlt wird (H.-W. Sinn [Fn.33], 9 [25]).

${ }^{41}$ Der verbleibende Wettbewerb um kostengünstige Ausführung ist unter dem Gesichtspunkt erwünschter Effizienzsteigerungen positiv $\mathrm{zu}$ bewerten und sollte sich durchaus beim Bürger in Form einer niedrigeren Abgabenbelastung niederschlagen.

42 De Mooij/Stevens EC Tax Review 2005, 9 (13); W. Eggert (Fn. 38), 185 f., 190; noch weitergehend für ein allgemeines Herkunftslandprinzip H.-W. Sinn (Fn. 33), 9 (49).

43 G. Färber in: M. Junkernheinrich (Hrsg.) Sonderbedarfe im bundesstaatlichen Finanzausgleich, 2005, 69 (71, 78); zum Zusammenhang von Steuerwettbewerb und Verschuldung s. Wiss. Beirat beim BMF Gutachten zum Länderfinanzausgleich in der Bundesrepublik Deutschland, in: Gutachten und Stellungnahmen 1988 - 1998, 103 (164). 
durchschnittlichen Einnahmen, die aufgrund nicht kostendeckender Steuersätze entstehen, einem Steuerunterbietungswettbewerb Vorschub leistet, nimmt eine zu weitgehende Abschöpfung von überdurchschnittlichen Einnahmen nicht nur den Anreiz unerwünschter steuerlicher, sondern auch erwünschter außersteuerlicher Ansiedlungspolitik. ${ }^{44}$

Damit ergibt sich ein erstes Zwischenfazit: Auch wenn die Entfachung eines Abgabenwettbewerbs nicht das vorrangige Ziel von Finanzautonomie nachgeordneter Ebenen sein kann, ${ }^{45}$ sprechen die negativen praktischen Erfahrungen in der EU nicht grundsätzlich gegen die Autonomieforderung. Sie belegen nur, dass dem durch Autonomie ermöglichten Fiskalwettbewerb von vornherein systemimmanente Grenzen zu setzen sind. ${ }^{46}$

\section{Finanzautonomie in gestuften Rechtsordnungen: Eigenverantwortung im gesamtstaatlichen Interesse}

\section{Finanzielle Eigenverantwortung}

\section{a) Demokratische Kontrolle staatlicher Mittelbeschaffung und -verwendung}

Für Finanzautonomie nachgeordneter Ebenen, im Besonderen regionale Einnahmeautonomie in Abhängigkeit zur Sachautonomie streitet die Stärkung der demokratischen Kontrolle staatlicher Ausgabenpolitik. ${ }^{47}$ Finanzielle Eigenverantwortung setzt zunächst als materielles

44 O.-E. Geske Der bundesstaatliche Finanzausgleich, 2001, $31 \mathrm{f}$.; Thöne/Jacobs Länderfinanzausgleich in Deutschland, 2000, $49 \mathrm{ff} . ;$ W. Wiegard in: Wendisch/Fonger (Hrsg.) Reform des föderalen Finanzsystems in Deutschland, 2006, 19 (20ff.).

45 Zurückhaltend ebenfalls H. Siekmann in M. Sachs (Hrsg.) GG-Kommentar, 3. Auf. 2003, vor Art. 104a Rz. 25, Art. 105 Rz. 59; H. P. Bull DÖV 1999, $269 \mathrm{ff}$; R. Seer in: Dolzer/Vogel/Graßhof (Hrsg.) BK-GG, Art. 108 Rn. 183; J.-P. Schneider Der Staat 2001, 272 (291): Folgeprobleme nicht hinreichend ausgelotet.

${ }^{46}$ International und europarechtlich fehlt es bisher an derartigen systemimmanenten Grenzen. Die Bemühungen um explizite Begrenzungen konzentrieren sich mit begrenzter Wirksamkeit auf den unfairen Steuervergünstigungswettbewerb, s. EU-Verhaltenskodex zur Bekämpfung schädlichen Steuerwettbewerbs v. 1. 12. 1997, AB1. EG 1998 Nr. C 2/2 Anhang 1, BR-Drucks. 814/97; OECD Harmful Tax Competition. An Emerging Global Issue, 1998; OECD The OECD's Project on Harmful Tax Practices: The 2004 Progress Report, Paris 2004.

47 Grundsätzlich BVerfGE 9, 268 (281): Demokratische Kontrolle setzt erkennbare Verantwortlichkeit voraus; ausführlich P. M. Huber 65. DJT (2004), Gutachten D, 33 ff.: „Demokratieprinzip als Grundlage eines Entflechtungsgebots“; ferner K. Kruis DÖV 2003, 10 (13); J. Wieland FS Selmer, 2004, 973 (984); ders. ZRP 2002, 503 (507); Göke Der Staat 2006, 1 (23); R. Grawert FS v. Unruh, 1983, 587 (590); R. Wendt HStR IV, § 104 Rn. 43; S. Oeter (Fn. 14), 521; zum Zusammenhang zwischen Demokratieprinzip und Verantwor- 
Substrat ${ }^{48}$ eine aufgabengerechte Finanzausstattung voraus. Das Interesse des Bürgers an der Bewirtschaftung dieser Mittel wird jedoch in der Regel erst dann geweckt, wenn für ihn nicht nur der Nutzen, sondern auch die Kosten in Form von Abgabenlasten individuell spür- und beeinflussbar werden. ${ }^{49}$ Im demokratischen Steuerstaat ${ }^{50}$ ist die Steuer nicht nur Haupteinnahmequelle, sondern alltäglicher Übersetzungsmechanismus, Mittler zwischen Wählerwillen und Politik.

Voraussetzung demokratiewirksamer Finanzautonomie ist eine klare Kompetenzverteilung und Kostentransparenz. ${ }^{51}$ Jede Ebene sollte die von ihrer eigenen Sachpolitik verursachten Kosten unmittelbar demokratisch verantworten müssen, allerdings auch nur diese. Nur wenn Aufgaben-, Ausgaben- und Einnahmeentscheidung in einer Hand liegen, kann die Verantwortung für die Kosten einer allzu expansiven Staatstätigkeit eindeutig zugeordnet werden. Nivellierende Finanzausgleichsbeziehungen verstellen dagegen den Blick auf die wahren Politikkosten ebenso wie die Kreditfinanzierung staatlicher Ausgaben. ${ }^{52}$

Bei funktionaler Trennung von Gesetzgebungs- und Ausführungskompetenz ${ }^{53}$ bleibt der demokratische Verantwortungszusammenhang

tung BVerfGE 9, 268 (281); zum Abbau von Verflechtung als Aufgabe der Verwirklichung eines „Verantwortungsföderalismus“s. auch P. Kirchhof FS Badura, 2004, 237 (254); S. Korioth 65. DJT (2004), Teil P, 99; I. Kesper, Bundesstaatliche Finanzordnung, 1998, 148; P. Selmer, AöR 101 (1976), 239 (240); R. Wendt (Fn. 14), 17 (25f.); S. Oeter (Fn. 14), 581; Stamm/Merkl ZRP 1998, 467 (468ff.); E. Schmidt-Jortzig DÖV 1998, 746 (748); Sachverständigenrat zur Begutachtung der gesamtwirtschaftlichen Entwicklung Jahresgutachten 1990/91, Tz. 432ff.; zu den rechtlichen Kategorien der Verantwortungszurechenbarkeit, s. P. Lerche in: Maunz/Dürig (Hrsg.) GG, Art. 83 Rn. $107 \mathrm{ff} . ; 111 \mathrm{ff}$. (1983).

48 H.-G. Henneke Öffentliches Finanzwesen, 2000, 327.

49 J. M. Buchanan Public Finance in Democratic Process, 1967, 126ff.; allgemein zum Merklichkeitsgrundsatz P. Bohley Die Öffentliche Finanzierung, 2003, $461 \mathrm{f}$.

50 Grundlegend zum Steuerstaat als Staatsform J. Isensee FS H. P. Ipsen, 1977, $409 \mathrm{ff}$. Dabei ist die Steuer nicht nur Indikator für die demokratische Kontrolle von Ausgaben, sondern der steuerliche Einnahmebeschaffungseingriff bedarf auch seinerseits in besonderem Maße der demokratischen Legitimation und Kontrolle, vgl. die historische Forderung des „nullum tributum sine repraesentatione“; „, no taxation without representation“, s. auch BVerfGE 63, 343 (367).

51 Zur Bedeutung von Transparenz als Voraussetzung demokratischer Kontrolle in der Mehrebenenrechtsordnung s. J. Kokott VVDStRL 63 (2004), 7 (33).

52 H. Grossekettler in: R. Caesar (Hrsg.) Zur Reform der Finanzverfassung und Strukturpolitik der EU, 1997, 111 (121 ff.); Demokratieprinzip als Argument gegen Nivellierung durch Finanzausgleich, vgl. P. M. Huber in: v. Mangoldt/Klein/Starck (Hrsg.) Bonner GG, 5. Aufl. 2005, Art. 107 Rn. 131.

${ }^{53}$ Dies ist und bleibt auch nach der zaghaften Entflechtung durch die Föderalismusreform die Hauptursache der Finanzverflechtung in Deutschland, s. F. W. Scharpf MPIfG Working Paper 99/3, 11. 
nur dann erhalten, wenn die anordnende Körperschaft die ausführende Körperschaft nach dem Grundsatz der Gesetzeskausalität von den Vollzugskosten freistellt. Zwar wird für die Kostentragung durch die vollziehende Körperschaft nach der Konzeption von Art. 104a Abs. 1 GG zu Recht vorgebracht, sie sichere die Effizienz und Sparsamkeit der Gesetzesausführung. ${ }^{54}$ Doch gerade im Fall von Leistungsgesetzen mit geringen Ausführungsspielräumen birgt die Vollzugskausalität die Chance, politische Verantwortung für Leistungsniveau und Kostenfolge zu Lasten Dritter abzuwälzen. ${ }^{55}$ Insofern wäre Einnahmeautonomie, mit der sich die ausführungs-, aber nicht entscheidungsbefugte Körperschaft vor dem Wähler verantworten muss, geradezu kontraindiziert.

\section{b) Berücksichtigung lokaler und regionaler Wählerpräferenzen nach ökonomischer Äquivalenz}

Ökonomisch wird für die Stärkung der Kompetenzen nachgeordneter Ebenen - durchaus in Einklang mit der demokratiestaatlichen Argumentationslinie - das Prinzip fiskalischer Äquivalenz angeführt. ${ }^{56}$ Dezentralisierung ermögliche effiziente Mittelversorgung entsprechend der lokalen Präferenzen der Bürger. ${ }^{57}$ Diese Effizienzbetrach-

54 Vgl. nur BT-Drucks. 2/480, Tz. 53, 55; 5/2861, 113; Troeger-Kommission Gutachten über die Finanzreform in der Bundesrepublik Deutschland, 2. Aufl. 1966, Tz. 199, 201. $\mathrm{Zu}$ den Argumenten für und wider die Verwaltungskonnexität ausführlich G. Trapp Das Veranlassungsprinzip in der Finanzverfassung der Bundesrepublik Deutschland, 1997, $78 \mathrm{ff}$.

55 Für eine Änderung von Art. 104a GG i. S. eines allgemeinen Verursachungsprinzips F. Kirchhof VVDStRL 52 (1993), 71 (94); H.-G. Henneke DÖV 1996, 713 (717ff.). Der verfassungsändernde Gesetzgeber ist der Forderung einer klareren Verantwortungszuordnung für Geldleistungsgesetze nur unvollkommen mit der dem Ziel der Entflechtung zuwiderlaufenden Ausweitung der Zustimmungspflichtigkeit (Art. 104a Abs. 4 GG n.F.) und ohne materielle Kostentragungsverpflichtung des Bundes nachgekommen. Allerdings müsste bei strenger Gesetzeskausalität angesichts des eklatanten Problems missbräuchlicher Inanspruchnahme staatlicher Leistungen die Verausgabung seitens der verwaltenden Körperschaft durch die finanzierende Körperschaft engmaschig kontrolliert und ein nachlässiger Vollzug sanktioniert werden.

${ }^{56}$ H. Haller FinArch. n.F. 21 (1961), 248 ff.; E. Thöni (Fn. 5), 1986, 15f.; H. Zimmermann in: HdFW Bd. IV, 3. Aufl. 1983, 9f.; zur Bedeutung des Äquivalenzprinzips für die Kompetenzordnung vgl. ferner aus juristischer Sicht $A$. Schmehl Das Äquivalenzprinzip im Recht der Staatsfinanzierung, 2004, $251 \mathrm{ff}$.

57 F. A. Hayek American Economic Review 1945, $519 \mathrm{ff}$; M. Tiebout An Economic Theory of Fiscal Decentralization, in: Public Finances: Needs, Sources and Utilization, 1961, 79 ff.; M. Olson American Economic Review 1969, $479 \mathrm{ff}$.; W. Oates in: W. Oates (Hrsg.) Federal Fiscalism, 1972, 3 (5 ff.); Wiss. Beirat beim BMF (Fn. 43), 103 (146). 
tung findet sich wieder im juristischen Subsidiaritätsverständnis, ${ }^{58}$ wie es in Art. 5 Abs. 2 EGV positiviert ist, in Art. 30, 72 Abs. 2 GG anklingt. 59

Allerdings eignen sich keineswegs alle Aufgaben für eine Dezentralisierung. ${ }^{60}$ Umverteilung, ${ }^{61}$ stabilitätspolitische ${ }^{62}$ Aufgaben oder die Außenbeziehungen zu anderen Staaten, insbesondere die Gewährleistung internationaler Wettbewerbsfähigkeit, können grundsätzlich nur zentral oder koordiniert verwirklicht werden. Voraussetzung der Dezentralisierung nach fiskalischer Äquivalenz sind geringe Externalitäten, weil nur dann die Koinzidenz von Kostenträgern und Nutznießern gewährleistet ist. ${ }^{63}$ Die Möglichkeiten der Entflechtung stoßen an Grenzen, wenn Nutzeneffekte auf andere Gebiete ausstrahlen (sog. spillover-Effekte). Trägt eine Körperschaft, was in vielen Fällen schlichtweg unvermeidbar ist, Kosten für von ihr ausschließlich oder teilweise im gesamtstaatlichen oder im Interesse einzelner gleichgeordneter Körperschaften wahrgenommen Aufgaben, resultieren hieraus Mischfinanzierungen und Ausgleichsansprüche. 64

Bestes Beispiel liefert das Hochschulwesen und seine umstrittene Finanzierung. Trotz der traditionellen Zuordnung zur Kulturhoheit der Länder trifft im Zeitalter eines internationalen Wettbewerbs um human resources die Verantwortung für ein wettbewerbsfähiges Hochschulsys-

${ }^{58}$ Zum Verhältnis von Föderalismus und Subsidiarität A. Leisner-Egensperger Vielfalt - ein Begriff des öffentlichen Rechts, 2004, 112.

59 G. Schmidt DÖV 1995, 657 ff.; R. Sannwald in: Schmidt-Bleibtreu/Klein (Hrsg.) GG, 10. Aufl. 2004, Art. 42; R. Wendt (Fn. 14), 17 (24); Feld/Kirchgässner Wirtschaftsdienst 2005, 562 (568).

${ }^{60}$ Hierzu S. Korioth (Fn. 10), 188 ff.; J. Popitz Der Finanzausgleich, in: HdFW, Bd. II, $346 \mathrm{f}$.

61 W. Renzsch in: T. Büttner (Hrsg.) Finanzverfassung und Föderalismus in Deutschland und Europa, 2000, 39 (50): Sozialstaatlich veranlasste und bundesgesetzliche Ausgaben sollten einer gesamtstaatlichen Finanzierungsverantwortung unterliegen.

62 R. Peffekoven Finanzausgleich II, in: HdFW, Bd. II, 608 (616); H. Haller FinArch. n.F. 27 (1968), 250 (251 ff.); H. H. v. Arnim HStR IV, § 103 Rn. 46; C. Gwosć Ein Verschuldungsrecht für die EU?, 2001, 100.

63 F. W. Scharpf MPIfG Working Paper 99/3, 11; G. Färber (Fn. 43), 69 (72).

${ }^{64}$ Dabei lassen sich durchaus auch hier Entflechtungserfolge erzielen, indem die Ausgleichsbeziehungen genauer am Interesse an der Aufgabenwahrnehmung ausgerichtet werden. So ist die sog. Einwohnerveredelung der Stadtstaaten ( 9 Abs. 2 FAG) im allgemeinen Länderfinanzausgleich des Art. 107 Abs. 2 GG fehl am Platz, soweit hierdurch den gesteigerten Versorgungsaufgaben von Ballungszentren Rechnung getragen werden soll, weil hiervon keineswegs alle Länder gleichermaßen, sondern in erster Linie die Anrainer profitieren, s. D. Carl Bund-Länder-Finanzausgleich im Verfassungsstaat, 1995, 87; S. Homburg in A. Oberhauser (Hrsg.) Fiskalföderalismus in Europa, 1997, 61 (82). 
tem (auch) den Gesamtstaat. ${ }^{65}$ Gleichzeitig lässt sich innerstaatlich die Kostenverantwortung nur schwer regional zuordnen. Der Nutzen der Hochschulausbildung realisiert sich am späteren Arbeitsort, der von Herkunfts- und Hochschulort oftmals verschieden sein wird. ${ }^{66}$ Der Streit um die Gemeinschaftsaufgabe Hochschulbau, ${ }^{67}$ das fallen gelassene Kooperationsverbot von Bund und Ländern ${ }^{68}$ ebenso wie der Vorschlag von Bildungsgutscheinen zur Verwirklichung eines horizontalen Hochschullastenausgleichs, vorbei am allgemeinen Länderfinanzausgleich belegen die letztlich unauflösbare Interessenverflechtung. ${ }^{69}$

\section{Verantwortung der finanzautonomen Körperschaft gegenüber dem Gesamtstaat \\ a) Ausgewogenheit der Lebensverhältnisse als Mindeststandard- garantie}

So gute Gründe es gibt, regionale Differenzierungen entsprechend der jeweiligen Wählerpräferenzen in sachlicher und finanzieller Hinsicht zuzulassen, für den politischen, wirtschaftlichen und sozialen Zusammenhalt jedes Bündnisses ist ein Mindestmaß an Ausgewogenheit der Lebensverhältnisse unerlässlich. Deshalb verpflichten Art. 72 Abs. 2 und Art. 106 Abs. 3 S. 4 GG zur Herstellung gleichwertiger bzw. einheitlicher Lebensverhältnisse, nennt Art. 158 EGV das Ziel des wirtschaftlichen und sozialen Zusammenhalts der Gemeinschaft als Ganzes. ${ }^{70}$

\footnotetext{
65 Vgl. Art. 91b Abs. 2 GG n.F.; ferner hierzu U. Mager VVDStRL 65 (2006), 275 (284).

66 Problem der Internalisierung sog. landesexterner Effekte im Bereich der Bildung vgl. Wiss. Beirat beim BMF (Fn. 43), 103 (159ff., 183); ferner Institut der deutschen Wirtschaft iwd 2006 Nr. 34, 4, mit dem Vorschlag eines bundesweiten Finanzierungsfonds für die Hochschulen.

${ }^{67}$ Dazu ausführlich I. v. Münch VVDStRL 31 (1973), 51 (61 ff.).

68 Vgl. Kommission von Bundestag und Bundesrat zur Modernisierung der bundesstaatlichen Ordnung, Dokumentation Zur Sache 1/2005, 483 ff.; Koalitionsvertrag von CDU, CSU und SPD v. 11. 11. 2005, Anlage 2, 207 ff.; Art. 104b Abs. 1 Satz 2 GG i. d. Fassung des Gesetzesentwurfs v. 7. 3. 2006, BT-Drucks. 16/813; fallen gelassen durch BT-Beschluss v. 30. 6. 2006, BR-Drucks. 462/06.

${ }^{69}$ Herstellen ließe sich fiskalische Äquivalenz ohne staatsinterne Abstimmungsnotwendigkeit nur durch eine kostendeckende Gebührenfinanzierung der Hochschulen oder durch eine strenge pro-Kopf Studierenden- oder Absolventen-Zuweisung im Rahmen des vertikalen Finanzausgleichs, vgl. F. W. Scharpf MPIfG Working Paper 99/3, 10.

${ }^{70} \mathrm{~S}$. auch Art. 2 EGV: kohärente und solidarische Gestaltung der Beziehungen zwischen den Mitgliedstaaten als Aufgabe der Gemeinschaft (hierzu Hilf/Pache in: Gra-
} 
Dass jedoch der damals noch als Einheitlichkeitsgebot formulierte Art. 72 Abs. 2 GG die Finanzautonomie der Länder nicht ausschalten, eine vollständige Nivellierung von Finanzkraftunterschieden durch den Finanzausgleich nicht begründen kann, haben Peter Selmer und Ferdinand Kirchhof schon auf der Jahrestagung 1992 überzeugend dargelegt. ${ }^{71}$ Seither ist nicht nur Art. 72 Abs. 2 GG neu gefasst ${ }^{72}$ und - insbesondere in den Bundesverfassungsgerichtsentscheidungen zu Altenpflege ${ }^{73}$ und Studiengebühren ${ }^{74}$ - neu interpretiert worden. Mit der Föderalismusreform sind die Sachkompetenzen der Länder nun vielfältig gestärkt, nicht nur zwecks Vereinfachung der Entscheidungsprozesse, sondern ausdrücklich auch um Differenzierung und Wettbewerb zu ermöglichen. ${ }^{75}$ Dementsprechend bedarf auch das bisherige Verständnis der Gleichwertigkeit der Lebensverhältnisse als Gleichwertigkeit staatlicher Leistungen ${ }^{76}$ mit der Folge eines weitgehenden, die Steuerertragshoheit der Länder konterkarierenden Finanzkraftausgleichs einer Revision. Zwar gilt im Bereich der Sozialleistungen mit dem größten Finanzierungsbedarf weiterhin Bundeseinheitlichkeit, ${ }^{77}$ was einer drastischen Reduzie-

bitz/Hilf [Hrsg.] Das Recht der Europäischen Union, Art. 2 EUV Rn. 1) und Art. 136 EGV, der die Gemeinschaft aber (noch) nicht zur Sozialunion macht, s. R. Rebhahn in: J. Schwarze (Hrsg.) EU-Kommentar, 2000, Art. 136 Rn. 17. Anders als die föderale Ordnung der Bundesrepublik Deutschland ist die Gemeinschaft bisher nicht auf Einheitlichkeit oder Gleichwertigkeit der Lebensverhältnisse angelegt, A. v. Bogdandy in: Grabitz/Hilf (Hrsg.) Das Recht der Europäischen Union, Art. 2 EGV Rn. 29.

${ }^{71}$ F. Kirchhof (Fn. 14), 71 (84); P. Selmer VVDStRL 52 (1993), $10 \mathrm{ff}$., auf der Grundlage von BVerfGE 1, 117 (132); 72, 330 (386); 86, 148 (215); 101, 158 (222).

72 Gesetz v. 27. 10. 1994, BGB1. I 1994, 3146.

73 BVerfGE 106, 62ff.

74 BVerfGE 112, $226 \mathrm{ff}$.

75 Vgl. BT-Drucks. 16/813, 7: Verbesserung der Handlungs- und Entscheidungsfähigkeit, deutlichere Zuordnung von Verantwortlichkeiten, Steigerung der Zweckmäßigkeit und Effizienz der Aufgabenerfüllung, neue Ausbalancierung der Elemente der Solidarität und Kooperation einerseits und des Wettbewerbs andererseits.

${ }^{76}$ K. M. Hettlage VVDStRL 14 (1956), 2 (19); H. Pagenkopf Finanzausgleich im Bundesstaat, Theorie und Praxis, 1981, 158, 294; krit. P. Selmer (Fn. 72), 10 (20). Dabei handelt es sich weder um ein Verfassungsgebot, vgl. P. Lerche FS Berber, 1973, 299; J.-P. Schneider, Der Staat 2001, 272 (293); S. Oeter (Fn. 14), $532 \mathrm{ff}$., noch um ein Staatsziel (M. Kloepfer DÖV 2004, 566 [567]; H. Hohmann DÖV 1991, 191 [196]). Zum Sozialstaatsprinzip als einzig tragfähiger Quelle des Gleichwertigkeitspostulats s. P. Selmer (Fn. 72), 10 (29).

77 Abhilfe könnte nur eine Verlagerung der Gesetzgebungskompetenzen für Sozialleistungen auf die Länder schaffen, wie dies aus ökonomischer Sicht gelegentlich gefordert wird, s. W. Wiegard (Fn. 44), 19 (28); S. Homburg Kommission von BT und BR zur Modernisierung der bundesstaatlichen Ordnung, Kommissionsdrucksache 0024, 8, allerdings mit erheblichen Auswirkungen für die Gleichwertigkeit der Lebensverhältnisse. 
rung des Finanzausgleichs entgegensteht. ${ }^{78}$ Dennoch müssen aus der Stärkung der Länderkompetenzen Konsequenzen für Gestaltbarkeit und Verteilung der Einnahmen gezogen werden. Mit wachsender regionaler Sachautonomie lässt sich ein Gebot gleichmäßig hoher Steuerbelastung oder nivellierender Umverteilung der Einnahmen immer weniger begründen. Im Gegenteil, Abgabenlast und staatliche Leistungserbringung stehen dergestalt in einem äquivalenztheoretischen ${ }^{79}$ Abhängigkeitsverhältnis, dass die Gleichwertigkeit der Lebensverhältnisse überhaupt nur dann gewahrt ist, wenn auch die Abgabenlast entsprechend dem staatlichen Leistungsniveau differiert.

Im Übrigen kann Wanderbewegungen, die das bundesstaatliche Sozialgefüge gefährden, ${ }^{80}$ - hierfür liefert die Entvölkerung der Ostdeutschlands ein aufrüttelndes Beispiel ${ }^{81}$ - ohnehin nicht durch Angleichung

${ }^{78}$ Auf diese Weise bleiben die Mindeststandards zur Sicherung des sozialen und wirtschaftlichen Friedens auf jeden Fall gewahrt, vgl. BVerfGE 106, 62 (144); P. Selmer (Fn. 72); ähnlich H. Wilms ZRP 2003, 86 (89).

79 Das Äquivalenzprinzip dient sowohl allgemein der Steuerrechtfertigung (s. zur staatlichen Leistungserbringung als allgemeine Steuerrechtfertigung. K. Vogel StuW 1996, 193 [196]) als auch der territorialen Abgrenzung von Steuerhoheiten auf der Gleichordnungsebene (s. J. Hey StuW 2002, 314 [319f.]). Welche Bedeutung dem Äquivalenzprinzip darüber hinaus für die Auswahl von Steuerquellen und die Ausgestaltung der steuerlichen Bemessungsgrundlage zukommt, gehört dagegen zu einer der ungeklärten Streitfragen der Steuerwissenschaften (dazu aus finanzwissenschaftlicher Sicht B. Hansjürgens Äquivalenzprinzip und Staatsfinanzierung, 2001, 204, 216 ff.: Abgeltung von Sondervorteilen; übernommen von $A$. Schmehl [Fn. 57], $97 \mathrm{ff}$.). Gestützt auf das Äquivalenzprinzip wird insbes. gefordert, Ertragsteuern mit ertragsunabhängigen Elementen zu versehen, weil staatliche Leistungen auch in ertraglosen Zeiten in Anspruch genommen würden. Indes werden hier die kategorialen Unterschiede zwischen Steuern und Vorzugslasten verwischt. Das Äquivalenzprinzip stellt für die Ausgestaltung von Personen- und Unternehmenssteuern keine Alternative zum Leistungsfähigkeitsprinzip dar (J. Lang NJW 2006, 2209 [2211]).

$80 \mathrm{Vgl}$. BVerfGE 112, 226 (247 ff.), wohingegen gewisse Wanderbewegungen durchaus in den durch die föderale Rechtsordnung eröffneten Differenzierungsmöglichkeiten angelegt sind.

${ }^{81}$ Dabei hat möglicherweise gerade dieses Verständnis des Gleichwertigkeitspostulats als einheitliches staatliches Leistungsniveau die wirtschaftliche Integration der fünf neuen Länder behindert. Statt langsamer Annäherung, wurde trotz der eklatanten Unterschiede in der Wirtschaftskraft zwischen Ost und West durch die Übertragung des westdeutschen Leistungsniveaus auf die neuen Länder ein Finanzbedarf geschaffen, der für Differenzierungen auf der Einnahmeseite keinen Raum ließ und den Finanzausgleich erheblich belastet. Dies dürfte zudem ein Grund dafür sein, dass es trotz der gemeindlichen Hebesatzautonomie, die bis zum Jahr 2004 sogar einen vollständigen Verzicht auf Gewerbesteuer zugelassen hätte, nicht zu einem spürbaren Steuerwettbewerb zwischen ost- und westdeutschen Kommunen gekommen ist, vgl. IFSt-Schriften, Entwicklung der Realsteuerhebesätze, Nr. 420 (2004), 48; Nr. 434 
der staatlichen Leistungen, sondern nur durch eine Annäherung des aus eigener Kraft erwirtschafteten Sozialprodukts vorgebeugt werden. Diesem Konzept der Hilfe zur Angleichung der Wirtschaftskraft anstelle eines Finanzkraftausgleichs folgt die Kohäsionsfondspolitik der Europäischen Union. ${ }^{82}$ Einer Egalisierung staatlicher Einnahmepolitik bedarf es hierfür nicht.

\section{b) Bündnistreue als Solidarpflicht, Fairness- und Rücksichtnahmegebot}

Die Ausgestaltung und Ausübung der Finanzautonomie aller Ebenen unterliegt jedoch im gesamtstaatlichen Interesse Solidar- und Treuepflichten. ${ }^{83}$ Gerade dies unterscheidet die Finanzautonomie in gestuften Rechtsordnungen von der autonomer Staaten.

Verhaltenssteuernd und kompetenzbegrenzend wirken die in Bundes- ${ }^{84}$ wie Gemeinschaftstreue ${ }^{85}$ enthaltenen Gebote gegenseitiger Rücksichtnahme ${ }^{86}$ und Fairness. ${ }^{87}$ Sie setzen dem Fiskalwettbewerb in föde-

(2005), 39. Inzwischen geht der Wettbewerb von den osteuropäischen Nachbarstaaten aus.

${ }^{82}$ A. v. Bogdandy in: Grabitz/Hilf (Hrsg) Das Recht der Europäischen Union, Stand 2004, Art. 2 EGV Rn. 29.

${ }^{83}$ Dabei hängt der Grad der finanziellen Bündnis- und Einstandspflichten davon ab, welchem Integrationsziel die Rechtsordnung verpflichtet ist, vgl. C. Waldhoff ZEuS 2000, 201 (237): Korrespondenz von Integrationsstand und Integrationsfinanzierung (in der EU).

${ }^{84}$ Grundlegend H. Bauer Die Bundestreue, 1992; krit. gegenüber zu weitreichenden Folgerungen M. Jestaedt HStR II, 3. Aufl. 2004, § 29 Rn. 74.

${ }^{85}$ M. Zuleeg in: von der Groeben/Schwarze (Hrsg.) EUV/EGV, 6. Aufl. 2003, Art. 10 Rn. 1: Umfassendes Treue und Loyalitätsgebot zwischen Gemeinschaft und Mitgliedstaaten sowie zwischen den Mitgliedstaaten; zu strukturellen Ähnlichkeiten mit der Bundestreue A. Bleckmann DVBl. 1976, 483 (486ff.); M. Hilf ZaöRV 35 (1975), 51 (58f.); K. Zweigert RabelsZ 28 (1964), 601 (620); M. Lück Die Gemeinschaftstreue als allgemeines Rechtsprinzip im Recht der Europäischen Gemeinschaft, 1992, 79 ff. (Identität von Gemeinschafts- und Bundestreue); zur Kritik an dieser Gleichsetzung W. Kahl in: Callies/Ruffert (Hrsg.) EUV/EGV, 2. Aufl. 2002, Art. 10 Rn. 4 ff.

86 Zurückzuführen auf $R$. Smend in: Staatsrechtliche Abhandlungen und andere Aufsätze, 3. Aufl. 1994, 39; ferner R. Pitchas Verwaltungsverantwortung und Verwaltungsverfahren, 1990, 510; zum Gebot gegenseitiger Rücksichtnahme der Länder BVerfGE 4, 115 (140ff.); 43, 291 (348); 98, 106 (118); 112, 226 (248); zum gemeinschaftsrechtlichen Rücksichtnahmegebot s. C. Callies Subsidiaritäts- und Solidaritätsprinzip in der EU, 1996, 157 ff.; A. Bleckmann DVB1. 1976, 483 (486); W. Kahl in: Callies/Ruffert (Hrsg.) EUV/EGV, 2. Aufl. 2002, Art. 10 Rn. 8: Eigenständiges Subprinzip der Gemeinschaftstreue.

${ }^{87}$ Das Fairnessgebot wirkt als völkerrechtliche Regel selbst bei institutionell nicht gebundenen Staaten - wie die OECD-Bemühungen gegen unfairen Steuerwettbewerb 
ralen Rechtsordnungen Grenzen. Zwar kann Wettbewerb nicht solidarisch sein. ${ }^{88}$ Allenfalls können Solidaritätspflichten die Hilfe gegenüber den Verlierern des Wettbewerbs gebieten. Wettbewerb kann aber fair organisiert werden, indem eine rücksichtslose Ausnutzung der Rechtsmacht im Sinne einer „beggar my neighbour policy“ unterbunden wird. ${ }^{89}$ Gleichermaßen verpflichtet das Gebot der Rücksichtnahme zur Respektierung fremder bzw. maßvollen Ausnutzung gemeinsamer Steuerquellen. ${ }^{90}$ Dem entsprechen die Gleichartigkeitsverbote in Art. 105 Abs. 2a S. $1 \mathrm{GG}^{91}$ und Art. 33 Abs. 1 der 6. Mehrwertsteuerrichtlinie. ${ }^{92}$

Der Gedanke der Solidargemeinschaft rechtfertigt einen umverteilenden Finanzausgleich, um die Leistungsfähigkeit sämtlicher Glieder zu gewährleisten, aber eben nicht eine Eigenstaatlichkeit und Verantwortungszusammenhänge sprengende systematische Nivellierung. ${ }^{93}$

Schließlich gebietet bündische Solidarität Hilfe in Notlagen und wirft damit sogleich die schwierige Frage nach verhaltensabhängigen Grenzen auf. Verliert den Anspruch auf Unterstützung, wer unfair handelt,

zeigen (s. Fn. 46) - begrenzend, vgl. zur Ableitung von internationalen Grenzen der Steuerhoheit aus dem „Prinzip Rücksicht“ W. Ritter BB 1984, 1109ff.; K. Vogel FS W. Ritter, 1997, 771 ff.; krit. H. Schaumburg (Fn. 12), $599 \mathrm{f}$.

88 Vgl. H. P. Bull DÖV 1999, 269 (276): „Solidarität trotz Konkurrenz - die Quadratur des Kreises?".

89 BVerfGE 4, 115 (140); H. Bauer Die Bundestreue, 1992, $356 \mathrm{ff}$.

90 BVerfGE 32, 333 (338): Der Bund ist nicht berechtigt, auf der Grundlage von Art. 106 Abs. 1 Nr. 6 GG eine Ergänzungsabgabe einzuführen, die wegen ihrer Höhe die dem Bund und den Ländern gemeinsam zustehende Einkommen- und Körperschaftsteuer aushöhlen würde. Auch in den im Ausland praktizierten Zuschlagssystemen mit autonomem Zugriffsrecht mehrerer Körperschaften auf eine Steuerquelle sind alle Beteiligten zur Mäßigung aufgerufen; s. ferner T. Maunz VVDStRL 14 (1956), 37 (45).

91 Dazu grundlegend M. Küssener Die Abgrenzung der Kompetenzen des Bundes und der Länder im Bereich der Steuergesetzgebung sowie der Begriff der Gleichartigkeit von Steuern, 1992; ferner M. Jachmann in: v. Mangoldt/Klein/Starck (Hrsg.) Bonner GG, 5. Aufl. 2005, Art. 105 Rn. 48 ff. Dabei bietet die Steuerkonkurrenzregel aufgrund des weitgehenden Fehlens einer materiellen Steuerkonkurrenzlehre und der formalistischen, mit der Bereichsausnahme der „herkömmlichen“ Steuern wenig rationalen Rechtsprechung (BVerfGE 40, 56 [62f.]; 49, 343 [355]; 65, 325 [351]) keinen besonders wirksamen Schutz; s. etwa die Kritik von K. H. Friauf in: BVerfG und GG II, 1976, 300 (316f.). In gleicher Weise soll die restriktive Sonderabgabenrechtsprechung des BVerfG eine kompetenzwidrige Aushöhlung fremder Steuerquellen verhindern, vgl. etwa BVerfGE 55, 274 (300f.).

92 Grundlegend EuGH, Slg. 1992, I-2217 - Dansk Denkavit; vgl. ferner Grabitz/Nettesheim EWS 1990, 246 ff.; C. Ohler Die fiskalische Integration in der Europäischen Gemeinschaft, 1997, $161 \mathrm{ff}$.

${ }^{93}$ Vgl. BVerfGE 101, 158 (221): Korrektur der grundsätzlich gewollten Ertragsaufteilung, soweit sie auch unter Berücksichtigung der Eigenstaatlichkeit der Länder aus dem bundesstaatlichen Gedanken der Solidargemeinschaft unangemessen ist. 
die eigene Notlage selbst verschuldet hat? Das bündische Füreinandereinstehen soll die Stabilität des Bündnisses als solches gewährleisten. Mithin kann die Unterstützung nicht allein vom Verhalten des Not leidenden Gliedstaates abhängig gemacht werden. ${ }^{94}$ Andererseits konterkariert eine verschuldensunabhängige Vergemeinschaftung finanzieller Risiken die Eigenverantwortlichkeit der Gliedstaaten. ${ }^{95}$ Auflösen lässt sich dieses Dilemma nur, indem Fehlentwicklungen ex ante durch Aufsichts- und Beanstandungsverfahren entgegengewirkt wird. So erteilt Art. 103 EGV - obwohl die Europäische Union durchaus als Solidargemeinschaft auch in finanzieller Hinsicht $\mathrm{zu}$ sehen is $\mathrm{t}^{96}$ - wechselseitigen finanziellen Einstandspflichten eine ausdrückliche Absage, um die nationale Haushaltsverantwortung nicht zu unterlaufen. ${ }^{97}$ Stattdessen wird auf die Präventionswirkung des Defizitverfahrens gesetzt. Lediglich aufgrund außergewöhnlicher, unbeherrschbarer Notlagen lässt Art. 100 Abs. 2 EGV 98 eine Unterstützung zu.

Im Übrigen ist Bündnistreue keine Einbahnstraße, auf die sich Länderegoismen stützen lassen. ${ }^{99}$ Wer außerordentliche finanzielle Hilfen in Anspruch nimmt, ist mitwirkungs- und rechenschaftspflichtig. ${ }^{100}$ Kontrolle und inhaltliche Vorgaben für die Mittelverwendung lassen sich rechtfertigen, mehr noch: sind demokratiestaatlich geboten, wenn Steuereinnah-

94 Vgl. auch BVerfGE 8, 122 (140); M. Sachs in: M. Sachs (Hrsg.) GG, 3. Aufl. 2003, Art. 20 Rn. 69.

95 BVerfGE 86, 148 (214); 101, 158 (225).

96 Sowohl die Eigenmittel-Bemessung als auch die durch sie finanzierten Kohäsionsund Strukturfonds berechtigen zu dem Schluss, dass die EU auch auf finanziellem Gebiet eine Solidargemeinschaft ist, vgl. (noch ohne Hinweis auf eine konkrete Vorschrift) EuGH, Slg. 1969, 523 Rn. 14 - Kommission/Frankreich: „Pflicht zur Solidarität“; und grundlegend C. Tomuschat Solidarität in Europa, in: Liber Amicorum Pierre Pescatore, 1987, $729 \mathrm{ff}$. Gerade die geforderte Solidarität hebt die Gemeinschaft von rein internationalen Beziehungen ab und weist in Richtung auf eine föderale Struktur, vgl. J. Ukrow in: Callies/Ruffert (Hrsg.) EUV/EGV, 2. Aufl. 2002, Art. 2 EGV Rn. 24.

97 J. Pipkorn Common Market Law Review 1994, 263 (273); U. Häde (Fn. 9), 563 f.; vgl. auch E. Gnan in: von der Groeben/Schwarze (Hrsg.) EUV/EGV, 6. Aufl. 2003, Art. 103 Rn. 2: Absicherung marktgerechter Kreditaufnahmebedingungen und Vermeidung eines „bail out“.

${ }^{98}$ Dem Wortlaut nach schließt Art. 100 Abs. 2 EGV ein Einspringen aufgrund verfehlter Politik nicht aus, allerdings dürften ,außergewöhnliche Ereignisse“ nur dann mit Naturkatastrophen gleichgestellt werden können, wenn sie in ähnlicher Weise unvorsehbar und plötzlich auftreten, was für Fehlsteuerungen in einem demokratischen Prozess in der Regel zu verneinen ist; ebenso B. Smulders in: von der Groeben/Schwarze (Hrsg.) EUV/EGV, 6. Aufl. 2003, Art. 100 Rn. 27.

99 BVerfGE 43, 291 (348f.).

100 BVerfGE 86, 148 (263 ff., 270); § 12 Abs. 4 MaßstG. 
men, die nur im Verhältnis zu der ertragsberechtigten Körperschaft demokratisch legitimiert sind, an andere Körperschaften weitergeleitet werden. ${ }^{101}$

\section{Gesamtverantwortung für ein rationales und gerechtes Steuersystem}

Bisher war nur von staatsorganisationsrechtlichen Grundsätzen die Rede. Doch die staatsinterne Aufteilung von Steuergesetzgebungs-, ertrags- und -verwaltungshoheit entfaltet darüber hinaus weitreichende Rückwirkungen auf die inhaltliche Ausgestaltung des Steuersystems und damit auf das Verhältnis zwischen Staat und Bürger. ${ }^{102}$

\section{a) Interdependenzen zwischen gestufter Finanzordnung und Steuerrechtsordnung}

So zeichnen Sachkompetenzen ohne Steuerkompetenzen den Weg in den Gebührenstaat, ${ }^{103}$ verleiten zur Erfindung parafiskalischer Sonderabgaben. Steuererfindungsrechte aller Ebenen erschweren die Entwicklung rationaler Steuersysteme mit der Folge eines - häufig lenkungspolitisch maskierten, in Wirklichkeit aber aus Haushaltsnot geborenen Steuerwildwuchses, ${ }^{104}$ wie er etwa im Bereich der örtlichen Verbrauchund Aufwandsteuern besteht. ${ }^{105}$ Die Zuordnung der Steuerertragshoheit entscheidet über die Anspannung einzelner Steuern. Welche Steuern erhöht werden, hängt von der - aus steuersystematischer Sicht sachfremden - Erwägung ab, wem das Aufkommen zusteht und ob es mit anderen Körperschaften geteilt werden muss. ${ }^{106}$ Das staatliche Stetig-

\footnotetext{
101 So wäre m.E. eine stärkere inhaltliche Kontrolle der Solidarpakt II-Mittel nicht nur ökonomisch sinnvoll (s. R. Peffekoven Wirtschaftsdienst 2006, 215 [218]), sondern auch im Hinblick auf die Autonomie der Empfängerländer insofern gerechtfertigt, als etwa der Solidaritätszuschlag vom Bund gegenüber dem Steuerzahler verantwortet werden muss.

102 T. Maunz (Fn. 91), 37 (58), hielt insofern einen „kurzen Blick“ für ausreichend.

103 Dazu F. Kirchhof Die Verwaltung 21 (1988), $137 \mathrm{ff}$.; C. Gramm Der Staat 1997, 267 ff.; R. Hendler DÖV 1999, 749 ff.; B. Hansjürgens ZG 1999, 186 ff.; Sacksofsky/Wieland (Hrsg.) Vom Steuerstaat zum Gebührenstaat, 2000; grundlegend zur Steuerstaatlichkeit der Bundesrepublik Deutschland J. Isensee in: FS H. P. Ipsen, 1977, $409 \mathrm{ff}$.

104 W. Renzsch in: T. Büttner (Hrsg.) Finanzverfassung und Föderalismus in Deutschland und Europa, 2000, 39 (51); Kritik am Vielsteuersystem der Mehrebenenrechtsordnung auch schon bei T. Maunz (Fn. 91), 37 (59).

${ }_{105} \mathrm{Zu}$ diesem Steueranachronismus (Hunde-, Zweitwohnungs-, Verpackungs- und Vergnügungssteuer) s. die beißende Kritik von K. Tipke StRO II, 2. Aufl. 2003, 1103 ff.; ders. DÖV 1995, $1027 \mathrm{ff}$.

106 So tendiert der Bund bei steigendem, von ihm allein zu tragendem Mittelbedarf (zB für die Bezuschussung von Renten- und Krankenversicherung) zur Erhöhung der ihm allein zugewiesenen Verbrauchsteuern. Dies erklärt, warum die Mineralölsteuer
} 
keitsbedürfnis verleitet vor allem dann zu Verletzungen des Leistungsfähigkeitsprinzips durch Betriebsausgabenabzugsverbote und Verlustverrechnungsbeschränkungen, wenn eine Körperschaft bei geringer Ausgabenelastizität in erster Linie über konjunkturanfällige Steuerquellen verfügt. ${ }^{107}$ Schließlich deformiert Steuerwettbewerb Besteuerungsgegenstände und Bemessungsgrundlagen.

\section{b) Gesamtstaatliche Verantwortung für die Verwirklichung gleichmäßiger Besteuerung nach der wirtschaftlichen Leistungsfähigkeit}

Zwar ist die Aufteilung der Steuerhoheit durch Zuordnung einzelner Steuerquellen - abgesehen davon, dass sie nach dem Deckungsprinzip $^{108}$ aufgabengerecht erfolgen muss - vorrangig eine verfassungspolitische Frage. Sie entscheidet aber zugleich über die Qualität der Steuerrechtsordnung und wird somit zur Optimierungsaufgabe zwischen Autonomieforderung und Grundrechtsbindung. ${ }^{109}$ Die staatsinterne Verteilung kann Verletzungen der Gleichmäßigkeit der Besteuerung nach Maßgabe des Leistungsfähigkeitsprinzips ${ }^{110}$ und seiner Subprinzi-

mittlerweile nach Einkommen- und Umsatzsteuer die drittstärkste Steuerquelle ist, obwohl angesichts des hohen Weltmarktpreises die überproportionale Anspannung der Mineralölsteuer wachstumsfeindlich wirkt.

107 Dies erklärt den Widerstand der Kommunen gegen die Abschaffung der gewerbsteuerrechtlichen Hinzurechnungstatbestände. Dabei können die Hinzurechnungen in $\S 8$ GewStG nicht mit dem besonderen Stetigkeitsbedürfnis der Kommunen (vgl. Zimmermann/Postlep Wirtschaftsdienst 1980, 248 [251]; G. Schwarting Kommunale Steuern, 1999, 34) gerechtfertigt werden. Das Stetigkeitsbedürfnis bleibt reines Fiskalinteresse und ist als solches zwar geeignet, die Besteuerung generell zu rechtfertigen, nicht aber gleichheitssatzwidrige Verletzungen des objektiven Nettoprinzips.

108 BVerfGE 55, 274 (300); 72, 330 (388); 86, 148 (213; 215); 101, 158 (220). K. A. Friauf JA 1984, 618 (619); Wiss. Beirat beim BMF (Fn. 43), 103 (138); P. M. Huber in: v. Mangoldt/Klein/Starck (Hrsg.) Bonner GG, 5. Aufl. 2005, Art. 107 Rn. 28.

${ }^{109}$ Zum Verhältnis von Grundrechtsschutz und bundesstaatlicher Vielfalt s. grundlegend H. Bethge AöR 110 (1985), 169 (199ff.); zu weitgehend C.-F. Menger VerwArch. 73 (1982), 98, der aus der Optimierungsaufgabe gestützt auf Art. 28 Abs. 3 GG eine ungeschriebene Eingriffskompetenz ableiten will.

110 Das Leistungsfähigkeitsprinzip ist zwar nicht selbst in der Verfassung verankert, als gleichmäßige Besteuerung nach der wirtschaftlichen Leistungsfähigkeit aber Maßstab für die Anwendung von Art. 3 Abs. 1 GG, ständige Rspr., z.B. BVerfGE 61, 319 (342f.); 82, 60 (86); umfassend zur verfassungsrechtlichen Dimension des Leistungsfähigkeitsprinzips als Fundamentalprinzip der Besteuerung K. Tipke Die Steuerrechtsordnung, Bd. I, 2. Aufl., 2000, 321 ff.; 479f.; $R$. Wendt DÖV 1988, 712 (713f.). Zur universellen, gesamteuropäischen Geltung des Leistungsfähigkeitsprinzips vgl. K. Tipke FS K. Vogel, 2000, 561 (567 ff.); J. Lang in: Tipke/Lang (Hrsg.) Steuerrecht, 18. Aufl. 2005, § 4 Rn. 82; J. Hey StuW 2005, 317 (325). 
pien ${ }^{111}$ oder des Übermaßverbots nicht rechtfertigen. Die finanzverfassungsrechtliche Diskussion sollte daher von der steuerverfassungsrechtlichen nicht getrennt werden. ${ }^{112}$

Dabei soll hier nicht die „offene Flanke“ des Art. 3 Abs. 1 GG geschlossen werden. ${ }^{113}$ Die Gleichmäßigkeit der Besteuerung wird durch regionale Belastungsunterschiede finanzautonomer Gebietskörperschaften nicht verletzt. Sie lassen sich auch steuersystematisch rechtfertigen, weil zwischen verschiedenen Jurisdiktionen regelmäßig Unterschiede im staatlichen Leistungsangebot bestehen. ${ }^{114}$

Etwas anders verhält es sich meiner Ansicht nach hinsichtlich der Gleichmäßigkeit des Steuervollzugs. Erst die gleichmäßige Durchsetzung rechtfertigt den Steuereingriff. ${ }^{115}$ Bezugsgruppe der Rechtsanwendungsgleichheit ist die Gesamtheit aller einem Steuergesetz unterworfenen Steuerpflichtigen, sie endet nicht an Landesgrenzen. Damit steht das Gebot steuerlicher Rechtsanwendungsgleichheit einem Konkurrenzföderalismus auf dem Gebiet der Verwaltung bundeseinheitlicher Steuergesetze grundsätzlich entgegen;116 es zwingt vielmehr die Gliedstaaten zu Kooperation, die Zentralebene zu Koordination. ${ }^{117}$ Im Übri-

111 Insbesondere objektives Nettoprinzip als Gebot der Folgerichtigkeit s. BVerfGE 99, 280 (290).

112 So aber S. Korioth Diskussion, 65. DJT (2004), Teil P, 277.

${ }^{113}$ M. Dürig in Maunz/Dürig (Hrsg.) GG, Art. 3 Abs. 1 Rn. 233; grundlegend auch H. Bethge AöR 110 (1985), 169 (199f.; 207f.). Zur föderal beschränkten Geltung von Art. 3 Abs. 1 GG vgl. BVerfGE 10, 354 (371); 32, 346 (359f.); 51, 43 (75); für das Steuerrecht: BVerfGE 21, 54 (68); ausführlich S. Boysen (Fn. 6), 100ff.; 191, jeweils mit zahlr. Nachweisen der ganz h. L.

114 Ebenso K. Tipke (Fn. 111), 363 ff.; F. Schoch DVB1. 1988, 866 (870f.).

115 Grundlegend zur Bedeutung für das Steuerrecht BVerfGE 84, 239; BVerfGE 110, 94; vgl. ferner R. Eckhoff Rechtsanwendungsgleichheit im Steuerrecht, 1999.

116 R. Seer in: Dolzer/Vogel/Graßhof (Hrsg.) BK-GG, Art. 108 Rn. 46; zur besonderen Bedeutung der Verteilung der Steuerverwaltungshoheit im Hinblick auf die Gewährleistung der Gleichmäßigkeit der Besteuerung vgl. ferner V. Schlette in: v. Mangoldt/Klein/Starck (Hrsg.) Bonner GG, 5. Aufl. 2005, Art. 108 Rn. 2; H. Vogel Ungleichheiten beim Vollzug von Steuergesetzen im Bundesstaat, 2000, $274 \mathrm{ff}$.; aA (untergeordnete Bedeutung) R. Caesar in: W. Zohlnhöfer (Hrsg.) Europa auf dem Wege zur Politischen Union?, 1996, 145 (152).

117 Keine „wesentlichen“ Verschiedenheiten beim Vollzug bundeseinheitlicher Gesetze durch die Länder, vgl. BVerfGE 11, 6 (18); vgl. ferner zu der aus Gleichheitssatz und Bundestreue abgeleiteten Kooperationspflicht der Länder BVerfGE 33, 303 (357); 73, 118 (196f.). Zwar wird auch das Gebot der Rechtsanwendungsgleichheit durch die Bundesstaatlichkeit relativiert ( $R$. Seer in: Dolzer/Vogel/Graßhof (Hrsg.) BK-GG, Art. 108 Rn. 44), indes sind die föderativen Gestaltungsspielräume beim Vollzug bundeseinheitlicher Gesetze generell deutlich geringer als im Bereich der Gesetzgebung 
gen sind die Gliedstaaten auch im Hinblick auf den Finanzausgleich zur Durchsetzung von Steuergesetzen angehalten. ${ }^{118}$ Ist die Schwäche der eigenen Finanzkraft auf einen nachlässigen Steuervollzug zurückzuführen, kann ein Ausgleich zu Lasten der Solidargemeinschaft nicht verlangt werden. ${ }^{119}$

Von der Zulässigkeit regionaler Belastungsunterschiede zu unterscheiden, ist das in gestuften Rechtsordnungen auftretende Problem vertikaler und horizontaler Mehrfachzugriffe. Die gleichheits- und freiheitsrechtlich zu rechtfertigende Belastung erschließt sich erst aus der Summe der Einzelzugriffe. Stets wird auf dieselbe Leistungsfähigkeit zugegriffen. ${ }^{120}$ Die Grundrechtsbindung aller am Besteuerungsvorgang beteiligter Ebenen verbietet eine Segmentierung. Die Finanzautonomie ist so zwischen den einzelnen Körperschaften zu verteilen und zu begrenzen, dass eine insgesamt leistungsfähigkeitsgerechte und verhältnismäBige Besteuerung gewährleistet wird. ${ }^{121}$

Bei vertikaler Teilung von Steuerquellen ergibt sich hieraus eine gemeinsame Pflicht der zugriffsberechtigten Körperschaften zur Einhaltung von Belastungsobergrenzen, ${ }^{122}$ wie sie das Bundesverfassungsgericht jüngst ganz selbstverständlich für das Zusammentreffen von Einkommen- und Gewerbesteuer angenommen hat. ${ }^{123}$

Auf der Horizontalebene sind die Probleme komplexer, weil hier Fragen zwischenstaatlicher Verteilungsgerechtigkeit nach Territorialität ${ }^{124}$ mit

(vgl. P. Kirchhof, HStR V, § 124 Rn. 178 ff.). Dies muss umso mehr für den Vollzug bundeseinheitlicher Steuergesetze gelten; ebenso H. Vogel (Fn. 117), $278 \mathrm{ff}$.

$118 R$. Wendt HStR IV, § 104 Rn. 100; R. Seer in: Dolzer/Vogel/Graßhof (Hrsg.) BK-GG, Art. 108 Rn. 45f.; W. Strobel BB 1986, 809 (820); A. Dittmann FS Dürig, 1990, 221 (235ff.); K. Tipke (Fn. 111), 364.

119 Auch dies ist eine Form der beggar-my-neighbour-policy, wenn gleichzeitig Vollzugskosten eingespart werden, s. W. Strobel B B 1986, 809 (820).

${ }^{120}$ K. Tipke (Fn. 111), 301 ff.; K. H. Friauf in: BVerfG und GG II, 1976, 300 (316).

${ }^{121}$ R. Wendt (Fn. 14), 17 (18); H. Siekmann in: M. Sachs (Hrsg.) GG, 3. Aufl. 2003, Art. 105 Rn. 45.

122 Ob Obergrenzen aus den Grundrechten, namentlich Art. 14 GG (BVerfGE 93, 121 [138]), oder aus dem Übermaßverbot (so jetzt BVerfG, NJW 2006, 1191 [1193] unter ausdrücklicher Zurückweisung eines „Halbteilungsgrundsatzes“ und zuvor BVerfGE 16, 147 [161]; 38, 61 [80f.]; 95, 267 [300]) abgeleitet werden, ist dabei unerheblich.

123 Vgl. BVerfG, NJW 2006, 1191 (1192ff.). Bei Annahme einer Verletzung des Übermaßverbots wäre hinsichtlich der Rechtsfolge allerdings einigermaßen unklar gewesen, welche Körperschaft - Bund/Länder oder Kommunen - ihren Besteuerungsanspruch hätte zurücknehmen müssen.

124 Vgl. BVerfGE 101, 158 (221): Anspruch der Länder auf das „örtliche“ Aufkommen, d.h. „das Entstehen von Steuerkraft im Zuständigkeitsbereich des jeweiligen Landes“. Die Zuweisung einer Steuerquelle zur autonomen Ausschöpfung berechtigt zunächst zur territorialen Anknüpfung sowohl an Wohnsitz als auch Quelle (zu den hieraus resul- 
individuell gerechter Lastenausteilung nach Leistungsfähigkeit in Einklang $\mathrm{zu}$ bringen sind. Dabei geht es nicht um die Einebnung bundesstaatlicher Vielfalt, sondern um die Auflösung von Regelungskonkurrenzen. ${ }^{125}$ Die aus dem internationalen Steuerrecht bekannten Phänomene der Benachteiligung Gebietsfremder und der Doppelbesteuerung grenzüberschreitender Sachverhalte treten nämlich auch innerhalb gestufter Rechtsordnungen auf, wenn die regionale Steuerautonomie insoweit nicht zurückgenommen wird. Dies ist - anders als zwischen unabhängigen Staaten, deren völkerrechtliche Beziehungen keinem Doppelbesteuerungsverbot unterliegen ${ }^{126}$ - innerhalb der Bundesrepublik Deutschland und der Europäischen Union sowohl verfassungs- als auch gemeinschaftsrechtlich geboten. Innerstaatlich folgt ein Verbot der Benachteiligung überregionaler Sachverhalte sowohl aus Art. 11 GG ${ }^{127}$

tierenden Fragen für eine leistungsfähigkeitsgerechte Besteuerung $K$. Vogel DBA, 4. Aufl., 2003 Einl. Rn. 23 ff.; H. Schaumburg FS K. Tipke, 1995, 124ff.). Dieses Nebeneinander begründet die internationale Doppelbesteuerung grenzüberschreitender Sachverhalte. Dabei entspricht dem Quellenprinzip eine äquivalenztheoretische Kompetenzabgrenzung nach den staatlicherseits zur Erwirtschaftung des Aufkommens geleisteten Verursachungsbeiträgen, was sich mit dem oben angesprochenen Prinzip der Kostenverantwortung deckt. Dagegen macht die Anknüpfung an die Vereinnahmung in Art. 107 Abs. 1 Satz 1 GG für die staatsinterne Bestimmung des Steueranteils der Länder die Zerlegung von den - verwaltungstechnischen Zielsetzungen geschuldeten - Zuständigkeitsregeln abhängig, die nicht notwendigerweise mit dem Ort der Erwirtschaftung übereinstimmen (und deshalb durch Zerlegungsvorschriften korrigiert werden müssen, vgl. BVerfGE 72, 330 [3. Leitsatz]); krit. hierzu Wiss. Beirat beim BMF (Fn. 43), 103 (142); R. Wendt GS Burmeister, 2005, 457 (459ff.); J. Wieland FS 50 Jahre BVerfG II, 771 (788f.); J. Hidien Die horizontale Steuerverteilung gem. Art. 107 Abs. 1 des Grundgesetzes, 1997, 22; dagegen P. M. Huber in: v. Mangoldt/Klein/Starck (Hrsg.) Bonner GG, 5. Aufl. 2005, Art. 107 Rn. 68: verfassungskonforme Konkretisierung des Prinzips des örtlichen Aufkommens. Indes ist eine exakte Abgrenzung vielfach schwierig. So verzichtet etwa der an die Löhne anknüpfende grobe Zerlegungsmaßstab der Gewerbesteuer (§ $29 \mathrm{GewStG}$ ) bewusst auf eine den Lasten der Gemeinde entsprechende Zuordnung des Gewerbesteuermessbetrags, vgl. P. Güroff in: Glanegger/Güroff, Gewerbesteuer, 5. Aufl. 2002, § 33 Rn. 1; BFH BStB1. III 1967, 324. Umfassend zur horizontalen Steuerzerlegung Thöne/Jacobs Länderfinanzausgleich in Deutschland, 2000, $61 \mathrm{ff}$.

125 S. auch BVerfGE 33, 303 (352): Begründung von Kooperationspflichten, wenn Sachverhalte der Natur der Sache nach gebietsüberschreitend verwirklicht werden.

126 BFH BStB1. II 1975, 497 (498).

127 Siehe BVerfGE 19, 101 (111); 65, 325 (355): Verbot der steuerlichen Schlechterstellung von Auswärtigen ohne sachlichen Grund; H. H. v. Arnim StuW 1982, 53 (65); noch weitergehend Koops/Völker DStR 1998, 1455 (1457) mit Parallelen zur steuerlichen Freizügigkeitsrechtsprechung des EuGH. Dagegen soll Art. 11 GG nach hM keinen Schutz gegenüber steuerlichen Beschränkungen des Wegzugs durch die Herkunftskörperschaft begründen. Ein unmittelbarer Eingriff sei im Fall steuerlicher Nachteile zu verneinen, vgl. Krüger/Pagenkopf in: M. Sachs (Hrsg.) GG, 3. Aufl. 2003, Art. 11 Rn. 20; 
als auch aus Art. 3 Abs. 1 GG. ${ }^{128}$ Idealerweise sollten auf der Horizontalebene angelegte Doppelbesteuerungskonflikte durch zentrale Festlegung einheitlicher Anknüpfungspunkte, z.B. nur Wohnsitz oder nur Quelle, reduziert werden. ${ }^{129}$ Verbleibende Jurisdiktionskonflikte müssen unter beiderseitiger Zurücknahme des Besteuerungsanspruchs auf der Gleichordnungsebene gelöst werden. Zwar lässt sich aus höherrangigem Recht nicht ableiten, wer den Verzicht leisten muss, denn zunächst sind beide beteiligten Körperschaften gleich souverän und damit gleich berechtigt. Innerhalb der Bundesrepublik Deutschland folgt eine Kooperationspflicht jedoch aus der Mitverantwortung der Länder für die Verwirklichung der Grundrechte. ${ }^{130}$ In gleicher Weise ist die umstrittene Frage eines europarechtlichen Verbots der Doppelbesteuerung grenzüberschreitender Sachverhalte ${ }^{131}$ zu bejahen. ${ }^{132}$ Die freie Betätigung im

Randelzhofer in: Dolzer/Vogel/Graßhof (Hrsg.) BK-GG, Art. 11 Rn. 29; J. Ziekow in: Berliner Kommentar zum GG, Art. 11 Rn. 91 ff.; 95. Dies führt zu der befremdlichen Konsequenz, dass Art. 11 GG schwächer wirkt als die europarechtlichen Freizügigkeitsgebote, die eine Rechtfertigung jeden Nachteils der Grenzüberschreitung verlangen und nicht erst, wenn die Grenzüberschreitung praktisch unmöglich gemacht wird.

${ }_{128}$ H. Schaumburg (Fn. 12), 602, der aus Art. 3 Abs. 1 GG sogar einen Anspruch auf Vermeidung internationaler Doppelbesteuerung ableitet; vgl. ferner die Rechtslage in der Schweiz, wo aus Art. 127 Abs. 2 BV (Garantie der Gleichmäßigkeit der Besteuerung) ein Verbot steuerlicher Schlechterstellung Gebietsfremder und Doppelbesteuerung Kantonsgrenzen überschreitender Sachverhalte abgeleitet wird; dazu Höhn/Mäusli Interkantonales Steuerrecht, 4. Aufl. 2000, $35 \mathrm{ff}$.

${ }^{129}$ Die zentrale Festlegung vermeidet eine beschwerliche Selbstkoordination. Zudem kann die Wahl des Anknüpfungspunktes Wanderbewegungen steuern, Steuerwettbewerb anheizen oder unterbinden. So lassen sich durch Kombination von Wohnsitz- und Arbeitsortprinzip etwa die Probleme von Stadtstaaten und Kernstädten mit überwiegenden Einpendlern lösen, s. Wiss. Beirat beim BMF (Fn. 43), 103 (150; 160).

${ }^{130}$ Hierzu s. BVerfGE 33, 303 (357); 73, 118 (196f.); s. auch J. Frowein, VVDStRL 31 (1972), 13 (46f.); H. Bethge AöR 110 (1985), 169 (215 ff.); P. Lerche FS Maunz, 1981, 218; krit. W. Rudolf HStR IV, § 105 Rn. 82; S. Boysen (Fn. 6), 199 ff.; s. ferner (rechtsvergleichend) C. Starck (Hrsg.) Zusammenarbeit der Gliedstaaten im Bundesstaat, 1988.

131 Zwar besteht zwischen den Mitgliedstaaten ein nahezu flächendeckendes Netz von Doppelbesteuerungsabkommen auf der Grundlage des OECD-Musters, zu dessen Entstehung Art. 293 2. Spiegelstrich EGV maßgeblich beigetragen hat, auch sieht das Übereinkommen über die Beseitigung der Doppelbesteuerung im Falle von Gewinnberichtigungen zwischen verbundenen Unternehmen (90/436/EWG), AB1. EG Nr. L 225 vom 20. 8. 1990, $10 \mathrm{ff}$., ein Verfahren zur Auflösung von Doppelbesteuerungskonflikten vor, damit werden aber keineswegs alle Doppelbesteuerungsprobleme gelöst. Trotz ihrer enormen praktischen Relevanz harrt diese Frage noch der Antwort durch den EuGH.

132 Ebenso W. Schön GS Knobbe-Keuk, 1997, 743 (773); J. Englisch Dividendenbesteuerung, 2005, $251 \mathrm{ff}$. (mit ausführlicher Begründung); A. Cordewener Europäische Grundfreiheiten und nationales Steuerrecht, 2002, 877; V. Heydt EuZW 2000, 33; aA 
Binnenmarkt wird auch dann behindert, wenn der Nachteil erst durch das Zusammentreffen zweier Jurisdiktionen entsteht. ${ }^{133}$ Die Mitgliedstaaten haften in diesem Fall gesamtschuldnerisch ${ }^{134}$ für die Verwirklichung der Grundfreiheiten. 135

Ein deutliches Spannungsverhältnis besteht schließlich zwischen dem Grundsatz der Einfachheit der Besteuerung ${ }^{136}$ und der Verwirklichung von Steuerautonomie in gestuften Rechtsordnungen. Zwar gilt das Verhältnismäßigkeitsprinzip nicht für die innerstaatliche Kompetenzverteilung, ${ }^{137}$ es wirkt aber über die Staat-Bürger-Beziehung mittelbar auf die Finanzordnung ein. Der Nutzen der durch regionale Steuerautonomie ermöglichten Vielfalt muss gegen die hiermit für den Bürger verbundene Komplizierung abgewogen werden. Dabei ist zu bedenken, dass auch Steuerautonomie als demokratisches Kontrollinstrument auf Transparenz angewiesen ist, so dass es föderaler Regelungsvielfalt im Bereich steuerlicher Bemessungsgrundlagen nicht nur nicht bedarf, im Gegenteil, sie ist eher hinderlich, weil sie zu intransparenter Steuersubventionspolitik verführt.

H. Schaumburg (Fn. 12), 598f.; E. Wessel Doppelbesteuerung und EWG-Vertrag, 1988; C. Ohler (Fn. 93), $150 \mathrm{f}$, der nur im Bereich der harmonisierten Mehrwertsteuer ein Doppelbesteuerungsverbot annimmt, ein solches aber für die Personensteuern ablehnt. Geltungsgrund des Doppelbesteuerungsverbots sind allein die Grundfreiheiten. Art. 293 2. Spiegelstrich EGV hält die Mitgliedstaaten nur zum Abschluss von Doppelbesteuerungsabkommen an, ohne ein materielles Verbot von Doppelbelastungen oder gar eine Aufteilungsregel zu normieren, vgl. EuGH; Slg. 1998, I-2793 Rn. 16 - Gilly.

133 Allgemein zum Problem der Grundrechtsbindung bei grenzüberschreitenden Sachverhalten S. Boysen (Fn. 6), 189 ff.; zu der Frage einer staatenübergreifenden Gesamtschau im Steuerrecht s. J. Englisch (Fn. 133), $269 \mathrm{ff}$. und passim; W. Schön IStR 1995, 119 (121); O. Thömmes DB 2002, 2397 (2400).

134 S. auch EuGH, Slg. 1983, 1013 Rn. 31 - Kommission./.Frankreich; EuGH, Slg. 1991, I-2797 Rn. 57 - Athanasopoulos./.BfA: Gemeinschaftstreue begründet eine Pflicht zur Zusammenarbeit der Mitgliedstaaten.

135 Unstreitig wirken die Grundfreiheiten als Beschränkungsverbote und Inländergleichbehandlungsgebote auch gegenüber mittelbaren steuerlichen Diskriminierungen, st.Rspr., vgl. etwa EuGH, Slg. 1995, 225 Rn. 29 - Schumacker.

136 Technisches Prinzip mit materiellrechtlichen Auswirkungen auf die Gleichmäßigkeit der Besteuerung, vgl. J. Lang (Fn. 111), § 4 Rn. 131; § 8 Rn. 3, 14.

${ }^{137}$ F. Ossenbühl FS Lerche, 1993, 151; C. Degenhart in: M. Sachs (Hrsg.) GG, 3. Aufl. 2003, Art. 70 Rn. 58; Art. 72 Rn. 10. 


\section{Ein Zwischenfazit: Verantwortung als Leitmotiv der Ausgestaltung gestufter Finanzordnungen}

Zusammenfassend ergibt sich ein dreifaches Verantwortungsgefüge: Sowohl demokratiestaatliche als auch ökonomische Gesichtspunkte effektiver Ressourcenallokation sprechen für finanzielle Eigenverantwortung aller mit Sachkompetenzen ausgestatteter Ebenen, sowohl auf der Ausgaben- als auch auf der Einnahmenseite. Gleichzeitig verpflichten Bündnis- und Treuegebote die einzelnen mit Finanzautonomie ausgestatteten Körperschaften zu einer verantwortungsbewussten, am Interesse des Gesamtstaates ausgerichteten Bewirtschaftung der einheitlichen Finanzmasse. Schließlich aktiviert die Grundrechtsbindung aller Ebenen die gemeinsame Verantwortung gegenüber dem zur Finanzierung herangezogenen Steuerbürger für eine leistungsfähigkeitsgerechte und verhältnismäßige Gesamtsteuerlast.

VI. Reform der Finanzbeziehungen in der Bundesrepublik Deutschland: Stärkung der Finanzautonomie von Ländern und Kommunen durch maßvolle Entflechtung

\section{Ausgangssituation nach der ersten Stufe der Föderalismusreform}

Welche Folgerungen lassen sich für die föderalen Finanzbeziehungen in Deutschland ziehen? Bereits die Föderalismusreform I hat den Bundesstaat an die Grenzen seiner Reformfähigkeit geführt. Dabei war der Streit um die Sachkompetenzen immer dort besonders erbittert, wo es in Wirklichkeit um Finanzierungsfragen ging (Stichwort: Hochschulwesen). ${ }^{138}$ Mut für die als zweite Stufe bisher nur vage angekündigte Finanzverfassungsreform macht das nicht. ${ }^{139}$ Doch eine Föderalismusre-

138 Dazu oben IV.1b.

$139 \mathrm{Ob}$ die Reform gelingt, hängt ganz entscheidend von ihrer Umsetzung ab. Sie muss einerseits kontinuitätswahrend, d.h. evolutionär (J.-P. Schneider Der Staat 2001, 272 [284ff.]) allen betroffenen Körperschaften Verhaltensanpassungen ermöglichen, dem Prinzip der Budgetsicherheit Rechnung tragen, die Wechselwirkungen einzelner Bausteine beachten und zugleich zwischen Reformgewinnern und -verlierern ausgleichen (hierin dürfte der Hauptgrund für die geringe Reformbereitschaft liegen, vgl. B. Grzeszick in: Maunz/Dürig [Hrsg.] GG, Art. 20 IV Rn. 195; U. Volkmann DÖV 1998, 613 [622]). Andererseits eröffnen gerade die aufgezeigten Wechselbezüglichkeiten der einzelnen Elemente der Finanzverfassung die Chance, durch intelligente Systeme des Übergangs und die richtige Chronologie der Reformen (M. Kops [Fn. 145], 23 [25]) Anpassungen zu ermöglichen. Das System bietet genügend flexible Parameter, die zur Abfederung des Transformationsprozesses, z.B. im Wege eines Übergangs-Finanzaus- 
form ohne Reform der Finanzverfassung ist ein Torso, ${ }^{140}$ schlimmer: eine Täuschung. Die Länder werden die gewonnene Sachautonomie nur dann in einem Wettbewerb der Systeme um beste Lösungen ${ }^{141}$ nutzen können, wenn die Entscheidung in der Sache nicht dem Diktat des finanziellen status quo unterworfen ist. Gestärkt werden muss die Verantwortlichkeit nicht nur für die Inhalte, sondern auch für die Kosten der Gesetzgebung.

Dabei kann die Frage nach notwendigen Anpassungen der Finanzbeziehungen nicht abstrakt anhand der Leitbilder eines komparativen oder kooperativen Föderalismus beantwortet werden, ${ }^{142}$ sondern muss mit dem vorrangigen Ziel, die Verantwortlichkeiten klarer herauszuarbeiten - ihren Ausgangspunkt von den konkreten Problemen der Finanzverfassung her nehmen. Problemorientierter Lösungsansatz ist indes nicht mit punktuellen Maßnahmen zu verwechseln. Das hier verschiedentlich skizzierte Zusammenspiel ${ }^{143}$ der einzelnen Elemente der Finanzordnung spricht gegen jeden Versuch unabgestimmter, einzelnormorientierter Entflechtung. ${ }^{144}$ Für ihr Funktionieren ist die Finanzordnung in ganz besonderem Maße auf Widerspruchsfreiheit angewiesen. ${ }^{145}$

gleichs, eingesetzt werden können; zu Ausgestaltungsmöglichkeiten s. S. Homburg (Fn. 78), $20 \mathrm{ff}$.

140 L. Michael JZ 2006, 884; R. Peffekoven Wirtschaftsdienst 2006, 215 (218ff.). Zwar wurden im Zuge der Föderalismusreform I einige zum Teil zu begrüßende Änderungen im Bereich der Gemeinschaftsaufgaben, der Haftung für Defizitüberschreitungen und der Finanzhilfen (insb. degressive Ausgestaltung, Befristungs- und Überprüfungspflicht (Art. 104b Abs. 2 S. 2 und 3 GG n.F.) unternommen. Doch Verflechtungen bei der Steuergesetzgebung, unklare Verantwortungsstrukturen im Bereich von Ausgabenentscheidungen und Staatsverschuldung sind bisher nicht angetastet worden.

${ }^{141}$ S. in diesem Sinne das Plädoyer von L. Michael JZ 2006, 854, für den experimentellen Bundesstaat.

142 R. Scholz FS Badura, 2004, 491 (494).

${ }^{143}$ Siehe oben III.2.

${ }^{144}$ Nur wenn die der normativen Ordnung vorgelagerten ökonomischen Gesetzmäßigkeiten beachtet werden, lassen sich angestrebte Ziele erreichen und die Effekte kontrollieren, ebenso M. Kops in: R. Caesar (Hrsg.) Zur Reform der Finanzverfassung und Strukturpolitik der EU, 1997, 23 (25 ff.); I. Kesper (Fn. 47), 145; E. Schmidt-Jortzig Diskussionsbeitrag, 65. DJT (2004), Teil P, 272, und sehr prägnant H. Fischer-Menshausen DÖV 1948, 10 (12); ferner Thöne/Jacobs Länderfinanzausgleich in Deutschland, 2000, 59; s. auch W. Wiegard (Fn. 44), der nachweist, dass der in $\S 3 \mathrm{MaßstG}$ eingefügte Eigenbehalt, der zur Anreizsteigerung dienen soll, das Gegenteil bewirkt.

${ }^{145}$ Zur Bindungswirkung der Gebote der Sach- und Systemgerechtigkeit bei der Abfassung der Finanzverfassung vgl. P. M. Huber in: v. Mangoldt/Klein/Starck (Hrsg.) Bonner GG, 5. Aufl. 2005, Art. 107 Rn. 60 ff.; Huber/Storr Der kommunale Finanzausgleich als Verfassungsproblem, 1999, 104; K.-A. Schwarz in: v. Mangoldt/Klein/Starck 
2. Föderale Schuldenordnung als Einstieg in eine grundlegende Reform der Finanzverfassung

Das dringlichste Problem des Finanzwesens in der Bundesrepublik Deutschland liegt nicht in den laufenden Einnahmen und ihrer Verteilung, sondern im erreichten Ausmaß ex- und impliziter Staatsverschuldung auf allen Ebenen des Bundesstaates. ${ }^{146}$ Die Hinterlassenschaft von Zins- und Pensionslasten schränkt die demokratischen Gestaltungsspielräume zukünftiger Parlamente empfindlich ein; ${ }^{147}$ sie durchbricht den Konnex zwischen staatlicher Ausgabenentscheidung und Kostenverantwortung. Deshalb hat eine Reform des Staatsschuldenrechts mit dem Ziel effektiverer Neuverschuldungsgrenzen, ${ }^{148}$ gesamtstaatlicher Schuldenprävention und einem Entschuldungskonzept Priorität. Sie könnte zugleich Ausgangspunkt für weitere Reformschritte sein.

Dabei liegt der Fehler hier nicht in zu wenig, sondern in zu viel, genauer: falsch gewichteter Autonomie der Länder. Bislang erklärt Art. 109

(Hrsg.) Bonner GG, 5. Aufl. 2005, Art. 106 Rn. 110; A. Dittmann in: R. Caesar (Hrsg.) Zur Reform der Finanzverfassung und Strukturpolitik der EU, 1997, 55 (60); allgemein zur Widerspruchsfreiheit der bundesstaatlichen Ordnung M. Sachs in: M. Sachs, GG, 3. Aufl. 2003, Art. 20 Rn. 62.

146 Seit 1993 (1564 Mrd. DM) hat sich die Gesamtverschuldung der öffentlichen Haushalte nahezu verdoppelt (2005: 1447,3 Mrd. Euro; davon Bund: 887,9 Mrd. Euro, Länder: 468,2 Mrd. Euro, Kommunen: 91,2 Mrd. Euro; s. BMF Finanzbericht 2006).

147 W. Höfling Staatsschuldenrecht, 1993, $168 \mathrm{ff} . ; 185 \mathrm{ff}$; Musgrave/Musgrave/Kullmer Die öffentlichen Finanzen in Theorie und Praxis, Bd. 3, 4. Aufl. 1992, 144f.; C. Gröpl Die Verwaltung 2006, 215 (228); W. Heun Die Verwaltung 1985, 1 (4). Die Zinslast des Bundes betrug schon in 2004 38,5 Mrd., d.h. rd. $20 \%$ der Steuereinnahmen des Bundes, vgl. BMF Finanzbericht 2006, 139. Gleichzeitig büßt die äquivalenztheoretische Legitimation des Steuerstaats ihre Überzeugungskraft ein, wenn die Steuerbürger von heute für die Finanzierung in der Vergangenheit verursachter Lasten aufkommen müssen, soweit die Ausgaben der Vergangenheit nicht in die Zukunft fortwirken; dazu C. Jahndorf Grundlagen der Staatsfinanzierung durch Kredite und alternative Finanzierungsformen im Finanzverfassungs- und Europarecht, 2003, $148 \mathrm{ff}$; H. Haller FinArch n.F. 21 (1961), 248 (252f.). Das finanzwissenschaftliche Argument, Kreditfinanzierung ermögliche eine intertemporale Nutzen- und Lastenverteilung (Musgrave/Musgrave/ Kullmer Die öffentlichen Finanzen in Theorie und Praxis, Bd. 3, 4. Aufl. 1992, $144 \mathrm{ff}$.), vermag nur im Hinblick auf Investitionen in langfristige Infrastrukturmaßnahmen zu überzeugen.

148 Der Sache nach ist das dirigistische Staatsschuldenrecht des Grundgesetzes durch Europäisierung und Globalisierung überholt, s. Kritik und Reformforderungen etwa von W. Göke ZG 2006, 1 (18); J. Wieland FS Selmer, 2004, 973 (988). Als Alternative bieten sich zB Brutto-Inlandsprodukt basierte Verschuldungsgrenzen nach EU-Vorbild oder Orientierung am Modell der sog. „Schweizer Schuldenbremse“ an, vgl. dazu Feld/ Kirchgässner in: Neck/Storm (Hrsg.) Die Nachhaltigkeit der öffentlichen Finanzen, 2005. 
Abs. 1 GG Bund und Länder in ihrer Haushaltswirtschaft als ,selbständig“, auch wenn in Absatz 2 beide auf das gesamtwirtschaftliche Gleichgewicht verpflichtet. Nach der Entscheidung des BVerfG aus dem Jahr $1992^{149}$ schien es, als seien die Länder durch die Rückversicherung der Bundeshilfe im Fall extremer Haushaltsnotlagen in letzter Konsequenz von der Haftung freigestellt. ${ }^{150}$ Dies liefe auf Verschuldungsautonomie ohne Verschuldungsletztverantwortung hinaus, mag das Bundesverfassungsgericht die Anforderungen auch jüngst verschärft haben. ${ }^{151}$ Überdies sind die Länder bisher nicht hinreichend in den das nationale Staatsschuldenrecht überlagernden Europäischen Stabilitätspakt ${ }^{152}$ eingebunden.

Nicht nur europarechtlich, sondern auch weil alle Ebenen auf dieselbe Haftungsmasse des Bruttosozialprodukts zurückgreifen, bedarf es einer „konsolidierten gesamtstaatlichen Verschuldungsrechnung“ mit Koordination der Verschuldungspolitik durch den Bund. ${ }^{153}$ Der durch die Föderalismusreform I eingeführte Art. 109 Abs. 5 GG greift zu kurz, indem er die Länder lediglich an allfälligen Sanktionen nach Art. 104 EGV beteiligt, also erst auf der Rechtsfolgenebene ansetzt. Steuerungsmecha-

149 BVerfGE 86, 148 (262ff.).

150 Zwar folgt aus der Selbständigkeit grundsätzlich auch die Haushaltsverantwortung, vgl. etwa M. Rodi in: Dolzer/Vogel/Graßhof (Hrsg.) BK-GG, Art. 109 Rn. $124 \mathrm{ff}$. Der Verantwortungszusammenhang wird aber durch die Aussicht auf Hilfeleistungen des Bundes durchbrochen.

151 BVerfG v. 19. 10. 2006, www.bundesverfassungsgericht.de.

152 Zum Verhältnis zwischen EU-Verschuldungsgrenzen und nationalen Verschuldungsregeln C. Ohler (Fn. 93), 301 ff. Gem. Art. 3 des Protokolls zum Maastrichtvertrag sind die Regierungen der Mitgliedstaaten für die Defizite des gesamten Staatssektors verantwortlich. Sie müssen durch innerstaatliche Verfahren die Einhaltung der Verpflichtungen sicherstellen, vgl. Art. 2 des Protokolls über das Verfahren bei einem übermäßigen Defizit. Zum öffentlichen Defizit gehören auch die Defizite der regionalen und kommunalen Gebietskörperschaften sowie der Sozialversicherungseinheiten (Schlussakte der Maastrichter Konferenz v. 7. 2. 1992, BGB1. II, 1317).

153 W. Höfling ZRP 1997, 231 (234); H.-G. Henneke (Fn. 48), 222 ff.; M. Rodi in: Dolzer/Vogel/Graßhof (Hrsg.) BK-GG, Art. 109 Rn. 590 ff.; C. Jahndorf (Fn. 148), $421 \mathrm{f}$. Die in Art. 109 Abs. 2 GG normierte gemeinsame Pflicht, den Erfordernissen des gesamtwirtschaftlichen Gleichgewichts Rechnung zu tragen, ist zu wenig konkret, als dass sie in der Vergangenheit zu einer koordinierten gesamtstaatlichen Haushaltspolitik geführt hätte und gibt dem Bund keine Befugnisse gegenüber den Ländern, vgl. C. Hillgruber in: v. Mangoldt/Klein/Starck (Hrsg.) Bonner GG, 5. Aufl. 2005, Art. 109 Rn. 79; H. Jarass in: Jarass/Pieroth, GG, 8. Aufl. 2006, Art. 109 Rn. 6; auch die auf die Bundestreue gestützte (s. K. Stern FS Everling II, 1995, 1469 [1481]) Verpflichtung der Länder zur Einhaltung der Maastricht-Kriterien hat extreme Haushaltsnotlagen nicht verhindern können. Die Tätigkeit des Finanzplanungsrates (§ 51 Haushaltsgrundsätzegesetz) kann eine verfassungsrechtliche Regelung nicht ersetzen. 
nismen auf Bundesebene zur Vermeidung haushaltsrechtlicher Notlagen der Länder - wie sie das Bundesverfassungsgericht schon $1992^{154}$ und erneut als bundesstaatlicher Handlungsauftrag im Berlin-Urteil ${ }^{155}$ gefordert hat - sind bisher ebenso wenig vorgesehen wie eine ex-ante Aufteilung des Verschuldungsvolumens. Nur eine verbindliche Aufteilung 156 der gesamtstaatlichen Verschuldung zwischen den Ebenen und auf die einzelnen Länder ermöglicht aber rechtzeitige Intervention. Vorzusehen wäre ein Frühwarnsystem mit formalisiertem Feststellungs-, Sanierungs- und Sanktionsverfahren. ${ }^{157}$ Der derzeit praktizierte Rückgriff auf allgemeine Grundsätze der Bündnistreue bietet keine hinreichend klaren Regeln. ${ }^{158}$

\section{Stärkung der Steuerautonomie der Länder}

\section{a) Schaffung einer Alternative zur Kreditfinanzierung}

Die Klage des Landes Berlin hat dem Bundesverfassungsgericht Gelegenheit gegeben, ${ }^{159}$ seine bisherige Rechtsprechung zur Hilfestellung in extremen Haushaltsnotlagen zu präzisieren. ${ }^{160}$ Zutreffend betont das

154 BVerfGE 86, 148 (266f.); ebenso J. Wieland JZ 2006, 751 (756); Rossi/Schuppert ZRP 2006, $8 \mathrm{ff}$. (Haushaltsnotlagengesetz).

155 BVerfG v. 19. 10. 2006, www.bundesverfassungsgericht.de, Tz. 204.

156 Hierfür etwa S. Korioth 65. DJT (2004), Teil P, 121; L. Micker ZRP 2004, 229 (231ff.); zu unterschiedlichen Aufteilungsverfahren s. Wiss. Beirat beim BMF Zur Bedeutung der Maastricht-Kriterien für die Verschuldungsgrenzen von Bund und Ländern, in: Gutachten 1988-1998, 267 (284ff.); vgl. ferner S. Funke Die Verschuldungsordnung, 1995, 475: „Grundsatz der teilautonomen Verschuldungspolitik“ mit beschränkter Verschuldungskompetenz zur Verfolgung allokationspolitischer Zwecke; H. Grossekettler in: Grossekettler (Hrsg,) Zwei Beiträge zur finanzwirtschaftlichen Ordnungspolitik, 1994, 1 (15): „gebundenes Trennsystem der Verschuldungspolitik“; zu den politischen und volkswirtschaftlichen Schwierigkeiten der Aufteilung C. Jahndorf (Fn. 148), 246 ff.

157 Wiss. Beirat beim BMF Haushaltskrisen im Bundesstaat, Bd. 78 (2005), $17 \mathrm{ff} .:$ Orientierung am Insolvenzverfahren. Im Hinblick auf die Glaubwürdigkeit einer derartigen Ordnung müsste sichergestellt werden, dass die Verschuldungsgrenzen auch gegenüber politisch mächtigen Ländern durchgesetzt werden können. Nur ein stark formalisiertes Verfahren kann Beeinflussungsversuche unterbinden. Es muss gleichzeitig mit Rechtsschutzinstrumenten versehen werden, um unverhältnismäßige Eingriffe in die Eigenstaatlichkeit der Länder zu verhindern.

158 C. Hillgruber in: v. Mangoldt/Kein/Starck (Hrsg.) GG, 5. Aufl. 2005, Art. 109 Rn. 147.

159 BVerfG v. 19. 10. 2006, www.bundesverfassungsgericht.de.

160 Zuvor BVerfGE 86, 148 (263 ff.); 101, 158 (222). Zur Rechtsprechungsentwicklung Wiss. Beirat beim BMWi Zur finanziellen Stabilität des Deutschen Föderalstaates, 2005, 14 ff.; krit. im Hinblick auf die mangelnde Klarheit der bisherigen Rechtsprechungspra- 
Gericht den ultima ratio-Charakter der Bundeshilfe. ${ }^{161}$ Für eine zukünftige Verschuldungsordnung ist sie aber nur von eingeschränktem Erkenntniswert. Denn das Schuldenproblem der Länder ist unabhängig von individuellen Fehlentscheidungen auch Folge eines Systemfehlers:162 Den Ländern fehlt es einnahmeseitig an tragfähigen Alternativen zur Kreditaufnahme. ${ }^{163}$ Dies ist umso problematischer, als Staatsverschuldung für den Wähler eine abstrakte Größe bleibt. Er reagiert nur auf die aktuelle, individuelle Belastung. Ohne gleichzeitige Stärkung der Steuerautonomie der Länder ${ }^{164}$ bliebe eine Reform des Staatsschulden-

xis H. Siekmann in: M. Sachs (Hrsg.) GG, 3. Aufl. 2003, Art. 107 Rn. 41a; H.-B. Brockmeyer in: Schmidt-Bleibtreu/Klein (Hrsg.) GG, 10. Aufl. 2004, Art. 106 Rn. 2a; s. aber auch M. Jestaedt HStR II, 3. Aufl. 2004, § 29 Rn. 74, der aus der Bundestreue einen verschuldensunabhängigen Anspruch auf Absicherung eines „staatsnotwendigen Existenzminimums“ ableiten will.

161 BVerfG v. 19. 10. 2006, www.bundesverfassungsgericht.de, Tz. 172, zum Zielkonflikt zwischen Autonomie und Hilfeleistung Tz. 187, wobei das Gericht hierauf nicht im Einzelnen eingehen musste, da es bereits den Tatbestand der extremen Haushaltsnotlage verneinte. Konkretisierung der Grenzen s. auch P. Selmer NordÖR 2006, 221 (225): Grenze der drohenden Selbstgefährdung.

162 Neben Steuerautonomie aller mit Ausgabenpflichten belasteten Ebenen bedarf es effektiver Mechanismen zur Anpassung der Aufteilung des vorhandenen Finanzvolumens zwischen den Ebenen, weil andernfalls die Gefahr besteht, dass ohne Not entweder die Gesamtsteuerbelastung oder die Staatsverschuldung erhöht werden. Insofern ist der „bewegliche Puffer“ (K. Stern Staatrecht II, 1980, § 47 III 4a) der einfachgesetzlichen Umsatzsteuerbeteiligung in Art. 106 Abs. 3 S. 3 und 4 GG unverzichtbar.

163 Aufgabenübertragung ohne gleichzeitige finanzielle Kompensation führt geradezu zwangsläufig in die Verschuldung (Wiss. Beirat beim BMF [Fn. 158], 9), wenn steigendem Mittelbedarf weder durch Leistungskürzungen noch durch Steuererhöhungen begegnet werden kann. Die den Ländern zugestandene Steuerertragshoheit ermöglicht nur eine mittelbare, schwer steuerbare Beeinflussung des Finanzvolumens durch Ansiedlungspolitik, H. Zimmermann in: J. Ipsen (Hrsg.) Kommunale Aufgabenerfüllung im Zeichen der Finanzkrise, 1985, 70, s. aber auch BVerfG v. 19. 10. 2006, www.bundesverfassungsgericht.de, Rz. $250 \mathrm{ff}$., zu nicht ausgeschöpften Einnahmemöglichkeiten des Landes Berlin, wobei die Erhöhung des Gewerbesteuerhebesatzes angesichts der Positionierung im innerdeutschen Standortwettbewerb eine kaum realistische Option darstellt.

164 Breit konsentierte Forderung, vgl. etwa Sachverständigenrat zur Begutachtung der gesamtwirtschaftlichen Entwicklung Jahresgutachten 2003/2004, BT-Drucks. 15/2000, 304 Tz. 511 ff.; H. Siekmann in: M. Sachs (Hrsg.) GG, 3. Aufl. 2003, Art. 105 Rn. 56; R. Wendt (Fn. 14), 17 (30f.), der schon heute außerhalb von Art. 106 GG ein Steuererfindungsrecht der Länder annimmt (dagegen M. Küssener [Fn. 92], 55); zurückhaltender, aber ebenfalls zumindest für partielle Steuersatzautonomie der Länder C. Degenhart ZfA 1993, 409 (420); S. Korioth 65. DJT (2004), Teil P, 108 ff.; kritisch im Hinblick auf den Grundsatz der Einheitlichkeit der Besteuerung J. Hidien in: Dolzer/Vogel/ Graßhof (Hrsg.) BK-GG, Art. 106 Rn. 1546. 
rechts unvollständig. ${ }^{165}$ So setzen etwa Sanierungsbeiträge in Form einer Erhöhung der Ländersteuern, ${ }^{166}$ die auch den Bürgern den Ernst der Lage vor Augen führen, entsprechende Steuergesetzgebungsautonomie voraus.

\section{b) Steuergesetzgebung über Ländersteuern}

Im Bereich der als „zentralistischer Scheitelpunkt“167 der Finanzverfassung bezeichneten Steuergesetzgebungskompetenzen besteht zudem der größte Entflechtungsbedarf. 168

Als besonders problematisch gilt, dass der Bund gem. Art. 105 Abs. 2 iVm. Art. 72 Abs. 2 GG die konkurrierende Gesetzgebung auch für die Steuern an sich gezogen hat, deren Aufkommen ausschließlich den Ländern oder Kommunen zusteht. ${ }^{169}$ Einzig für die Festsetzung des Steuersatzes der Grunderwerbsteuer gibt Art. 105 Abs. 2a S. 2 GG jetzt die Kompetenz an die Länder zurück.

Dabei stellt sich bereits aufgrund der geltenden Fassung von Art. 72 Abs. 2 GG $^{170}$ die Frage, ob der Bund - ungeachtet der Sperrwirkung ${ }^{171}$

$165 \mathrm{Zu}$ diesem Zusammenhang auch S. Funke (Fn. 157), 476; J. Wieland JZ 2006, 751 (755); allgemein zum Verhältnis von Kreditaufnahme und Steuererhebung als staatliche Finanzierungsinstrumente H. Siekmann in: M. Sachs (Hrsg.) GG, 3. Aufl. 2002, Vor Art. 104a Rn. 107.

166 Vgl. Wiss. Beirat beim BMF (Fn. 158), 17, 23.

167 S. Korioth 65. DJT (2004), Teil P, 108.

168 Kompromisshaftigkeit und Halbheiten der Steuergesetzgebung werden durch die Vetopositionen der gem. Art. 105 Abs. 3 GG im Bundesrat beteiligten Länder mit oft sehr heterogenen Interessen verschärft ( W. Schwanengel DÖV 2004, 553 (559); S. Oeter (Fn. 14), 513f.). Jedoch ist das viel beklagte Steuerchaos keineswegs nur der Zustimmungspflicht im Bundesrat anzulasten. Die miserable Qualität des Steuerrechts liegt daran, dass sich niemand für das System verantwortlich fühlt, sondern das Steuerrecht als Lenkungsinstrument einerseits, als Finanzierungsinstrument andererseits gesehen wird, nicht aber als Gerechtigkeitsordnung. Bundes- und Landesfinanzministerien agieren als steuergerechtigkeitsferne Haushaltsministerien.

${ }^{169} \mathrm{Zu}$ einer der gängigen Forderungen der Finanzentflechtung gehört deshalb, den Ländern die Steuergesetzgebung für die Steuern einzuräumen, deren Aufkommen ihnen oder den Kommunen ausschließlich zusteht, vgl. R. Scholz FS Badura, 2004, 491 (506); S. Korioth 65. DJT (2004), Teil P, 111 und 65. DJT (2004), Beschluss 32; etwas anders K. Kruis DÖV 2003, 10 (15): Rahmengesetzgebungskompetenz; aA dezidiert R. Mußgnug FS F. Klein, 1994, $651 \mathrm{ff}$. im Hinblick auf die Rechtseinheitlichkeit.

170 Mit restriktiver Interpretation der Erforderlichkeit durch BVerfGE 106, 62 (135ff.); 112, 226 (244ff.); zustimmend zB W. Schwanengel DÖV 2004, 553 (556); kritisch hinsichtlich der Beschneidung der Bundeskompetenzen C. Degenhart ZfA 1993, 409 (415 ff.): Gefahr der Rechtszersplitterung.

171 Möglichkeit der Entsperrung durch das BVerfG nach Art. 93 Abs. 2 GG n. F. 
der bestehenden Bundesgesetze ${ }^{172}$ und notwendiger Anpassungen des Finanzausgleichs - überhaupt noch zur Gesetzgebung über reine Ländersteuern befugt ist. So plausibel es unter Entflechtungsgesichtspunkten klingt, Ertrags- und Gesetzgebungszuständigkeit in eine Hand zu legen, kann diese Frage meiner Ansicht nach jedoch nicht pauschal, sondern nur steuerartenspezifisch ${ }^{173}$ beantwortet werden. Bei Landessteuern auf immobile Steuergegenstände wie der Grundsteuer und Grunderwerbsteuer, bei denen Doppelbesteuerungsprobleme und Steuerwettbewerb von vornherein ausgeschlossen sind, ist eine bundeseinheitliche Regelung nicht erforderlich. ${ }^{174}$ Erforderlich bleibt eine bundeseinheitliche Regelung dagegen in zwei Fällen: Erstens - unter dem Gesichtspunkt gleichwertiger Lebensverhältnisse - für Steuern auf besonders mobile Steuerquellen zur Begrenzung von Steuerwettbewerb, zweitens - unter dem Gesichtspunkt der Rechts- und Wirtschaftseinheit - für Steuern, die an Sachverhalte anknüpfen, welche typischerweise über das gesamte Bundesgebiet hinweg verwirklicht werden. ${ }^{175}$ Das Erfordernis einer bundeseinheitlichen Regelung erstreckt sich dabei zunächst nur auf die Bemessungsgrundlagen. Einheitliche Steuersätze sind zur Wahrung der Einheit der Rechts- und Wirtschaftsordnung

172 Besonders brisant hinsichtlich der außer Kraft getretenen, aber nicht aufgehobenen Vermögensteuer, vgl. hierzu M. Jachmann in: v. Mangoldt/Klein/Starck (Hrsg.) Bonner GG, 5. Aufl. 2005, Art. 105 Rn. 45; H. Siekmann in: M. Sachs (Hrsg.) GG, 3. Aufl. 2003, Art. 105 Rn. 8, 27. ME kann eine verfassungswidrige Steuer die Länder nicht an der Ausübung ihres Gesetzgebungsrechts hindern, es sei denn der Bund habe gerade mit der Nichtaufhebung zum Ausdruck bringen wollen, dass eine Vermögensteuer nicht mehr erhoben werden solle; aA BVerfGE 98, 265 (318ff.): Sperrwirkung verfassungswidrigen Bundesrechts bejaht; zur Frage der Sperrwirkung der Aufhebung von Steuern durch den Bund R. Mußgnug FS F. Klein, 1994, 651 (660ff.): Notwendigkeit einer Verfassungsänderung zur Abschaffung von Ländersteuern durch den Bund.

173 Ausführlich, insb. vor dem Hintergrund von BVerfGE 112, $226 \mathrm{ff}$. (Studiengebühren) J. Hey FS Solms, 2005, 35 (36ff.); ebenso wohl auch M. Jachmann (Fn. 173), Rn. 41; pauschal abgelehnt wird die Erforderlichkeit von J. Lang (Fn. 111), § 3 Rn. 30; zweifelnd auch H. Siekmann in: M. Sachs (Hrsg.) 3. Aufl. 2003, GG, Art. 105 Rn. 21; aA W. Heun in: H. Dreier (Hrsg.) GG, 2000, Art. 105 Rn. 35.

174 Ähnliche Differenzierung zwischen mobilen und immobilen Steuerquellen Sachverständigenrat zur Begutachtung der gesamtwirtschaftlichen Entwicklung Jahresgutachten 2004/05, Tz. 801, allerdings mit der weitergehenden, mE abzulehnenden Empfehlung von Steuererfindungsrechten für die Länder. H.-B. Brockmeyer in: Schmidt-Bleibtreu/ Klein (Hrsg.) GG, 10. Aufl. 2004, Art. 105 Rn. 5, nimmt übrigens bereits heute aufgrund der Formulierung „die übrigen Steuern“ in Art. 105 Abs. 2 GG ein Steuererfindungsrecht der Länder an.

175 Vgl. aber S. Boysen (Fn. 6), $194 \mathrm{ff}$., die bei überregionaler Freiheitsbetätigung sowohl eine Bundeskompetenz kraft Natur der Sache als auch eine Selbstkoordinationspflicht der Länder ablehnt. 
grundsätzlich nicht erforderlich, ${ }^{176}$ sondern allenfalls zur Begrenzung von Steuerwettbewerb. ${ }^{177}$

\section{c) Beibehaltung des Steuerverbundes mit teilautonomer Steuersatzgestaltung der Länder}

Beibehalten werden sollte auch bei einer Reform der Art. 105, 106 GG der Steuerverbund ${ }^{178}$ aus Einkommen-, Körperschaft- und Umsatzsteuer, allerdings flexibilisiert durch Zuschlagsrechte nicht nur für den Bund (s. Art. 106 Abs. 1 Nr. 6 GG), sondern auch für die Länder. ${ }^{179}$ Unter Autonomiegesichtspunkten sind Trennsysteme einem Steuerverbund zwar überlegen, ${ }^{180}$ weil sich hier nicht nur Steuersatz-, sondern auch Bemessungsgrundlagenautonomie verwirklichen lässt. Bei näherer Betrachtung überwiegen jedoch die Nachteile. ${ }^{181}$ Zum einen verspricht die Beteiligung sowohl an indirekten als auch an direkten Steuern eine gröBere Risikostreuung und Aufkommensstabilität. ${ }^{182}$ Zum anderen ziehen

176 Ebenso K. Kruis DÖV 2003, 10 (15).

177 Ein Einschreiten des Bundesgesetzgebers zur Unterbindung von Steuerwettbewerb wäre aber auch hier nur dann i. S. von Art. 72 Abs. 2 GG erforderlich, wenn die Länder sich entweder unfairer Praktiken (identifizierbar anhand des EU-Verhaltenskodex [s. Fn. 46]) bedienen oder der Steuerwettbewerb ein ruinöses Ausmaß annehmen würde und hierdurch das Gebot der bündischen Rücksichtnahme verletzt wird. Auch in diesem Fall ließe sich aber nur die bundeseinheitliche Vorgabe eines Mindeststeuersatzes oder eines Steuersatzkorridors rechtfertigen.

178 Seine Bedeutung erklärt sich daraus, dass rd. 3/4 des Gesamtsteueraufkommens auf die Gemeinschaftssteuern entfallen. Die Ländersteuern i. S. von Art. 106 Abs. 2 GG machen demgegenüber nur einen Anteil von rd. 4,5\% aus.

179 Für die Einführung von Hebesatzrechten auf Einkommen- und Körperschaftsteuer Sachverständigenrat zur Begutachtung der gesamtwirtschaftlichen Entwicklung Jahresgutachten 1990/91, Tz. 454; W. Wiegard(Fn. 44), 19 (29f.); C. Waldhoff Diskussionsbeitrag, 65. DJT (2004), Teil P, 263 f.; R. Soltwedel Die Weltwirtschaft 1987, 129 (137); R. Sturm Föderalismus in Deutschland, 2001, 109; Wiss. Beirat beim BMF (Fn. 43), 103 (163ff.); aA 65. DJT (2004), Teil P, Beschluss 30b.

180 Vor allem unter Ökonomen finden sich Befürworter von Trennsystemen: K.-D. Henke StwStp. 4 (1993), 10 (11f.; 14f.); ders. StwStp. 6 (1995), 643 ff.; Lenk/Schneider Jahrbücher für Nationalökonomie und Statistik 1999, 409 ff.; K. Littmann StwStp. 2 (1991), 31 (35ff.); Ottnad/Linnartz Föderaler Wettbewerb statt Verteilungsstreit, 1996, 194 ff; für eine Auflösung des Steuerverbundes ferner R. Scholz FS Badura, 2004, 491 (506): Länder ESt/KSt/ErbSt/KfzSt; Bund MwSt/MinölSt, Tabak-/Alkoholsteuern; H. Hofmann ZRP 1999, 465 (468).

${ }^{181}$ So wohl hM, vgl. etwa W. Wiegard (Fn. 44), 19 (29); zT noch weitergehende Bedenken bei K. Tipke StRO III, 1993, 1088 ff.; S. Korioth (Fn. 10), 426ff.; J. Lang (Fn. 111), $\S 3 \mathrm{Rn} .5$.

${ }^{182}$ Gegen eine Auflösung des Steuerverbundes spricht vor allem, dass das relative Gewicht der einzelnen Gemeinschaftssteuern im internationalen Steuerwettbewerb er- 
Trennsysteme einen derart hohen Selbstkoordinationsbedarf ${ }^{183}$ in Form von Harmonisierungsmaßnahmen nach sich, dass sich der Autonomiegewinn letztlich nicht realisiert. Demokratiewirksame Einnahmeautonomie lässt sich zudem auch im Steuerverbund verwirklichen. Ein $\mathrm{Zu}$ schlagsrecht ${ }^{184}$ auf die bundeseinheitliche Bemessungsgrundlage der Einkommensteuer würde die Kosten der Landespolitik für die breite Masse aller einkommensteuerpflichtigen Wähler erfahrbar machen. ${ }^{185}$ Eine Flexibilisierung des Körperschaftsteuersatzes sollte dagegen allenfalls innerhalb ganz enger Grenzen vorgesehen werden, um die Probleme des europäischen Steuerwettbewerbs nicht auf das Inland zu übertragen.

Einen echten Entflechtungsbeitrag könnte ein Zuschlagsmodell nur dann leisten, wenn gleichzeitig auf die in Art. 105 Abs. 3 GG angeordnete Zustimmungspflicht bezüglich der bundesgesetzlichen Ausgestal-

heblichen Veränderungen unterliegt, so dass die notwendige Einnahmestabilität nur bei Beteiligung von Bund und Ländern an direkten und indirekten Steuern gewährleistet ist.

${ }^{183}$ Harmonisierungsprojekte wie die Vereinheitlichung der Schweizer Kantonsteuern (Bundesgesetz über die Harmonisierung der direkten Steuern der Kantone und Gemeinden v. 14. 12. 1990, SR 642.14) oder die US-amerikanische Multistate Tax Commission (dazu Hildreth/Murray/Sjoquist National Tax Journal 2005, $575 \mathrm{ff}$.) belegen, dass auch in gestuften Rechtsordnungen mit ausgeprägter Finanzautonomie und Trennsystemen zur Komplexitätsreduktion Vereinheitlichung angestrebt wird. Vgl. auch die positive Beurteilung der Vereinheitlichung des vormals zersplitterten Grunderwerbssteuerrechts durch A. Pahlke in: Pahlke/Franz (Hrsg.) GrEStG, 3. Aufl. 2005, Einleitung Rn. 3 f.; P. Möllinger DVR 1985, 18. Gegen eine Verfassungspflicht zur Harmonisierung W. Rudolf HStR IV, § 105 Rn. 82.; Rudolf/Jutzi ZRP 1987, 2 ff.

${ }^{184} \mathrm{Zu}$ den unterschiedlichen Ausgestaltungsmöglichkeiten von Zuschlagsrechten Überblick bei I. Kesper (Fn. 47), $338 \mathrm{ff}$; S. Korioth (Fn. 10), $349 \mathrm{ff}$.; Wiss. Beirat beim $B M F$ (Fn. 43), 103 (168ff.) mit Vorschlägen zu einer zwischen Lohnsteuer, Kapitalertragsteuer, veranlagter Einkommensteuer und Körperschaftsteuer differenzierenden Lösung. Ein Landeszuschlag auf die Umsatzsteuer wäre zwar wohl mit Art. 33 der 6. MwSt-RL vereinbar, würde aber zu einer erheblichen Komplizierung des Systems des Vorsteuerabzugs führen. Denkbar wäre aber eine Landesverbrauchsteuer als einphasige Einzelhandelssteuer, vgl. W. Birkenfeld Mehrwertsteuer der EU, 5. Aufl. 2003, 156.

185 I. Kesper (Fn. 47), 338; J. Hinnendahl Die Steuerverteilung zwischen Bund und Ländern in der Bundesrepublik Deutschland, 1973, 179. Die - zusätzlich einzuräumende - Steuersatzautonomie im Bereich der Ländersteuern wird dem Postulat der Merklichkeit dagegen nur begrenzt gerecht. Das neue Steuersatzbestimmungsrecht für die Grunderwerbsteuer (Art. 106 Abs. 2 Nr. 4 i.V.m. Art. 105 Abs. 2a S. 2 GG) erreicht nur den kleinen Ausschnitt der grundbesitzenden Wähler. Auch Erbschaft- und Vermögensteuer (Art. 106 Abs. 2 Nr. 1 und 2 GG) werden bei der verfassungsrechtlich gebotenen freiheitsschonenden Ausgestaltung mit hohen Freibeträgen nur für eine kleine Gruppe fühlbar. Ob Kfz-, Feuerschutz-, Rennwett-, Lotterie- und Biersteuer (Art. 106 Abs. 2 Nr. 3, 4, 5 GG) das Wahlvolk zu mobilisieren in der Lage sind, scheint ebenfalls eher zweifelhaft. 
tung der Bemessungsgrundlagen verzichtet würde. Dies ist jedoch unabhängig von der Ansiedlung der Verwaltungskompetenz - kaum vorstellbar. Zwar liegt das entscheidende Moment der Finanzautonomie in der Möglichkeit der Beeinflussung der Höhe der Einnahmen über den Steuersatz. ${ }^{186}$ Jedoch birgt die Festlegung der Bemessungsgrundlage durch Normierung von Steuervergünstigungen erhebliches Gestaltungspotential mit Aufkommensrelevanz für die Länder. Und umso mehr muss die Mitwirkung der Länder erhalten bleiben, wenn der Bundesgesetzgeber vermittels der steuerlichen Lenkungsnorm in fremde Sachkompetenzen eindringt. ${ }^{187}$

\section{Bundessteuerverwaltung}

Den verflechtungsspezifischen Mängeln im Bereich der Finanzverwaltung kann nur durch stärkere Zentralisierung wirkungsvoll begegnet werden. Trotz diverser Einwirkungsrechte des Bundes, ${ }^{188}$ etwa durch BMF-Schreiben, ${ }^{189}$ und komplexer Verfahren der Selbstkoordination der Länder mit einer Flut gleich lautender Ländererlasse wird die Gleichmäßigkeit der Gesetzesanwendung im Bundesgebiet nicht erreicht, ${ }^{190}$ zumal die Länder wenig Anreiz zur Effektuierung des Steuervollzugs haben, weil landesspezifische Durchsetzungsmängel durch den Finanzausgleich kompensiert werden. ${ }^{191}$ Beim derzeitigen Stand bun-

186 AA J. Lattmann Diskussionsbeitrag, 65. DJT (2004), Band II, Teil P, 266: Bemessungsgrundlagenautonomie.

187 In diesem Sinne auch F. Kirchhof VVDStRL 52 (1993), 71 (99); vgl. auch BVerfGE 98, 106, wo das Gericht die Frage, ob für die Normierung der mit Lenkungsnormen verfolgten Sachzwecke zusätzlich zur Steuergesetzgebungszuständigkeit die Sachkompetenz zu fordern ist, allerdings verneint hat.

188 Umfassend dazu J. Bonsels Einwirkungs- und Mitwirkungsrechte des Bundes bei der Verwaltung der Steuern durch die Länder, 1995. Dabei versagt das Zeiterfordernis des mehrseitig-konsensualen Zustandekommens der BMF-Schreiben (Steuerungsinstrument eigener Art, vgl. R. Seer (Fn. 190). § 22 Rn. 36; aA [allgemeine Weisungen]: Müller/Zeitler DStZ 1975, 467 [474]; A. Uelner FS Friauf, 1996, 217 [225]) den Steuerbürgern die vor allem nach Gesetzesänderungen dringend benötige Planungssicherheit.

189 Die Einfügung von § 21a FVG (Föderalismus-Begleitgesetz v. 5. 9. 2006, B GB1. I, 2098) soll - allerdings ohne Anpassung von Art. 108 Abs. 7 GG - die Praxis der in Bund-Länder-Kooperation ergehenden Schreiben des BMF gesetzlich absichern.

190 Vgl. die kontinuierlichen Beanstandungen durch den Bundesrechnungshof, bereits BT-Drucks. VI/559, 31 f.; BT-Drucks. 10/223, $111 \mathrm{ff}$. und aktuell Präsident des Bundesrechnungshofes Probleme beim Steuervollzug, 2006.

191 Krit. zur geltenden Praxis zT bewusster Nachlässigkeit im Vollzug zur Schwächung der eigenen Finanzkraft A. Dittmann FS Dürig, 1990, 221 (234); aus diesem Grund für einen Übergang vom Finanzkraftausgleich zu einem Wirtschaftskraftaus- 
deseinheitlicher Steuergesetze spricht daher vieles für eine Änderung von Art. 108 Abs. 2 und 3 GG $^{192}$ und eine Bundessteuerverwaltung. ${ }^{193}$ Aber auch Hebesatzrechte der Länder stünden bei weiterhin einheitlichen Bemessungsgrundlagen einer deutlich stärkeren Rolle des Bundes bei der Finanzverwaltung nicht im Wege. ${ }^{194}$

\section{Notwendige Anpassungen des Finanzausgleichs}

Die Bedeutung des als komplex, undurchschaubar und streitanfällig 195 kritisierten ${ }^{196}$ deutschen Finanzausgleichs erklärt sich nicht zuletzt aus der Konzentration der Steuergesetzgebungshoheit beim Bund. ${ }^{197}$ Dort wo eine finanzautonome Körperschaft die Steuern erhöhen würde, um eine vorübergehende Haushaltsschieflage zu bekämpfen, bedarf es ohne entsprechende Gestaltungsmöglichkeiten finanzieller Zuweisungen.198 Gleichzeitig rückt der auch nach Inkrafttreten des Finanzausgleichsgesetzes $2005^{199}$ weiterhin hohe Nivellierungsgrad das verschachtelte Fi-

gleich Sachverständigenrat zur Begutachtung der gesamtwirtschaftlichen Entwicklung Jahresgutachten 2004/05, Tz. $801 \mathrm{f}$.

${ }_{192}$ Der als Ausnahmevorschrift konzipierte Art. 108 Abs. 4 Satz 1 GG ermöglicht zwar schon heute die Übertragung des Vollzugs von Landesgesetzen auf den Bund (V. Schlette in: v. Mangoldt/Klein/Starck [Hrsg.] Bonner GG, 5. Aufl. 2005, Art. 108 Rn. 83), trägt allerdings keine Umkehr der in den Absätzen 2 und 3 normierten Landeszuständigkeiten, zutr. R. Seer in: Dolzer/Vogel/Graßhof (Hrsg.) BK-GG, Art. 108 Rn. 117.

193 Jetzt eindringlich der Präsident des Bundesrechnungshofs (Fn. 191), 181 ff., für die Verwaltung der Gemeinschaftssteuern; ferner H. Vogel (Fn. 117), 293 ff.; gescheitert ist die Gesetzesinitiative der FDP v. 22. 5. 1951, BT-Drucks. 1/2260 (mit Sachverständigengutachten in Anlage zu BT-Drucks. 1/4300, $1 \mathrm{ff}$.); s. ferner $G$. Wacke FinArch. n.F. $1950 / 51,713 \mathrm{ff}$.

${ }^{194}$ So erhebt in Kanada der Bund in der Regel die Steuern für die Provinzen, wenn diese die gleiche Bemessungsgrundlage anwenden oder ihr Besteuerungsrecht als Zuschlag auf die Bundesteuerschuld wahrnehmen, vgl. Boadway/Hobson Intergovernmental Fiscal Relations in Canada, 1993, $51 \mathrm{ff}$.

195 Vgl. nur die drei grundlegenden BVerfG-Entscheidungen BVerfGE 72, 330; 86, $148 ; 101,158$.

196 Umfassender Überblick über Kritik und Reformdebatte bei J. Hidien in: Dolzer/ Vogel/Graßhof (Hrsg.) BK-GG, Stand 2002, Art. 106 Rn. $1532 \mathrm{ff}$.

197 H. P. Bull DÖV 1999, $275 \mathrm{f}$.

198 BVerfGE 101, 158 (225) bleibt die Antwort, wie - außer durch Erhöhung der Verschuldung - „eine kurzfristige Finanzschwäche selbst zu überbrücken“ ist, schuldig.

199 Die Reaktion auf BVerfGE 101, 158, ist letztlich bescheiden ausgefallen (B. Grzeszick in: Maunz/Dürig (Hrsg.) GG, Art. 20 IV Rn. 195); vgl. § 7 Abs. 2 FAG 2005: Bei überdurchschnittlicher Entwicklung der Steuereinnahmen Kürzung um maximal 12\%; $\S 11$ Abs. 2 FAG 2005: Grenze für Ergänzungszuweisungen bei lediglich 77,5\% des zur Erreichung von 99,5\% der Ausgleichszahl erforderlichen Ausgleichsbetrags. 
nanzausgleichsgebäude in die Nähe eines Überweisungssystems und entwertet die Steuerertragshoheit der Länder.

Erhalten die Länder Steuersatzautonomie, muss für Zwecke des Finanzausgleichs statt auf die vereinnahmten Steuern auf die Steuerkraft, d.h. das Aufkommenspotential (Soll-Aufkommen), abgestellt werden, ${ }^{200}$ wie dies für die Grunderwerbsteuer in Art. 107 Abs. 1 S. 4, letzter Hs. GG n.F geschehen ist. Ausgleichsansprüche können erst dann entstehen, wenn ein Land seine Steuerquellen ausgeschöpft hat. ${ }^{201}$

$\mathrm{Ob}$ gleichzeitig auch das Angleichungsniveau reduziert wird,202 um den Länderfinanzausgleich gerade im Hinblick auf den zu begrüßenden außersteuerlichen Standortwettbewerb insgesamt anreizfreundlicher auszugestalten, ${ }^{203}$ hängt davon ab, welche Bedeutung man einer Stärkung der Sach- und Finanzautonomie der Länder beimisst. Zwischen den Eckpfeilern der zur autonomen Wahrnehmung der Sachkompetenzen erforderlichen Mindestausstattung ${ }^{204}$ und dem Nivellierungsverbot $^{205}$ sind seitens der Verfassung bezifferbare Vorgaben, etwa im Sinne eines finanzausgleichsrechtlichen Halbteilungsgrundsatzes, ${ }^{206}$ nicht er-

200 BVerfGE 86, 148 (217); W. Heun Der Staat 1992, 205; R. Mußgnug JuS 1986, 872 (879).

201 Der einfache Gesetzgeber hat es in der Hand, durch entsprechende Festlegung normierter Einnahmen anhand von fiktiven Steuersätzen die Steuersatzunterschiede und damit den Steuerwettbewerb zwischen den Ländern zu regulieren, s. G. Färber (Fn. 43), 69 (71, 78); zur Anwendung gestaffelter fiktiver Hebesätze im Rahmen des kommunalen Finanzausgleichs als Verfassungsgebot s. P. Kirchhof DVB1. 1980, 711 (718); für die Grunderwerbsteuer jetzt $\S 5$ Abs. 1 Satz $2 \mathrm{MaßstG:} \mathrm{Länderdurchschnitt.}$

202 Zurückhaltend J. Wieland JZ 2006, 751 (756): einer „fühlbaren“ Absenkung des Ausgleichsniveaus stehe die Geschichte der unitarischen Ausgestaltung der Bundesrepublik Deutschland entgegen.

${ }^{203}$ Hierfür Sachverständigenrat, Jahresgutachten 2004/05 (Fn. 175): Absenkung auf $60 \%$.

204 Dabei darf sich die Mindestausstattung nicht allein an den übertragenen Aufgaben orientieren, sondern muss ausreichend Spielraum für die Verfolgung eigener politischer Ziele lassen, vgl. BVerfGE 86, 148 (213f.); K.-A. Schwarz in: v. Mangoldt/Klein/Starck (Hrsg.) Bonner GG, 5. Aufl. 2005, Art. 106 Rn. 109; ders. ZKF 2000, 1 (5); J. Popitz Der künftige Finanzausgleich zwischen Reich, Ländern und Gemeinden, 1932, $12 \mathrm{ff}$. Dabei sollte jedoch - unter der Prämisse, dass jeder Gliedstaat seine Einnahmen autonom beeinflussen kann - die Verfolgung eigener politischer Ziele vorrangig aus eigenen Steuermitteln finanziert werden.

205 Vgl. BVerfGE 1, 117 (131); 72, 330 (398); 101, 158 (222); BVerfG v. 19. 10. 2006, www.bundesverfassungsgericht.de, Tz. 177; U. Häde (Fn. 9), 238 ff.; S. Korioth (Fn. 10), 611 ff.; A. Leisner-Egensperger (Fn. 59), 114.

206 Vgl. Arndt/Schumacher NJW 1995, 2603 (2604); zu Recht krit. hinsichtlich der Übertragbarkeit eines etwaigen grundrechtlichen Halbteilungsgrundsatzes auf die staatsorganisationsrechtliche Ausgestaltung des Finanzausgleichs H. P. Bull NJW 1996, 
kennbar. ${ }^{207}$ Konkretisierungen können allenfalls aus der Finanzverfassung selbst gewonnen werden. Entscheidet sich der Verfassungsgeber für die Ausstattung der einzelnen Ebenen mit Steuergesetzgebungs- und Steuerertragshoheit, ist es ein Gebot der Widerspruchsfreiheit, dass der Finanzausgleich einen hinreichenden Abstand zu einem reinen Zuweisungssystem wahrt.

\section{Länderneugliederung und -sanierung als Vorbedingung einer sinnvollen Reform der Finanzverfassung?}

Stärkung der Finanzautonomie der Länder - ohne Länderneugliederung? Vielfach wird dies für nicht möglich gehalten. ${ }^{208}$ Neugliederung als conditio sine qua non einer Reform der Finanzverfassung würde freilich sämtlichen Reformbemühungen ein schnelles Ende bereiten.

Denn eine planmäßige Länderneugliederung 209 in wirtschaftlich ungefähr gleich starke Gebiete, so sinnvoll sie in Verbindung mit einem egalisierenden Entschuldungskonzept ${ }^{210}$ für einen chancengleichen Start in den föderalen Wettbewerb wäre, ${ }^{211}$ wird es nicht geben. ${ }^{212}$ Und zwar

281; ders. DÖV 1999, 269 (276); J.-P. Schneider in: Denninger/Hoffmann-Riem/Schneider/Stein (Hrsg.) Alternativkommentar zum GG, 3. Aufl. 2001, Art. 105 Rn. 25; P. Helbig (Fn. 5), $34 \mathrm{ff} ., 222 \mathrm{ff}$.

207 Vgl. auch J.-P. Schneider Der Staat 2001, 272 (292), der zu Recht die diesbezügliche Zurückhaltung des Bundesverfassungsgerichts lobt, vgl. BVerfGE 1, 117 (134): keine verfassungsrechtliche, sondern eine finanzpolitische Frage; BVerfGE 101, 158 (238): Finanzverfassung enthält keine unmittelbar vollziehbaren Maßstäbe, sondern verpflichtet den Gesetzgeber.

${ }^{208}$ Siehe den - allerdings vage gehaltenen - Hinweis auf eine Neugliederung in BVerfGE 1, 117 (134); 86, 148 (270); ferner M. Kloepfer DÖV 2004, 566 (571): Ohne Länderneugliederung keine grundlegende Bundesstaatsreform; J. J. Hesse in: T. Büttner (Hrsg.) Finanzverfassung und Föderalismus in Deutschland und Europa, 2000, 9 (15ff.); W. Göke ZG 2006, 1 (23): Länderneugliederung als Schlüssel zum Ausweg aus der Schuldenfalle; J. Wieland FS Selmer, 2004, 973 (975); H.-W. Arndt Wirtschaftsdienst 1998, 76; U. Leonardy ZParl 1999, 135 (136ff.); noch weitergehend: W. Erbguth in: M. Sachs (Hrsg.) GG, 3. Aufl. 2003, Art. 29 Rn. 73 ff.; R. Timmer FS Ernst, 1980, 463: Neugliederung ist notwendig zur Sicherung des Überlebens des föderativen Systems; zu den Zusammenhängen zwischen Gemeinschaftsaufgaben und Neugliederung I. v. Münch VVDStRL 31 (1973), 51 (58).

209 In diese Richtung H. Hohmann DÖV 1991, 191 (197f.).

210 Zum Problem unterschiedlicher Anfangsausstattung J.-P. Schneider Der Staat 2001, 272 (290); F. W. Scharpf MPIfG Working Paper 99/3, $11 \mathrm{f}$.

211 W. Göke Der Staat 2006, 1 (23); J. Isensee in: K. Bohr (Hrsg.) Föderalismus, 1992, 139 (142ff.); M. Haedrich ThürVBl. 1992, 97 (99f.); Stamm/Merkl ZRP 1998, 467 (475).

212 Dezidiert gegen eine finanzverfassungsrechtliche Neugliederungspflicht $S$. Oeter (Fn. 14), 574 ff.; A. Leisner-Egensperger (Fn. 59), 116; gegen eine Zwangsfusion zur Be- 
nicht nur wegen des jetzigen Zuschnitts von Art. 29 GG, der sich ändern ließe, sondern vor allem weil sie den Frieden im Bundesstaat ernsthaft gefährden könnte. Gerade eine Finanzverfassungsreform beinhaltet jedoch die Chance, den Druck auf freiwillige Länderneugliederungen oder doch zumindest Kooperationen ${ }^{213}$ zu erhöhen. ${ }^{214}$ Art. 29 Abs. 2 GG macht die Neugliederung in einer für die repräsentative Demokratie unüblichen Weise von der unmittelbaren Entscheidung des Volks abhängig. ${ }^{215}$ Gleichzeitig manipuliert die heutige Finanzverfassung den Wählerwillen, indem sie ihm einseitig nur den vermeintlichen Nutzen, nicht die Kosten der bestehenden Strukturen vor Augen hält. ${ }^{216}$ Verschuldungsverantwortung und Steuerautonomie der Länder sowie der Verzicht auf die Berücksichtigung der Sonderlasten der Kleinheit ${ }^{217}$ im Finanzausgleich könnten die Kostentransparenz und damit auch die Bereitschaft zur Überwindung überkommener Strukturen erhöhen. ${ }^{218}$

\section{Steuerautonomie als Chance für die fünf neuen Länder?}

Die Situation der fünf neuen Länder bleibt prekär; ihnen hülfe auch eine Länderneugliederung nicht. Alle Transfers der letzten 16 Jahre haben dem deutschen Osten nicht aus der andauernden Wirtschafts- und

wältigung von Haushaltskrisen auch Wiss. Beirat beim BMF(Fn. 158), 15; W. Däubler FS Mahrenholz, 1994, 455 (469); H. P. Bull DÖV 1999, 269 (281): Forderung nach Zusammenlegung finanzschwacher Länder durch die finanzstarken Länder als ,grobe Verletzung der Bundestreue"; für eine zwangsweise Neugliederung dagegen Ottnad/Linnartz (Fn. 181), $175 \mathrm{ff}$.

213 Vgl. Scharpf/Benz Kooperation als Alternative zur Neugliederung, 1991.

${ }^{214}$ Der von BVerfGE 55, 274 (300); 72, 330 (388), aufgestellten verfassungsrechtlichen Pflicht zur Unterhaltung und finanziellen Unterstützung der Länder in ihrem aktuellen Zuschnitt, steht $\mathrm{mE}$ die Heranziehung der Nutznießer, dh der Bevölkerung, zur Finanzierung nicht entgegen. A. A. P. Selmer VVDStRL 52 (1993), 10 (61), der Finanzausgleich müsse sich dem status quo der Ländergliederung anpassen und nicht umgekehrt; ebenfalls aA P. Lerche FS Berber, 1973, 299 (310ff.); P. M. Huber in: Mangoldt/ Klein/Starck (Hrsg.) Bonner GG, 5. Aufl. 2005, Art. 107 Rn. 30; ders. Deutschland in der Föderalismusfalle, 2003, $19 \mathrm{ff} . ;$ T. Christmann DÖV 2000, 315 (320): „Finanzausgleich ist kein taugliches Vehikel zur Länderneugliederung“.

215 Hierzu J. Dietlein in: Dolzer/Vogel/Graßhof (Hrsg.) BK-GG, Art. 29 Rn. 24.

${ }^{216}$ H.-B. Brockmeyer in: Schmidt/Bleibtreu/Klein (Hrsg.) Kommentar zum GG, 10. Aufl. 2004, Art. 107 Rn. 2a.

217 P. M. Huber in: v. Mangoldt/Klein/Starck (Hrsg.) Bonner GG, 5. Aufl. 2005, Art. 107 Rn. 154 ff.; W. Heun in: H. Dreier (Hrsg.) GG, 2000, Art. 107 Rn. 35; H.-B. Brockmeyer in: Schmidt/Bleibtreu/Klein (Hrsg.) Kommentar zum GG, 10. Aufl. 2004, Art. 107 Rn. 2a.

218 Allerdings würde einem Zusammenschluss unterschiedlich wirtschaftsstarker Länder wohl die Bevölkerung des Stärkeren im Bunde die Gefolgschaft versagen. 
Finanzschwäche helfen können,219 die Peter Selmer 1992 als Hinderungsgrund galt, die Länder in mehr Steuerautonomie zu entlassen. ${ }^{220}$

Doch vielleicht ist es - nachdem die Transfer-Rezepte der Vergangenheit wenig gefruchtet haben - an der Zeit, es stattdessen mit wettbewerblichen Instrumenten zu versuchen. Zwar würde Steuerautonomie allein die neuen Länder noch nicht in die Lage versetzen, den Zugewinn an Gestaltungsmöglichkeiten als Instrument des Standortwettbewerbs einzusetzen. ${ }^{221} \mathrm{Zu}$ stark wird das Ausgabenniveau, insbesondere der Sozialleistungen, nach wie vor vom Bund determiniert. Die seit der Wiedervereinigung erreichte Angleichung im staatlichen Leistungsniveau lässt sich nicht mehr zurückdrehen. Stattdessen könnte die Steuerautonomie aber zunächst in einer Weise durch den Finanzausgleich flankiert werden, die es den ostdeutschen Ländern ermöglicht, in einem gewissen Rahmen Steuerdumping zu betreiben, um Unternehmensansiedlungen $\mathrm{zu}$ forcieren. Rechtstechnisch bedürfte es hierfür der Festlegung zwischen Ost und West differenzierender Normsätze für die Bemessung der finanzausgleichsrelevanten Steuerkraft. Zudem müsste eine derart über den Finanzausgleich subventionierte Ausübung der Finanzautonomie wohl durch die EU-Kommission beihilferechtlich genehmigt werden. ${ }^{222}$

219 Nach wie vor sind die neuen Länder von der Sonderförderung des Solidarpaktes II abhängig ( 11 Abs. 3 FAG 2005). Trotz der im Zeitraum 1990 - 2004 geleisteten Transfers in Höhe von 1,2 Billionen Euro bleiben die neuen Länder strukturschwach, haben mit überdurchschnittlich hoher Arbeitslosigkeit zu kämpfen und liegen in ihrer Finanzkraft weit zurück (Überblick Berthold/Fricke/Drews/Vehrkamp Die Bundesländer im Standortwettbewerb, 2003). Das um Transfereinkommen bereinigte Bruttoinlandsprodukt pro Einwohner erreicht selbst in den wirtschaftsstärkeren Regionen Ostdeutschlands nur rd. $55 \%$ des westdeutschen Durchschnitts, vgl. J. Ragnitz Wirtschaft im Wandel 2005, 134ff. Das Pro-KopfSteueraufkommen der fünf neuen Länder liegt bei lediglich $38 \%$ des Westniveaus. Besorgniserregend ist vor allem die Stagnation. Die Finanzkraft der neuen Länder verharrt seit 1995 auf nahezu gleich bleibend niedrigem Niveau (1995: 25225 Mio. Euro; 2005: 25424 Mio. Euro). Der leichte Anstieg ist allein dem Zuwachs des Landes Brandenburg zu verdanken (zum Vergleich s. die Entwicklung der Finanzkraft West: 1995: 142208 Mio. Euro; 2004: 155263 Mio. Euro). Gleichzeitig ist der Gesamtstaat nicht nur, aber auch über den Wiederaufbau Ost insgesamt in eine haushaltspolitische Schieflage geraten.

${ }^{220}$ P. Selmer VVDStRL 52 (1993), 66 (Leitsatz 15); ebenso J. Hidien in: Dolzer/ Vogel/Graßhof (Hrsg.) BK-GG, Art. 106 Rn. 1543.

${ }^{221}$ Dies erklärt, warum die ostdeutschen Kommunen bisher nicht in der Lage waren, ihre Hebesatzautonomie im Rahmen der Gewerbesteuer als Wettbewerbsinstrument einzusetzen. Zum einen mussten sie ein hohes Ausgabenniveau finanzieren, zum anderen wäre die Grundsteuer als einzige weitere Stellschraube nicht in der Lage gewesen, die (anfänglichen) Steuerausfälle aufzufangen.

222 Zur Zulässigkeit steuerlicher Sonderzonen in einzelnen Mitgliedstaaten s. C. Pinto Intertax 1998, 386 (403ff.); s. ferner grundlegend die Schlussanträge des Generalanwalts Geelhoed v. 20. 10. 2005, Rs. C-88/03. 


\section{Neuordnung der Kommunalfinanzen}

Obwohl die Kommunen als durch die Länder mediatisierte ${ }^{223}$ Selbstverwaltungseinheiten der Eigenstaatlichkeit einer gleichrangigen dritten Ebene $^{224}$ entbehren, verfügen sie derzeit über mehr Steuergesetzgebungsautonomie als die Länder, die den Gemeinden sogar das einzige ihnen grundgesetzlich ausschließlich zugewiesene Kompetenzfeld der örtlichen Verbrauchs- und Aufwandsteuern überlassen haben. ${ }^{225}$ Dennoch indiziert die in steigenden Kassenkrediten ${ }^{226}$ und sinkenden Investitionen widergespiegelte notorische Finanzknappheit ${ }^{227}$ der Kommunen Schwächen des Systems.228

Soweit die Kommunen in der Vergangenheit wehrlos der Überbürdung kostenträchtiger Aufgaben durch Bund und Länder ausgesetzt waren, hat sich ihre Situation sowohl durch Verschärfung der landesverfassungsrechtlichen Konnexitätsgrundsätze ${ }^{229}$ als auch durch die Einfügung des Durchgriffsverbots ${ }^{230}$ in Art. 85 Abs. 1 S. 2 GG n.F. verbessert. ${ }^{231}$

${ }^{223}$ Mangels eigener Einwirkungsrechte im Gesetzgebungsverfahren sind die Kommunen darauf angewiesen, dass die Länder ihre Interessen gegenüber dem Bund vertreten. Allerdings darf die institutionelle Schwäche der Kommunen nicht mit politischer Machtlosigkeit verwechselt werden. Die Gemeinden artikulieren ihre Interessen sehr wirkungsvoll über die kommunalen Spitzenverbände. Die starke kommunalpolitische Verwurzelung der Abgeordneten in Bundes- und Länderparlamenten sorgt für ausreichendes Gehör und parteiübergreifende Interessenbünde.

${ }^{224}$ Siehe allerdings $P$. M. Huber in: v. Mangoldt/Klein/Starck (Hrsg.) Bonner GG, 5. Aufl. 2005, Art. 107 Rn. 35, der aus der Neufassung von Art. 28 Abs. 2 GG folgert, die Kommunen hätten sich aus dem Schatten der Länder zu einer dritten Ebene im verfassungsrechtlichen Finanzverbund emanzipiert; zur kommunalen Finanzautonomie s. S. Schmitt Inhalt, verfassungsrechtliche Stellung und Bedeutungsgehalt der kommunalen Finanzautonomie, 1996.

225 Entsprechend der Intention des Verfassungsgebers, vgl. BT-Drucks. V/2861, 87.

226 Vgl. A. Faber in: Henneke/Pünder/Waldhoff (Hrsg.) Recht der Kommunalfinanzen, 2006, § 34 Rn. 3; Gemeindefinanzbericht 2005 in: Der Städtetag 5/2005: Kassenkredite aller Kommunen 2005: 23,7 Mrd. Euro. Anstieg seit Anfang 2000 um 17,5 Mrd. Euro.

227 Vgl. Gemeindefinanzbericht 2005 in: Der Städtetag 5/2005.

228 E. Schmidt-Jortzig Diskussionsbeitrag, 65. DJT (2004), Teil P, 271.

${ }^{229} \mathrm{Vgl}$. zu den in Bayern und Nordrhein-Westfalen daneben eingeführten Konsultationsverfahren, die allerdings keinen Beitrag zur Entflechtung darstellen, H.-G. Henneke in: Henneke/Pünder/Waldhoff (Hrsg.) Das Recht der Kommunalfinanzen, 2006, § 4 Rn. $11 \mathrm{ff}$.

230 Zur Neuregelung H.-G. Henneke DVB1. 2006, 867 (869); zuvor zur Verfassungsmäßigkeit des Durchgriffs BVerfGE 22, 180 (209f.); 75, 108 (150); 77, 288 (299).

231 Dazu im Einzelnen H.-G. Henneke in: Henneke/Pünder/Waldhoff (Hrsg.) Das Recht der Kommunalfinanzen, 2006, § 4 Rn. 2 ff. 
Dringlicher ist die Reform der Einnahmeseite. ${ }^{232}$ Das geltende System der Gemeindefinanzierung mit der Gewerbesteuer als Hauptfinanzierungsquelle verstößt gegen nahezu jeden Grundsatz eines rationalen dezentralen Steuersystems. ${ }^{233}$ Die Gewerbesteuer ${ }^{234}$ verletzt die Grundsätze der Gleichheit und Allgemeinheit der Besteuerung, erreicht nur einen schmalen Ausschnitt des kommunalen Wahlvolks und taugt in ihrer heutigen Gestalt als Großbetriebsteuer noch nicht einmal als Band zwischen Wirtschaft und Kommune, begründet vielmehr nicht selten eine fatale Abhängigkeit von einem einzigen Großunternehmen. Überdies ist das Aufkommen der Gewerbeertragsteuer in besonderem Maße konjunkturreagibel und stützt sich auf mobile Unternehmensgewinne, die nicht nur interkommunalem, sondern auch internationalem Wettbewerb unterliegen. ${ }^{235}$ Entsprechend volatil ist das Gewerbesteueraufkommen, obwohl gerade die Gemeinden aufgrund kommunalrechtlicher Kreditaufnahmerestriktionen ${ }^{236}$ ein besonderes Stetigkeitsbedürfnis haben.

Gleichzeitig ist die Gewerbesteuer ein Extrembeispiel der Verflechtung und Intransparenz, indem einerseits durch die Gewerbesteuerumlage Bund und Länder, durch die Kreisumlage die Kreise ${ }^{237}$ am Erfolg kommunaler Steuerpolitik partizipieren, andererseits über die seit 2001 geltende pauschale Anrechnung der Gewerbesteuer auf die Einkommensteuer ein paraverfassungsrechtlicher Finanzausgleich installiert wurde, 238 nicht staatsintern, sondern offen unter Heranziehung der Steuerbürger zu Ermittlungs- und Entrichtungsdiensten. Schließlich

232 Überblick zum Reformbedarf bei H.-G. Henneke (Fn. 233) § 4 Rn. $72 \mathrm{ff}$.

${ }^{233} \mathrm{Zu}$ den Anforderungen an das kommunale Steuersystem s. P. Bohley Die Öffentliche Finanzierung, 2003, $460 \mathrm{ff}$.

${ }^{234}$ Die Kritik an der Gewerbesteuer ist Legion, vgl. mit zahlreichen Nachweisen K. Tipke StRO II, 2. Aufl. 2003, 1132 ff. sowie die Vorlagen des Nieders. FG, EFG 1997, 1456 (zurückgewiesen durch BVerfG, BStBl. II 1999, 509) und FR 2004, 907; 2005, 690.

235 Dies führt angesichts des hohen Anteils der Gewerbesteuer (12-14\%) an der Gesamtbelastung von Kapitalgesellschaftsgewinnen (37-39\%) zu dem greifbar sachwidrigen Ergebnis, dass den Kommunen als schwächstem Glied in der Kette eine erhebliche Mitverantwortung für die internationale Wettbewerbsfähigkeit des Standortes Deutschland aufgebürdet wird.

${ }^{236}$ Dazu H.-G. Henneke (Fn. 48), $225 \mathrm{ff}$.

237 Dazu H.-G. Henneke (Fn. 233), § 14 Rn. $102 \mathrm{ff}$.

238 Zweifel an der Kompatibilität von $\S 35 \mathrm{EStG}$ mit der finanzverfassungsrechtlichen Ertragsverteilung äußern J. Hidien, BB 2000, 485 ff.; M. Wendt, FR 2000, 1173, 1175; W. Schön, StuW 2000, 151, 156. Dagegen spricht, dass $§ 35$ EStG nicht die in Art. 106 GG geregelte primäre Ertragsverteilung verändert. Vielmehr handelt es sich um eine materielle Steuerkonkurrenznorm, wie sie zahlreich vorkommen, wie hier M. Heintzen in: v. Münch/Kunig, GG, 5. Aufl. 2003, Art. 106 Rz. 10 a.E. 
werden kommunale Standortpolitik und Hebesatzautonomie zum einen durch den kommunalen Finanzausgleich ${ }^{239}$ zum anderen durch einen 2004 zur Unterbindung exzessiven Steuerwettbewerbs ${ }^{240}$ angeordneten Mindesthebesatz von 200 Punkten ( $\$ 16$ Abs. 4 S. 2 GewStG) ${ }^{241}$ in ein enges Korsett gezwängt.

Dabei könnte aus der Nähebeziehung der örtlichen Gemeinschaft, die dem Bürger mit Leistungen der Daseinsvorsorge im Alltag begegnet, ${ }^{242}$ in besonderem Maße kontrollfördernde Transparenz zwischen Ausgabenentscheidung und Abgabenbelastung erwachsen. ${ }^{243}$ An der durch Art. 28 Abs. 2 S. 3 GG abgesicherten ${ }^{244}$ kommunalen Steuerautonomie ist deshalb nicht nur festzuhalten, sie sollte sogar noch gestärkt werden. So sehr sich die kommunalen Spitzenverbände gegen das Danaergeschenk eines autonom festzusetzenden Zuschlags auf die Einkommen-

239 Steigt der Gewerbeertrag einer Kommune aufgrund erfolgreicher Ansiedlungspolitik, hat dies sinkende Schlüsselzuweisungen bzw. steigende Finanzkraftausgleichsumlagen zur Folge. Gleichzeitig steigen Gewerbesteuer- und Kreisumlage, so dass nur ein Teil der Steuermehreinnahmen bei der Kommune verbleibt. Ansiedelungspolitik als Pflege der Steuerquellen lohnt sich folglich nicht, stattdessen entsteht ein Anreiz zur Anhebung der Hebesätze. Dabei wirken Steuerkraftmesszahlen und Bedarfsmesszahlen gegenläufig, indem bei der Steuerkraftmesszahl die Großstädte stärker zu Ausgleichspflichten herangezogen werden, gleichzeitig aber bei der Bedarfsmesszahl von einem höheren Pro-Kopf-Bedarf der Großstädte ausgegangen wird. Ausführlich zu Intransparenz und schädlichen Anreizwirkungen des kommunalen Finanzausgleichs am Beispiel Niedersachsens En $\beta /$ Schwager Diskussionsbetrag Nr. 127, Volkswirtschaftliches Seminar Göttingen, 2006, 11; allgemein zu den Strukturen des kommunalen Finanzausgleichs H.-G. Henneke (Fn. 48), $367 \mathrm{ff}$.

${ }^{240} \mathrm{Im}$ Hinblick auf die Anwerbung von Finanztransaktionen durch einige kleine ländliche Gemeinden, weshalb das Gesetz auch als „lex Norderfriedrichskoog“ bezeichnet wird. Zu verfassungsrechtlichen Bedenken s. H. Jochum StB 2005, 254 (260); H. Montag in: Tipke/Lang (Hrsg.) Steuerrecht, 18. Aufl. 2005, § 12 Rn. 1; 39; Walz/Sü $\beta$ DStR 2003, 1637 (1639ff.); O. Otting DB 2004, 1222. Dem ist insofern zuzustimmen, als eine Hebesatzbegrenzung zur Bekämpfung schädlichen Steuerwettbewerbs zwar grundsätzlich berechtigt ist (B. Pieroth in: Jarass/Pieroth GG, 8. Aufl. 2006, Art. 106 Rn. 16; Selmer/Hummel, NVwZ 2006, $14 \mathrm{ff}$; zu eng BVerfGE 21, 54 [68], wonach einer Gemeinde im Hinblick auf Art. 28 Abs. 2 GG nicht abverlangt werden könne, sich an den Regelungen anderer Gemeinden zu orientieren), die konkrete Regelung jedoch unverhältnismäßig war, da man dem Problem der Verlagerung von Finanztransaktionen in ländliche Regionen mit Nullsteuersätzen auch durch Auslegung des GewStG hätte begegnen können.

241 Eingeführt durch Gesetz v. 23. 12. 2003, BGB1. I 2922.

242 BVerfGE 79, 127 (152f.).

243 P. M. Huber Gutachten, 65. DJT (2004), D 43; Feld/Kirchgässner Wirtschaftsdienst 1995, 562 (568).

${ }^{244}$ Zur Bedeutung von Art. 28 Abs. 2 Satz 3 GG s. etwa W. Löwer in: v. Münch/Kunig (Hrsg.) GG, 5. Aufl. 2001, Art. 28 Rn. 88 ff. 
steuer ${ }^{245}$ sträuben, so sehr würde dieser in Art. 106 Abs. 5 S. 3 GG bereits vorgesehene offene Ausweis der heute staatsinternen, damit dem Bürger weithin unbekannten Einkommensteuerbeteiligung die Kommunalparlamente unter Rechtfertigungszwang setzen und der Verwirklichung demokratiefördender Transparenz gerade auch auf dieser dritten staatlichen Ebene Rechnung tragen. ${ }^{246}$ Die Gewerbesteuer sollte dagegen im Interesse der Planbarkeit kommunaler Haushaltspolitik in ihrer relativen Bedeutung zurückgenommen und zumindest partiell durch stetigere Einnahmequellen ${ }^{247}$ - etwa eine Erhöhung des kommunalen Umsatzsteueranteils oder eine Beteiligung am Lohnsteueraufkommen ersetzt werden. ${ }^{248}$

In eine derartige Neuordnung des kommunalen Steuersystems muss der kommunale Finanzausgleich einbezogen werden, zum einen um derzeit bestehende Fehlanreize ${ }^{249}$ zu beseitigen, zum anderen um im Übergang interkommunale Aufkommensverschiebungen auszugleichen, an denen bisher jeder Versuch einer Gewerbesteuerreform gescheitert ist.

245 Vorgeschlagen als sog. „Bürgersteuer“ durch die Stiftung Marktwirtschaft, ausführliche Darstellung in: Der Städtetag 2005, Heft 5 (mit Kritik der kommunalen Spitzenverbände); M. Jachmann StuW 2006, 115.

246 M. Jachmann StuW 2006, 115 (121).

${ }^{247}$ Mit Art. 28 Abs. 2 Satz 3 GG wäre eine Abschwächung der relativen Bedeutung der Gewerbesteuer jedenfalls dann vereinbar, wenn die Gemeinden gleichzeitig ein Hebesatzrecht auf die ebenfalls wirtschaftskraftbezogene Einkommensteuer erhalten. Hinter der aA des Deutschen Städtetages (vgl. Karrenberg/Münstermann Der Städte$\operatorname{tag} 5 / 2005,11$ [30ff.]) stehen verteilungspolitische Überlegungen, die sich gegen eine Verlagerung der kommunalen Steuerpolitik von der Wirtschaft auf die Bürger als Adressaten richten, aber keine Stütze in Art. 28 Abs. 2 Satz 3 GG finden. Im Übrigen enthält Art. 28 Abs. 2 Satz 3, 2. Halbsatz GG keine status quo-Garantie und ist, solange das Hebesatzrecht nicht ausgehöhlt wird, nicht verletzt, zutreffend B. Pieroth in: Jarass/ Pieroth GG, 8. Aufl. 2006, Art. 106, Rn. 16. Die ablehnende Haltung gegenüber dem offenen Ausweis des gemeindlichen Einkommensteueranteils ist allerdings insofern nachvollziehbar, als die Kommunalhaushalte mit zentral vorgegebenen, auch im Rahmen der Ausführungskompetenzen nicht beeinflussbaren Sozialleistungen belastet sind; s. auch T. Büttner in T. Büttner (Hrsg.), Finanzverfassung und Föderalismus in Deutschland und Europa, 2000, 61 (79).

${ }^{248} \mathrm{Zu}$ den derzeit in Deutschland diskutierten Reformvorschlägen vor dem Hintergrund der geglückten Abschaffung der Gewerbesteuer in Österreich Knirsch/Niemann StuW 2006, $278 \mathrm{ff}$.

249 Vgl. Fn. 241. 


\section{Reform der Finanzbeziehungen in der Europäischen Union zur Begrenzung des Autonomieverlusts durch Steuerwettbewerb}

Lassen Sie mich zum Schluss den Blick von den Kommunen nach Europa wenden und die eingangs erwähnten Widersprüche der gemeinschaftsrechtlichen Finanzordnung aufgreifen.

\section{Status quo: Rechtliche und faktische Schranken der Finanzautonomie bei gleichzeitiger Haushaltsverantwortung}

Nur formal verfügen die Mitgliedstaaten nach wie vor über weitgehende Einnahme- und Ausgabenautonomie.250 Auf der Ausgabenseite diszipliniert durch den europäischen Stabilitätspakt, geraten die Einnahmen zunehmend unter Druck. Die Berufung auf die nationale Steuerertragshoheit ist nach Auffassung des Europäischen Gerichtshofs nicht dazu angetan, Beschränkungen der Freizügigkeit $\mathrm{zu}$ rechtfertigen, ${ }^{251}$ so dass die nationalen Fisci dem Abfluss von mobilem Steuersubstrat in andere Mitgliedstaaten weitgehend machtlos zusehen müssen. ${ }^{252}$ Grundfreiheiten und Beihilfevorschriften ${ }^{253}$ entfalten weitreichende Rückwirkungen auf die Ausgestaltung einzelner Steuerrechtsnormen. ${ }^{254}$ Noch gravierender zwingt der Steuerwettbewerb die Mitgliedstaaten zum Umbau ihrer Steuersysteme. ${ }^{255}$ Dieser sowohl rechtliche als auch faktische Autonomieverlust ${ }^{256}$ steht in Widerspruch zu der fortbestehenden nationalen Haushaltsverantwortung.

\footnotetext{
${ }^{250}$ Insbesondere der große Kostenblock der Sozialausgaben ist bisher nicht vereinheitlicht H. Reichenbach in: Pommerehne/Ress (Hrsg.) Finanzverfassung im Spannungsfeld zwischen Zentralstaat und Gliedstaaten, 1999, 134 (136).

251 Ständige Rspr., zB EuGH, Slg. 2001, I-1727 Rn. 59 - Metallgesellschaft; Slg. 2002, I-8147 Rn. 56 - Danner; s. allerdings auch den neuen Rechtfertigungstopos der „Wahrung der Aufteilung der Besteuerungsbefugnisse“ in Marks \& Spencer, EuGH, NJW 2006, 891.

${ }^{252} \mathrm{Zu}$ den zum Teil dramatischen Auswirkungen der EuGH-Rechtsprechung auf die nationalen Haushalte $O$. Thömmes Intertax 2005, 560.

${ }^{253}$ Kritisch gegenüber diesem „supranationalen Genehmigungsvorbehalt“ nationaler Steuergesetzgebung als massiver Eingriff in die mitgliedstaatliche Steuerhoheit V. Götz FS K. Vogel, 2000, 579 (582ff.).

254 „Fallweise Deformierung des nationalen Steuerrechts entlang der Entscheidungen des EuGH“, vgl. D. Birk FR 2005, 121 (127).

255 S. dazu Besteuerung von Einkommen - Aufgaben, Wirkungen und europäische Herausforderungen, 66. DJT (2006); R. Müller StuW 2006, $173 \mathrm{ff}$.

256 J. Lang NJW 2006, 2209 (2210); De Mooij/Stevens EC Tax Review 2005, $9 \mathrm{ff}$.
} 
2. Autonomieerhaltende Regelbindung des europäischen

Steuerwettbewerbs

a) Einzelnormorientiertes Konzept des Verhaltenskodex gegen unfairen Steuerwettbewerb

Obwohl sich der Steuerwettbewerb inzwischen für die Mehrzahl der Mitgliedstaaten $\mathrm{zu}$ einem ernsthaften Problem entwickelt hat, lässt er sich aktuell nicht eindämmen. Die Verständigung auf den - rechtlich unverbindlichen - Verhaltenskodex gegen „harmful tax competition“257 und der Einsatz des Beihilferechts gegen selektive Vergünstigungen ${ }^{258}$ leisten zwar einen wichtigen Beitrag zur Transparenz des Wettbewerbs. Ihnen liegt aber ein einzelnormorientiertes Verständnis mangelnder Fairness und Schädlichkeit zugrunde, das gegen den allgemeinen Steuersatzwettbewerb nichts auszurichten vermag.

Unfair ist indes auch ein Steuerdumping, ${ }^{259}$ dessen nicht kostendeckende Steuersätze durch von den Wettbewerbern aufgebrachte Transfers finanziert werden, ${ }^{260}$ soweit keine Übereinkunft dahingehend besteht, dass es sich hierbei um ein zusätzliches indirektes Förderelement handelt. ${ }^{261}$ Ungerecht ist aus der Sicht der Steuerbürger nicht nur die selektive Steuervergünstigung, sondern auch die Verlagerung der Steuerbelastung von Kapital zu Arbeitseinkommen und Konsum.

\section{b) Wettbewerbsoffenheit des Europäischen Gerichtshofs}

Der Europäische Gerichtshof kann allenfalls begrenzt zur Lösung der zugrunde liegenden Verteilungskonflikte zwischen den Mitgliedstaaten beitragen. Seine Interpretation des Binnenmarktes als einheitlicher

\footnotetext{
257 S. Fn. 46.
}

258 Mitteilung der Kommission über die Anwendung der Vorschriften über staatliche Beihilfen auf Maßnahmen im Bereich der direkten Unternehmensbesteuerung, BStBl. I 1999, 205; dazu V. Götz FS K. Vogel, 2000, 579 ff.; F. Vanistendael EC Tax Review 2000, $152 \mathrm{ff}$; I. Gross RIW 2002, $46 \mathrm{ff}$.

259 Dazu Jarass/Obermair Wirtschaftsdienst 2004, 152 (158f.).

${ }^{260}$ Mangels Selektivität keine Beihilfe iSd Art. 87 EGV, zur beihilferechtlichen Kontrolle von Steuervergünstigungen vgl. EuGH, Slg. 1999, I-2981 Rn. 15 ff. - Italien/Kommission.

261 S. die sog. Sarkozy-Initiative, dazu H. O. Ruding EC Tax Review 2005, 2 (3). Ob sich Steuerdumping als Verstoß gegen das Gebot der Gemeinschaftstreue durch Beeinträchtigung des Finanzierungssystems der Gemeinschaft mittels einseitiger Maßnahmen (EuGH, Slg. 1986, 29 [83] - Hurd/Jones) verstehen lässt, ist insofern zweifelhaft, als Steuerwettbewerb - wenn er erfolgreich ist - nur dazu führt, dass die Mitgliedstaaten schneller aus den Fördermaßnahmen herauswachsen und damit mit Zielen der Angleichung der Wirtschaftskraft konform gehen. Treuwidrig ist allenfalls, dass sich Steuerdumping dem geordneten Verfahren der Strukturpolitik entzieht. 
Steuerraum entspricht der vertraglichen Zielsetzung effektiver Ressourcenallokation (Art. 98 EGV). ${ }^{262}$ Gerade aus der fortbestehenden nationalen Steuerhoheit folgert der Gerichtshof, dem Steuerpflichtigen dürfe die Ausnutzung des hierdurch ermöglichten Belastungsgefälles nicht verwehrt werden. ${ }^{263}$ Gestaltungsfreundlich haben die Judikate bisher den Grundfreiheiten auch dann den Vorrang eingeräumt, wenn ihre Betätigung die territoriale Zuordnung des Steueraufkommens entsprechend der von den Mitgliedstaaten geleisteten Verursachungsbeiträge aufhebt. ${ }^{264}$ Andererseits zeigt der jüngste Versuch einer Wahrung der zwischenstaatlichen Aufteilung der Steuerquellen in der Rechtssache Marks \& Spencer, ${ }^{265}$ dass im Dreiecksverhältnis zweier um Aufkommen konkurrierender Staaten und dem Steuerbürger eine konsistente Aussöhnung zwischen nationaler Steuerertragshoheit und Grundfreiheiten ohne ein Zusammenwirken der beteiligten Mitgliedstaaten nicht möglich ist. ${ }^{266} \mathrm{Um} \mathrm{zu}$ einer Besteuerung zu gelangen, die sowohl den Grundfreiheiten als auch den Vorstellungen zwischenstaatlicher Verteilungsgerechtigkeit entspricht, bedürfte es der Etablierung von Finanzausgleichsbeziehungen ${ }^{267}$ zwischen den Mitgliedstaaten. Aber

262 A. v. Bogdandy in: Grabitz/Hilf (Hrsg.) Das Recht der Europäischen Union, Stand 2004, Art. 2 EGV Rn. 37 f. Der weit auszulegende Begriff der Wirtschaftspolitik in Art. 98 EGV (D. Hattenberger in: J. Schwarze, EU-Kommentar, 2000, Art. 98 EGV, Rn. 8) umfasst auch die wirtschaftsbezogene Steuerpolitik. Deutlich wird der hohe Stellenwert der Neutralitätsverpflichtung etwa im Beihilfenverbot, dessen Aufgabe es ist, eine Verzerrung ökonomischer Entscheidungen zu verhindern.

263 Jüngst EuGH v. 12. 9. 2006, Rs. C-196/04 Rn. 38 - Cadbury Schweppes: Ausnahme „künstliche Gestaltungen“.

264 Nicht die Verlegung der wirtschaftlichen Aktivität in einen anderen Mitgliedstaat verletzt die Steuersouveränität, sondern die - legale - Nutzung rechtlicher Gestaltungsmöglichkeiten zur Verlagerung von Gewinnen in einen anderen Mitgliedstaat.

265 EuGH, NJW 2006, 891.

266 Für die Herstellung praktischer Konkordanz durch offene Abwägung der mitgliedstaatlichen Ertragshoheit mit den Grundfreiheiten im Rahmen der VerhältnismäBigkeitsprüfung jetzt dezidiert C. Seiler 66. DJT (2006), Gutachten, Teil F, $22 \mathrm{f}$.

${ }^{267}$ Dabei geht es nicht um einen allgemeinen Finanzkraftausgleich (hierzu F. Wathes Europäischer Finanzausgleich, 1996; S. Homburg [Fn. 65] $61 \mathrm{ff} . ;$ H. Grossekettler in R. Caesar [Hrsg.], Zur Reform der Finanzverfassung und Strukturpolitik der EU, 1997, $111 \mathrm{ff}$. mit Hinweis insb. auf die politikökonomischen Probleme). Für über Krisen-, Struktur und Aufbauhilfe hinausgehende Ausgleichspflichten sind, selbst wenn man ein deutlich niedrigeres Angleichungsniveau zugrunde legte als im deutschen Finanzausgleich, Steuersysteme, wirtschaftliche Verhältnisse und staatliche Ausgabenpolitiken in den einzelnen Mitgliedstaaten zu unterschiedlich; ähnlich J. Wieland JZ 2004, 774 (778), der einen Finanzausgleich gegenüber den Strukturfonds als vorzugswürdig erachtet, die Zeit hierfür aber noch nicht als reif erachtet, weil ein solcher ein höheres $\mathrm{Maß}$ an „Zusammengehörigkeitsgefühl“ erfordere, als es heute gegeben ist. 
selbst wenn der EuGH ungelöste Aufkommensverteilungskonflikte grenzüberschreitender Sachverhalte zu Lasten der Grundfreiheiten entscheiden würde, der Verlagerung wirtschaftlicher Aktivität und damit dem Wettlauf der Mitgliedstaaten um niedrige Steuersätze auf mobile Steuerquellen kann die dem Einzelfall verpflichtete Rechtsprechung nicht Einhalt gebieten. Nur die Mitgliedstaaten selbst sind in der Lage, die Disharmonie zwischen der Binnenmarkt-Freiheitsordnung und einer der Nationalstaatlichkeit der Mitgliedstaaten verhafteten Finanzordnung aufzulösen.

\section{c) Rückgewinnung der Finanzautonomie durch Harmonisierung?}

Folgerichtig verschafft der ungebremste Steuerwettbewerb seit einigen Jahren der Forderung nach einer Harmonisierung der Unternehmensbesteuerung wieder Gehör. ${ }^{268}$ Eine Angleichung der körperschaftsteuerrechtlichen Bemessungsgrundlage, wie sie jetzt die EU-Kommission vorbereitet, ${ }^{269}$ ist nicht Selbstzweck, ${ }^{270}$ sondern einerseits Voraussetzung für transparenten Steuersatzwettbewerb, andererseits unerlässlich, um diesen Wettbewerb durch die Festlegung von Mindeststeuersätzen zu begrenzen und eine Basis für eine an der Wertschöpfung orientierte Aufkommensverteilung zwischen den Mitgliedstaaten zu schaffen. Die identitätsstiftende Wirkung der steuertechnischen Erfassung von Unternehmensgewinnen, namentlich der Besteuerung von Kapitalgesellschaften ist - anders als die Besteuerung natürlicher Personen - gering. Deshalb erscheint eine derart begrenzte Souveränitätseinbuße ein angemessener Preis für eine verursachungsgerechte Verteilung des Steueraufkommens innerhalb der Gemeinschaft. Derart geschlossen könnte die Gemeinschaft dann den internationalen Wettbewerb gegenüber Drittstaaten aufnehmen.

\footnotetext{
${ }^{268}$ Aus ökonomischer Sicht für eine weitgehende Harmonisierung von Bemessungsgrundlagen und Sätzen: H.-W. Sinn (Fn. 33), 9 (48ff.); C. Spengel StuB 2003, $786 \mathrm{ff}$.; ders. in E. Reimer (Hrsg.) Unternehmen Europa - Unternehmen in Europa, 2006; N. Herzig StuW 2006, $156 \mathrm{ff}$.

269 Vgl. zur Common Consolidated Corporate Tax Base Mitteilung der Kommission v. 23. 10. 2001, KOM [2001] 582 endg., s. BR-Drucks. 971/01, 17.

${ }^{270}$ Dies entspricht dem funktionalen Verständnis von Art. 94 ff. EGV: Rechtsangleichung als Mittel und Zweck zur Erfüllung der insb. in Art. 2 EGV genannten Aufgaben, vgl. H. von der Groeben NJW 1970, 359; C. Tietje in: Grabitz/Hilf (Hrsg.) Das Recht der Europäischen Union, Vor Art. 94-97 EGV Rn. 6; H.-H. Herrnfeld in: J. Schwarze (Hrsg.) EU, 2000, Art. 94 Rn. 1.
} 
Dennoch stehen die Einigungschancen nicht allzu hoch. ${ }^{271}$ Das Einstimmigkeitsprinzip verhindert die Durchsetzung von Mehrheits- und Gemeinschaftsinteressen gegen individuelle Länderinteressen. Zwischen den Profiteuren des Steuerwettbewerbs und den Wettbewerbsverlierern wird sich ein Konsens kaum herstellen lassen. ${ }^{272}$ Anderseits ändert die Gefahr der unsolidarischen Ausnutzung der Vetoposition nichts daran, dass beim derzeitigen Integrationsstand nur Einstimmigkeit der Bedeutung der Finanzautonomie für die Eigenstaatlichkeit der Mitgliedstaaten gerecht wird. ${ }^{273}$ Kann man nicht auf Einsicht hoffen, wird man die $\mathrm{Zu}-$ stimmung der neuen EU-Mitgliedstaaten zu einer Begrenzung des Steuerwettbewerbs möglicherweise durch Erhöhung der Mittel des Kohäsionsfonds erkaufen müssen. ${ }^{274}$ Damit ist zwar ein verflechtungstypisches Gegengeschäft angesprochen. Es hält sich aber in der Logik der Wechselwirkungen der Finanzordnung, wenn man die Alternativität von Steuerwettbewerb und Transferzahlungen zur Angleichung der wirtschaftlichen Verhältnisse zugrunde legt.

Mit diesem Europäischen Steuerparadoxon möchte ich schließen: Finanzautonomie in gestuften Rechtsordnungen braucht dem Gesamtwohl verpflichtete Regeln verantwortungsvoller Ausübung, sonst richtet sie sich selbst zugrunde. Dies ist Einbindung, wenn Sie so wollen, Verflechtung um der Autonomie willen.

${ }^{271}$ Insbesondere aufgrund der im Erweiterungsprozess gewachsenen Disparitäten in der EU; vgl. J. J. Hesse in: T. Büttner (Hrsg.) Finanzverfassung und Föderalismus in Deutschland und Europa, 2000, 9 (13). Zu den institutionellen Verfahrensmängeln aus politikwissenschaftlicher Sicht $P$. Genschel Steuerharmonisierung und Steuerwettbewerb in der Europäischen Union, 2002, $272 \mathrm{ff}$.

272 Weder die Kommission noch der EuGH haben eine Handhabe, außerhalb der im Vertrag niedergelegten Einzelpflichten Gemeinschaftstreue zu erzwingen, zutr. A. Hatje in: J. Schwarze (Hrsg.) EU, 2000, Art. 10 Rn. 6. Der Zentralebene fehlt insofern die Handlungsfähigkeit (F. W. Scharpf Politische Vierteljahresschrift Bd. 26 [1985], 323 [326]). Eine der institutionellen Antworten auf innereuropäische Gruppendifferenzen liegt in der Konzeption des „Europas der zwei Geschwindigkeiten“ mit dem Instrument der verstärkten Zusammenarbeit gem. Art. 43 EUV; dazu C. v. Buttlar ZEuS 2001, 649 ff. Doch um dem ruinösen Steuerwettbewerb Einhalt zu gebieten, müssen alle Mitgliedstaaten zusammenwirken.

${ }^{273}$ Ebenso A. Bleckmann Europarecht, 6. Aufl. 1997, Rn. 1308f.; C. Waldhoff ZEuS 2000, 201 (237); P. Kirchhof (Fn. 26), 9 (29), zu Recht ist deshalb auch in Art. III-171 und Art. III-172 Abs. 2 iVm Art. III-173 des Verfassungsvertrages für die Steuerpolitik weiterhin Einstimmigkeit vorgesehen.

${ }^{274} \mathrm{Zu}$ derartigen Gegengeschäften s. auch U. Häde (Fn. 9), 548. 
Leitsätze der 2. Berichterstatterin über:

\title{
Finanzautonomie und Finanzverflechtung in gestuften Rechtsordnungen
}

\author{
I. Zu den Besonderheiten der Finanzbeziehungen in gestuften \\ Rechtsordnungen
}

(1) Finanzautonomie als konstituierendes Merkmal von Eigenstaatlichkeit beinhaltet in einem umfassenden Sinne das Recht zu eigenständiger Einnahme- und Ausgabenpolitik.

(2) Während der autonome Staat nur durch den Grundsatz der Territorialität in seiner Finanzautonomie beschränkt wird, bedarf es in gestuften Rechtsordnungen zunächst der vertikalen Aufteilung der Ressourcen des Gesamtstaates zwischen Zentralebene und Gliedstaaten. Sodann sind die Kompetenzen der Gliedstaaten horizontal nach Territorialität abzugrenzen.

(3) Die den einzelnen Ebenen zuzugestehende Finanzautonomie korrespondiert notwendig mit der Verteilung der Sachkompetenzen. Je mehr Gestaltungsspielraum im Bereich der Sachgesetzgebung besteht, desto mehr finanzieller Gestaltungsspielraum ist erforderlich. Haben die nachgeordneten Ebenen dagegen in erster Linie die Aufgabe, die von der Zentralebene erlassenen Gesetze auszuführen, bedarf es einer möglichst gleichmäßigen Verteilung der Finanzmasse.

(4) Diesem Ziel trägt Finanzverflechtung als gegenüber der zentralen Mittelbewirtschaftung vordergründig autonomieerhaltendes Verfahren Rechnung, dessen Ineffizienzen und Unbeweglichkeit aber letztlich zu Handlungsunfähigkeit und damit Autonomieverlust aller Ebenen führt. Hieraus resultiert die Forderung nach Entflechtung in erster Linie als Stärkung der Finanzautonomie nachgeordneter Ebenen.

\section{Finanzautonomie als Voraussetzung von Differenzierung und Wettbewerb}

(5) Einnahmeautonomie nachgeordneter Ebenen ermöglicht Differenzierung und Wettbewerb. 
(6) In der Theorie dient Fiskalwettbewerb als Entdeckungsverfahren zum Auffinden optimaler Problemlösungen, führt zu Effizienzsteigerungen des staatlichen Leistungsangebots und bietet unterentwickelten Regionen Aufholchancen.

(7) In der Praxis der Europäischen Union hat der Abgabenwettbewerb zwar bisher nicht zum "race to the bottom “ unabdingbarer Staatsfunktionen geführt, wohl aber zu Prinzipienerosion und wuchernder Abwehrgesetzgebung. Besteuert wird nach Mobilität statt nach Leistungsfähigkeit. Steuerwettbewerb erweist sich nicht als Wettbewerb um die gerechteste Steuerrechtsordnung, sondern als Steuersubstratwettbewerb.

(8) Vor dem Hintergrund dieser Erfahrungen verbietet sich jede Verklärung eines Konkurrenzföderalismus auf abgabenrechtlichem Gebiet. Allerdings muss Steuerautonomie nicht in ruinösem Wettbewerb enden. Die gestufte Finanzordnung hat vielfältige Möglichkeiten systemimmanenter Grenzziehungen. Zum einen kann die Autonomie auf weniger mobile Steuerquellen beschränkt werden, zum anderen reduzieren ein relativ einheitliches Aufgabenniveau sowie Verschuldungsgrenzen die Spielräume einseitiger (kreditfinanzierter) Steuersatzsenkungen. Schließlich lässt sich dem Wettbewerb durch die Ausgestaltung des Finanzausgleichs ein Rahmen setzen.

\section{Finanzautonomie und Eigenverantwortung}

(9) Für Finanzautonomie, besonders Steuergesetzgebungsautonomie aller mit Sachkompetenzen ausgestatteten Ebenen sprechen vor allem demokratiestaatliche Gründe. Sachautonomie kann nur dann eigenverantwortlich genutzt werden, wenn die handelnde Körperschaft auch die Höhe der eingesetzten Mittel gegenüber dem Bürger verantworten muss. Sein Interesse an demokratischer Kontrolle staatlichen Ausgabeverhaltens wird durch den individuell spürbaren Übersetzungsmechanismus der Abgabenbelastung nachhaltig gefördert.

(10) Voraussetzung ist Kostentransparenz, sowohl durch Konzentration von Kompetenzen als auch durch die Ausgestaltung der Abgabenbelastung nach den Grundsätzen der Merklichkeit und Allgemeinheit. Transfers und Kreditfinanzierung verstellen dagegen den Blick auf die wahren Politikkosten. Aus demokratiestaatlicher Sicht ist die Kreditaufnahme der Steuerfinanzierung nicht äquivalent.

(11) Auch das ökonomische Ziel optimaler Allokation spricht für eine dezentrale Bündelung von Aufgaben-, Ausgaben- und Einnahmeentscheidungen. Auf diese Weise kann lokalen und regionalen Nutzenpräferenzen Rechnung getragen und eine effiziente Bereitstellung öffentlicher Güter gewährleistet werden. Dabei beschränkt sich die Möglichkeit einer Entflech- 
tung durch Dezentralisierung nach den Grundsätzen fiskalischer Äquivalenz jedoch auf Aufgaben mit geringen Externalitäten. Lässt sich die Nutzenfunktion nicht eindeutig zuordnen, resultiert hieraus das Bedürfnis nach finanziellem Ausgleich (Beispiel Finanzierung der Hochschulbildung).

IV. Begrenzung der Finanzautonomie nachgeordneter Körperschaften im Interesse des Gesamtstaates

(12) Art. 72 Abs. 2, Art. 106 Abs. 3 S. 4 Nr. 2 GG stehen einer Stärkung der Finanzautonomie umso weniger entgegen, je mehr regionale Differenzierungsmöglichkeiten durch Rückverlagerung von Sachkompetenzen auf die Länder geschaffen werden. Gleichwertigkeit der Lebensverhältnisse iSv Art. 72 Abs. 2 GG ist überhaupt nur dann gewahrt, wenn sich Unterschiede auf der Leistungsseite auch auf der Abgabenseite abbilden.

(13) Ausgestaltung und Ausübung der Finanzautonomie müssen sich jedoch am Interesse des Gesamtstaates orientieren. Bündnistreue verpflichtet alle Ebenen zur Rücksichtnahme auf die begrenzte Leistungsfähigkeit der Volkswirtschaft, damit zur Respektierung fremder Steuerquellen sowie zu fairem Wettbewerb. Finanzielle Eigenverantwortung und solidarische Einstandspflichten für Not leidende Gliedstaaten sind im Wege der Prävention zum Ausgleich zu bringen. Beispielhaft zu nennen ist das Defizitverfahren in Art. 104 Abs. 2 EGV unter gleichzeitiger Beschränkung finanzieller Hilfeleistungen auf unbeherrschbare Notlagen (Art. 100 Abs. 2, 103 EGV).

\section{Gesamtverantwortung für ein gerechtes Steuersystem}

(14) Die Ausgestaltung gestufter Finanzordnungen entfaltet weitreichende Rückwirkungen auf die Gerechtigkeitsqualität des Steuersystems. Finanzverfassungsrechtliche und steuerrechtliche Diskussion dürfen daher nicht getrennt werden. Die staatliche Kompetenzverteilung muss so organisiert sein, dass sie optimale Individualrechtsverwirklichung ermöglicht, namentlich eine leistungsfähigkeitsgerechte und freiheitsschonende Besteuerung.

(15) Zwar steht der Grundsatz der Gleichmäßigkeit der Besteuerung regionalen Belastungsunterschieden nicht entgegen, wohl aber verpflichtet das Gebot der Rechtsanwendungsgleichheit auch über Ländergrenzen hinweg zu einheitlichen Standards beim Vollzug bundeseinheitlicher Gesetze.

(16) Aus der Grundrechtsbindung aller Ebenen folgt eine Pflicht zur Vermeidung unabgestimmter Mehrfachzugriffe auf das einheitliche Zugriffsobjekt steuerlicher Leistungsfähigkeit. Bei vertikaler Teilung von Steuerquellen gilt es, die Zugriffe so aufeinander abzustimmen, dass verfassungsrechtliche 
Belastungsobergrenzen eingehalten werden. Auf der Horizontalebene verbietet sich eine abgabenrechtliche Diskriminierung Gebietsfremder und gebietsüberschreitender Sachverhalte. Durch Regelungskonkurrenz entstehende Doppelbelastungen jurisdiktionsüberschreitender Sachverhalte sind aufzulösen.

(17) Schließlich muss das finanzielle Autonomiebedürfnis nachgeordneter Ebenen mit dem Interesse des Bürgers an Einfachheit der Besteuerung und der Vermeidung übermäßiger Verwaltungslasten zu einem Ausgleich gebracht werden. Dabei verbindet eine auf Steuersätze beschränkte Autonomie der Gliedstaaten das Anliegen der Einheitlichkeit und Gleichmäßigkeit der Besteuerung mit dem Autonomieziel in geradezu idealer Weise, weil auch demokratische Kontrolle Transparenz verlangt.

VI. Zwischenfazit: Verantwortungsföderalismus als Leitbild für die Ausgestaltung gestufter Finanzordnungen

(18) Die Konstruktion einer Finanzordnung zwischen Autonomie und Verflechtung stellt die gestufte Rechtsordnung vor eine mehrdimensionale Gestaltungsaufgabe der Beziehungsebenen Staat - Staat und Staat - Bürger. Dabei müssen die Finanzbeziehungen in gestuften Rechtsordnungen mehr als von Konkurrenz vom Leitbild des Verantwortungsföderalismus angeleitet werden. Es ergibt sich ein dreifaches Verantwortungsgefüge: Sowohl demokratiestaatliche als auch ökonomische Gesichtspunkte effektiver Ressourcenallokation sprechen für finanzielle Eigenverantwortung aller mit Sachkompetenzen ausgestatteter Ebenen, sowohl auf der Ausgaben-als auch auf der Einnahmenseite. Gleichzeitig verpflichten Bündnis- und Treuepflichten die einzelnen mit Finanzautonomie ausgestatteten Körperschaften zu einer verantwortungsbewussten, am Interesse des Gesamtstaates ausgerichteten Bewirtschaftung der einheitlichen Finanzmasse. Schließlich aktiviert die Grundrechtsbindung aller Ebenen die gemeinsame Verantwortung gegenüber dem zur Finanzierung herangezogenen Steuerbürger für eine leistungsfähigkeitsgerechte und verhältnismäßige Gesamtsteuerlast.

VII. Einige Folgerungen für die Reform der Finanzbeziehungen in Deutschland und der Europäischen Union

(19) Bundesrepublik:

a) Aufgrund des Ausmaßes der auf allen Ebenen erreichten Staatsverschuldung muss eine Reform der Finanzbeziehungen der Bundesrepublik mit dem Staatschuldenrecht beginnen. So wenig Einnahmeautonomie die Länder sonst 
besitzen, im Bereich der Verschuldung verfügen sie über weitreichende Autonomie. Da alle Ebenen auf dieselbe Haftungsmasse zugreifen, bedarf es einer verbindlichen Aufteilung der gesamtstaatlich zulässigen Verschuldung zwischen Bund und Ländern sowie auf die einzelnen Länder. Nur so lässt sich Haushaltsnotlagen der Länder vorbeugen und ihre Verantwortung für die Einhaltung des europäischen Stabilitätspakts sachgerecht erfassen.

b) Die Einhaltung verbindlicher Verschuldungsgrenzen kann nur gefordert werden, wenn die Länder eine autonom gestaltbare alternative Einnahmequelle erhalten. Hierzu bedürfen sie begrenzter Steuergesetzgebungsautonomie, vor allem in Form von Steuersatzautonomie. Die Möglichkeiten der Entflechtung des Steuergesetzgebungsverfahrens sind allerdings eher gering. Auch im Bereich der Länder- und Kommunalsteuern bleiben zur Wahrung der Rechts- und Wirtschaftseinheit sowie zur Vermeidung eines die Gleichwertigkeit der Lebensverhältnisse gefährdenden Steuerwettbewerbs in großem Umfang bundeseinheitliche Regeln iSv Art. 105 Abs. 2 iVm Art. 72 Abs. 2 GG erforderlich. Beizubehalten ist ferner der Steuerverbund (Art. 106 Abs. $3 \mathrm{~S}$. $1 \mathrm{GG}$ ), flexibilisiert durch teilautonome Tarifgestaltung der Länder. Auf die Zustimmungspflichtigkeit der vom Bund erlassenen Gesetze (Art. 105 Abs. 3 GG) kann nicht verzichtet werden.

c) Eine Stärkung der Steuerautonomie der Länder wiederum bedingt Anpassungen des Finanzausgleichs, indem zukünftig an Soll-statt an Isteinnahmen anzuknüpfen ist.

d) Als Problem wird angesehen, dass eine Stärkung der Finanzautonomie die Länder in sehr unterschiedlicher Ausgangsposition träfe. Dennoch scheidet eine von oben dekretierte Länderneugliederung zur Schaffung gleicher Startchancen - unabhängig einer Reform des Art. 29 GG - aus. Eine Stärkung der finanziellen Eigenverantwortung mit für die Landesbevölkerung spürbaren Auswirkungen erhöht aber die Chancen freiwilliger Neugliederung und Kooperation.

e) Obwohl die Gemeinden über Hebesatzautonomie für Grund- und Gewerbesteuer verfügen, ist auch das kommunale Finanzsystem reformbedürftig. Die Gewerbesteuer ist als Hauptfinanzquelle der Gemeinden ungeeignet. Sie verfehlt sowohl die Ziele der Allgemeinheit als auch der Stetigkeit. Für eine Stärkung der Kontrolle der Kommunalparlamente wäre der offene Ausweis des kommunalen Einkommensteueranteils durch ein begrenztes Hebesatzrecht (Art. 106 Abs. 5 GG) wünschenswert. Zudem müsste die Gewerbesteuer in ihrer Bedeutung für den kommunalen Haushalt zurückgenommen und durch verstetigende Elemente ergänzt werden.

(20) Europäische Union:

a) Trotz formal fortbestehender Finanzautonomie der Mitgliedstaaten sind ihre Gestaltungsmöglichkeiten rechtlich durch Grundfreiheiten und Beihilferecht, faktisch durch den europäischen Steuerwettbewerb mittler- 
weile empfindlich beschnitten. Dieser schleichende Verlust an nationaler Einnahmeautonomie steht in einem Spannungsverhältnis zu der fortbestehenden nationalen Haushaltsverantwortung.

b) Ursächlich ist der vom Europäischen Gerichtshof zugrunde gelegte Vorrang der Grundfreiheiten vor der mitgliedstaatlichen Finanzautonomie. Diese Rechtsprechung orientiert sich am Ziel effektiver Ressourcenallokation (Art. 98 EGV), ohne der fehlenden Integrationsbereitschaft der Mitgliedstaaten auf finanziellem Gebiet Rechnung zu tragen.

c) Weder die einzelnormorientierten Mechanismen des Verhaltenskodex gegen unfairen Steuerwettbewerb und des Beihilferechts noch die einzelfallorientierte Judikatur des Gerichtshofs sind in der Lage, den Widerspruch zwischen europäischer Freiheitsordnung und nationaler Haushaltsverantwortung aufzulösen.

d) Dies wäre Aufgabe der Mitgliedstaaten. Sie müssten sich auf eine begrenzte Harmonisierung der Besteuerungsregeln für mobile Steuerquellen, namentlich der Besteuerung von Unternehmen und Kapital (Bemessungsgrundlagen, Gewinnabgrenzungsregeln, ggf. Mindeststeuersätze) einigen. Nur eine derartige partielle Verflechtung kann die Finanzautonomie aller Beteiligten langfristig erhalten. 


\section{Aussprache und Schlussworte}

\section{Finanzautonomie und Finanzverflechtung in gestuften Rechtsordnungen}

Diskussionsleiter (F. Kirchhof): Es liegen schon viele Diskussionsmeldungen vor. Deshalb darf ich als Redner schon im Voraus um zeitliche Gesprächsdisziplin bitte. Wir beginnen wie angekündigt mit dem ersten Punkt „Grund und Grenzen der Finanzautonomie“.

Gröpl: Zum Thema „Finanzautonomie“ möchte ich mit einem Beitrag grundsätzlicher Art beginnen. Finanzautonomie weist eine Einnahmeund eine Ausgabeseite auf. Die Probleme der Einnahmenautonomie haben die Referenten sehr schön herausgearbeitet und dafür auch gute Lösungsperspektiven aufgezeigt. Insbesondere halte ich ein Hebesatzrecht oder Ergänzungsanteile für die Länder, etwa zur Einkommensteuer, für kluge Ideen, die weiterverfolgt werden sollten. - Wie aber sieht es mit der Ausgabenautonomie aus? Stark in Mitleidenschaft gezogen wird sie durch die sog. zwangsläufigen Ausgaben, die bundesgesetzlich zu Lasten der Länder begründet werden. Natürlich haben beide Vorträge dieses Problem angeschnitten, wir kennen es gut. Die Frage ist bloß: Wie gehen wir damit um? Dürfen wir uns mit den Ansätzen der diesjährigen Verfassungsreform begnügen? Reicht es also aus, dass der Bund hier nach Maßgabe von Art. 104a Abs. 2 bis 4 GG n.F. die sog. Zweckausgaben trägt und der Bundesrat anderenfalls zustimmen muss? Oder gehen wir nicht lieber einen Schritt weiter, indem wir fordern, dass der Bund seine Ausgabenverpflichtungen zu Lasten der Länder zurückfährt? Diesen Punkt haben Sie, sehr geehrte Frau Hey, ja auch angesprochen, nämlich im Bereich des Sozialrechts. Eine echte Ausgabenautonomie der Länder ließe sich nur erreichen, wenn das Sozialrecht und andere ausgabenträchtige Bereiche föderalisiert würden. Dies stieße freilich eine heiße politische Diskussion an, bei der sich völlig verschiedene Standpunkte vertreten lassen. Wichtig ist aber, sich schonungslos darüber klar zu werden, dass echte Ausgabenautonomie vor allem durch Aufgabenautonomie erreicht wird. Das ist, finde ich, ein ganz essentieller Punkt, der vielleicht ein wenig zu kurz gekommen ist. 
Kotzur: Beiden glanzvollen Referaten ging es sehr intensiv um die Freiheit - Freiheit nicht nur verstanden als Finanzautonomie, sondern als individuelle Freiheit. Insbesondere Herr Waldhoff hat in seiner Legitimationstheorie mit großer Überzeugungskraft und sehr zu recht die Freiheit des Individuums, die Autonomie des Individuums in den Mittelpunkt gerückt. Damit hat er das alte Revolutionsideal der Freiheit finanzverfassungsrechtlich kontextualisiert. Was mich in diesem Zusammenhang interessiert: Wie verhält sich dieses Ideal der Freiheit zu dem lange, aber glücklicherweise in beiden Referaten nicht vergessenen Ideal der Brüderlichkeit, modern gesprochen dem Ideal der Solidarität. Frau Hey hat es beim Namen genannt, in dem sie von „bündischer Solidarität“" gesprochen hat. Wäre auch dieses Ideal der Solidarität eine der Legitimationsvoraussetzungen des Finanzverfassungsrechts, wie sie es beschrieben haben? Und in welchem Zusammenhang steht dieses Ideal der Brüderlichkeit dann zur Freiheit? Wäre die Brüderlichkeit gleichsam freiheitlich radiziert? Sie haben ja an eindrucksvollen Beispielen belegt, dass Solidarität keine nivellierende Gleichmacherei bedeuten oder zu einer völligen Überforderung des Staates, provoziert durch zu viele Aufgaben etc., führen darf. Eine abschließende Bemerkung: Gleich ob man nun die individuelle Freiheit oder den Solidargedanken in den Mittelpunkt der Legitimationstheorie stellt, sei eine kritische Nachfrage zur These von der finanzrechtlichen Mediatisierung des Unionsbürgers, die Herr Waldhoff angesprochen hatte, erlaubt. Sie hat derzeit gewiss (noch) große Überzeugungskraft, aber sie muss vielleicht doch nicht das letzte Wort sein. Es mag für den Unionsbürger eine schmerzvolle, vielleicht sogar desintegrierende Erfahrung sein, dass auch europäische Freiheit etwas kostet, dass sie Geld kostet. Überzeugend ausgestaltet könnte diese Erfahrung aber letztlich ihr ganz eigenes Integrationspotenzial entwickeln.

Engel: Beide Referenten haben in das Zentrum die Forderung gestellt: mehr Wettbewerbsföderalismus. Verfassungspolitisch habe ich dafür selbstverständlich viel Sympathie. Analytisch bin ich allerdings nicht ganz so sicher, wie weit die Wettbewerbsmetapher tatsächlich trägt. Sie trägt relativ gut in dem Fall, über den Sie nicht zu sprechen hatten, nämlich Delaware. Also Inkorporation an einer bestimmten Stelle. Die Leistung des Staats besteht in dem Rechtsrahmen für die Inkorporation. Die direkte Gegenleistung besteht darin, dass man Gebühren zahlt. Die indirekte Gegenleistung besteht darin, dass man die örtliche Anwaltschaft nutzt, die ihrerseits zu den Finanzen dieser Gebietskörperschaft beiträgt. Die Fälle, über die Sie gesprochen haben, waren einmal die Standortwahl von Unternehmen - das ist schon eine relativ hoch aggregierte 
Entscheidung. Oder die individuelle Freizügigkeit - das ist das höchste $\mathrm{Maß}$ an Aggregration, das man sich überhaupt vorstellen kann. Man verändert seinen Lebensmittelpunkt. Ich habe erhebliche Zweifel, ob wir bei dieser Art von Entscheidung noch die Erwartung haben können, die in der Metapher mitklingt: dass Wettbewerb ein sich selbst steuernder Prozess ist.

Wenn nicht, kommen wir in ein Dilemma. Je besser die Metapher funktioniert, desto problematischer werden die Dinge normativ. Die Befürchtung, dass da Umgehungsgeschäfte passieren könnten, ist nicht von der Hand zu weisen. Die Gefahr realisiert sich nicht immer, aber sie besteht. Je höher die Entscheidung der Nachfrager aggregiert ist, desto leichter fällt das normative Urteil dagegen. Denn eine Umgehung zwingender Regeln ist dann viel weniger wahrscheinlich. Gleichzeitig passt der analytische Apparat dann aber nicht mehr besonders. Weshalb ich vorschlagen würde, ihn zu ersetzen durch die Metapher von Hirschman: Abwanderung und Widerspruch. Man würde dann sagen: was wir bislang im Staat haben, ist vor allem Widerspruch. Sie ergänzen das um die Vorstellung der Abwanderung.

Das hat zwei interessante Implikationen. Die eine Implikation ist demokratie-theoretischer Natur. Bislang stellen wir uns Legitimation nur über Widerspruch vor. Kann Legitimation auch darüber erreicht werden, dass wir eine Abwanderungsmöglichkeit eröffnen? Und ist Abwanderung verfassungspolitisch eigentlich noch so völlig unproblematisch? Oder können wir uns vorstellen, dass die Länder, der Bund oder die Europäische Union gegen Abwanderung vorgehen, wenn sie als problematisch erscheint? Könnten die Betroffenen dem ein Grundrecht auf Abwanderung entgegenstellen?

Heun: Beide Referate haben sich ja in den allgemeinen Trend eingereiht, für mehr Finanzautonomie zu plädieren. Ich möchte einige Zweifel und Einwände formulieren. Zuerst zu Herrn Waldhoff, der in erster Linie das Demokratieprinzip bemüht hat, und hierzu drei Einwände. $\mathrm{Zu}$ nächst einmal ist doch die Frage: Was ist eigentlich der Bezugspunkt des Demokratieprinzips? Wenn man das Demokratieprinzip in erster Linie auf den Bund ausrichtet und hier den ausschlaggebenden Demokratiefaktor sieht, dann ist es doch so, dass der Gesichtspunkt der Einheitlichkeit der Lebensverhältnisse eine stärkere Rolle spielt als wenn man die einzelnen Gliedstaaten in den Vordergrund rückt. Und mir scheint es schon so zu sein, dass in der Bundesrepublik das Übergewicht auf der Bundesebene liegt und daraus ergeben sich dann auch für die Finanzaufteilung Konsequenzen. Zweiter Einwand, Herr Waldhoff, als Sie so sehr das Demokratieprinzip bemühten, habe ich mich gefragt, warum 
Sie nicht so konsequent sind wie Frau Hey und sagen: Dann müssen wir auch die Gesetzgebungskompetenzen dezentralisieren. Die Konsequenz ziehen Sie aber nicht. Und man muss weiter sagen: Wenn man das Demokratieprinzip so stark macht, dann muss man eigentlich alle Aufgaben, Funktionen und die Finanzen stärker dezentralisieren und den Bund auf einige wenige Aufgaben beschränken. Dann frage ich mich natürlich auch - dritter Einwand -, wenn Sie so maßgeblich das Demokratieprinzip heranziehen, warum kommt dann eigentlich nur die kleine Maus Zuschlagsrecht heraus? Der Gesichtspunkt des Wettbewerbs bei Frau Hey erweckt bei mir ebenfalls einige Zweifel, in wie fern dieser so weit trägt, wie hier angenommen worden ist. Erstens findet bereits Wettbewerb auf der Ausgabenseite statt. Zweites Argument: Die Wettbewerbsspielräume der Länder sind relativ gering, selbst wenn man ihnen Steuerkompetenzen zuweist. Und drittens: Der Wettbewerb in den USA findet in erster Linie nicht zwischen den Gliedstaaten statt, sondern zwischen den Kommunen. Darum geht es hier aber gar nicht. Und insofern ist doch sehr fraglich, ob man tatsächlich mit dem Wettbewerbsargument so viel gewinnt, wie Sie mit Ihrem Vortrag unterstellen.

G. Müller: In beiden Referaten, die mir sehr gut gefallen haben - nahe liegender Weise, nachdem das schweizerische System ja als „BlauPause“ bezeichnet worden ist -, in beiden Referaten ist zurecht der $\mathrm{Zu}$ sammenhang zwischen Aufgabenverteilung und Finanzordnung betont worden. Föderalismusreform besteht aus Neuverteilung der Aufgaben und aus Reform der Finanzordnung, Herr Waldhoff hat in einer Schlussthese gesagt, dass die gerade in Kraft getretene Föderalismusreform ohne eine Reform der Finanzverfassung Stückwerk bleibe. Wir haben in der Schweiz - das wurde gestern schon angesprochen - Ende 2004 eine Teilrevision der Verfassung beschlossen, die als „Neugestaltung des Finanzausgleichs und der Aufgabenteilung zwischen Bund und Kantonen" bezeichnet wurde. Also könnte man sagen, wir haben den methodisch richtigen Ansatz gewählt und beides zusammen gemacht: Neuverteilung der Aufgaben und neue Finanzordnung. Das Vorgehen ermöglicht auch einen größeren Einigungsbereich im Aushandlungsprozess: Man kann über die Aufgabenverteilung und zugleich über die Finanzen diskutieren. Dieser einheitliche Ansatz ist grundsätzlich positiv zu bewerten, hat aber auch Nachteile. Ich möchte das Ihnen sagen, weil Sie in Deutschland, wenn ich das richtig verstanden habe, ja in zwei Etappen vorgehen: Die Finanzreform kommt erst nach der Föderalismusreform. Es besteht bei der gleichzeitigen Reform der Aufgaben- und Finanzverteilung die Gefahr, dass die Ziele der Reform verwässert werden, weil im Blick auf die Finanzordnung Abstriche gemacht werden bei 
der Aufgabenentflechtung. Es besteht auch die Gefahr, dass die Finanzen das Ganze dominieren. Diese Gefahr hat sich in der Schweiz realisiert. Das kommt schon im Titel der Vorlage zum Ausdruck, der die Finanzen zuerst und dann die Neuverteilung der Aufgaben nennt. Ich möchte Ihnen das auch kurz am Beispiel des Verfassungstextes zeigen, den wir im Rahmen der beschlossenen Teilrevision eingefügt haben: Da findet sich jetzt eine Verfassungsbestimmung - sie ist noch nicht in Kraft - (ich sehe, die Ampel ist auf Gelb, ich kann also nur kurz zitieren), da heißt es jetzt zum Beispiel in unserer Verfassung, das Gemeinwesen, in dem der Nutzen einer staatlichen Leistung anfällt, trägt die Kosten. So eine wichtige Bestimmung haben wir jetzt in der Verfassung! Man hätte auch schreiben können: „Wer zahlt befiehlt“. Das wäre ebenso verfassungswürdig! Ein Beispiel noch zur Aufgabenentflechtung, die beabsichtigt war, aber wegen der Auswirkungen auf die Finanzordnung nicht eingetreten ist: In Art. 112b der Verfassung heißt es: „Der Bund fördert die Eingliederung Invalider durch die Ausrichtung von Geld- und Sachleistungen. Die Kantone fördern die Eingliederung Invalider, insbesondere durch Beiträge an den Bau und Betrieb von Institutionen, die dem Wohnen und dem Arbeiten dienen." Sie sehen, so differenziert ist das dann bei der Aufgabenverteilung herausgekommen! Ich möchte Ihnen sagen, Sie können sich trösten: Auch wenn Sie in Deutschland - methodisch an sich falsch - in zwei Schritten vorgehen und die Finanzreform nach der Aufgabenneuverteilung durchführen, ist die Chance, dass Sie zum Ziel kommen, nicht viel kleiner, als wenn Sie beides in einem Schritt machen.

Emmerich-Fritsche: Beide Referenten, denen ich sehr für die exzellenten Vorträge danke, haben ganz selbstverständlich angenommen, dass die Europäische Union keine Finanzautonomie hat und offensichtlich auch künftig eine solche nicht haben wird. Art. 6 Abs. 4 EUV lautet: „Die Union stattet sich mit den Mitteln aus, die zum Erreichen ihrer Ziele und zur Durchführung ihrer Politiken erforderlich sind.“ Das Bundesverfassungsgericht hat im Maastricht-Urteil verhindert, dass diese Vorschrift als Kompetenz-Kompetenz oder als Finanzautonomie der Gemeinschaft ausgelegt wird. Sie gilt nur als politische Zielbestimmung, insbesondere auch, weil ein sie näher bestimmendes Verfahren fehlt. Nun meine Frage: Der Unionsverfassungsvertrag, der derzeit noch nicht in Kraft ist, nimmt diese Vorschrift in Art. I-54 auf und begrenzt sie auf Finanzmittel. Außerdem sieht er ein Gesetzgebungsverfahren vor, das diese Vorschrift näher bestimmt und damit Verbindlichkeit impliziert. Würden sich Ihre Konzepte ändern, wenn, sofern der Verfassungsvertrag mit einem solchen Inhalt in Kraft tritt, nun doch eine par- 
tielle Finanzautonomie der Gemeinschaft auf den Weg gebracht wird? Insbesondere auch vielleicht an Herrn Waldhoff die Frage, wie beurteilen Sie dann die Frage der demokratischen Legitimation?

Selmer: Ich darf mich zunächst für die überzeugenden Referate herzlich bedanken und insbesondere Ihnen, Frau Hey, meine Bewunderung dafür aussprechen, dass Sie nicht der Versuchung erlegen sind, auf die Ihnen bisher eher vertrauten Gefilde des Steuerrechts auszuweichen, sondern sich den spezifischen Herausforderungen der Finanzverfassung in glänzender Weise gestellt haben. In diesem Zusammenhang einige Bemerkungen zum Thema Finanzautonomie der Länder: Bundesverfassungsgericht hat in seinen Finanzausgleich-Entscheidungen von 1986 und 1992 unmissverständlich die Eigenverantwortlichkeit der Länder für die Folgen ihrer finanzpolitischen Entscheidungen hervorgehoben, sie allerdings durch einen - bis heute nicht näher erläuterten - Ausnahmevorbehalt für den Fall eine Haushaltsnotsituation relativiert. Vor seinem Hintergrund hat das Gericht 1992 ein Fass aufgemacht, von dem ich hoffe, dass es dies am 19. Oktober wieder schließen wird; Herr Wieland wird das freilich anders sehen. Sie selbst, Frau Hey, haben in diesem Kontext die Grenzen der Nothilfepflicht der anderen Bundesgenossen angesprochen und diese auf „unbeherrschbare Notlagen“ beschränkt. Diese Formel, die sich überdies sowohl in die Vergangenheit als auch in die Zukunft projizieren lässt, bedarf, weil für sich genommen wenig ergiebig, gewiss noch der weiteren Aufhellung. Meinerseits tendiere ich zu der Auffassung: Es gibt, abgesehen vom Staatsnotstand, außerhalb des verfassungsrechtlich vorgegebenen Finanzausgleichs einschließlich der insoweit zugelassenen Bundesergänzungszuweisungen, keine weitere bundesgenossenschaftliche Hilfe bei (extremen) Haushaltsnotlagen. Jeder muss grundsätzlich mit dem auskommen, was ihm zusteht. Dass dies wie auch die Einhaltung der verfassungsrechtlichen Verschuldungsgrenzen den Ländern bei Zuweisung einer gestaltbaren Steuerquelle leichter fiele, trifft gewiss zu, Frau Hey. Bis dahin hilft eben nur der Ausweg größerer Sparsamkeit.

Häberle: Herr Waldhoff gehört zusammen mit Herrn Voßkuhle zu jenen Mitgliedern unserer Vereinigung, die sich als Studenten nach dem vierten Semester im zentralistischen Bayern aus Bayreuth entfernt haben und sich in München zu Höherem berufen fühlten. Dies haben wir beiden eigentlich nie verziehen. Darum werde ich auch in einem Punkt zu Herrn Waldhoff kritisch sprechen; von Ihnen Frau Hey bin ich natürlich sehr beeindruckt. Ich stelle folgende Frage: Müssten wir uns nicht in einem tieferen Sinne mindestens mittelfristig - dies zielt gegen 
Ihren Leitsatz 21, Herr Waldhoff - mit dem Gedanken vertraut machen, eine EU-eigene Steuer zu erheben? Ich begründete dies mit der Umkehrung eines klassischen Satzes von 1776 in: „no respresentation without taxation“. Klassikertexte können ja auch dann richtig sein, wenn man sie umkehrt: Hier zeigt sich in Sachen Wahrheit eine tiefe Dialektik in der Geistesgeschichte. Jetzt näher zur europäischen Integration. Es gibt neben den „harten“ Integrationsfaktoren wie dem Euro auch „weiche“, die nachhaltig im Ensemble der europäischen Teilverfassungen wirken. Ich nenne als identitätsstiftendes Element die Europahymne Beethovens und den Europatag, ich nenne die Europaflagge als weiteres kulturelles Identitätselement des werdenden Europa, so offen dessen „Finalität“ ist und so erkennbar Integrationsdefizite sind. Wenn wir aber Europa konsequent vom Bürger her denken, und die Unionsbürgerschaft gibt ja den positivrechtlichen, vom EuGH verstärkten Ansatz hierzu - dann kommen wir doch zu einem Punkt, an dem wir für eine EU-Kompetenz zu einer eigenen EU-Steuer votieren sollten, so schmerzlich dies, zumal für einen Schwaben, auch sein mag. Der Bürger muss Europa in vielfacher Hinsicht „spüren“ können. - Gerne sage ich noch etwas Positives zu Ihnen, Herr Waldhoff. Ich beziehe mich auf Ihren Leitsatz 16. Dort heisst es, der Bundesstaat sei ein „bewegliches System“. Dieser Ansatz erlaubt uns, den Klassikertext meines akademischen Lehrers Konrad Hesse, den „unitarischen Bundesstaat“ von 1962, als ein Element zu verbinden mit anderen Aspekten des gemischten Föderalismus: mit dem kooperativen und dem separativen Föderalismus, dem Konkurrenzföderalismus und dem zeitlich begrenzten solidarischen „fiduziarischen Föderalismus" im Blick auf den innerdeutschen Finanzausgleich von West nach Ost. Hier stimme ich Ihnen, lieber Herr Waldhoff, vorbehaltlos zu.

G. Jochum: Ich habe eine Frage zu Frau Hey. Ich kann Ihnen in jeder Beziehung zustimmen, dass die Rechtsprechung des EuGH insbesondere zu den Grundfreiheiten und den Steuern dazu führt, dass die Finanzautonomie der Mitgliedstaaten zunehmend ausgehöhlt wird. Ich bin allerdings nicht Ihrer Meinung, dass der EuGH da nichts gegen tun könnte. Der EG-Vertrag, zumindest seit Maastricht weißt ja nun eine klare Verpflichtung der Mitgliedstaaten zu einer gesunden Haushaltspolitik auf und es stellt sich in der Tat die Frage, ob die Rechtsprechung des EuGH nämlich fiskalische Gründe als Beschränkung oder Diskriminierung von grenzüberschreitenden Besteuerungssachverhalten nicht zuzulassen vor dem Hintergrund des Art. 104 haltbar ist. Ich bin mir zwar bewusst, dass ich damit ein Fass aufmache, das vielleicht die gesamte Rechtsprechung umkehren würde, aber ich bin der Meinung solange die Mitgliedstaaten nicht in der Lage sind, die Besteuerungsgrund- 
lagen zu harmonisieren und solange die Rechtsprechung des EuGH Anreize für die Mitgliedstaaten schafft, Steuerdumping zu betreiben, wäre es vielleicht aus integrationspolitischer Sicht sinnvoll, wenn der EuGH jetzt eine umgekehrte Richtung einschlägt und den Art. 104 als gemeinschaftsrechtlichen Fiskalvorbehalt zur Rechtfertigung diskriminierender Besteuerungen zulässt.

Pernice: Auch ich möchte den Punkt ansprechen, den Herr Jochum eben angesprochen hat, nur unter einem allgemeineren Gesichtspunkt, meine Frage richtet sich an Frau Hey. Sie sprechen von einer Haushaltsautonomie, einer formalen Haushaltsautonomie, und bedauern dann, dass sich in der Grundfreiheitsrechtsprechung, im Beihilfenrecht - und ich würde auch die Praxis zur Haushaltsdisziplin hinzufügen - Einschränkungen dieser Autonomie finden. Muss man aber doch nicht einfach zugeben, dass diese Schranken der Haushaltsautonomie gewollt sind, weil die EG besteht, mit ihren Grundfreiheiten? Diese Schranken sind notwendig, weil sonst dieser Binnenmarkt nicht funktioniert. Damit muss sich der nationale Gesetzgeber eben abfinden, oder gibt es eine andere Lösung?. - Ich habe eine zweite Bemerkung zu Herrn Waldhoff und seiner These 14. Sie gehen davon aus, das auf jeder Ebene eine Mindesteinnahmeautonomie bestehen muss, auf jeder Aufgabenebene. Ich habe dann aber, Herr Häberle hat es schon angesprochen, in These 21 gefunden, dass das offenbar nicht für die europäische Ebene gilt. Ist das ein Widerspruch oder ist es eine Einschränkung? Ich habe eine weitere Frage zu These 19. Da geht es um Zuteilungskriterien, wo Sie sagen, statt Effizienz sollte man doch lieber die demokratische Legitimation als Zuteilungskriterium heranziehen. Mir leuchtet das natürlich ein, weil demokratische Legitimation immer das Wesentliche ist. Die Frage ist aber, wie das aussehen soll? Wie funktioniert ein solches Kriterium, und entspricht diese Lösung dem Subsidiaritätsprinzip? Letzter Satz: In These 17 am Ende ist angedeutet, dass mit zunehmender inter- und supranationaler Verflechtung der Gedanke der einheitlichen oder gleichwertigen Lebensverhältnisse weiter an Bedeutung verlieren würde. Gilt nicht gerade das Gegenteil? Mir kam da das Prinzip der Kohäsion, der Einheitlichkeit der Lebensverhältnisse als Grundlage für den Zusammenhalt des Staates in dem Kopf. Ist das auf europäischer Ebene anders? Wozu sonst sollte die gesamte Kohäsionspolitik, die eines Tages auf einen Finanzausgleich auf europäischer Ebene hinauslaufen könnte, dienen? Ich glaube, ein gewisses Maß an wirtschaftlichem und sozialem Zusammenhalt ist Grundbedingung für das Funktionieren eines politischen Systems, auf welcher Ebene auch immer. 
Michael: Ich habe eine dogmatische Nachfrage an Frau Hey. Sie haben völlig zutreffend klargestellt, der allgemeine Gleichheitssatz binde jeden Steuergesetzgeber nur ihm Rahmen seiner Verbandskompetenz, greife also nicht gegenüber Ungleichheiten jenseits der Landesgrenzen. Sie haben dann aber im Gegensatz dazu betont, der allgemeine Gleichheitssatz binde die Landessteuerverwaltung und gebiete also einen bundesgleichmäßigen Vollzug von Verfassung wegen. Was soll das konkret bedeuten? Mir fallen dazu drei denkbare Konsequenzen ein. Die erste Möglichkeit haben Sie betont, nämlich Art. 3 Abs. 1 GG als institutionelles Gebot zu interpretieren. Das sehe ich sehr kritisch. Gebietet der allgemeine Gleichheitssatz wirklich, ja spricht er überhaupt dafür, eine bundeszentrale Steuerverwaltung einzuführen? Dann wäre - auch jenseits der Steuerverwaltung - jede Ausführung der Bundesgesetze durch die Länder als eigene Angelegenheit in Frage zu stellen. Dann wäre Art. 84 Abs. 1 S. 1 GG als zentraler Bestandteil unseres Bundesstaates sozusagen vor Art. 3 Abs. 1 GG zu rechtfertigen. Da habe ich meine Bedenken. Ich denke, dass die institutionelle Bündelung im Rahmen der Jurisdiktion, also im Bundesfinanzhof, ausreichen müsste. Die zweite Möglichkeit wäre, Art. 3 Abs. 1 GG als Willkürverbot zu verstehen, womit sich wohl jeder anfreunden könnte. Dann könnte man aber auch sagen, dass sich Ihre Forderung in der nach der rechtsstaatlichen Gesetzesbindung der Steuerverwaltung erschöpft. Wir brauchen dann den Gleichheitssatz als dogmatischen Anknüpfungspunkt allenfalls, um die Zulässigkeit einer Verfassungsbeschwerde zu eröffnen. Die dritte Möglichkeit - und mich würde interessieren, ob Sie auch das gemeint haben - wäre die Interpretation von Art. 3 Abs. 1 GG als Gebot verhältnismäßiger Gleichbehandlung. Das halte ich für denkbar und spannend, würde mich aber dafür interessieren, was das in der Praxis bedeuten würde und ob Sie dabei gegebenenfalls an konkrete Fälle gedacht haben.

Kloepfer: Wir haben zwei relativ einmütige Referate gehört, die sich auch zum großen Thema der Integration des Finanzwesens in das Gesamtgefüge der Verfassung geäußert haben. In der Tat scheint mir dies eine wichtige Grundfrage zu sein, die man vielleicht noch ein bisschen akzentuieren könnte: Wo ist eigentlich heute noch die heutige Legitimation für die Sondersituation der Finanzverfassung? Man könnte hier versucht sein zu argumentieren, dass es praktisch gar nicht anders gehe, weil die Probleme der Finanzverfassung wegen ihrer Kompliziertheit einer Spezialregelung bedürften. Zwingend ist das aber nicht. Dies alles ist ja im übrigen nicht nur eine politische und rechtliche Frage, sondern natürlich auch eine wissenschaftspolitische Frage für die Rechtswissenschaft. Vor noch gar nicht so langer Zeit fand das Finanzverfassungs- 
recht jedenfalls in den kleineren Lehr- und Anleitungsbüchern des Staatsrechts praktisch überhaupt keine Beachtung. Das beginnt sich glücklicherweise etwas zu verändern und hier würde ich ganz gerne noch etwas zur stärkeren Integration des Finanzverfassungsrechts in das allgemeine Staatsrecht hören - auch im Hinblick auf die Föderalismusreform II. Wo ist die heutige Legitimation dafür, dass die Finanzverfassung noch eine getrennte Verfassungsregelung ist? Jedenfalls brauchen wir künftig mehr Integration zwischen der allgemeinen Verfassung und der Finanzverfassung.

Steuern und individuelle Freiheit - der Gesichtspunkt ist ja außerordentlich anregend von beiden Referenten aufgenommen worden. Herr Waldhoff, es läge doch in der Konsequenz Ihrer Ausführungen, noch etwas mehr zu der Frage zu erfahren: Wie verhält sich eigentlich das Steuerwesen zu den Grundrechten? Vielleicht könnte man hier doch noch stärker konturieren als Sie haben andeuten können. Das Verfassungsrecht steht ja nach wie vor etwas ratlos vor der Frage nach dem Verhältnis von Art. 14 GG zu den öffentlichen Abgaben, vor allen Dingen im Hinblick auf die Gesamtbelastung durch Abgaben, also vor dem Problem der Belastungskumulation durch Abgaben selbst oder durch Abgaben und sonstige Steuerungsinstrumente. Hier sind noch wichtige dogmatische Aufgaben zu leisten. Interessant ist daher der schüchterne Versuch des Grundgesetzes in Art. 106 Abs. 3 S. 4 Nr. 2 GG, (bei der Regelung der Grundsätze der Umsatzsteuerverteilung zwischen Bund und Ländern) die nur föderalistische Sichtweise der Finanzverfassung auszuweiten und auch die Individualsphäre des Steuerpflichtigen in den Blick zu bekommen, wenn dort die Vermeidung einer Überbelastung des Steuerpflichtigen zum Verfassungsgebot wird. Jedenfalls ist dies ein Hinweis darauf, dass mehr Integration zwischen allgemeiner Verfassung und Finanzverfassung geleistet werden könnte.

Nur noch eine kurze Bemerkung zum Verhältnis Steuern und nichtsteuerliche Abgaben. Ich meine, die Legitimation der Sonderbehandlung von nicht-steuerlichen Abgaben beginnt abzunehmen. Die Föderalismusreform II würde zu kurz springen, wenn sie sich nicht auch diesem Thema stellen würde. Ist die Sondersituation der Sonderabgaben und der vielen neuen Abgaben gegenüber der steuerbezogenen Finanzverfassung eigentlich heute noch gerechtfertigt? Wie kann man die nichtsteuerlichen Abgaben dort stärker in das Finanzverfassungsrecht anbinden? Brauchen wir eine Finanzverfassung auch für nichtsteuerliche Abgaben?

Damit hängt ein letzter Punkt zusammen. Wir nehmen bisher als völlig selbstverständlich an, dass der erste Teil der Finanzverfassung unseres Grundgesetzes (Art. 104a-109 GG) nur eine Steuerfinanzverfassung 
ist, während sich der zweite Teil der Finanzverfassung (Art. 110-115 GG) beim Haushaltsverfassungsrecht plötzlich für alle Einnahmen und damit auch für alle Abgabenarten öffnet. Das ist einer der Brüche der bisherigen Verfassung, der auch bedacht werden muss, wenn eine Föderalismusreform II mit Tiefgang gelingen soll.

Drïen: Ich möchte eine Rückwirkung des Finanzausgleiches unterstreichen, die Frau Hey nur kurz angesprochen hat. Es geht um die Frage, wie der Finanzausgleich auf den gleichmäßigen Steuervollzug im Bundesstaat zurückwirkt. Der Bundesrechnungshof hat mehrfach die Vollzugsdivergenzen im Bundesstaat gerügt, Herr Michael hat dazu aus grundrechtsdogmatischer Sache bereits etwas gesagt. Ich meine, eine Ursache liegt in der Fehlsteuerung durch die Finanzverfassung. Die Situation ist am greifbarsten am Beispiel der Betriebsprüfungspraxis im föderalen Steuerstaat. Es besteht seit jeher ein Nord-Süd-Gefälle mit einem milderen Klima im Süden und seit der deutschen Wiedervereinigung auch ein West-Ost-Gefälle. Das liegt daran, dass die Geberländer wenig Veranlassung sehen, mehr in die Prüfungsdienste zu investieren, weil die Personalkosten ihren Haushalt belasten, wohingegen die Mehrsteuern in den Finanzausgleich fließen. Spiegelbildlich haben die Nebenländer nur geringen Anreiz die Steuerquellen gleichmäßiger auszuschöpfen, weil ihre Finanzzuweisungen entsprechend gekürzt werden. Das ist eine Störwirkung des Finanzausgleichs, die bei der Finanzreform mit in den Blick zu nehmen ist. Frau Hey hat als Reformvorschlag das Stichwort der Zentralisierung der Steuerverwaltung genannt. Ob man wirklich zu einer Bundessteuerverwaltung kommen sollte, die seinerzeit die Alliierten verhindert haben, darüber muss man sorgsam nachdenken. Jedenfalls bei den Prüfungsdiensten für international oder bundesweit tätige Großbetriebe und Konzerne spricht viel für eine Zentralisierung, weil hier ein steueradministrativer Konkurrenzföderalismus fehl am Platze ist. Wesentlich scheint mir die allgemeine Erkenntnis, dass die föderale Steuererhebung nicht hinter einem Schleier des Nichtwissens über den Finanzausgleich erfolgt.

Häde: Zuerst eine Bemerkung zu Herrn Waldhoff. Demokratische Rückkoppelung, das klingt immer gut. Mir erscheint es nur in der praktischen Umsetzung gerade bei diesem Thema etwas fraglich. Ein Beispiel dafür ist Ihre These 15, wo es um die Abgrenzung der notwendigen von den tatsächlichen Ausgaben geht. Theoretisch stimme ich dem zu, dass es notwendige Ausgaben geben muss und nicht-notwendige Ausgaben. Es ist aber praktisch nie gelungen, eine solche Abgrenzung zu treffen. Ich kann mich noch gut an die mündliche Verhandlung vor dem 
Bundesverfassungsgericht erinnern, die $\mathrm{zu}$ der Finanzausgleichsentscheidung 1999 führte. Damals hat Herr Vogel versucht, dem Senat nahe zu bringen, dass diese Unterscheidung praktisch nicht durchführbar ist. Leider ist ihm das nicht gelungen. Das Bundesverfassungsgericht hat in seinem Urteil das Maßstäbegesetz erfunden und gefordert, dass dort eine Abgrenzung zwischen notwendigen und sonstigen Ausgaben zu treffen sei. Die Praxis hat das ignoriert, weil es wohl nicht umsetzbar war. Eine zweite Bemerkung, diesmal zur These Nr. 13 von Frau Hey. Diese These bringt meines Erachtens die EG sehr stark in die Nähe eines Bundesstaates. Sie sprechen davon, dass Eigenverantwortung und Einstandspflichten der Gliedstaaten im Wege der Prävention zum Ausgleich zu bringen seien. Und im Zusammenhang mit dem Begriff Gliedstaaten gehen Sie dann gleich über zu den Art. 104 und 103 EG-Vertrag. Mir erscheint insoweit der Hinweis wichtig, dass diese Vorschriften direkt nur auf der EG-Ebene und zwischen den Mitgliedstaaten und der Gemeinschaft gelten, aber gerade nicht im innerstaatlichen Bereich. Wir können also etwa den Haftungsausschluss des Art. 103 EGV nicht auf das Verhältnis zwischen Bund und Ländern anwenden. Deshalb gibt es derzeit drei laufende Verfahren vor dem Bundesverfassungsgericht, in denen Berlin, das Saarland und Bremen Haushaltsnotlagen-Bundesergänzungszuwendungen einfordern. Hier geht es letztlich um das Einstehen, das Haften für fremde Schulden. Die beiden Ebenen - die der EG und die innerstaatliche - sind also einerseits deutlich voneinander zu trennen. Andererseits habe ich in beiden Referaten den Versuch vermisst, diese Ebenen dann doch wieder etwas zu verschränken. Der Art. 104 EGV ist jetzt schon zweimal genannt worden. Ich möchte ihn noch einmal erwähnen und zumindest als Frage in den Raum stellen, ob es nicht doch möglich ist, dass Art. 104 EG-Vertrag, der die gemeinschaftsrechtliche Haushaltsdisziplin regelt, so stark auf das innerstaatliche Recht einwirkt, dass ein Urteil wie 1992 (BVerfGE 86, 148) inzwischen gemeinschaftsrechtswidrig sein könnte. Der EG-Vertrag in der neuen Fassung durch den EU-Vertrag gilt erst seit dem 1. 11. 1993. Dass das Gemeinschaftsrecht seither Haushaltsdisziplin fordert, muss doch auch innerstaatlich Auswirkungen haben. Wie genau wirkt sich das aus? Insoweit habe ich eine Stellungnahme in den Referaten vermisst. Vielleicht können Sie die noch nachholen.

Püttner: Ich kann unmittelbar daran anschließen. Auch ich habe Zweifel, ob und wie die Haushaltsdisziplin funktionieren kann. Und da beziehe ich mich, Frau Hey, auf Ihre These Nr. 19, wo Sie ein System vorschlagen, nach dem die Länder in die Pflicht genommen werden sollen. (Was übrigens Abbau von Länderautonomie bedeuten würde.) Es ist in- 
teressant: wenn es konkret wird, dann geht man eher auf den Rückzug. Aber wir müssen doch konstatieren, dass sowohl der Art. 115 GG als auch dieser Art. 104 EGV mit dem Stabilitätspakt im Grunde genommen das Ziel nicht ganz erreicht hat. Denn immer wenn es ernst wird, hat man ja vor Konsequenzen zurückgeschreckt. Die anderen Länder waren nicht bereit, Deutschland und andere wirklich zu packen, als es nicht lief, weil man Angst hatte, dass man ja selber auch belastet werden könnte. Und so stellt sich dann doch die Frage, welche Sanktion Sie sich vorstellen, wenn da nach Ihrer These 19a Quoten festgelegt werden sollen für die Verschuldung von Bund und Ländern. Man müsste wissen, was geschieht, wenn es einer doch anders macht. Und ich bin auch der Meinung, der Bund müsste sich dann auch binden, also nicht nur die Länder. Und das Gefährliche an solchen Quoten ist natürlich, dass dann fast eine Einladung vorliegt, die Quoten noch auszuschöpfen. Das ist eine gefährliche Sache, deshalb würde ich meinen, man sollte darüber noch mal nachdenken. Aber das Ganze wird ja wohl ohnehin nicht ganz gehen, denn diese gestaltbare alternative Einnahmequelle, die Sie dann fordern, da hab ich den Eindruck, die gibt es nicht. Ich lasse mich aber gern eines anderen belehren.

Götz: In der EU fehlen für einen Finanzausgleich jenseits der Strukturpolitik die integrationspolitischen Voraussetzungen. Eine Feststellung von Herrn Waldhoff, die ich nachdrücklich unterstreichen würde. Bei einem Finanzausgleich, wenn wir richtig von ihm sprechen, wird es darum gehen, die Gesamtheit der Finanzbeziehungen in einem Bundesstaat oder in einem vergleichbaren Gebilde so zu gestalten, daß jeder Teil die von ihm durch die Gesamtverfassung zugewiesenen Aufgaben wahrnehmen kann. Eine solche Gesamtverfassung, die die EU und die Mitgliedstaaten umfasst und eine Aufgabenverteilung bewirkt, existiert nicht. Sie würde auch nach Inkrafttreten der künftigen EU-Verfassung nicht existieren. Nun zur These 21 von Herrn Waldhoff, zur Asymmetrie hinsichtlich der Entscheidungen über Einnahmen und Ausgaben in der EU. Mir scheint, daß durch die Betonung der Asymmetrie vielleicht nicht hinreichend zum Ausdruck kommen könnte, wie stark in den finanzverfassungsrechtlichen Entscheidungsprozessen in der EU die Verschränkung der Entscheidungen über Einnahmen und Ausgaben ist. Der Entscheidungsprozeß erfolgt in vier Stufen. Am Anfang steht die siebenjährige finanzielle Vorausschau, eine Einigung der Staats- und Regierungschefs auf höchster Ebene. Wir haben soeben den Vorgang für die Periode 2007 bis 2013 erlebt. Es ist dies, wie man populär wohl sagen darf, ein Hauen und Stechen. Unentwegt werden Einnahmen- und Ausgabenentscheidungen miteinander verknüpft. Bei letzteren geht es 
vor allem um die großen relevanten Blöcke der Strukturmittel und der Agrarausgaben. Von allen Staaten wird durchgerechnet, wie am Ende der Saldo zu ihren Lasten oder Gunsten aussieht. Im zweiten Schritt kommt das Europäische Parlament ins Spiel. Ihm werden die Ergebnisse der Einigung der Staats- und Regierungschefs als Grundlage einer interinstitutionellen Vereinbarung vorgelegt. Der Eigenmittelbeschluß als dritte Stufe bringt wiederum die nationalen Parlamente ins Spiel, da er ratifikationsbedürftig ist. Schließlich folgen viertens die jährlichen Haushaltsprozeduren zwischen Rat und Europäischem Parlament. Sie sind zwar vorgeprägt durch die finanzielle Vorausschau, weisen aber doch noch gewisse politische Handlungsspielräume auf. Alles in allem besteht eine prononcierte Verknüpfung der Entscheidungen über Einnahmen und Ausgaben. Ich möchte diese Gelegenheit wahrnehmen, um Zweifel zum Ausdruck zu bringen, ob der Beitragsschlüssel, nach dem die Aufbringung der Eigenmittel der EU berechnet wird und der sich im wesentlichen an der absoluten Höhe des Bruttosozialprodukts der Mitgliedstaaten ausrichtet, wirklich geeignet ist zur Herstellung der notwendigen Lastengleichheit und Beitragsgerechtigkeit. Dies sind wichtige Anforderungen, die die Position der Staaten betreffen. Nachdem wir heute von Herrn Waldhoff so viel über den Individualbezug der Finanzverfassung gehört haben, darf man die Gleichheits- und Gerechtigkeitsforderung auch auf die Individuen beziehen. Ich meine, das Kriterium des relativen Wohlstandes und daher des Pro-Kopf-Bruttosozialproduktes wäre sachgerechter. Nach diesem Kriterium ist Deutschland schon seit 2003 auf den elften Platz in der Union zurückgefallen.

Winter: Erlauben Sie mir, dass ich angesichts der vorgestellten großen Entwürfe gewissermaßen eine Froschperspektive einnehme, nämlich die eines Not leidenden Bundeslandes: des Stadtstaates Bremen. Ich fürchte, anders als bei den bekannten Fröschen wird Bremen lange strampeln können, ohne dass sich Butter unter seinen Füßen bildet, auf der es aus seiner Schuldenfalle herauskommen kann. 2004 wurden die Bundesergänzungszuweisungen eingestellt. Seitdem sind bei einem Haushalt von ca. 4 Mrd € jährlich ca. 1 Mrd. € als Kredtit aufzunehmen. Davon fließt die Hälfte in die Bedienung der zur Zeit 13 Mrd. € Schulden, die bis 2009 auf 16 Mrd. $€$ angewachsen sein werden. Die Strategie Bremens ist, über eine Klage beim Bundesverfassungsgericht weitere Bundesergänzungszuweisungen zu bekommen. Nach dem Berliner Urteil des Bundesverfassungsgerichts muss man wohl skeptisch sein, ob das Erfolg verspricht. Bremen könnte deshalb ebenso wie Berlin und vielleicht auch das Saarland mit der Verschuldung selbst fertig werden müssen. Hier stellen sich eine Reihe von Fragen, die ich gern der Referentin und 
dem Referenten vorlegen würde. Vier Elemente möchte ich kurz andeuten, die alle zu einem Gesamtpaket gehören, das geschnürt werden muss. Das eine ist natürlich Ausgabenkürzung, aber bitte sehr, das wurde schon gesagt, es ist illusorisch anzunehmen, dass man die Landes- und Gemeindeausgaben auf die bundes- und landesverfassungsrechtlichen Pflichtausgaben kürzen kann. Am Beispiel Bremens: das Land hat sehr stark und erfolgreich in die Wissenschaft investiert. Da dies kaum eine Pflichtaufgabe ist - sollen die Universität und die Hochschulen nun geschlossen werden? Welches sind also die inhaltlichen Kriterien einer Begrenzung der Kreditaufnahme in der Haushaltsnotlage? Wie immer sie aussehen, nur über Ausgabenkürzung ist kein Herauskommen aus der Verschuldung. Zweitens: Steigerung der Einnahmen. Denkbar wäre eine Entschuldungsabgabe auf die Einwohner und die in Bremen Arbeitenden, eine Abgabe, mit der sie sich bekennen müssten, ob sie Bremen als Bundesland weiter wollen oder nicht. Frau Hey, sie sagten, das sei finanzverfassungsrechtlich unzulässig. Wenn man die Abgabe aber nicht als Steueraufschlag sondern als Finanzierungssonderabgabe ausgestaltet, meinen Sie nicht, dass sie den Homogenitätskriterien des Bundesverfassungsgerichts genügen würde? Drittens: Eine Entschuldung wird nur funktionieren, wenn in das Gesamtpaket der Haushaltssanierung auch die in- und ausländischen Gläubiger einbezogen werden. Ich kenne die Gegenargumente: dass die Banken wegen höherer Risiken dann höhere Zinsen verlangen werden. Warum denn nicht? Sind die Zinsen wirklich erheblich höher? Hätten sie vielleicht nützlich erzieherische Effekte bei der Neuverschuldung? Haben andererseits nicht auch die Banken ein Interesse daran, ihre Gelder anzulegen? Meine Frage ist also: wäre eine teilweise Aufhebung von Schulden verfassungs- und völkerrechtlich zulässig? Viertens: Die Finanzverfassungsreform muss zu einem transparenteren und gerechteren Ausgleich kommen. Bremen wird nach Meinung von Finanzwissenschaftlern durch das Wohnsitzprinzip bei der Einkommensteuer und die Umsatzsteuerverteilung arm gerechnet und erscheint dadurch als Bittsteller im Finanzausgleich. Herr Waldhoff, Sie akzeptieren das Wohnsitzprinzip bei der Einkommensteuerzerlegung, aber stimmen seine historischen und wirtschaftlich-sozialen Voraussetzungen noch für die Stadtstaaten? Und was die Umsatzsteuer angeht: Glauben Sie, dass die Verteilung nach Einwohnerzahlen so verstanden werden könnte, dass die Einwohner bereits an dieser Stelle gewichtet werden? Schließlich: Ist der bis zu 25-prozentige Vorabzug für notleidende Länder vielleicht verfassungswidriges Verfassungsrecht, weil er gegen das Stufenprinzip der Finanzverfassung verstößt? 
Meyer: Wenn ich mich auf die Finanzverfassung des Grundgesetzes beschränken kann so hat sie zwei Besonderheiten. Eine systematische und eine politische. Das ist wichtig zu erkennen, wenn man im Sinne von Kloepfer unsere Strategie, nämlich die Strategie der Wissenschaft zu diesem Problem ordentlich fixieren will. Die systematische Besonderheit besteht darin, dass erstens der Kern der jetzigen Finanzverfassung Anfang der fünfziger Jahre durch einfaches Gesetz in das Grundgesetz gekommen ist. Schon damals, also 1949, war man sich darüber im Klaren, dass eine Zweidrittel-Mehrheit vermutlich nicht zu erreichen ist. Es ist der einzige Abschnitt des Grundgesetzes, der durch einfaches Gesetz auf Grund einer parlamentarischen Ermächtigung Verfassungsrecht geworden ist. Die zweite Besonderheit ist, dass es der einzige Abschnitt des Grundgesetzes ist, der unsinnige Bestimmungen enthält. Zwei von diesen unsinnigen Bestimmungen sind hier genannt worden und aus ihnen sind auch Schlüsse gezogen werden. Die erste unsinnige Bestimmung ist Art. 106 Abs. 5 GG. Dort ist von gemeindlichen Hebesätzen die Rede, die eingeführt werden können. Dummerweise aber nicht Hebesätze auf Steuerquellen, die allein Sinn machen, sondern Hebesätze auf Steuererträge. Was wirklich keinen Sinn macht. Das ist ein Relikt der Trögerkommission, das geblieben ist, obwohl die Grundlage weggefallen ist, weil für sie keine Mehrheit vorhanden war.

Die zweite unsinnige Bestimmung, die auch in beiden Referaten vorkommt, ist Art. 106 Abs. 3 S. 4 Nr. 2 GG: Die berühmte Einheitlichkeit der Lebensverhältnisse, die gewahrt, noch nicht einmal hergestellt werden soll. Dies steht in einem Kontext, der damit überhaupt nichts zu tun hat. Die Einheitlichkeit der Lebensverhältnisse könnten sie vielleicht durch unterschiedliche Steuersätze oder durch unterschiedliche Steuerertragsverteilung erreichen. In 106 Abs. 3 S. 4 Nr. 2 GG ist aber ausschließlich davon die Rede, wie eine Steuer, die schon erhoben ist, für die der Bürger also schon geschröpft worden ist und zwar gleichmäßig, verteilt wird auf den Bund und - jetzt kommt es - auf die Ländergesamtheit. Es geht also um eine Quote für die Ländergesamtheit. Damit können sie aber die Einheitlichkeit der Lebensverhältnisse weder wahren noch herstellen. Das ist eine unsinnige Forderung. Irgendjemand wollte eine der Lebenslügen eher des politisch linken Spektrums irgendwo im Grundgesetz stehen haben. Und zu meiner großen Verwunderung gibt es viele Kollegen, die schlicht diesen Terminus zitieren und nicht merken, dass er in diesem Zusammenhang gar keinen Sinn ergibt.

Die dritte, durch die neue Reform in das Grundgesetz gekommene Unsinnigkeit ist Art. 104a Abs. 4 GG. Hier wird ein Zustimmungsrecht des Bundesrates bei bestimmten finanziell belastenden Gesetzen des Bundes statuiert, dem Bund aber nicht die verfassungsrechtliche Mög- 
lichkeit gegeben, entgegen Art. 104a Abs. 1 GG durch völlige oder teilweise Übernahme der Kosten das Zustimmungsrecht „abzukaufen“. Welchen Sinn soll das Zustimmungsrecht haben? Wer soll schon einer Belastung zustimmen, die er nicht durch das Zustimmungsrecht mindestens mindern könnte. Die Finanzverfassung sollte also ein ganz besonderes Objekt unserer Zuneigung sein und daraus sollte sich auch die Strategie entwickeln.

Die zweite Eigenheit ist eine politische. Die Finanzverfassung wird von der Politik - und das haben Herr Kirchhof wie ich, die in der Kommission gerade auch bei den Finanzfragen beteiligt gewesen sind, erfahren - nicht strukturell gesehen, sondern ausschließlich mit dem Rechenschieber. Das führt zur der Warnung, auf eine Finanzverfassungsreform von struktureller Bedeutung zu hoffen. Die jetzige Reform hat sieben Jahre gedauert und ist nur erfolgreich gewesen, weil es zum Schluss eine große Koalition gegeben hat. Die Finanzverfassungsreform wird mindestens sieben Jahre dauern. Und es ist nicht zu erwarten, dass wir dann weiterhin eine große Koalition haben werden. Außerdem gab es innerhalb der Länder durchaus politische Vorbehalte gegen das Reformvorhaben und nur auf Druck der ostdeutschen Länder wurde ein Nachdenken darüber konzediert. Die Konsequenz für unsere Strategie ist, wir müssen sehen, dass wir unsere strukturellen Überlegungen mit dem geltenden Verfassungsrecht verbinden. Und das lässt sich durchaus. Ich will es an einem Beispiel zeigen, bei dem ich mit Herrn Waldhoff nicht übereinstimme. Herr Waldhoff, Sie haben ja das Steuererhebungsrecht oder die ganze Finanzverfassung individualrechtlich basiert, haben dann aber den Gemeinden ein eigenes Steuererfindungsrecht abgesprochen. Dies ist kein zwingender Schluss, erst recht nicht aus Art. 28 GG, aber auch nicht aus Art. 105 Abs. 2a GG. Denn dieser sagt nur, inwieweit eine ausschließliche Landesgesetzgebungskompetenz besteht. Er besagt aber nichts über die Frage, ob die Kommunen andere bisher nicht geregelte Steuerquellen erschließen können. Und ich denke, das wäre man in der Lage $\mathrm{zu}$ propagieren, und dann würde einem Ihrer Petita durchaus Rechnung getragen.

Volkmann: Weil ich nun der vorletzte Redner bin, möchte ich beiden Referenten noch einmal danken: Ich habe eigentlich von der Materie keine Ahnung und trotzdem alles verstanden. Das scheint mir ein gutes Zeichen. Ich möchte aber doch zwei kritische Anmerkungen machen. Die erste betrifft den von beiden Referenten weitgehend zustimmend übernommenen Vorschlag, den Ländern ein eigenes Hebesatzrecht bei der Einkommensteuer zuzuerkennen. Unserer Vorsitzender, Herr Schoch, hat dazu gestern den Politikern empfohlen, sie möchten doch den Vor- 
schlägen aus der Staatsrechtslehrervereinigung Folge leisten; dann wären sie gut beraten. Ich kann nur sagen: Jeder Politiker, der ernsthaft daran interessiert ist, in sein Amt wiedergewählt zu werden, wäre denkbar schlecht beraten, wenn er gerade diesem Vorschlag Folge leisten wollte. Die Annahme, es sei in der Bundesrepublik durchsetzbar oder auch nur von einer Mehrheit gewünscht, dass etwa in Mainz signifikant andere Steuersätze für die Einkommensteuer gelten sollen als im unmittelbar benachbarten Wiesbaden, ist völlig illusorisch. Ein Politiker der das vertreten wollte, kann im Grunde nur darauf bauen, dass seine Verantwortlichkeit in den diffusen Zurechnungs- und Verantwortungszusammenhängen unserer Mehrebenensysteme so verwischt wird, dass am Ende niemand mehr erkennen kann, wer am Anfang dahinter gesteckt hat. Die zweite Anmerkung ist grundsätzlicherer Art und knüpft, Herr Waldhoff, an Ihren Vorschlag an, die Finanzautonomie in der individuellen Freiheit zu verankern und dort rückzukoppeln. Ich weiß nicht, wie das mit unserer Vorstellung vom Staat und seinem derzeitigen Erscheinungsbild zusammengehen soll. Der Staat erhebt Abgaben, um seine Aufgaben zu finanzieren. Diese Aufgaben bestehen aber heute, ob wir das nun wahrhaben wollen oder nicht, nicht ausschließlich und nicht einmal mehr in erster Linie in der Freiheitssicherung und der Freiheitswahrung. Sondern der Staat hat - und auch da können wir darüber streiten, ob das sinnvoll ist; wir können von mir aus sagen, er sei eine Hydra, die man bekämpfen muss - mittlerweile eine Globalverantwortung für die Herstellung erwünschter Lagen aller Art übernommen. In einer demokratischen Ordnung kann dies im Grunde auch gar nicht anders sein, denn jede demokratische Ordnung hat es an sich, dass jedes gesellschaftliches Problem politisch werden kann und dann an den Staat zur Lösung herangetragen wird. Eine Rückbindung der Finanzautonomie an die Freiheitssicherung mochte dann plausibel sein in einer Zeit, in der sich der Staat weitgehend auf die Aufgabe der Ordnungswahrung und damit auf die Freiheitssicherung beschränkte. Mit der umfassenden Aufgabenverantwortung des heutigen Staates ist sie aber nicht zur Deckung zu bringen. Dann müsste man vielleicht doch darüber nachdenken, die Finanzautonomie in einigen korrigierenden Prinzipien zu verorten.

J.-P. Schneider: Keine Sorge es wird ganz kurz. Nur ein Brückenschlag zwischen heute Morgen und gestern Nachmittag. Das heutige Thema betraf unter anderem die die Steuerverwaltung. Dabei sprach Frau Hey das Problem der Vermeidung von Ungleichheiten und Vollzugsdefiziten an, was in der Diskussion am Beispiel der Betriebsprüfung exemplifiziert und verdeutlicht wurde. Als eine denkbare Lösung zog Frau Hey eine Zentralisierung der Vollzugskompetenzen in Betracht. Insoweit 
könnte man sich jedoch auch von Europa und der europäischen Verbundverwaltung anregen lassen und zusätzliche Optionen herausarbeiten. Dort gibt es nämlich eine Reihe von Instrumenten zur zentralen Kontrolle der dezentralen Kontrolltätigkeiten z.B. anhand festgelegter Qualitätskriterien für Kontrollen. Die Zentrale muss dann Kontrollen nicht selbst vornehmen, steuert aber systematisch den Vollzug der unteren Ebene. Dies wirft innerstaatlich natürlich die Frage der Zulässigkeit von Mischverwaltungen auf. Darauf will ich nun nicht mehr eingehen, um den Schlussworten angemessen Platz zu lassen.

Hey: Zunächst danke ich Ihnen herzlich für die vielfältigen Anregungen, selbstverständlich auch für die Kritik. Lassen Sie mich beginnen mit den grundsätzlichen Fragen nach Grund und Grenzen der Finanzautonomie. Der zentrale Punkt ist von Herrn Gröpl angesprochen worden. Die Frage, wie viel Finanzautonomie die einzelnen Ebenen benötigen, wie viel finanzielle Verantwortung ihnen gerechterweise auferlegt werden darf, entscheidet sich anhand der Verteilung der Sachkompetenzen. Damit ist Finanzentflechtung in erster Linie eine Frage der Sachentflechtung. Und solange der Hauptkostenblock der Sozialgesetzgebung weiterhin bundeseinheitlich geregelt bleibt, damit der Einflussnahmemöglichkeit der Länder weitgehend entzogen ist, ist es nicht legitim, den Ländern die Kostenverantwortung hierfür zu überbürden. Dass Finanzentflechtung ohne Entflechtung der Sachkompetenzen nicht gelingen kann, wird an Art. 104a Abs. 4 GG deutlich. Die Länder haben hier - zu Recht - eine Vetoposition erhalten.

Gleichzeitig hängt das Ausmaß der Entflechtung von Sachkompetenzen entscheidend vom Verständnis der Gleichwertigkeit der Lebensverhältnisse ab. Und hier scheint mir bei all den technischen Themen, die sich anschließen, das Kernproblem zu liegen. Wollen wir wirklich z.B. die Aufgabenwahrnehmung im Bereich des Sozialrechtes auf die Länder übertragen? Dann würde man sehr viel Autonomie verwirklichen können, wie es beispielsweise in den USA der Fall ist, aber um den Preis regional unterschiedlicher Sozialleistungen. Wenn wir das nicht wollen, muss auch die Forderung nach mehr Finanzautonomie der Länder zurückgenommen werden. Übrigens ergibt sich aus der Zuordnung der Sozialausgaben zum Bund noch ein Folgeproblem: Die Finanzkrise des Bundes resultiert maßgeblich aus den Zuschüssen zu den Sozialversicherungssystemen. Dies spräche für eine Anpassung der Umsatzsteuerverteilung zugunsten des Bundes. Damit ist aber auch deutlich, solange kein Wille zu nachhaltiger Dezentralisierung besteht, bedarf es weiterhin starker Finanzausgleichselemente. Trotzdem meine ich, und insoweit haben Herr Waldhoff und ich ja übereingestimmt, dass eine, wenn auch 
nur zurückhaltende Stärkung der Finanzautonomie der Länder in dem Maße wie sie über Sachkompetenzen verfügen, eine Verbesserung der demokratischen Legitimation und Kontrolle des staatlichen Ausgabeverhaltens verspricht, selbst wenn es nur darum geht, wie die Akzente gesetzt werden, z. B. wird in Bildungspolitik investiert? In Kinderbetreuung? Dieser Kontrollmechanismus funktioniert umso besser, je unmittelbarer die Beziehung zwischen Staat und Bürger ist. Am besten lässt sich ein demokratischer Legitimationszusammenhang im Bereich der Kommunalfinanzierung hinsichtlich der Angelegenheiten der örtlichen Gemeinschaft herstellen Deshalb habe ich mich hier für ein Hebesatzrecht der Kommunen auf die Einkommensteuer ausgesprochen.

Die Gleichwertigkeit der Lebensverhältnisse und die hieraus resultierenden Ausgleichsbedürfnisse waren auch Gegenstand der Fragen von Herrn Kotzur und Herrn Heun, denen es um das Verhältnis zwischen Solidarität und Freiheit bzw. Verantwortung im Bundesstaat ging. Man muss diese Frage auf zwei Ebenen betrachten: Aus der Perspektive des Bürgers eröffnet der Fiskalwettbewerb, den ich keineswegs so positiv sehe, wie es vielleicht aus meinem Vortrag herausgekommen ist, einen Zuwachs an Freiheit mit der Möglichkeit, sich solidarischen Umverteilungsmaßnahmen zu entziehen. Der Mobile ist in der Lage zu gehen, sich hohen Abgabenlasten zu entziehen. Der weniger Mobile ist gezwungen zu bleiben und kann sich des Finanzierungsbeitrags nicht entziehen. Damit werden die solidarischen Umverteilungsgemeinschaften kleiner. Gleichzeitig wirft die zwischenstaatliche Ebene der Länder die Frage nach bündischen Einstandspflichten, nach Solidarität für Not leidende Länder auf. Damit ist das Thema der Verschuldungsordnung angesprochen, das in verschiedenen Fragen angeklungen ist. Die Problematik der Verschuldung wird zunächst einmal dadurch begründet, dass die Länder im Augenblick Aufgaben ausführen müssen, die ihnen vom Bund vorgegeben sind. Dies reicht aber nicht aus, um sich von der Verantwortung freizuzeichnen, sondern es gibt selbstverständlich auch hausgemachte Länderverschuldung, die aus einer generösen Ausgabenpolitik der Länder resultiert und die dann umso mehr die Frage aufwirft, inwieweit hierfür die Gemeinschaft einstehen muss. Die Schwierigkeit liegt in der Grenzziehung aus der ex post-Perspektive. Kann hier - das wird das Bundesverfassungsgericht beantworten müssen - wirklich mit einer individuellen Verschuldensfrage, mit der Frage, wo hätte das Land sparen können, welche Aufgaben waren gerechtfertigt, argumentiert werden? Dann bewegen uns automatisch in einer Staatsaufgabendiskussion, die kaum zu hinreichend konkreten Ergebnissen führen wird. Das war der Grund dafür, dass ich mich für Präventivmechanismen ausgesprochen habe, indem der Haushaltsnotlage der Länder vorgebeugt 
wird, Haushaltsdisziplin also von vornherein eingefordert wird. Eine zweite Frage ist, welches Modell der Schuldenbegrenzung man präferiert. Dass Art. 115 GG in seiner heutigen Konzeption reformbedürftig ist, steht außer Frage. Unabhängig davon, welchem Konzept man dann folgt, der Übertragung der EU-Defizitgrenzen, gegen die allerdings zum Teil eingewandt wird, derartige Verschuldungsgrenzen verführten dazu, sie sofort voll auszuschöpfen, oder anderen Modellen wie der Schweizer Schuldenbremse, wichtig erscheint mir, dass derartige Grenzen für Bund und Länder parallel eingeführt werden, dass für alle Ebenen dieselben Anforderungen an die Haushaltsdisziplin gestellt werden. Natürlich ist damit nicht das verfahrensrechtliche Problem der Sanktion von Verstößen gelöst. Hätten die Länder aber Steuerautonomie, dann wäre es zumindest denkbar, wie vom wissenschaftlichen Beirat des Bundesfinanzministeriums vorgeschlagen, dass ein verschuldetes Land nur dann unterstützt wird, wenn es gleichzeitig Sanierungsbeiträge in Form von Zuschlägen zur Einkommensteuer von der Landesbevölkerung einfordert, um auch die Bürger für die Folgen staatlichen Ausgabeverhaltens zu sensibilisieren und zur Verantwortung zu ziehen. Es wurde in diesem Zusammenhang gefragt, warum denn die Länder, wenn sie Steuerautonomie erhalten, nur die kleine Maus des Steuersatzes bekommen sollen. Nun, unter Finanzautonomiegesichtspunkten ist dies aus meiner Sicht eigentlich eine große Maus. Zur Einnahmegenerierung reicht Steuersatzautonomie. Die Bemessungsgrundlage, das mag die Steuerrechtlersicht sein, sollte aber möglichst frei von politischer Gestaltung gehalten werden. Damit wird den Ländern zwar ein Instrument der Sachgestaltung in Form von Lenkung durch Steuervergünstigungen vorenthalten. Doch unter dem Gesichtspunkt der Rechts- und Wirtschaftseinheit sollte die Ausgestaltung der Bemessungsgrundlagen aus meiner Sicht dringend beim Bund bleiben sollte, nur so kann zudem dem Anliegen eines transparenten föderalen Wettbewerbs Rechnung getragen werden. Das Thema des Wettbewerbs, das Sie, Herr Engel, sehr kritisch angesprochen haben, hat ja zwei Aspekte. Zum einen haben wir den Wettbewerb als Entdeckungsverfahren für beste Regelungen. Hierzu bräuchte es in der Tat Bemessungsgrundlagenautonomie. Doch muss man nüchtern feststellen, hier hat sich das Steuerrecht in der Vergangenheit eigentlich immer als gänzlich ungeeignet gezeigt hat. Wir hatten im Grunderwerbssteuerrecht bis 1983 Ländergesetzgebung, die sich in einem völligen Wildwuchs von Steuervergünstigungen, Ausnahmetatbeständen etc. niedergeschlagen hat. das ist kein Wettbewerb um beste Lösungen wie im Falle Delawares, sondern es ist in erster Linie ein Steuersubstratwettbewerb. Und deshalb war mein Eintreten für den Wettbewerb auch ein eher vorsichtiges, weil Steuerwettbewerb eben 
sehr schnell - das liegt an steuerrechtlichen Besonderheiten - ausgenutzt wird. Sie können unternehmerische Gewinne heutzutage in Europa einfach herumschicken und da zur Besteuerung entstehen lassen, wo die niedrigsten Steuersätze gelten. Angesichts dieser Gefahren müsste ein Steuerwettbewerb sehr stark reguliert werden. Dann aber meine ich, dass die Steuersatzautonomie ausreicht, um die politischen Verantwortungszusammenhänge zu verdeutlichen und gleichzeitig die für funktionierenden Wettbewerb nötige Transparenz herzustellen. Lassen Sie mich ein letztes Wort zum Thema EU sagen: Ich meine nicht, dass die Berufung auf die nationale Haushaltsverantwortung der Mitgliedstaaten das Problem des europäischen Steuerwettbewerbs wirklich lösen kann. Es handelt sich letztlich um ein reines Fiskalargument. Ebenso wenig wie ungerechte, gleichheitssatzwidrige Steuern mit dem schlichten Aufkommensbedarf des Staates gerechtfertigt werden können, lassen sich Einschränkungen der Grundfreiheiten auf bloße Haushaltsinteressen stützen. Allenfalls in Randbereichen der Legitimation von Abwehrmaßnahmen gegen missbräuchliche Steuergestaltungen mag hierin eine Lösung liegen.

Waldhoff: Ich möchte mein Schlusswort in drei Blöcke gliedern. Erstens möchte ich Stellung nehmen zu den Anregungen und Kritiken im Zusammenhang mit dem Autonomieprinzip - dem Kern der Sache -, zweitens zu einem Punkt, den zwei Diskutanten angesprochen haben und der im Referat selbst unterbelichtet bleiben musste, der verfassungsrechtlichen Begrenzung der Steuerlast und schließlich drittens zur EU-Problematik.

Herr Heun fragte, was eigentlich der Bezugspunkt des Demokratieprinzips sei. Denken wir in Deutschland nicht immer bei Demokratie vom Gesamtstaatsvolk her? Das ist historisch betrachtet richtig, verstehbar und auch erklärbar. In meinem Modell ist jedoch die demokratische Legitimation der Landesebene im Prinzip gleichwertig. Neuere Arbeiten zur Bundesstaatstheorie in Verbindung mit dem Demokratieprinzip rekonstruieren dies auch so. Auch ein Rechtsvergleich - etwa zur Schweiz oder zu den USA - könnte in dieser Frage Erkenntnisse bringen. Der zweite Kritikpunkt von Herrn Heun ging in die Richtung, dass mit meinem Ansatz ein großes Theoriegebäude aufgebaut werde und dann nur die „kleine Maus“ der Hebesatzautonomie der Länder heraus komme, wird dadurch relativiert. Diese Zurückhaltung in den konkreten rechtspolitischen Vorschlägen ist der Koordination der Finanzkompetenzen mit den Sachkompetenzen der Länder geschuldet. Durch die Föderalismusreform 2006 haben die Länder gewisse - wenn auch nicht überragende - Erweiterungen in ihrer Sachautonomie, in ihren 
Gesetzgebungskompetenzen erhalten. Ein - ohnehin unwahrscheinlicher - Systemwechsel im Bereich der Finanzautonomie würde - wie in verschiedenen Diskussionsbemerkungen zu Recht betont wurde - dem nicht entsprechen. Die „kleine Maus“ des Hebesatz- oder Zuschlagsrechts für die Länder im Bereich bestimmter Steuern erweist sich damit als kompatibel mit dieser gemäßigten Erweiterung der Sachgesetzgebungskompetenzen der Gliedstaaten. Der in der Tat vorhandene $\mathrm{Zu}$ sammenhang, die Kongruenz zwischen Sachautonomie und Finanzautonomie bleibt gewahrt. Ganz ausdrücklich möchte ich auch noch einmal darauf hinweisen, dass das von mir hier vertretene Hebesatzoder Zuschlagsmodell eine Sachlogik, die im Steuertatbestand selbst angelegt ist, aufnimmt indem die technischen, europarechtsinduzierten Fragen der Steuerbemessungsgrundlage (bundes-)einheitlich geregelt bleiben und die Rechtszersplitterung dadurch ein vernachlässigbarer und beherrschbarer Faktor ist, während der Steuertarif, das politische Element der Steuer der (Landes-)Autonomie überlassen bleibt. Die Sachlogik des Steuertatbestands wird hier in der bundesstaatlichen Kompetenzverteilung aufgenommen. Die Frage, wie hoch die Steuerbelastung sein soll, ist in erster Linie eine politische und keine rechtliche Frage. Aber die gleichheitsgerechte Ausgestaltung der Steuerbemessungsgrundlage ist eine durch das Verfassungsrecht stark vorgezeichnete und durch gemeinschaftsrechtliche Überlagerungen gekennzeichnete Rechtsfrage; in diesem Bereich sollte man der Rechtszersplitterung in der Tat vorbeugen. Herr Engel hat unter Berufung auf das Standardwerk von Albert Hirschmann („Abwanderung und Widerspruch“) darauf hingewiesen, dass die Abwanderung an die Stelle des Widerspruchs treten könnte. Meiner Ansicht nach sind Abwanderung und Widerspruch, und so habe ich Hirschmann auch verstanden, komplementär. Es wird mit der Abwanderung gedroht; die Abwanderung ist kostenintensiv; wenn wirklich ein Unternehmen - und nicht nur Kapital - abwandert, bezieht der Unternehmer die Frage in seine Überlegungen ein, ob er angesichts einer niedrigeren Steuerbelastung auch adäquate staatliche Gegenleistungen erhält. Das politische Drohpotenzial aus der Abwanderung, die Umsetzung einer Abwanderungsoption in politischen Druck, in politisches Engagement, in Einflussnahme etc. im demokratischen Prozess erscheint mir selbstverständlich und begrüssenswert zu sein. Herr Gröpl hat darauf hingewiesen, dass die Ausgabenautonomie zu kurz komme. Dem würde ich insofern widersprechen, dass meine Konzeption von Autonomie gerade aus einer Koppelung von Einnahmen- und Ausgabenautonomie besteht. Der verfassungsrechtliche und der politische $\mathrm{Zu}-$ sammenhang zwischen Einnahmen und Ausgaben sollte gerade hergestellt werden. Das ist ganz nah an dem Einwand von Herrn Volkmann. 
Sie sagen, politisch sei es nicht durchsetzbar, dass die Steuerbelastung in Mainz unterschiedlich hoch sei im Vergleich zu dem nur 15 Kilometer entfernten Wiesbaden. Nach meinem Ansatz ist im Grunde schon die Frage falsch gestellt. Die Frage an den Bürger, die Frage an die Erwartungshaltung des Bürgers müsste dahin gehen, ob diese bereit sind Steuerbelastungen angesichts eines bestimmten Aufgabenerfüllungsniveaus zu tragen. Es muss also bei der Frage nach Steuerbelastungsdifferenzen zugleich die Ausgabenseite stets einbezogen werden. Eine solche Fragestellung ist jedoch in Deutschland - was interessant ist - angesichts der (von mir als Folge hypertropher Einheitlichkeitsvorstellungen) langen Tradition bundesweit einheitlicher Abgabenbelastung unüblich geworden. Die politisch zu stellende Frage müßte insoweit neu formuliert werden. Wenn die Steuerbelastung überall gleich ist, erwartet die Bevölkerung auch gleiche Lebensverhältnisse. Die Frage müsste demgegenüber sein, ob eine demokratisch fundierte Entscheidung über den Zusammenhang von Geben und Nehmen hergestellt werden kann. Besonders dankbar bin ich für die Bemerkungen von Herrn Kloepfer, der darauf hingewiesen hat, die Sonderstellung der Finanzverfassung sei eigentlich beendet. Die „Finanzblindheit der deutschen Staatsrechtslehre“, die noch in den fünfziger oder sechziger Jahren beschworen wurde, würde ich so heute nicht mehr diagnostizieren (Insofern ist es auch hochproblematisch, wenn die Lehr- und Prüfungspläne vieler Länder das Finanzverfassungsrecht aus der Staatsrechtsvorlesung explizit ausklammern: Wie soll das Bundesstaatsprinzip ohne bundesstaatliche Finanzverfassung erklärt werden?) Gleichwohl haben wir einen eigenen Grundgesetzabschnitt (im Grundgesetz übrigens zum ersten Mal in der deutschen Verfassungsgeschichte). In den Vorgängerverfassungen, der Weimarer Reichsverfassung und der Reichsverfassung des Bismarckreichs, war das Finanzverfassungsrecht in das allgemeine Organisationsrecht eingearbeitet. Darauf aufbauend stellt sich dann in der Tat heute das Problem, dass die Finanzverfassung bei uns Steuerfinanzverfassung ist, dass die nichtsteuerlichen Abgaben jedoch eine zunehmende und nicht unproblematische Rolle spielen. Mein Beispiel der Sonderabgaben darf nicht so fehlverstanden werden, dass ich Sonderabgaben als in der Verfassung überhaupt nicht vorgesehenen Abgabentypus propagieren würde; im Gegenteil: Ich habe dieses Beispiel nur herangezogen, um einen Mechanismus zwischen der Abgabenrechtfertigung dem Bürger gegenüber und bundesstaatlichen Verteilungsfragen (also Organisationsfragen) zu verdeutlichen. In seiner Sonderabgabenjudikatur musste das Bundesverfassungsgericht diesen Weg gehen, weil es kein Organisationsrecht für die Sonderabgaben gibt, denn der zehnte Abschnitt des Grundgesetzes trifft insofern keine Aussagen. 
Ein zweiter Bereich, den ich ansprechen möchte, ist die verfassungsrechtliche Begrenzung der Steuerlast. Mein Modell hat den alles andere als unerwünschten Nebeneffekt, den ich im Referat nicht ausgeführt habe, dass die Steuerlast durch ein institutionelles Arrangement in Grenzen gehalten werden kann. Alle Versuche die Höhe der Steuerbelastung verfassungsrechtlich (etwa durch Grundrechte) einzugrenzen sind letztlich gescheitert. Der Halbteilungsgrundsatz ist gerade in der von Frau Hey auch herangezogenen Entscheidung zur Kumulation von Gewerbe- und Einkommensteuer verabschiedet worden. Das Ersatzmodell, das uns der zweite Senat jetzt anbietet, die Verhältnismäßigkeitsprüfung, wird letztlich nicht funktionieren. Interessanterweise wird dort, um die Zumutbarkeit oder Angemessenheit der Steuerbelastung (als dritter Stufe der Verhältnismäßigkeitsprüfung) bewerten zu können, auf einen internationalen Steuerbelastungsvergleich verwiesen. Wenn die Steuerbelastung in Deutschland im internationalen Vergleich vergleichsweise hoch sein sollte, gerate - um die Verhältnismäßigkeit zu gewährleisten - der Steuergesetzgeber in Deutschland unter eine Rechtfertigungslast. Dabei handelt es sich im Grunde um ein durch die Hintertür eingeführtes Wettbewerbsmodell: Der Vergleich mit anderen Staaten und daraus resultierende Begründungslasten sprengen jedoch die übliche Verhältnismäßigkeitsprüfung. Hinsichtlich verfassungsrechtlicher Grenzen der Steuerbelastung hat Herr Kloepfer hat völlig zu Recht auf einen Ansatzpunkt in der Finanzverfassung hingewiesen: Nach Art. 106 Abs. 3 S. 4 Nr. 2 GG, eine Norm aus den Maßstäben für die bewegliche Umsatzsteuerertragsverteilung zwischen Bund und Ländern, ist eine Überbelastung der Steuerpflichtigen zu vermeiden. Herr Meyer hat darauf hingewiesen, dass die Absätze 3 und 4 des Art. 106 GG zu den dunkelsten Vorschriften der Finanzverfassung gehören und letztlich nicht funktionieren. Ich sehe seine Funktion hier als Anhaltspunkt dafür und das kann in einem freiheitlichen Verfassungsstaat niemals anders sein -, dass auch die Steuerbelastungshöhe eine verfassungsrechtliche Grenze finden muss. Insofern halte ich diese versteckte und kryptische Normierung für eine wichtige Vorschrift. Diese Vermeidung einer Überbelastung der Steuerpflichtigen würde ich, wie ausgeführt, weniger durch grundrechtliche Vorgaben, durch materielles Verfassungsrecht gewährleisten, als durch eine vorsichtige Öffnung auf institutioneller Ebene mittels Wettbewerb, also durch institutionelle Arrangements.

Mein dritter und letzter Diskussionspunkt betrifft die Frage nach eigenen EU-Steuern. Herr Häberle hat zu Recht darauf hingewiesen, dass es „harte“ und „weiche“ Integrationsfaktoren gebe. Besteuerungsrechte zählen, ähnlich wie die Ausübung physischen Zwangs, zu den „ganz harten“ Integrationsfaktoren. Deshalb haben im derzeitigen Integrations- 
stadium die Gemeinschaften insofern auch kaum Kompetenzen. Ich würde mich dagegen wehren, über diesen harten Sachpolitikbereich die Integration voranzutreiben. Wenn die Integration sich weiterentwickelt, können und müssen wir über eine eigene EU-Steuer neu nachdenken. Im derzeitigen Modell ist das keine relevante Frage. Auch Art. 6 Abs. 4 EU-Vertrag, den das Bundesverfassungsgericht im Maastricht-Urteil zutreffend als deklaratorische Norm dargestellt hat, würde selbst im neuen Verfassungsvertrag nichts verändern, denn das Eigenmittelsystem, das die Mitgliedstaaten als „Herren über die Einnahmen der EU“ belässt, soll nach den zunächst gescheiterten Entwürfen erhalten bleiben.

Diskussionsleiter: Mir bleibt zum Schluss nur die angenehme Aufgabe, den Referenten für einen anregenden Vormittag zu danken. Sie haben uns souverän durch alle Ebenen des Finanzsystems geführt. Ich wusste schon immer, dass es bei der Finanzverfassung, salopp gesprochen, um „Mäuse“ geht. Aber dass in diesem Mehrebenensystem auf den einzelnen Ebenen tatsächlich Mäuse herumlaufen, von denen wir lediglich nicht wissen, ob sie große oder kleine sind, dass war mir neu. Ich habe gelernt; ich habe darüber nachzudenken beim Mittagessen. 